
10. 13016y 40.30 (1) 


Digitized by the Internet Archive in 2007 with funding from Microsoft Corporation 




\section{A History of the \\ Association Psychology}

BY

HOWARD C. WARREN

Stuart Professor of Psychology, Princeton University

$\frac{167269}{15.11}$

CHARLES SCRIBNER'S SONS 


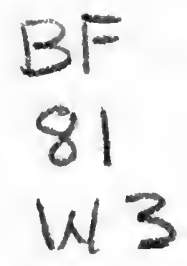

Copyright, 1921. BY

CHARLES SCRIBNER'S SONS

THE SCRIBNER PRESS 


\section{PREFACE}

THIs study of the Association Psychology was originally projected in I903. After the first six chapters were substantially completed the work was laid aside for more urgent matters. The material for the remaining chapters has been gathered from time to time and the whole revised within the past year.

The writer is personally quite sympathetic with the Association Psychology. Its defects have always seemed attributable to the imperfect knowledge of mental data and nervous processes in past generations, rather than to the analytic and empirical methods employed by the school. The present study, while essentially historical in character, aims to bring out the general consistency of the Associationist movement and to trace back certain recent developments of psychology to their source in the writings of this school.

A sympathetic historian is ever in danger of reading into earlier writers the more definite results of later analysis, or of attributing to them his own views. I have endeavored to avoid this by quoting verbatim from the writers examined. This puts the reader in a position to judge whether the interpretations offered by the historian are correct.

It was originally intended to add a chapter on the criticisms preferred against the Associationists by their contemporaries. This plan was abandoned on account of the length of time required to complete the study. For the same reason the French sensation-associationist movement has been less fully dealt with than was originally proposed.

I wish to acknowledge the assistance of my former 
colleague J. Mark Baldwin, at whose instance the work was undertaken, and to whom I am greatly indebted for suggestions in outlining the volume.

Thanks are due to my colleague Edmund Y. Robbins, of the Greek department (Princeton), for valuable assistance in interpreting passages from Aristotle, and to my friend John B. Watson (Johns Hopkins) for various suggestions. The courtesy of the Psychological Review Company is acknowledged for permission to use an article which appeared in the Psychological Review. This paper is substantially identical with Chapter II. I am also indebted to my office assistants for painstaking aid in preparing manuscript and proof.

Princeton, New Jersey,

Howard C. WARREN.

October, 1920. 


\section{CONTENTS}

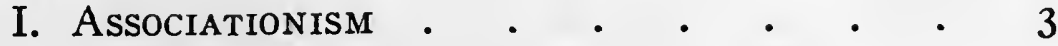

I. Origin of the Term 'Association of Ideas,' 3.

2. Definitions of Association, 6.

-3. The Association School and its Rivals, 9.

4. Philosophical Standpoints of the Associationists, 13.

5. Outline of the Association Psychology, I5.

6. Source Books, 18.

II. Mental Association from Pláto to Hume .

I. Aristotle, 23.

2. Post-Aristotelian Contributions; Descartes, 28.

3. Thomas Hobbes, 33.

4. John Locke, 36.

5. George Berkeley, 40.

6. David Hume, 43.

7. Other Contributions, 47.

III. David Hartley and the Earlier AssociaTIONISTS • • • .

I. Hartley's General Standpoint, 50.

2. Hartley's Conception of Association, 53.

3. Hartley's Applications of the Principle, 57.

- 4. Deficiencies in Hartley's System, 63.

5. Other XVIIIth Century Associationists, 64.

6. Thomas Brown's Standpoint, 70.

7. Brown's Laws of Suggestion, 72.

8. Brown's Analysis of Mental Phenomena, 74.

9. Brown's Theory of Relative Suggestion, 77.

IV. James Mill and the Later Associationists

I. James Mill, 8I.

2. James Mill's Conception of Association, 84 .

3. J. Mill's Analysis of Cognitive Phenomena, 89.

4. J. Mill : Motor and Affective Phenomena, 93.

5. John Stuart Mill's Law of Association, 95.

6. J. S. Mill's Analysis of Belief, roo.

7. Alexander Bain's Conception of Association, I04. vii 
8. Bain's Derivation of Mental Phenomena, 109.

9. Culmination of Pure Associationism, II5.

V. Evolutionary Associationism • • • II8

I. The Evolution Concept in Psychology, II8.

2. Herbert Spencer's Psychological Standpoint, I2I.

3. Spencer's Interpretation of Association, 124.

4. Derivation of Higher Mental States, I3O.

5. Spencer's Relation to Earlier Writers, 133.

6. The Psychology of G. H. Lewes, I37.

- 7. Association and Logical Grouping, I40.

8. Lewes's Analysis of Mental Phenomena, 146.

9. Lewes's Contributions to the Problem, I50.

so. Other XIXth Century Associationists, I52.

VI. Summary of English Associationism .

I. Development of the Association Concept from Hobbes to Hume, I54.

2. Contributions of Hartley and Brown, I57.

3. The Two Mills and Bain, 163 .

4. Spencer and Lewes, 168.

5. Estimate of English Associationism, 175.

VII. Continental Associationalism . . • I8I

I. French Associationism; Condillac, I8I.

2. Bonnet and Helvétius, 186.

3. The Ideologists, 191.

4. Later French Associationism, 194.

5. Italian Contributions, 200.

6. German Contributions, 203.

7. Herbart and Beneke, 205.

8. Transition to the Experimental Movement, 210.

VIII. Experimental Studies of Association .

I. Beginnings of Experimental Investigation, 213.

2. Effects of Repetition and Lapse of Time, 2I7.

3. Reaction Time of Association, 222.

4. Association and Apperception, 223.

5. Mediate Association, 225.

6. Association Tests and Mental Diagnosis, 229.

7. Miscellaneous Investigations, 235.

8. Laws of Association: Similarity and Contiguity, $24 \mathrm{I}$.

9. Classifications of Association, 247. 
IX. Nature and Laws of Association .

I. The Nature of Association, 258.

2. Role of the Nervous System, 266.

3. The Modes of Association, 273.

4. The Laws of Association, 282.

5. Typical Interpretation of the Associative Process, 287.

X. The Associational Analysis of Mental States • • • • • • • • • • $29 \mathrm{I}$

I. Fundamental Concepts, 29 I.

2. Cognitive Experiences, 295.

3. Conation, 299.

4. Affective Consciousness, 303.

5. Completion of the Analysis, 305.

BibliogRAPHY INDEX .

Chronological Chart (at end of volume). 



\section{A HISTORY OF THE ASSOCIATION PSYCHOLOGY}


$B^{k} c^{5}$

$$
\begin{aligned}
& 35 \\
& -55
\end{aligned}
$$




\section{CHAPTER I}

\section{ASSOCIATIONISM}

\section{Origin of the Term 'Association of Ideas'}

THE phrase association of ideas was first used by John Locke. In the fourth edition (I 700) of his 'Essay concerning Human Understanding' he inserted a new chapter, entitled "Of the Association of Ideas," ${ }^{2}$ in which he discusses the connections between experiences.

"Some of our ideas," he says, "have a natural correspondence and connection with one another: it is the office and excellency of our reason to trace these and hold them together in that union and correspondence which is founded in their peculiar beings. Besides this, there is another connection of ideas wholly owing to chance or custom. Ideas that in themselves are not at all of kin come to be so united in some men's minds that it is very hard to separate them; they always keep in company, and the one no sooner at any time comes into the understanding, but its associate appears with it; and if they are more than two which are thus united, the whole gang, always inseparable, show themselves together. This strong combination of ideas not allied by nature the mind makes in itself either voluntarily or by chance, and hence it comes in different men to be very different, according to their different inclinations, education, interests, etc." ${ }^{3}$

1 Marin Cureau de La Chambre in his work, 'Système de l'âme,' published in 1664, speaks of "l'union et la liaison des images" as an integrant action in our knowledge (Hamilton, ed. of Reid's 'Works,' Note $D^{* *}$ ).

2 Bk. II, ch. 33 .

$3 \S 5$, 6. In quoting earlier English writers spelling, italics, capitalization, and punctuation are altered to conform with prese'st- 
We are thus indebted to Locke for a term which later gained currency as applied to a doctrine of peculiar prominence in English psychology; of such prominence, indeed, that the system of psychology which these writers worked out came to be known as Associationism. Furthermore, the exposition of mental association in various parts of Locke's 'Essay' furnished important data to the theory subsequently developed. But it should be noted at the outset that the epoch-making character of Locke's work in this field consists only in his introduction of the term 'association of ideas.' He neither founded the doctrine of association nor did he fix the historical signification of the name which he coined.

First, the laws of the association of remembered images according to similarity, contrast, and contiguity were originally formulated by Aristotle, who furnished hints of an association of sensations as well. These suggestions long escaped notice owing to the lack of interest in such problems. In modern times also, the notion of an associated sequence of thought was worked out in some detail, prior to Locke, by Thomas Hobbes, and his treatment furnished the model for later discussions of the subject. Locke emphasizes the fact, but does not work out the manner of association. This latter problem, one of the most notable features of the association psychology, rests historically on Aristotle's classification, which has been taken up and modified in various ways by writers of the association school; Hobbes's view of association as the mode of succession of ideational experiences is generally adopted as a starting-point in the analysis.

Again, the term idea was used by Locke in a broader

day usage. Citations are by chapter and section so far as practicable, rather than by page, in order to make any edition available. Names of authors and titles of works are given in full when first mentioned, and the edition consulted is referred to at the first definite citation. Where foreign writers are quoted the original text is not given unless the terminology or some vital point is open to question. 
sense than that fixed by later usage. Thus, when Locke speaks of the association of ideas he has reference to possible connections between all sorts of mental content; whereas from the time of David Hume onward the phrase refers to connections between representative data only. Locke's term has been retained, but its application is narrowed to a portion of the field to which he assigned it. This permanent fixing of the expression association of ideas with an altered meaning given to the term idea, has exerted some influence on the development of the doctrine itself. The connection between sensations, as for example in perception, has been ignored by some writers, while others have treated it as another sort of union, distinct from association. Where the union of sensations has been classed under the same general principles as associations between representative elements, the exposition has been weakened by the inappropriateness of the accepted phrase.

Finally, it should be borne in mind that the problem of association as Locke conceived it was an ethical and pedagogical one, not a problem of psychological analysis. He nowhere seeks to determine the different modes of connection between experiences as Hobbes has done. His real aim is to trace the rise of wrong associations and suggest practical remedies for the errors of judgment and action to which they lead. In the passage quoted Locke grants that a natural connection between ideas exists as well as chance association; but it is the associations of chance or custom, their origin, and the means of preventing and overcoming them, that constitute the material of his inquiry. The chapter on association was an afterthought, not an essential part of the 'Essay'; and although in harmony with the doctrine formulated in the rest of his book, it appears more in the light of a practical application of his theory that an investigation of the laws of association. 
In short, while the 'Essay concerning Human Understanding' furnished the name under which the principle has since become known, and has also afforded considerable material to assist later writers in developing the psychology of association, the two contributions stand apart: Locke's association doctrine is not worked out from the psychological standpoint, and it is not definitely attached to the phrase which he devised. The aim of his 'Essay,' it must be remembered, is essentially epistemological, and the psychological analysis which it undertakes is carried out only so far as necessary to demonstrate the empirical derivation of all knowledge.

\section{Definitions of Association}

The term association, ${ }^{1}$ as used by the English psychologists of the eighteenth and nineteenth centuries, applies primarily to the sequences that occur in trains of memory or imagination or thought: their problem was to formulate the principles involved in such sequences. According to the view generally adopted by these thinkers, one such experience follows another through certain definite relationships. Thus, one idea may serve to recall another which resembles it or which was contiguous to it in former experience. Here we have the narrowest view of association, conceived as the principle by which trains of ideas are induced. Starting with this fundamental conception, the scope of the principle has been broadened in various directions.

Thus, the rôle of association in respect to sensation is variously construed: All the writers belonging to the association school admit the rise of ideas following sensations, according to the same laws of association that hold where the antecedent is an idea. Some go further and

1 Hobbes calls the process "mental discourse," Tucker calls it "translation," and Thomas Brown prefers the term "suggestion." Other writers generally use "association." 
regard as a form of association the simultaneous presence of two or more sensations in consciousness, such as occurs in the act of perception. Others merely assume a nexus in such experiences without explicitly classing them as instances of association. On the other hand, all agree in denying that one sensation can bring up another sensation by association; it is generally admitted that the rise of sensations depends on something outside of consciousness, or at least on something apart from the individual human experience.

In the case of successive association, then, the general view has been that the antecedent may be either a sensation or an idea (including under the latter term any sort of representation), while the consequent is always an idea.

As regards simultaneous connections opinions differ: some affirm that such complexes of experience are instances of genuine association, while others deny this. Of the former, some writers believe that the associative laws hold equally well for sensations and ideas; others confine these laws to the union of ideas with either sensations or ideas, while others limit them still further to the welding together of ideas into a complex idea, whether of memory or imagination.

The manner in which association operates has also been variously stated. Similarity (or resemblance) ${ }^{1}$ and contiguity figure most prominently among the laws suggested.

1 The two words similarity and resemblance are not distinguished in the discussion. Some writers prefer one or the other; some use the two indiscriminately. Etymologically, similarity appears to be a likeness between coordinate factors, resemblance a likeness of one thing to another. Thus, two strangers may be of similar appearance, while a son may resemble his father, and the father be resembled by the son; two dollar bills are similar, but a counterfeit resembles the real dollar. If this distinction be brought over into psychology, two ideas should be termed similar or resembling according as they are coordinate or one depends on the other, but an idea can only resemble a sensation. This mode of association, then, would be termed similarity or resemblance according to the form of the doctrine which a given writer holds. 
Some writers conceive these as coordinate principles; a sensation or idea, it is held, introduces either another idea that resembles it, or one that (either as sensation or idea) has been experienced in the past in close conjunction with it temporally or spatially. Others reduce similarity to contiguity, contending that the similar parts of the two associated experiences are really identical, which leaves only the dissimilar elements in the new experience to be accounted for; the latter are explained through their previous contiguity with the identical elements.

On the other hand, contiguity has been reduced to similarity by an inversion of this same mode of reasoning. One experience, it is contended, introduces another solely by the fact of their similarity, the apparently contiguous elements being really essential parts of the resembling experiences.

Still another view subordinates the two principles to a single law, called redintegration or reinstatement. Here it is maintained that the fundamental fact involved is the reinstatement of a past experience through association with a present experience, the particular ground of reinstatement (likeness or some other relation) being a subsidiary question.

The association of unlike or contrasted experiences has been recognized by some as an additional principle, following the view of Aristotle, while by others it is regarded as merely a particular phase of the two laws already mentioned.

The factors determining the strength of any particular association-that is, the likelihood of its occurring in any given circumstances-have been analyzed in various ways. Prominent among the principles here recognized are the effects of habit (or repetition) and intensity. The frequent repetition of an experience, it is held, increases the probability of its revival by association, and the repetition of an association increases its liability to recur. Aside 
from the question of repetition, an experience of great intensity has been generally considered more likely to be revived by association than a weaker one. These and other factors which determine the degree of strength of association form a problem of analysis distinct from that of the modes of association, though many writers treat them under the same head, as Laws of Association.

\section{The Association School and its Rivals}

Despite these many differences in the analysis, classifcation, and interpretation of association among the writers who contributed to the development of psychology in England during the eighteenth and nineteenth centuries, and despite even greater divergence in other parts of their work, their systems represent a common standpoint. They are clearly and unmistakably differentiated from other psychological systems of the same period. The prominence of the conception of association in their analysis, the care with which they work out its laws even to minutiæ, their constant endeavor to apply these laws to the more complex forms of consciousness-all these characteristics justify us in grouping the English psychologists together as a distinct school and applying the term Associationism to the movement.

The British association psychology is distinguished on the one hand from the a priori psychology of J. C. von Wolff and a succession of thinkers in Germany, who maintain that the rational faculty is unanalyzable and selfvalidating, and who account for the growth of knowledge in the individual by the operation of innate factors. It is equally differentiated on the other hand from a group of semi-empirical psychologists in Scotland, who base their system on immediate, intuitive knowledge of objective data. The English school regards knowledge as a complex of experiences welded together empirically through the instrumentality of association. It is closely allied to 
the contemporary French movement initiated by Helvétius and Condillac, which based its psychology on the data furnished by the senses and whose recent successors (Taine and others) have modified the earlier sensationism into a true associationism.

The emphasis laid on association as the fundamental principle of mental activity by writers of the Englisb school is clearly due to their appreciation of its possibilities as a factor in explaining empirically the variety of mental functions. To account for the more complex types of consciousness in terms of experience is the aim of these thinkers. Proceeding along this line of inquiry, some principle depending on the character of experience itself is needed at the outset to account for the succession and complex union of experiences. Association appeared to furnish the requisite instrument: it was adopted and applied to its fullest extent. Hence, the association doctrine became the cardinal psychological principle of that school of thinkers which adopted the empirical method in philosophy. The epistemologists of the movement, such as Hume and John Stuart Mill, joined hands with the psychologists, David Hartley, James Mill, and Alexander Bain, in an endeavor to explain all complex forms of consciousness, including knowledge itself, by means of this single instrument.

The reason for such an alliance between philosophy and psychology is not difficult to understand. One of the chief problems of epistemology is to account for experience itself. Granting that the elementary data of experience, simple sensations, are due to stimuli affecting the

mind from 'without,' there remain certain other experiences, such as perceptions, memories, imaginations, and rational thought, which are not directly traceable to the same source. ${ }^{1}$ To explain the occurrence of these phe-

1 Perceptions belong here in so far as they are more than a series of isolated sensations. 
nomena in human experience is a psychological problem, and the philosopher who is not wholly dogmatic is confronted with the alternative of adopting the results attained by psychologists, or of undertaking an analysis of mental processes for himself.

The problem, then, which engages the attention of both psychologist and philosopher is this: Can the more complicated forms of experience be accounted for wholly in terms of the simpler? Or must we suppose, in addition, the existence of certain innate ideas, universal principles of knowledge, or a priori forms, furnished to the mind independently of experience? Those who adopt the former view, whether psychologists or epistemologists, declare themselves for empiricism, and their investigation is carried on along empirical lines. Those who prefer the latter interpretation must seek some other method and start with other premises. In either case the epistemologist lends willing comfort and support to that school of psychology whose method is the same as his own.

The modern $a$ priori or nativistic movement was inaugurated by René Descartes. Unable to explain the presence of the idea of God in the human mind as a product of mere experience, he concluded that this idea must be regarded as innately implanted by Deity himself. Immanuel Kant, basing his analysis on simpler material, finds it necessary to assume $a$ priori elements in all knowledge. Sensation, he says in the beginning of his ' Critique of Pure Reason,' corresponds only to the matter of the phenomenon; something else, the form, must lie a priori in the mind, since " that in which our sensations are merely arranged and by which they are susceptible of assuming a certain form, cannot be itself experience." 1 Thus at the very outset he assumes that there is something in knowledge not accounted for by the data of experience or by any of the complications of data based on the nature of experience

${ }_{1}^{1}$ Trans. Elementarlehre, Ite T., § I, Par. 3. 
itself; in other words, he posits something given to the mind independently of experience. The psychologists of the movement reach a similar conclusion as a result of their own analysis, and we have thus a union of philosophy and psychology on an a priori basis.

Compare this with Locke's primary assumption that all experience consists of sensation and reflection, or Hume's division of experience into sensations and ideas. Here is an epistemological attempt, followed out on the psychological side by Hartley and succeeding writers, to explain experiences solely in terms of experience itself. The success of such an attempt depends on the discovery of a principle or process in experience by which its simplest data-sensations-are transformed into more and more complex forms, ending with self-consciousness and rational knowledge. Association seemed best able to account for this transformation; hence, the empirical thinkers, both psychologists and epistemologists, devoted their energy largely to examining the nature of the associative process, formulating its laws, and applying them to all conceivable forms of complex experiences.

The third movement, Scottish intuitionism, which is contemporaneous with these two, exhibits the spirit of associationism in its philosophy and the spirit of the a priori movement in its psychology, though differing from both in the form of its doctrines. Thomas Reid, Dugald Stewart, and their followers, and more recently James McCosh, regard mind as a collection of faculties, each fully capable of performing its functions from the beginning - the memory capable of remembering, the rational faculty of reasoning, the perceptive faculty of perceiving objects as they exist in the outer world. But while their psychology is thus furnished with a priori elements for knowledge, the actual rise of knowledge is regarded as strictly empirical. The mind is held to be endowed with capacities for correct perception and knowl- 
edge; but actual perception and actual knowledge, whether of facts or of universal truths, are processes depending on the breadth or limitation of actual experience.

Historically the Scottish movement bears a twofold relation to associationism. The works of the Scottish writers being in the English language rendered them more accessible, and caused them to exert an 'unconscious' influence here and there on the views of the associationists. This is seen most notably, perhaps, in the increasing tendency of the English school, as time progressed, to separate the emotional and active sides of consciousness from intellectual experiences. But in addition to this general influence a direct relationship between the two movements was established by Thomas Brown, a pupil of Stewart, who adopted a thoroughgoing association method in his psychology, in connection with a modified form of the faculty view brought over from the Scottish school. We shall have occasion to note the influence of Brown, and through him of the Scottish movement, on the later phases of associationism.

The association movement, it should be observed, is by no means limited to England. It includes Scotch and Irish writers as well, and numbers many adherents outside of the British Isles. England, however, was the seat of its most notable achievements, and it is therefore not inappropriate to call associationism the 'English psychology.'

\section{Philosophical Standpoints of the Associationists}

The bond of union in the association movement, as we have seen, is found chiefly in the unwavering devotion of its adherents to the empirical method in psychology. The philosophical standpoints occupied by the associationists are most diverse. At one extreme we find George Berkeley, whose philosophy represents a radical type of ideal- 
ism resting on a theistic basis; at the other extreme the dualism of Hartley, which by its emphasis on brain func-

- tions led to an out-and-out materialistic philosophy in some of his disciples. Hume represents the skeptical attitude in philosophy, while Herbert Spencer declares for an agnostic position, which may be interpreted either in terms of monism or as a thoroughgoing dualism. Locke and John Stuart Mill are subjective dualists of different types, and Hobbes's standpoint, so far as his scattered utterances can be interpreted, is a dualism pure and simple.

The attitude of the associationists in logic and ethics also shows considerable variety. Their interpretation of the general notion is quite evenly divided between nominalism and conceptualism. On the question of the freedom of the will the deterministic position is generally accepted; but Berkeley, and Hume in one of his works (the 'Treatise'), incline to a modified libertarian view.

One must bear constantly in mind the influence of epistemological interests in fostering the investigation of association and molding the English school of psychology; unless this non-psychological motive be taken into account the historical development of the movement will be only imperfectly appreciated. But it is beyond the scope of the present work to discuss the philosophical side of the association problem. Whether knowledge derived through association of sensations is knowledge of things-in-themselves or only of phenomena, is a problem distinct from the analysis of the processes concerned in knowledge. The history of the latter-the association psychology-alone concerns us. We shall confine our examination to the role of association in mental activity as the associationists conceived or investigated it, passing over the philosophical implications into which they were inevitably drawn. Only in examining the theories of space perception does it 
seem impossible to avoid touching upon their views con-. cerning the nature of matter and objective reality.

\section{Outline of the Association Psychology}

The historical development of the association doctrine may be divided into four stages.

(I) There is first of all a precursory period beginning with the suggestions furnished by Aristotle, which bore little fruit till the time of Hobbes. Within this period should be included Hobbes and his successors, Locke, Berkeley, and others, whose analysis of mental association contributed important data to the doctrine before it became crystallized into a definite type of psychology. This preliminary stage ends with Hume. It is usual for writers of philosophy to class this thinker among the associationists. But Hume's aim, like that of Locke, was distinctly epistemological; he was interested in psychology-even the psychology of association-only as a stepping-stone to his theory of knowledge. From the psychologist's standpoint, then, it is more fitting to include Hume among the precursors of the movement, and to regard the association psychology proper as beginning with Hartley, whose ' Observations on Man,' published in 1749 , marks a new epoch in mental analysis. From this point on, associationism assumes the role of a psychological doctrine and school in Great Britain.

(2) The second stage of development extends from 1749 to 1829 . During this period Hartley, Brown, and their contemporaries built up a psychology which was fairly complete in covering the field of mental phenomena, though distorted by the crude physiology and burdened by the primitive anthropology of their time.

(3) With a better knowledge of the functions of the nervous system, and a dawning conception of the parallel between the growth of the child and the progress of the 
human race, the third stage was inaugurated in 1829 , by $f$ the appearance of James Mill's 'Analysis of the Phenomena of the Human Mind.' Following him came John Stuart Mill, Bain, and other writers, in-whose works the association psychology proper attains its complete development.

(4) The fourth stage may be said to date from 1855 , when Herbert Spencer published his 'Principles of Psychology.' In this work he unites his evolution philosophy, and later (in the revised edition of I872) the evolution biology of Charles Darwin, with the traditional empirical psychology. This resulted in transferring the association principle from individual to racial experience; or rather, the particular applications of mental association in individual experience are made subordinate to inherited associations, whose origin is in many cases traced back to remote times and to primitive types of organism. This conception was worked out more thoroughly by George Henry Lewes.

Along with the main development of associationism in England, should be noticed the contributions to the doctrine furnished from time to time by sympathetic Continental writers, notably Condillac and the sensationists of the eighteenth century, and the late nineteenth century French school of which Taine is the leading exponent. The connection between these writers and the British movement is too loose, however, to be brought within a single line of historical development. ${ }^{1}$

The association psychology culminated with Bain, Spencer, and Lewes. The evolution doctrine of the two last writers affords a wider scope to the play of association; but at the same time it opens the door to other factors, which have tended to lessen the importance of association in the eyes of the empirical investigator. The

1 The chronological chart at the end of the volume shows the parallel development of the two schools. 
emphasis now laid on biological continuity has stimulated a broader conception of mental development than the association notion taken by itself would allow. The better understanding of the anatomy and physiology of the nervous system brought about by recent research has led to a reconstruction of the older notions of mental structure and function. The application of mathematical methods to psychophysical research has drawn attention to new aspects of mental processes and has even altered somewhat our conception of the associative process itself. As a result the attitude of empirical psychology toward association has changed in recent years. The introspective associationism of half a century ago gradually lost its influence. The problems which it sought to solve have given place to others.

In the following chapters ${ }^{1}$ the rise of the association psychology will be traced through the four stages to its culmination in Spencer and Lewes, with a summary of the entire movement. ${ }^{2}$ A separate chapter ${ }^{3}$ will be devoted to the contributions of Continental associationists.

While the present-day aspects of the association problem scarcely fall within the province of an historical work, they cannot be altogether ignored. The transformation which has taken place in the standpoint of empirical psychology, and the new treatment of mental association which has resulted, seem to belong properly within the field of our inquiry. ${ }^{4}$

Bringing together the various historic interpretations given to the associative laws, and allowing for differences of terminology and emphasis, a composite picture may be obtained of the associative principle ${ }^{5}$ as conceived by the empirical school of psychologists, and of their application of these laws to the explanation of mental phenomena. ${ }^{6}$
${ }^{1}$ Ch. $2-5$.
2 Ch. 6.
${ }^{5}$ Ch. 9.
${ }^{3}$ Ch. 7.
${ }^{6}$ Ch. Io. 


\section{Source Books}

The most thorough treatment of associationism from the historian's standpoint, singularly enough, is by an Italian and is written in French. 'La psychologie de l'association,' by Luigi Ferri (I883), gives a very adequate and balanced presentation of the movement in Britain from Hobbes to Spencer. In Ferri's summary of the precursors of the school there is rather too little of Hobbes and too much of Berkeley. One may deem his treatment of James Mill too brief as compared with the emphasis laid on J. S. Mill and Bain. These are in the main attributable to the author's personal equation.

Not so defensible is his dismissal of Lewes in a brief paragraph, as a broad-minded follower of Spencer, "who did not devote his attention specially to the association doctrine, which he nevertheless accepts as a part of the more general doctrine of experience, together with evolution, which extends it indefinitely." 1 Apart from this single instance his perspective is well drawn, and his portrayal of the main features of each writer is good.

About one-third of the book is devoted to a critical estimate of the theory, and this part is particularly worthy of careful examination. Ferri's work is designedly limited to British writers, with only passing references to others; an exception is made, possibly from some national sentiment, in favor of the Italian writer Zanotti. This book has been of more assistance to the present writer than any other single work.

Another very complete history of associationism is found in ' $\mathrm{La}$ psychologie anglaise contemporaine,' by Th. Ribot (1870), ${ }^{2}$ which covers the movement from Hartley to Lewes in a very adequate manner. As a history of Associationism (which it does not claim to be) its chief defect is the omission of writers prior to Hartley,

1 P. 217.

2 Revised I875 and I892; also Engl. trans. 
the total neglect of Thomas Brown, and the inadequate discussion of Lewes.

These deficiencies are all easily explained. Lewes's chief works had not appeared when the volume was first published; Brown, on account of his affiliations with the Scottish school, did not seem to the author to belong among English writers; and, since Ribot's object was to portray merely the contemporary status of English psychology, Hobbes and his successors down to Hume appeared too remotely connected with the present-day situation to be noticed. Ribot's redundancy in other places may be explained on the same grounds. The less important and outlying doctrines of the writers from James Mill onward are given at greater length than would be desirable were the book concerned with the association problem alone.

Ribot's work has an advantage over Ferri's as a history, in that his own leaning toward associationism enables him to treat the writers of the school with more sympathetic insight. ${ }^{1}$

No general history of associationism has been written in Great Britain or America so complete and impartial as either of these, though numerous briefer surveys of the movement have appeared and many books and magazine articles dealing with special periods and writers. Only those of most importance from the historical standpoint need be mentioned.

The article on 'Association of Ideas' in the Encyclopedia Britannica, Ninth Edition, written by G. Croom Robertson, though far briefer than Ferri or Ribot, is

1 This is a real advantage only when combined with the historical instinct, as is the case with Ribot. Lewes's 'History of Philosophy' exhibits the disadvantages which may attend such agreement-it serves as an excuse for criticizing at length the minor points of difference between the historian and the authors examined. In the present work personal criticisms are confined to the footnotes; the criticisms in the text are based on the general consensus of associationism. 
perhaps the most adequate treatment of the association movement as a whole and the principles for which it stands. It covers the field from Aristotle down to Spencer thoroughly, with not a sentence of irrelevant matter. Lewes is omitted, possibly because the article was written before his chief work (the 'Problems') appeared. The synopsis and critique of the various conceptions of the associative principles contained in this article have been of great help to the present writer, especially in the preparation of chapters IX and X. The article is reprinted in Robertson's 'Philosophical Remains.' 1

In the Britannica, Eleventh Edition, the same article appears in somewhat condensed form, with a new section on recent criticisms of the school. The original article is preferable. Mention should also be made of the special examination of the several associationist writers found in the Britannica under their names. Most of these articles are very full and written from a broad standpoint; Bain and Spencer are missing from the list in the Ninth Edition, as they were still living when the work was prepared; they are included in the Eleventh.

The treatment in all the other English and American encyclopedias (usually under 'Association of Ideas') is too brief to be of much service, except to outline the doctrine; the same may be said of the articles 'Association of Ideas' and 'Associationism' by G. F. Stout in Baldwin's Dictionary of Philosophy and Psychology. The German Konversations-Lexika include only brief notices; the French Grande encyclopédie has a good summary by Ribot, also rather condensed.

Histories of philosophy by German writers treat the association movement very inadequately, on account of the overshadowing influence of Kant and his school on German thought. Ueberweg's work devotes considerable space to the individual writers, and is a good reference 1 Pp. $102 \mathrm{ff}$. 
work for this as for other movements. A most satisfactory historical treatment so far as the date of its publication permits is found in 'Speculative Philosophy in the Nineteenth Century,' by J. D. Morell (I 846$) ;^{1}$ another satisfactory discussion appears in the 'Histoire de la philosophie, les problèmes et les écoles,' by Paul Janet and Gabriel Séailles (1887-8). ${ }^{2}$ G. H. Lewes's 'History of Philosophy' (I 845-6) ${ }^{3}$ takes a sympathetic attitude but is quite inadequate as a view of the whole movement, though the treatment of Hartley is exceptionally good; Brown and James Mill are omitted altogether, and the later writers are only referred to briefly.4

The precursory period, from Aristotle to Hobbes, is covered exhaustively in an essay by Sir William Hamilton, appended as a Note to his edition of Reid's 'Works.' This is based on an earlier work by J. G. E. Maass, ${ }^{5}$ but contains many independent citations. S. T. Coleridge's essay on the early phase of associationism in his 'Bibliographia Literaria' ( 1847 ) in quite untrustworthy. Victor Cousin's 'Philosophie sensationiste de la $18^{\mathrm{e}}$ siècle' is especially good in its treatment of Hobbes.

'David Hartley and James Mill,' by G. S. Bower (I88I) gives an excellent summary of the association theory of these two writers, with some discussion of the younger Mill and of Spencer. While numerous magazine articles have appeared on the latest phase of associationism, ${ }^{6}$ and several important works have been written

1 Revised 1858.

2 Engl. trans. 1902.

3 Several revisions to 1880.

4 See Bibliography at end of this volume for other histories which are helpful in their discussion of specific periods or writers. Robert Blakey's treatment of Hartley and the other earlier writers, in his 'History of the Philosophy of Mind' (1848), Vol. III, may be cited as an excellent specimen in every respect of what an historical review should not be.

5 Hamilton refers to this as Maass's 'Beytraege' (I792). I am unable to find the work.

See Bibliography. 


\section{ASSOCIATIONISM}

from a controversial standpoint, there is nothing to be specially recommended "which covers the history of this period.

Interesting reviews of the experimental investigation of association, which has recently become prominent, and its relation to the older doctrine, are to be found in 'L'Association des idées,' by E. Claparède (I902), the 'Essai critique et théorique sur l'association en psychologie,' by Paul Sollier (I907), and 'The Psychology of Association,' by Felix Arnold (1906). 


\section{CHAPTER II}

\section{MENTAL ASSOCIATION FROM PLATO TO HUME}

\section{Aristotle}

THE notion that one idea or memory image follows another according to certain definite principles was the first step toward a general theory of association among mental states. This fundamental notion is found first, and in quite definite form, in the writings of Aristotle (B. C. 384-322). The earlier Greek philosophers were too engrossed in the problems of objective reality to examine the processes of experience.

I Plato suggests almost casually, in the 'Phædo,' the function of contiguity and similarity in the act of recollection. "What is the feeling of lovers when they recognize a lyre or a garment or anything else which the beloved has been in the habit of using? Do not they from knowing the lyre form in the mind's eye an image of the youth to whom the lyre belongs? And this is recollection: and in the same way anyone who sees Simmias may remember Cebes. ... And from the picture of Simmias you may be led to remember Cebes. ... Or you may be led to the recollection of Simmias himself. . . . And in all these cases the recollection may be derived from things either like or unlike. ... When we perceived something either by the help of sight or hearing or some other sense, there was no difficulty in receiving from this a conception of some other thing, like or unlike, which had been forgotten and which was associated with this." 1

Neither here nor in the 'Timæus,' which contains a 1 'Phaedo,' 73-6, Jowett trans. 


\section{ASSOCIATION FROM PLATO TO HUME}

fairly broad psychology, does he develop the notion further. According to Plato, knowledge is innate; learning consists merely in drawing out such knowledge as the soul had in previous existences. We draw out such knowledge, just as we recollect events of the present life, by means of similar experiences, or by unlike but 'contiguous' ones.

ARISTOTLE's systematic investigation of the whole realm of things knowable led him to examine mental facts quite as thoroughly as physical phenomena, and to employ for this purpose considerable self-observation. In the course of his study he noticed that the links in chains of thought which end in the recollection of particular facts succeed one another more or less systematically, and he believed that he had discovered the principles of their connection. Only three sorts of relationship, he affirms, are involved in the succession of thoughts: similarity, contrast, and contiguity. This and his doctrine of the fusion of experiences mark the historical startingpoint of associationism.

Aristotle's analysis of the sequence of mental processes is somewhat obscure, owing partly to the physical import of many of his terms, partly to the difficulty of getting at his real standpoint and interpreting his statements into modern psychological language. There are uncertainties too in the text at critical points, and one is always in danger of reading into his elliptical phraseology a meaning which he may never have intended. Sir William Hamilton's brilliant and exhaustive discussion of Aristotle's contributions to our theme is certainly open to this last objection.

It is in treating of memory and recollection in the 'De Memoria' that Aristotle brings out his notion of association. "A sense is capable of receiving into itself sensible forms without their matter, just as the wax receives into itself the mark of a ring without its iron or 
gold." 1 The persistence of such an impression constitutes memory, ${ }^{2}$ which is " neither sensation nor conceptual thought but the condition or modified form of one of these after the lapse of time." 3 "Memory is the possession of an experience potentially revivable." 4

The problem then arises, How is such a revival, which we call recollection, brought about?

"Recollection occurs," says Aristotle, "inasmuch as one experience naturally succeeds another. If [the succession be] necessary, it is plain that when the one is stimulated it will stimulate the other; if not necessary but habitual, then it will stimulate it only in most instances. It is a fact that some persons are more habituated after being stimulated once than others after many times; just so we remember some things better after seeing them once than other things after many times. Hence, when we are recollecting we keep stimulating certain earlier experiences until we have stimulated one which the one in question is wont to succeed. And just so we hunt through the sequence, thinking along from the present or some other [thing], and from similar or contrasted or contiguous. By this means the recollection comes; for the experiences are in some cases identical with [the one in question], in others simultaneous with it, in others they involve a portion, so that the remainder is small and is thereupon stimulated. In this way, then, persons make effort [to recollect], and in this way also without effort they do recollect, when the [experience] in question succeeds some other experience; though it is generally after a succession of other experiences such as we have mentioned that the one in question comes. It is not necessary to inquire how we remember the remote, but only the contiguous; for it is plain that the procedure

1 'De Anima,' II, Ch. XII, I; cf. 'De Memoria,' I, Io.

2 'De Mem.', I, Io.

3 'De Mem.', I, 4.

4 'De Mem.', II, 12 . 


\section{ASSOCIATION FROM PLATO TO HUME}

is the same-I mean, that of sequence-when we [recollect] without preliminary effort and even when we fail to recollect. For experiences habitually follow one another, this succeeding that. And so, when a person wishes to recollect, he will do this: he will endeavor to get some initial experience, which the one in question succeeded. Just so recollection comes most quickly and best [if it proceeds] from an initial point; for just as things are related to one another by sequence, so also are experiences; and such matters as have a regular order are easily remembered-for instance, mathematical science; others poorly and with difficulty." 1

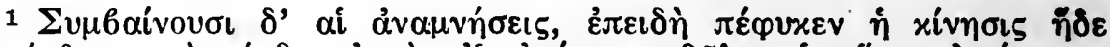

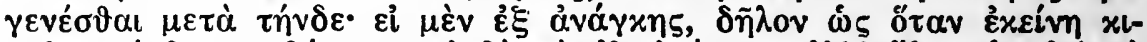

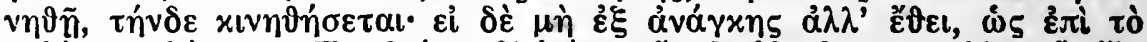

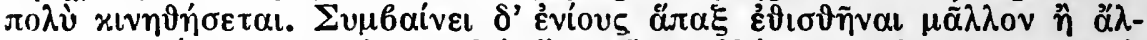

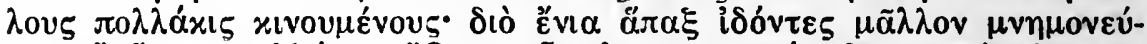

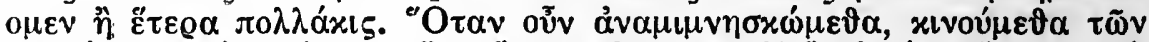

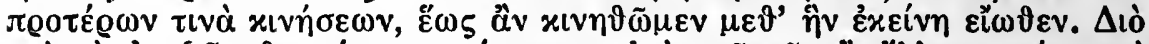

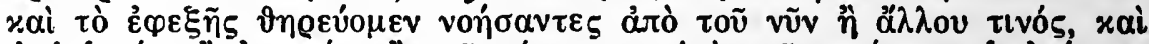

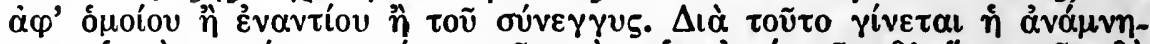

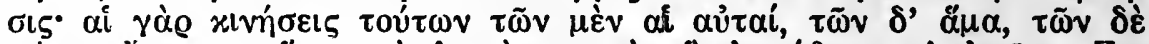

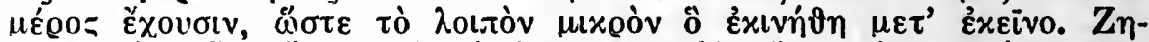

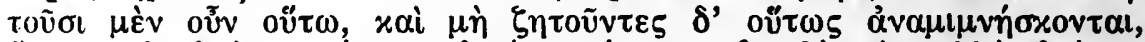

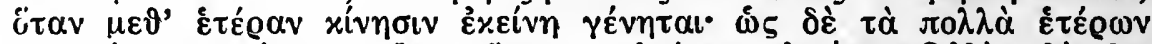

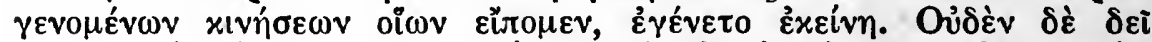

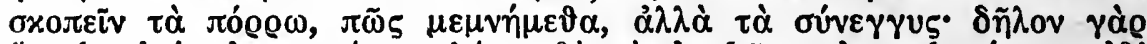

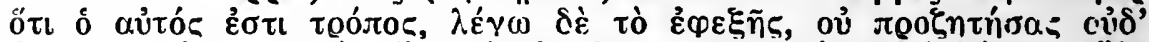

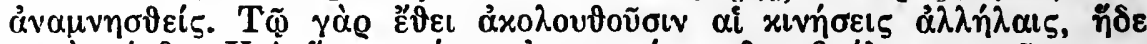

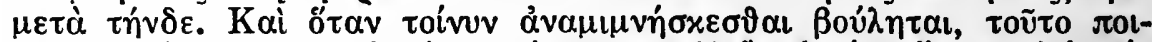

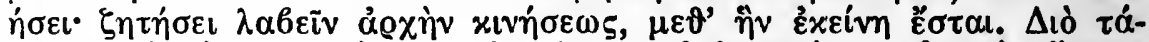

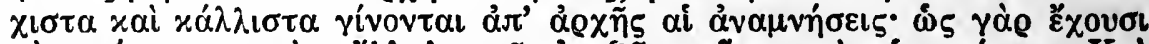

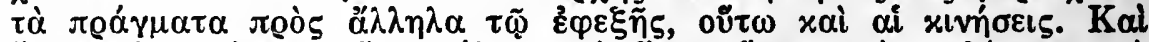

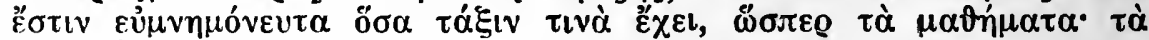

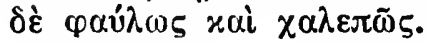

'De Mem.', II, 6-II (45I $b$ seq.). I am indebted to my colleague Professor E. Y. Robbins for assistance in this translation, which aims to go no further than the text justifies. The words in square brackets are our own insertions. Aristotle's use of physical terms in discussing mental facts will be understood if we render kirnous stimulation, instead of experience; the verb $k \iota v \omega$ has been translated stimulate. Aristotle uses the noun, like the verb, in the sense of movement or energy, but psychologists will find 'experience' or 'mental process' quite near his meaning-and more intelligible. The text used is Bekker's edition. Compare William Hamilton's rendering (Reid's 'Works,' Note $\mathrm{D}^{* *}$ ), and the excellent translation 
The conception of association developed in this remarkable passage covers a broader field than the mere act of recollection which it seeks to explain. Aristotle's main contentions may be restated in more modern form as fol- $\checkmark$ lows: In accounting for recollection we should observe that it depends on the sequence of mental processes. Mental processes always take the form of a series, or train. Their serial association-is due in some cases to a necessary connection, in others merely to their occurring together habitually. Habitual connection brings about actual association in most cases, but not always. Its power to do so varies with the individual and the sort of experience. The series may start with present experience (sensation?) or with something besides present experience. Its members follow one another according to similarity, contrast, or contiguity. ${ }^{1}$ The process is the same in efforts to recollect, whether successful or not, as in spontaneous recollection. Usually the series or train consists of several members. After some elaboration of the last two points the author makes this practical application: Since serial order is the natural characteristic of mental states, we shall recollect most readily what we wish if we begin by calling up something related to it; and similarly, subjects which have a natural order of sequence, such as mathematical truths, are those most easily fixed in memory.

Aristotle's contribution to the theory of successive association, if this interpretation be correct, is fourfold. (I) He was the first to point out clearly that the sequence of cognitive experiences is not mere chance, but occurs

by W. A. Hammond ('Aristotle's Psychology,' p. 204). Hammond's version has been used in other passages from Aristotle.

1 Professor E. B. Titchener agrees with Hamilton's interpretation of this passage, which makes temporal sequence a fourth law of association. While this reading is admissible it seems to the writer more likely that Aristotle conceived of the temporal sequence as underlying every association, and that the process itself follows the three laws here stated. 
through a definite process of natural association. (2) He recognizes habit as an important factor in determining association-subject, however, to individual variations. (3) Most important of all, he specifies the three principles of similarity, contrast, and contiguity as the sole bases of 'habitual' associative connection. (4) He declares that the same laws hold in purposive thinking as in the spontaneous flow of thought.

Fusion, or simultaneous association, was not altogether overlooked by Aristotle, though his discussion of this point contains more $a$ priori reasoning than introspection. Two separate simultaneous sensations, he says, are impossible. Even with a single sense, such as sight, the stronger of two sensations will displace the weaker; or if they be of equal strength they will counteract each other, leaving no sensation at all. But if they are not separate, they may combine and a new sensation arise, fused out of both elements. ${ }^{1}$ Much less can there be two separate simultaneous sensations from different senses, such as sight and taste. ${ }^{2}$ But in this case also fusion may occur, as for instance between white and sweet. This variety of fusion is attributed by him to "some unitary principle of the soul,' which senses the white and the sweet as a single unit. ${ }^{3}$ It is interesting to note that very similar conclusions regarding fusion are reached by a set of modern writers-based, however, on quite different premises.

\section{Post-Aristotelian Contributions; Descartes}

Aristotle's views on successive association do not seem to have been adopted or even understood by the thinkers of the centuries immediately following. In a few instances only was the problem even approached.

The psychology of the Sroics we know only at second

$$
1 \text { 'De Sensu,' VII, 3-4; }{ }_{3} \text { Ibf. 7. }{ }^{2} \text {., 24; cf. } 26 . \quad \text { Ibid., 9; cf. } 14 .
$$


hand. According to the summary of their doctrines given by Diogenes Laertes (ca. 200 A. D.), which is the nearest we can come to the original, the Stoics held that thoughts are formed by "similarity, or analogy, or transposition, or combination, or opposition. By a direct perception we perceive those things which are the objects of sense; by similarity, those which start from some point present to our senses; as, for instance, we form an idea of Socrates from his likeness." 1 It is not clear whether this view was held by Zeno of Cittium, the founder of the school (B. C. ca. 342-264), or was developed by his disciple Chrysippus (B. C. ca. 28r-208). The examples which are given of the other processes indicate a very superficial analysis, which does not touch the problem of the modes of association.

EPICURUS (B. C. 342-270), according to the same authority, held that ' every notion proceeds from the senses, either directly, or in consequence of some analogy, or proportion, or combination.' ' The recollection of an external object often perceived anteriorly' occurs as follows: "At the same moment that we utter the word man, we conceive the figure of a man, in virtue of a preconception which we owe to the preceding operations of the senses." 2 The notion of successive association is certainly implied in this, but it is not clearly brought out, and no analysis of the ways and means is given in the text. Nor do the disciples of Epicurus appear to have worked out the problem further.

Among the Sceptics, Carneades (B. C. ca. 21 5-129) definitely alludes to successive association. According to Sextus Empiricus, Carneades compares the succession of thoughts to "a chain, in which one link is dependent on another." 3

1 Diog. L., VII, Zeno, §36; Bohn's trans., p. 278.

2 Diog. L., Bk. X, § 21 ; Bohn, p. $435-6$.

${ }^{3}$ Sext. Emp., 'Adv. Math.,' Bk. VII, § 176; see Hamilton's 'Reid,' p. 894 . 
St. Augustine ${ }^{1}$ (A. D. 354-430), though indebted to Aristotle, takes a different view of memory and recollection, in that he lays more stress on association by contiguity. Memory, he says, receives within its gates all sorts of sense impressions. "Nor yet do the things themselves enter in, only the images of the things perceived." ${ }^{2}$ Out of this store we are continually weaving together new images of things which we have experienced. ${ }^{3}$ In darkness and silence we can bring up colors and sounds." "But what when the memory itself loses anything? ... Where do we search but in the memory itself? And there, if one thing be offered instead of another, we reject it, until what we seek meets us; and when it doth, we say, 'This is it.' . . . By the part whereof we had hold was the lost part sought for." 5 That the 'lost part,' when it is found, comes from memory, is shown by the fact that it is recognized. If we are trying to recollect a name, and some one mentions it, it comes to us not as something new, but as familiar. "Were it utterly blotted out of the mind, we should not remember it, even when reminded." 6

Augustine limits the associations involved in recollection to relations of contiguity; the experiences reinstated are 'parts' of the experience which calls them up. But as his illustration shows, the relation of parts is not limited to mere spatial contiguity; it embraces the totality of elements in any experience. He applies the principle of contiguity in its broadest sense.

The many commentators on Aristotle during the middle ages took up the passage on recollection which has been quoted. They discussed and amplified it, as they did every saying of the master, but without throwing any new light on association. Sir William Hamilton made an exhaustive search of this literature, which he presents in

1 L. Augustinus Aurelius.

2 'Confessions,' Bk. X., § 13 ; Parker's trans., 1885.

3 Ibid., § 14.

4 Ibid., \& I3.

s $\$ 28$.

6 Ibid. 
the voluminous note $\left(\mathrm{D}^{* *}\right)$ at the end of his edition of Reid's works. In none of the authors there cited, except those already mentioned, can one find any real contribution to the doctrine up to the time of Descartes and Hobbes. It must be borne in mind that during the latter part of the middle ages to depart from the dicta of Aristotle was regarded as akin to heresy. Any freshness or originality was frowned upon; the only advances came from new interpretations-and these too often were misinterpretations. The verbal contributions to the doctrine of association during this period are minutely treated in Hamilton's survey, which will delight a reader who cares for textual exposition. ${ }^{1}$ A single instance will serve to illustrate the vain groping after new light at the dawn of modern times.

LUIS VIVES (I492-I540), a Spanish commentator on Aristotle, was at the same time a writer of some originality. Commenting on the passage which we have examined, he ventures the view that recollection occurs 'by steps," "from cause to effect; from the latter to instrument; through the part to the whole; from this to situation; from situation to person; from person to earlier and later things; to contrary; to similar." ${ }^{2}$ "On looking at a place, from this there comes into the mind what we know to have happened in the place or to be situate there." 3 He thus recognizes the broad fact that trains of thought proceed in the direction of many sorts of logical

${ }^{1}$ Hamilton's citations are reliable, but not his interpretations of other writers. His criticisms are biased by his own standpoint and often reflect his prejudices. As already stated, he reads too much into Aristotle's elliptical phraseology. I am also of the opinion that he gives altogether too little credit to Hobbes and other writers of later date. Originality consists not always, nor chiefly, in collecting the raw material; more important is the shaping of the materialthe framing of a consistent viewpoint. A doctrine is not old because its elements have been used before, any more than a poem is old because previous writers have employed the same words or the same alphabet.

2 'De Anima,' Bk. II, ch. De Mem.

3 Ibid., Bk. I. 


\section{ASSOCIATION FROM PLATO TO HUME}

relationship; but he does not attempt to analyze these laws of association into their first psychological terms as did Aristotle.

Rene Descartes (I596-I650), the herald of the new era of thought, in spite of the great variety of topics which he treated, has little to say on the subject of memory and recollection. We may attribute this neglect to his doctrine of innate ideas, which made it seem to him of slight importance to explain how former experiences are 'recalled ' in memory.

In his posthumous work, the 'Traité de l'homme,' speaking of the action of objects on the nerves and brain, he says: "They have the strength to form for themselves there certain passages which still remain open after the action of the object ... has ceased, or which, if they close up, at least leave a certain disposition in the little fibers of which the brain . . . is composed, by means of which they can much more easily be opened again than if they had never been so before. . . . And also it must be noticed that if we open only certain ones ... this of itself may be the cause of others ... reopening also at the same time, especially if they had all been opened together several times and had not been used to being so one without the others. This shows how the recollection of one thing may be excited by that of another which was formerly impressed on the memory at the same time as it." 1 "The vestiges in the brain," he says elsewhere, " render it fit to move the soul in the same fashion as it was moved before, and thus to make it remember some thing, even as the folds which are in a piece of paper or a cloth make it more fit to be folded as it was before, than if it had never been so folded." 2

Descartes seems to hold that things which have been

1 Cousin's French ed., Vol. IV, pp. 400-I. The omissions, with one exception, are letters referring to an accompanying diagram. The translations from Descartes are mine.

2 'Lettres,' I, 36; French ed. of 1667. 
experienced together tend to be recalled together (contiguity), and that an experience will recall an earlier experience which partly-even though not wholly-resembles it (similarity). The reinstatement is made easier through habit, and is accomplished through the 'vestiges' of the former experience in the brain.

\section{Thomas Hobbes}

With Thomas HobBes, of Malmesbury (I 588-1679), began a new epoch in the development of the doctrine. Aristotle's work was mainly by way of enumeration and classification. He applies the laws of associative connection which he discovered to but one class of experiencesmemory. Only by implication are they extended to the relations between memory, sensation, and the other mental processes. And neither the later Greeks nor the Schoolmen, neither Augustine nor Descartes, despite their independent analyses, advanced perceptibly beyond his position. Augustine merely emphasizes the law of contiguity at the expense of similarity and opposition. For Descartes the associative process signifies a connection between brain states rather than experiences.

Hobbes's psychology is noteworthy as an initial attempt ( $I$ ) to establish the relation between different sorts of mental states on what we would today call a psychophysical basis; and (2) to trace all mental content ultimately to sense experience, doing away with the old notion of innate ideas. The real importance of Hobbes must be measured in the light of his influence on subsequent thought. The British thinkers who followed him developed their systems of psychology along the lines that he marked out; the notion of association, which he did little more than outline, became more and more prominent as the analysis was perfected. His historical value to associationism, therefore, lies not so much in his own 


\section{ASSOCIATION FROM PLATO TO HUME}

contributions to the doctrine, as in the fact that he established the type of psychology out of which associationism naturally and logically developed.

Hobbes's psychology is found in his two principal works, 'Human Nature' (1650), and 'Leviathan' (I65I). His standpoint is sensationistic, rather than associationistic. He is chiefly concerned in showing that the ' cognitive powers' of the mind deal only with material given by the senses. The effect which an object produces on the brain, he says, does not cease when the object ceases to work upon us; "though the sense [sensation] be past, the image or conception remaineth." 1 Imagination is any "conception remaining and by little and little decaying " from the act of sense. ${ }^{2}$ The strongest and clearest of these images are found in dreams and in visual after-images. ${ }^{3}$ A weaker sort is fancy, which he calls fiction: "The brain, or spirit therein, having been stirred by divers objects, composeth an imagination of divers conceptions that appeared single to the sense. As for example, the sense showeth at one time the figure of a mountain, and at another time the color of gold; but the imagination afterwards hath them both at once in a golden mountain." 4 Imagination in all its forms is "nothing but decaying sense. ${ }^{5}$ "Imagination and memory are but one thing." " Expectation is of the same nature; for, ' of our conceptions of the past we make a future.' ${ }^{7}$ Even science, the "knowledge of the truth of propositions, and how things are called, ... is remembrance." 8 All the ' cognitive powers' are thus brought into relation, directly or indirectly, with sensation. "There is no conception in a man's mind which hath not at first, totally or by parts, been begotten upon the organs of sense." 9

The succession of experiences remains to be accounted
1 'Human Nature,' ch. 3.
4 Ibid.
7 'Hum. Nat.,' ch. 4.
2 Ibid.
3 Ibid.
5 'Leviathan,' ch. 2.
8 I bid., ch. 6.
I Ibid.
9 'Lev.,' ch. I. 
for. Sensations arise from the action of external things upon our organs, ${ }^{1}$ and their succession requires no special psychological explanation. The sequence of imaginations is governed by sensation: "We have no transition from one imagination to another, whereof we never had the like before in our senses. . . . Those motions that immediately succeeded one another in the sense continue also together after the sense; insomuch as the former coming again to take place, and be predominant, the latter followeth by coherence of the matter moved. . . . But because in sense, to one and the same thing perceived sometimes one thing sometimes another succeedeth, it comes to pass in time that in the imagining of any thing there is no certainty what we shall imagine next; only this is certain: it shall be something that succeeded the same before at one time or another." ${ }^{2}$

Trains of thought are of two different sorts: (I) Such as are "unguided, without design, and inconstant";yet even in these, he remarks, we " may ofttimes perceive the way of it and the dependence of one thought upon another";-and (2) those "regulated by some desire and design." 3 Regulated trains of thought occur, either "when of an effect imagined we seek the causes or means that produce it," or "when, imagining anything whatsoever, we seek all the possible effects that can by it be produced." 4 The sequence from effect to cause is common to man and beast, while that from cause to effect belongs to man alone.

Hobbes thus concludes that contiguity in previous experience, which he terms 'coherence,' is the basis of all sorts of sequence of representations, but he finds it im-

1 Ibid.

2 Ch. 3.

${ }^{3}$ I Ibid. In the 'Human Nature' the trains are called 'casual and incoherent' and 'orderly' respectively. In this work also Hobbes attributes the succession of conceptions to their previous 'coherence or consequence' as sensations (ch. 4).

4 Ibid. 
possible in many cases to explain the preference of one association over another. Desire is a powerful agent in effecting the selection, ${ }^{1}$ and so is habit. ${ }^{2}$ Of the influence of habit on the succession of imaginations Hobbes says: "It is the nature of almost every corporal thing, being often moved in one and the same manner, to receive continually a greater and greater easiness and aptitude to the same motion, insomuch as in time the same becometh so habitual that, to beget it, there needs no more than to begin it." 3 Thus, man having invented language, "custom" hath so great a power that the mind suggesteth only the first word, the rest follow habitually and are not followed by the mind." 4 It is interesting to notice that Hobbes emphasizes our lack of attention to the subsequent terms of an habitual association train, in the same passage in which he insists on the strength of the cohesion between the members.

There is only a brief allusion to fusion of images in Hobbes's writings. In the passage on fancy already quoted he recognizes the possibility of joining together in one imagination two images which the senses have given at different times. But he appears to regard the 'coherence' of sensations as a physical rather than a mental phenomenon.

\section{John Locke}

To JoHn Locke (1632-I704), as already noted, belongs the credit of originating the phrase association of ideas. Locke's 'Essay concerning Human Understanding' ( 1690 ) is avowedly an attempt to combat the Cartesian theory of innate ideas by showing that knowledge arises from experience alone. It was important for this purpose that he should examine thoroughly the relations between different sorts of experience and the processes

$$
1 \text { 'Lev.,' ch. 3. } 2 \text { 'Hum. Nat.,' ch. 5. } \quad 3 \text { Ibid. } 4 \text { Ibid. }
$$


by which one experience leads to another. It should be borne in mind that Locke uses the term idea to denote any sort of experience. He has no single term to express representative experience, to which the term idea was later restricted.

Locke distinguishes between two sources of ideas, sensation and reflection, and calls the two classes of experience that arise therefrom ideas of sensation and ideas of reflection, respectively. ${ }^{1}$ Compared with Hobbes, he takes a more 'functional' attitude. Hobbes regards sensation as the source of all experience; the representative elements are merely corruptions of the original sense elements. According to Locke, the 'ideas of sensation' are transformed into other sorts of ideas by a separate function or faculty, which he calls reflection; and, further, there are certain ideas derived from reflection alone; among the latter are the ideas of the processes of ' remembrance, discerning, reasoning.' ${ }^{2}$

Ideas, or experiences, are fixed in memory by attention and by repetition, but still more effectually by the accompaniment of pleasure and pain. ${ }^{3}$ The reappearance of ideas as recollections is sometimes voluntary, sometimes passive. "The mind very often sets itself on work in search of some hidden idea, and turns as it were the eye of the soul upon it; though sometimes too they start up in our minds of their own accord and offer themselves to the understanding; and very often are roused and tumbled out of their dark cells into open daylight, by turbulent and tempestuous passions." 4

Locke has little to say regarding their mode of sequence, whether by contiguity or similarity. In a passage often quoted he distinguishes between ideas that "have a natural correspondence and connection with one another" and "another connection of ideas wholly owing to

1 'Essay,' 4th ed., I700, Bk. II, ch. I, § 24.
3 Ch. IO.

2 Ibid., ch. 6.

${ }^{4}$ Ch. ro, $\$ 7$. 
chance or custom." I It would not be difficult to resolve the former connection into similarity and the latter into contiguity. But Locke does not take the step. Elsewhere he says: "There comes by constant use to be such a connection between certain sounds and the ideas they stand for, that the names heard almost as readily excite certain ideas as if the objects themselves which are apt to produce them did actually affect the senses." ${ }^{2}$ This again implies association by contiguity, but Locke's purpose in the discussion is only to emphasize the strengthening effect of habit. Nowhere does he name or formulate the principles of the sequence of ideas, as Aristotle did.

On the other hand, Locke makes much of the phenomenon of simultaneous association, though his contributions to this phase seem to have been generally overlooked. The mind exerts its power over its simple ideas, he says, chiefly in three ways: (I) "Combining several simple ideas into one compound one," which gives us our complex ideas. (2) "Bringing two ideas, whether simple or complex, together, and setting them by one another, so as to take a view of them at once, without uniting them into one "-which gives us ideas of relations. (3) "Separating them from all other ideas that accompany them in their real existence; this is called abstraction," and is the means by which all our general ideas are formed. ${ }^{3}$ These processes correspond closely to our modern conception of fusion, complication, and analysis.

The unity of the complex idea arises "from an act of the mind, combining those several simple ideas together, and considering them as one complex one consisting of those parts," even where they do not exist together in nature." "All our complex ideas are ultimately resolvable into simple ideas, of which they are compounded and

1 Bk. II, ch. 33 .

$3 \mathrm{Bk}$. II, ch. I2.

2 Bk. III, ch. $2, \S 6$.

${ }^{4}$ Ch. $22, \S 4$. 
originally made up, though perhaps their immediate ingredients . . . are also complex ideas." 1

In another passage Locke gives the name of composition to the operation whereby the mind 'puts together several of those simple ideas it has received from sensation and reflection, and combines them into complex ones." "As simple ideas are observed [by the senses] to exist in several combinations united together, so the mind has a power to consider several of them united together as one idea; and that not only as they are united in external objects, but as itself has joined them together." 3 "The mind ... arbitrarily unites into complex ideas such as it finds convenient; whilst others that have altogether as much union in nature are left loose, and never combined into one idea, because they have no need of one name. It is evident, then, that the mind, by its free choice, gives a connection to a certain number of ideas, which in nature have no more union with one another than others that it leaves out." 4

In view of this rather extended discussion of simultaneous association, it appears certain that Locke had in mind the coexistence as well as the sequence of ideas when he wrote the historic chapter on Association. ${ }^{5}$

According to Locke's view association, whether concerned with the succession of ideas or their composition into complex experiences, is of two sorts: it is based either on their 'natural correspondence,' or on 'chance or custom.' The latter sort may be voluntary or involuntary, and is that which leads us into all kinds of error in thinking. The fact of association, the union or nexus between different experiences, though an important factor in his psychological analysis, is not the chief factor in his psychology, since it shares the field with other fundamental principles. Yet it requires only a little deeper

1 Ibid., § 9. 2 Ch. II, $\$ 6$. 4 Bk. III, ch. $5, \S 6$. ${ }^{3}$ Ch. I2, § I.

5 Bk. II, ch. 33 . 
analysis of his material to bring out explicitly the laws of similarity and contiguity.

Locke seconds Hobbes's attempt to derive all complex experience from simple experience, but differs with him in deriving simple experience from reflection as well as from sensation. He thereby abandons the field of pure sensationism; and in this respect he is followed by later English writers. His chief historic merit in psychology, however, is his contribution of the term association of ideas, which focused the attention of future thinkers on this factor as a means for the empirical derivation of knowledge. His emphasis of habit or custom as a factor in association also had considerable influence in determining subsequent analysis.

\section{George Berkeley}

George Berkeley (I685-I753), Bishop of Cloyne, lays considerable stress on the associative process, which he terms suggestion, and enumerates several of its modes. "Distance," he says, "is suggested to the mind by the mediation of some other idea, which is itself perceived in the act of seeing." 1 "That one idea may suggest another to the mind, it will suffice that they have been observed to go together, without any demonstration of the necessity of their coexistence." ${ }^{2}$

Berkeley divides our mental content into ideas of sense and ideas of imagination. "The ideas of sense are more strong, lively, and distinct than those of the imagination; they have likewise a steadiness, order and coherence, and are not excited at random . . . but in a regular train or series." ${ }^{3}$ The ideas of imagination " are more properly termed ideas or images of things which they copy and

1 'New Theory of Vision,' 1709, §16; cf. 'Principles of Human Knowledge,' I710, § 43.

2 'New Theory,' \$25.

3 'Princ.,' § 30. 
represent "1 - a hint toward our modern use of the term idea. "I find I can excite ideas in my mind at pleasure." 2 I can "by an act of my will . . . form a great variety of them and raise them up in my imagination," though "these creatures of my fancy are not altogether so . . . permanent as those perceived by my senses." 3 "We perceive a continual succession of ideas [both of sense and of imagination]; some are anew excited, others are changed or totally disappear." 4 The ideas themselves are inactive, so that one idea cannot produce or make any alteration in another, ${ }^{5}$ but the changes are caused by an "incorporal active substance or spirit." 6

The succession of one sensation to another is attributed by Berkeley to the power of Deity, ${ }^{7}$ while the succession of a representation to a sensation is due to habitual coexistence. "From a frequently perceived connection, the immediate perception of ideas by one sense suggests to the mind others, perhaps belonging to another sense, which are wont to be connected with them." 8 The same is true of the succession of one representation to another: "In certain cases a sign may suggest its correlate as an image, in others as an effect, in others as a cause. But where there is no such relation of similitude or causality nor any necessary connection whatsoever, two things by their mere coexistence, or two ideas merely by being perceived together, may suggest or signify one the other." 8 The modes of association of successive ideas, then, according to Berkeley, are similarity, causality, ${ }^{10}$ and coexist-

$1 \S 33$.

2 'Princ.,' § 28.

3 'Dialogues between Hylas and Philonous,' I7r3, II.

4 'Princ.,' § 26.

$5 \S 25$.

$6 \$ 26$.

7 \& 30 .

8 'Dial.,' I.

9 ' Theory of Vision Vindicated,' I733, § 39.

10 'Causality or some other necessary connection if there be such,' seems to be his meaning. 
ence or contiguity. Like Locke, Berkeley emphasizes the pedagogic side of association: "To the end their use be permanent and universal, these combinations must be made by rule and with wise contrivance." 1

The fact of simultaneous association is also brought out in Berkeley's writings. "A certain color, taste, smell, figure, and consistence, having been observed to go together, are accounted a distinct thing signified by the name apple; other collections of ideas constitute a stone, a tree, a book, and the like sensible things." 2 And "men combine together several ideas apprehended by divers senses or by the same sense at different times or in different circumstances, but observed, however, to have some connection in nature either with respect to coexistence or succession; all which they refer to one name and consider one thing." ${ }^{3}$ That is, the contiguity of sensations is the basis of the simultaneous association of ideas.

Berkeley's work transformed the problem of knowledge into a distinctively psychological one. Although his philosophical standpoint is idealistic, it rests on experience, and his analysis is more thoroughly empirical than that of Locke and Hobbes. His theory of visual space perception especially called attention to the fact that our knowledge of distance away from the eye is capable of resolution into simpler experiences; and this led his successors to go deeper into the analysis and synthesis of all classes of experience. That his idealistic metaphysics affected the trend of English thought comparatively little, while his psychological empiricism exerted so great an influence, would lead us to regard the psychological side of his theory as more important historically than the philosophical side.
1 'Princ.,' \&65.
2 'Princ.,' § I.
3 'Dial.,' III. 


\section{David Hume}

David Hume (I 7 I I-I 776) was the first after Aristotle to attempt a thorough classification of the modes of association. Indeed, he claims for himself entire originality in this field. "Though it be too obvious to escape observation that different ideas are connected together," he says, "I do not find that any philosopher has attempted to enumerate or class all the principles of association-a subject, however, that seems worthy of curiosity. To me there appear to be only three principles of connection among ideas, namely, resemblance, contiguity in time or place, and cause or effect. ... That this enumeration is complete . . . may be difficult to prove to the satisfaction of the reader, or even to a man's own satisfaction. All we can do in such cases is to run over several instances, and examine carefully the principle which binds the different thoughts to each other, never stopping till we render the principle as general as possible. The more instances we examine, and the more care we employ, the more assurance shall we acquire that the enumeration which we form from the whole is complete." 1 Whether Aristotle's classification was unknown to Hume, or was considered by him a mere casual list like Berkeley's, we cannot be sure; but it seems probable that Hume was not aware of Aristotle's attempt.

A significant contribution also, though only a verbal one, is Hume's alteration of the meaning of the term idea in the direction already suggested by Berkeley. Hume divides experience into impressions and ideas. Impressions consist of sensations, passions, and emotions ' which enter with most force' into consciousness. ${ }^{2}$ Ideas are ' faint images of these '; ${ }^{3}$ they are ' copies of our impres-

\footnotetext{
1 'Enquiry concerning Human Understanding,' 1748. §3; $c f$. 'Treatise on Human Nature,' I739, Bk. I, Pt. I, \$ 4. ' 'Treatise,' Bk. I, Pt. I, §I. 


\section{4

sions.' $^{1}$ Ideas are of two sorts: memories and imaginations; the former are more lively, while the latter are not restricted to the order or form of our original impressions. $^{2}$

Having settled his terminology, Hume proceeds to consider the nature of the connection between successive ideas. "It is evident," he says, " that there is a principle of connection between the different thoughts or ideas of the mind, and that in their appearance to the memory or imagination they introduce each other with a certain degree of method and regularity." 3 "Were ideas entirely loose and unconnected, chance alone would join them." 4 But since "the same simple ideas . . . fall regularly into complex ones," we must suppose "some bond of union among them, some associating quality by which one idea naturally introduces another." 5 "This uniting principle among ideas is not to be considered as an inseparable connection. . . . Nor yet are we to conclude that without it the mind cannot join two ideas. . . . But we are only to regard it as a gentle force, which commonly prevails." ${ }^{\circ}$ It is at this point in the discussion that he enumerates his three modes of association-resemblance, contiguity, and causality.

The most interesting part of Hume's subsequent analysis for our purpose is his attempt to reduce the relation of causality to an habitual experience of contiguity; for in the end Hume finds no justification for the conception of a 'necessary' relation of phenomena, such as the idea of causality ordinarily implies; the notion of a necessary connection, which Berkeley insisted upon, is based, according to Hume, not on knowledge or scientific reason-

1 'Enquiry,' § 2.

2 'Treatise,' Bk. I, Pt. I, §3. Impression as used by Hume includes what are today known as sensations and perceptions; his term idea includes both images and thoughts.

3 'Enq.,' § 3 .

4 'Treatise,' l. c., § 4 .

s Ibid.

B Ibid. 
ing, but on observation and experience. ${ }^{1}$ The so-called causal connection, therefore, resolves itself into a mental relation: "reason can never show us the connection of one object with another, though aided by experience and the observation of their constant conjunction in all past instances." 2 The mind, therefore, in its passage from one idea to another, is determined not "by reason, but by certain principles which associate together the ideas of these objects and unite them in the imagination." ${ }^{3}$ The belief in causation, and indeed the belief of the existence of objects, is " a lively idea related to or associated with a present impression." 4 The three principles which he adopts from Berkeley thus reduce to two: resemblance and (customary) contiguity in experience.

Hume makes only brief allusions to simultaneous association. Among the effects of the union or association of ideas, he says in the 'Treatise,' " there are none more remarkable than those complex ideas which are the common subjects of our thoughts and reasoning, and generally arise from some principle of union among our simple ideas." ${ }^{5}$ In the "Enquiry' the reference is still more vague: "Nothing is more free than the imagination of man; and though it cannot exceed that original stock of ideas furnished by the internal and external senses, it has unlimited power of mixing, compounding, separating, and dividing these ideas." 6

Throughout his two works Hume concerns himself particularly with the association of representative experiences. But in one place he notes that " there is an attraction or association among impressions as well as among ideas; though with this remarkable difference, that ideas are associated by resemblance, contiguity, and causation, and impressions only by resemblance." This is a mere

1 'Treat.,' Bk. I, Pt. III, §3.

4 Pt. III, \& 7.

7 'Treat.,' Bk. II, Pt. I, § 5 .

2 Ibid., § 6.

5 Bk. I, Pt. I, § 4 .

3 Ibid.

$6 \S 5$. 


\section{6 ASSOCIATION FROM PLATO TO HUME}

casual statement, however, and does not belong to his general analysis, which lags behind Hobbes and Locke in this respect. He alludes to an association of voluntary acts in the same casual way. ${ }^{1}$ Had he brought these concepts into vital connection with the rest of his work, his psychology would undoubtedly deserve to be classed as associational. But it was reserved for Hartley to extend the principle of association systematically to all classes of mental phenomena.

The psychology of Hume is a rounding out of Berkeley's and Locke's. Starting, like them, from the empirical standpoint, he employs a more rigid method, especially in analyzing the notions of causality and necessary connection, and advances to the epistemological conclusion that all knowledge is knowledge of experiences, and that the relations of 'things-in-themselves' can never be known.

Historically, his work forms the starting-point of two widely distinct movements in philosophy and psychology. The influence of Hume transformed the dogmatic attitude of the earlier German school into a critical one; Kant and his successors were impelled thereby to seek in experience some validation of the deductions of reason. On the other hand the British school, which had already abandoned the notion of innate ideas, sought by further analysis of consciousness in terms of association to obtain the utmost out of experience. In England, philosophy after Hume became associationistic as well as psychological; while the Scottish school, inaugurated by Thomas Reid in I764, followed Hume in the empirical analysis of consciousness, but held that experience gives a direct, intuitive knowledge of things; hence it found less need for the principles of association. In the line of direct development, Hartley's analysis is a natural extension of Hume's; but the publication of his chief work followed closely after Hume's 'Treatise' and was partly antici-

1 Ibid., Bk. II, Pt. III, § 5 . 
pated in an earlier article. We must therefore attribute to the influence of earlier writers much of the initiative for Hartley's elaboration of the associative laws.

\section{Other Contributions}

The trend of thought started by Hobbes had been taken up in the meanwhile by numerous other English writers. Their contributions were for the most part confined to philosophy and political science. In the former sphere may be cited Henry Dodwell (i64I-I7II), Anthony Collins (I676-I729), and ARTHUR Collier (i680I732); in the latter BeRnaRd DE MANDEville (I670I 733), whose 'Fable of the Bees' (I 705) attained a very wide circulation for those days.

Peter Browne (ca. I665-I 735), Bishop of Cork and Ross, deserves special mention on account of his psychological analysis. His 'Procedure, Extent and Limits of the Human Understanding' ( $\mathrm{I} 728$ ) is substantially in accord with Locke, but he rejects the latter's 'ideas of reflection' and takes a purely sensationist standpoint.

One other writer should be noticed before we pass to Hartley. JoHN GAY (I699-I745), a clergyman and cousin of the poet of like name, sought to derive the moral principles from association. His work appeared annoymously in I 73I, as a prefatory essay to the English translation by Edmund Law of Archbishop William King's 'Origin of Evil'; it was entitled 'Dissertation on the Fundamental Principle of Virtue,' and was acknowledged as Gay's in the fourth edition. In this 'Dissertation' our motives to action are attributed to pleasure and pain -man 'pursues the former and avoids the latter.' ${ }^{1}$ The aim being happiness, the course of action is regulated by the 'association of ideas' of pleasure or pain ${ }^{2}$ and these associations lead to 'habits.' ${ }^{3}$ That which man "appre-
$1 \S 3$; p. xxii, ed. of I73I.
2 P. xiv.
3 Ibid. 


\section{8 \\ ASSOCIATION FROM PLATO TO HUME}

hends to be apt to produce pleasure, he calls good and approves of." 1 Good and evil acts, even in the imagination, "have a present pleasure and pain annexed to them, proportionable to what is apprehended to follow them in real existence "; ${ }^{2}$ and certain things become "so tied together and associated in our minds" with pleasure or pain, that one cannot present itself but the other will occur; and the association remains even after that which at first gave them the connection is quite forgot. ${ }^{3}$ Some of these associations are not original, but are learned "by imitating those whom we admire." 4 Gay's theory was the direct precursor of the utilitarian movements in ethics.

In I 747 appeared a short anonymous work, entitled 'An Enquiry into the Origin of the Human Appetites and Affections, shewing how Each Arises from Association,' which has been attributed to Gay, ${ }^{5}$ though the authorship is not definitely established. The views which it advances may well have been Gay's, but the frequent references to Gay's 'Dissertation ' are entirely impersonal. ${ }^{6}$ Among the positions taken in this 'Enquiry' the following may be noticed.

(I) Inseparable union: "The joint appearance of two or more ideas frequently in the mind is for the most part changed into a lasting and sometimes an inseparable union "; ${ }^{7}$ this is illustrated by the child's hearing the sound of the word nurse, and at the same time seeing the nurse.

(2) Necessary connection: "There seems to be a necessary correspondence or connection betwixt some ideas and others." 8 Thus the ideas of space and time "associate themselves with and are inseparable concomitants

$1 \S 3$, p. xxii. $\quad 2$ Ibid.

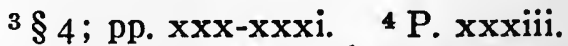

5 Reprinted, 1837, by Samuel Parr in the 'Metaphysical Tracts'; the latter were printed after Parr's death, and the publisher found no clue to the authorship of the 'Enquiry.'

6 E.g., § II, 26; VI, 22.

7 II, I8.

8 \& I. 
of all others "; ${ }^{1}$ the ideas of husband and wife are a 'natural' association, etc.

(3) Coalescence of ideas: "When two or more objects at the same time strike the same or different organs, if the impressions are again and again repeated the ideas they excite will coalesce and unite." ${ }^{2}$ The author also repeats the view given in the 'Dissertation' that some of our associations "we learn from imitation." ${ }^{3} \mathrm{He}$ calls attention to the decrease of pleasure and pain by repetition of the experience. The latter part of the 'Enquiry' is an application of association to ideational pleasure and pain and to the principles of morality.

1 Ibid.

2 Ibid.

$3 \S$ II, 43 . 


\section{CHAPTER III}

\section{DAVID HARTLEY AND THE EARLIER ASSOCIATIONISTS}

\section{Hartley's General Standpoint}

David Hartley (I705-I 757) was a contemporary of Hume and began his work on association before the publication of Hume's philosophical writings. Like Locke he was a physician and well versed in several sciences. His chief work, the 'Observations on Man, his Frame, his Duty, and his Expectations,' appeared in I 749, ten years after the-' Treatise' and one year after the 'Enquiry' of Hume. But according to the preface he had been for about eighteen years considering the power of association, having been led to do so first by hearing of Gay's theory, and later by reading the 'Dissertation' itself. Prior to the 'Observations,' he published anonymously a short treatise in Latin, entitled 'Conjecturae quaedam de sensu, motu, et idearum generatione,' giving in concise form a psychological analysis based on association. $^{1}$

The two fundamental points in Hartley's theory of mind are (I) his attempt to trace a close correspondence between mental and neural activity in terms of vibra-

1 The 'Conjecturae' appeared without date, and there is no direct evidence fixing the year, which is velieved to be I73I. Its 22 propositions and many of the corollaries and cases are stated in almost equivalent language with the first portion of the 'Observations,' so there can be no question of the authorship; but the discussion in the 'Conjecturae' is much briefer. Citations are from the reprint by Parr (Metaphysical Tracts) of the 'Conjecturae,' and from the fourth edition of the 'Observations,' London, I80I. 
tions, ${ }^{1}$ and (2) his elaboration of all experience according to the principles of association. Hartley's doctrine of vibrations, though it suggests certain modern theories of psychological parallelism, was not their direct precursor. The modes of neural activity were so little known in Hartley's time that it would be difficult to restate his doctrine in modern physiological terms. Even Joseph Priestley, the disciple and editor of Hartley, who upheld most of his other views, omitted the passages referring to the vibration theory in his abridged edition of the 'Observations.' But Hartley's theory of association, itself a natural development of the earlier attempts, was widely noticed and became the startingpoint for later developments of the association psychology.

The 'Observations on Man' is divided into two parts, the first comprising Hartley's psychology ("observations on the frame of the human body and mind "), the second his ethics and theology ("observations on the duty and expectations of mankind "). Only the former concerns us here. The work consists of a series of propositions, demonstrations, and corollariés-a literary form suggestive of Spinoza, and rather surprising in a treatise so thoroughly grounded on empiricism.

Hartley starts by dividing man into body and mind. Body is subject to investigations of the same sort "as the other parts of the external material world." Mind is "that substance, agent, principle, etc., to which we refer the sensations, ideas, pleasures, pains, and voluntary motions." ${ }^{2} \mathrm{He}$ divides experience, or 'internal feelings,' I into sensations and ideas. "Sensations are those internal feelings of the mind which arise from the impressions made by external objects upon the several parts of our

${ }^{1}$ Compare Aristotle's use of kivnous in both a physical and a mental sense, p. 26.

2 'Obs.,' Pt. I, introd. 
bodies. ${ }^{1}$ All our other internal feelings may be called ideas." "The ideas which resemble sensations are called ideas of sensation; all the rest may therefore be called intellectual ideas; " and he proposes to show that "the ideas of sensation are the elements of which all the rest are compounded." Pleasures and pains are either sensations or ideas, all experiences being "attended with some degree either of pleasure or pain." 2 Hartley expressly excludes reflection as a separate source of ideas, and in this way seeks to make his analysis simpler than Locke's.

In addition to the elements of experience (sensations and ideas), he assumes that the human mind is endowed with certain faculties, namely, "memory, imagination or fancy, understanding, affection, and will," 3 by means of which the elements are transformed. One must also consider the motor phenomena of the body in connection with mental experience. The motions of the body, he says, are of two kinds, automatic and voluntary; the former "are those which arise from the mechanism of the body in an evident manner," while the latter are "those which arise from ideas and affections, and which therefore are referred to the mind." 4 He proposes, then, (I) to lay down the general laws "according to which the sensations and motions are performed" and "ideas generated"; (2) to apply these laws in turn to each sort of sensation and motion; and (3) to apply them further to the genesis of each particular sort of idea, such as memory, imagination, etc. A fourth problem, which does not concern us here, is to furnish a history and analysis of the different classes of pleasures and pains. ${ }^{5}$

Sensations, according to Hartley, are due to vibrations in the small particles of white medullary substance of the

${ }^{1}$ Note the advance over Hume in this distinction between the physical impressions or stimuli and the resulting sensations.

2 Introd. $\quad 3$ Ibid. $\quad$ Ibid. 5 Ibid. 
brain, spinal cord, and nerves, occasioned by "external objects impressed upon the senses." 1 But these vibrations are of a corporeal nature, while sensations and ideas are of a mental nature; and it is impossible, he affirms, to discover in what way the former "cause or are connected with' the latter-a statement which distinctly repudiates the materialistic standpoint.

The genesis of ideas is attributed to the fact that "sensations, by being often repeated, leave certain vestiges, types, or images of themselves "; ${ }^{2}$ and that sensory vibrations beget in the brain substance "a disposition to diminutive vibrations . . . corresponding to themselves." ${ }^{3}$ These dispositions are the physical basis of ideas, and the ideas themselves occur and recur as the vestiges are stimulated and set in vibration. Ideas thus formed are called simple ideas of sensation, though they "are not entirely simple, since they must consist of parts, both coexistent and successive, as the generating sensations themselves do." \& The intellectual ideas are complex to a greater degree.

\section{Hartley's Conception of Association}

This brings Hartley to the law of association. "Any sensations, $A, B, C$, etc., by being associated with one another a sufficient number of times, get such a power over the corresponding ideas, $a, b, c$, etc., that any one of the sensations, $A$, when impressed alone, shall be able to excite in the mind $b, c$, etc., the ideas of the rest." 5 The succession of sensations is due solely to the order of sense impressions, and is not included in the law: a sensation $A$, however frequently it has occurred in connection with another sensation $B$, does not recall the latter, but only the corresponding idea $b$. But an idea (like a

1 Prop. IV. 4 Prop. VIII.

2 Prop. VIII.

${ }^{3}$ Prop. IX.

$\checkmark$ Prop. X. 
sensation) may serve to recall an idea; thus if a number of ideas, $a, b, c, d$, etc., have occurred often together, then the recurrence of one of these, such as $a$, "will frequently bring in all the rest, $b, c, d$, etc., and so associate all of them together still farther." 1

Similarly, he finds that association includes 'muscular motions' in the same way as ideas and sensations, and finally generalizes his law so as to include all three phenomena: "If any sensation $A$, idea $B[b]$, or muscular motion $C[\nu]$, be associated for a sufficient number of times with any other sensation $D$, idea $E[e]$, or muscular motion $F[\phi]$, it will at last excite $d$, the simple idea belonging to the sensation $D$, or the very idea $E$ $[e]$, or the very muscular motion $F[\varphi] ; "{ }^{2}$ it cannot by association " excite the real sensation $D$, because the impression of the sensible object is necessary for this purpose." 3

This is the law of successive association. Hartley finds that it can be extended to include simultaneous association of complex experiences also. Thus, if a sensation $A$ be associated at different times with different sensations $B, C, D$, etc., one at a time, then $A$ will at last be able to raise their ideas, $b, c, d$, etc., all together,-unless, indeed, they belong to the same region of the brain, in which case, he says, " $A$ will raise up something intermediate between them." Again, if a compound idea, $a+b+c+d$, due originally to a compound impression, $A+B+C+D$, be called up in any way, its parts, by the fact of their being repeated together, tend to be still more closely associated. "Simple ideas of sensation must run into clusters and combinations by association,

1 Prop. XII, 5.

2 Prop. XX, cor. 7. The lower case letters in brackets represent ideational elements, and Greek letters represent muscular equivalents; these should be substituted to carry out consistently the symbolism which Hartley himself suggests.

${ }^{3}$ Ibid. 
and these will at last coalesce into one complex idea, by the approach and commixture of the several compounding parts; . . . many of our intellectual ideas ... are in fact thus composed of parts, which by degrees coalesce into one complex idea." 1 "As simple ideas run into complex ones, by association, so complex ideas run into decomplex ones by the same; but the union in the latter case is not so close and permanent." 2

According to Hartley, then, the sole basis of association is contiguity; and he limits it to contiguity in time. Sensations must be simultaneous or in immediate succession in order that one may bring up the idea of the other; ideas must have occurred together or in close succession in order that one may bring up one or all of the others. His view seems to be that contiguity in space is no part of the mental law: if spatially contiguous objects are more likely to be sensed at the same time or successively than objects which lie far apart, this is a physical phenomenon; whether the objects be distant or adjacent, it is the simultaneity or succession of their impressions that leads to the association, not their space relation.

Hartley ignores the law of resemblance altogether. The only resemblance which he recognizes is that between the sensation and its corresponding idea. An idea does not recall similar ideas, but the same idea is repeated, and with it are associated others formerly experienced contiguously; a sensation recalls only its corresponding idea (the faint copy of itself), or ideas contiguously related to it in the past. Hartley is able to do without the law of resemblance because he believes that complex sensations and ideas are resolvable into simpler elements, and that these elements are actually repeated. What we generally call the resemblance of one experience to another is for him only the presence of certain identical simple elements in two complex experiences.

1 Prop. XII, cases I, 4, 5.

2 Ibid., cor. 4. 
On the other hand the function of habit plays an important part in his analysis of the associative process. Experiences, whether sensations or ideas or a group including both, when they have been frequently associated together tend to recall one another more readily; and a group of simultaneous experiences, by frequent recurrence as an associated group, tend to a firmer union, and at length become a single complex experience. Habit or repetition, then, tends to strengthen any union founded on contiguity of experience, and makes the succession more ready and the grouping more unitary.

Hartley broadens the conception of association by including the motor side in his discussion. He holds that muscular movements form associations of the same sort as the associations between ideas, so that the recurrence of one tends to reinstate others which formerly succeeded it. And he extends this notion so as to cover a general association between sensations, ideas, and movements: the recurrence of a movement may recall an idea formerly associated with it; or the recurrence of a sensation or idea may bring about the repetition of a movement.

Thus Hartley is able to formulate his explanation of volition in psychophysical terms. The notion of an association between experiences and human activity permits him to treat conative phenomena in the same way as intellectual and affective phenomena, a possibility which earlier analysis had overlooked. Hume had suggested that habit promotes facility in the performance of any action; but he did not analyze voluntary activity in terms of association, and he seems to have believed the mind capable of imagining and acting freely and arbitrarily apart from the force of association. ${ }^{1}$

In Hartley for the first time we find the principle of association stated broadly enough to cover the entire field of human experience and activity. In his subsequent

1'Treat.,' Bk. I, Pt. I, § 4; 'Enq..' §8; and elsewhere. 
analysis he proceeds to apply this principle to the discovery of elementary mental phenomena, first taking up sensation and resolving apparently simple sensations into more elementary units.

\section{Hartley's Applications of the Principle}

Hartley accepts the classical view that the senses are five in number. 'Heat, cold, and pressure,' as well as pain, he considers qualities of the sense of touch, or ' feeling. ' ${ }^{1}$ Much of his analysis of sensation is concerned with the vibration theory, but the principles of association are applied in accounting for the knowledge of space relations through each sense. Take touch, for instance. "The ends of the fingers give us so much more precise information concerning the tangible qualities of bodies than . . . the ends of the toes" on account of the custom of "rubbing the ends of the fingers against the tangible object "; ${ }^{2}$ this is the effect of "practice and habit,' that is, association. Again, in touch " distance is judged of by the quantity of motion, and figure by the relative quantity of distance "; ${ }^{3}$ we learn "what is the distance of the part touched from the mouth, nose, shoulder, elbow, or any other remarkable part, . . . by passing frequently from the mouth, nose, etc., to the part under consideration"; ${ }^{4}$ "we shall also, supposing us to have arrived at a sufficient degree of voluntary power over the muscles, be able at once to put our hand upon the part on which the impression is made ";. ${ }^{5}$ an application of the motor aspect of the associative law. In sight "we judge of motion by the motion of the pictures on the retina, or of our eyes in following the objects "; ${ }^{6}$ position is judged by the part of the retina on which the stimulus falls.

1 Prop. XXIII.

4 Prop. XXXI.
2 Ibid.

5 Ibid.
3 Prop. XXX.

6 Prop. LVIII. 
Visual size and distance are determined chiefly by the picture on the retina being larger when the magnitude, in terms of touch, is the same, etc.; but he specifies five ' associated circumstances' which at times influence the judgment: " the number of objects which intervene, the degree of distinctness in which the minute parts are seen, the degree of brightness, the inclination of the optic axes [convergence], and the conformation of the eye [accommodation]." 1 Hearing gives us little notion of distance, except in visual terms. ${ }^{2}$

Hartley finds in each sense certain closely associated elements of pleasures and pain; and in every sensory experience certain ideas are bound up with sensation, so that the portion of the experience contributed by the sense is relatively small.

Passing to complex mental phenomena, Hartley takes a broader view than Locke, Berkeley, or Hume. The chief concern of these writers being epistemological, they deal mainly with intellectual phenomena, while Hartley constantly introduces the motor side, both voluntary and involuntary, and devotes much attention to the analysis of the affective consciousness.

The association of ideas with words is a fundamental operation in man, according to Hartley; and this is the first type which he examines. "Words and phrases," he says, "must excite ideas in us by association," and by this means alone. ${ }^{3}$ Words may be considered "(I) as impressions made upon the ear; (2) as the actions of the organs of speech; (3) as impressions made upon the eye by characters; (4) as the actions of the hand in writing." 4 Their use is learned in the order named. From an early age, "many sensible impressions and internal feelings are associated with particular words and phrases, so as to give these the power of raising the cor-

1 Ibid.

3 Prop. LXXIX.
2 Prop. LXVI.

4 Ibid. 
responding ideas." Thus, the name of a visible object - for instance, the child's nurse- " is pronounced and repeated by the attendants to the child more frequently when his eye is fixed upon the nurse than when upon other objects. . . The association, therefore, of the sound nurse with the picture of the nurse upon the retina will be stronger than that with any other visible impression, and thus overpower all the other accidental associations." 1 The association is made more definite by changes in the 'non-essentials' of the object, as when the nurse appears in different surroundings, different dress, etc.; these conflicting associations tend to neutralize one another and strengthen the main association with the word. The other sorts of words, the speechmotor, visual, and hand-motor, fix and extend the "ideas and significance of words and phrases by new associations." 2

This genetic analysis has a very modern flavor. In another place he points out the results of repeated verbal associations with objects; in the end the connection becomes, so strong that when the sensations of the objects are felt, "they lead by association to the words expressing them, and thus we can distinguish" qualities "and declare in words what each is." ${ }^{3}$

The two phases of belief, assent and dissent, he defines as "those very complex internal feelings which adhere by association to such clusters of words as are called propositions." " Rational assent to any proposition is "a readiness to affirm it to be true, proceeding from a close association of the ideas suggested by the proposition, with the idea . . . belonging to the word truth"; while "practical assent is a readiness to act in such a manner as the frequent vivid recurrency of the rational assent disposes us to act." 5
1 Prop. LXXX.
2 Prop. LXXIX.
3 Prop. XXXIV. 
Passing on to the emotions or passions, Hartley declares them to be merely "aggregates of simple ideas united by association "; their constituent ideas are "traces of the sensible pleasures and pains" which "make up by their number and mutual influence upon one another for the faintness and transitory nature of each singly taken." 1 The will itself is only "a desire or aversion sufficiently strong to produce an action that is not automatic." It follows from this that the will is ' mechanical,' if we understand this term to include that which takes place by association. ${ }^{2}$

It is at this point that Hartley takes up the analysis of memory and imagination. When we consider that not only Aristotle but all of Hartley's forebears made use chiefly of memory to expound and illustrate the principles of association, the lateness of its appearance in Hartley's exposition is striking. The reason seems to be that while he has hitherto been discussing ideas as faint copies of sensations, he is now led to consider the concrete complex experiences which constitute actual recollections.

Memory is "that faculty by which traces of sensations and ideas recur, or are recalled, in the same order and proportion, accurately or nearly, as they were once presented." 3 The special problem is, how we can recollect accurately a very complex experience, say of 1000 particulars, fitting each memory image into its proper place. Hartley supposes the elementary facts to be impressed first, so that the child, for instance, will recall a mass of detached circumstances; gradually, by repetition of 'clusters' of sensations, the memory is extended to clusters and chains of ideas, and in the same way these groups come to be associated by repetition, and so united in memory. The growth of memory is aided by verbal associations; and certain associations-wrong ones-are

1 Prop. LXXXIX.

2 Ibid.

3 Prop. XC. 
prevented by "ideas of inconsistency, impossibility, and by methods of reasoning." " We distinguish a memory from an imagination partly by the greater vividness of the clusters of ideas which make up the former, but principally by " the readiness and strength of the associations by which they are cemented together." 2 And similarly we distinguish a remembered sensation (one which we know we have had before) from a new one by the fact that " the parts, associates, etc., of that which we remember strike us more strongly, are suggested by each other, and hang together, which does not hold of the new." 3 So too, a lessened vividness of memory suggests to us a greater lapse of time since the original impression occurred, and vice versa-which accounts both for the time reference of memories and for erroneous references in certain cases where the connection is disproportionately strengthened by interest and other influences.

The 'faculty' of memory thus turns out to be no new form of intuition; it is not a mind within the mind, or an " eye within the eye," to quote Hartley's simile, but only a name for certain distinctive experiences, differentiated by peculiarities of "vividness and connection in the ideas, with the other associates" peculiar to recollection. ${ }^{4}$

Hartley's view of the practical working of voluntary recollection is stated in language not unlike Aristotle's: "When a person desires to recollect a thing that has escaped him, suppose the name of a person or visible object, he recalls the visible idea, or some other associate, again and again, by a voluntary power, the desire generally magnifying all the ideas and associations, and thus bringing in the association and idea wanted at last. How-

1 Ibid.

2 Ibid.

3 Ibid.

4 Ibid. It is interesting to note the counter-criticism from an opposing standpoint, that there is no such "faculty as association at all: it is only memory with a new name" (Blakey, "History of the Philos. of Mind,' Vol. III, p. 287). 
ever, if the desire be great, it changes the state of the brain and has an opposite effect, so that the desired idea does not recur till all has subsided-perhaps not even then." ${ }^{1}$ He takes pains to declare that the voluntary power here mentioned is "of the nature of memory,"that is, voluntary recollection proceeds according to the same principles of association; and in fact, "the whole powers of the soul may be referred to the memory, when taken in a large sense," ${ }^{2}$ namely, as an ideal copy of sensation.

Imagination, or fancy, is " the recurrence of ideas, especially visible and audible ones, in a vivid manner, but without any regard to the order observed in past facts." 3 "Every succeeding thought is the result either of some new impression or of an association with the preceding; " $"$ so that the laws of association hold for the imagination, except where a new sense impression interrupts the flow. Dreams, which he analyzes at considerable length, are deducible from impressions and ideas, generally those recently received, and from their sequence according to associative principles; they are also dependent upon impressions due to the present "state of the body, particularly of the stomach and the brain." 5 The dreamer supposes his dream states to be real, that is, to be actual sensations, because he has no other reality to compare them with; for this reason, and because of "the increased heat of the brain " in sleep, dream experiences are more vivid than the ideas of our waking life. We do not notice their inconsistencies, because the associations which would lead us in waking life to observe them are here excluded, and moreover we pass very rapidly from one thing to another.

1 Ibid., obs. Io. 4 Ibid.

2 Obs. II, 12.

5 Ibid.

3 Prop. XCI. 


\section{Deficiencies in Hartley's System}

Strangely enough, Hartley does not follow up his discussion of imagination and dreams with any specific analysis of the 'understanding' in its highest manifestation, namely, reasoning. Instead he proceeds to consider abnormalities of reason and the intellect of the lower animals, and this completes his survey, except for a final chapter, which contains an over-minute analysis of intellectual pleasures and pains. ${ }^{1}$ The discussion of assent and dissent, already mentioned, takes us through judgment and belief. One would expect from so acute a thinker as Hartley some treatment of the relation between trains of imagination and trains of reasoning, if nothing more; and this we do not find anywhere. The relation between reasoning and other ideational trains is a vital point in the empirical psychology, and serves more than anything else to separate it from the rational school; the failure to analyze reasoning is probably the greatest de-fect in Hartley's work, regarded from his own standpoint.

Hartley's discussion of volition, though more adequate than that of his predecessors, is scattered about in various places and is nowhere brought together in a summary. But against this deficiency must be set the fact that the will is brought into vital relation with muscular activity in general, and that the motor theory is worked out along associational lines for the first time. Hartley's treatment of sensory pleasures and pains is too brief and fragmentary to be satisfactory, especially when contrasted with his minute analysis of ideational pleasures and pains. There is also a certain artificiality in his analysis of memory: he assumes that all the elementary experiences must be learned first, before we can begin to recall groups of events and successive experiences. This view could scarcely satisfy those who repeated the analysis from the 
same associational point of view. At times also Hartley's attention is arrested by rather superficial associations, and he attempts to explain important phenomena in terms of these, instead of probing deeper. His theory of the origin of shame ${ }^{1}$ is an instance of this.

Without ignoring these and other failures and unevennesses' in Hartley's analysis, we should give full credit to his work for its tremendous advance over all his predecessors. His is the first attempt at a consistent and exhaustive application of association to all experience and activity. He aims to explain our entire mental life in terms of the fusion and succession of elementary experiences. The sole data used are sensations and their ideational replica. A single principle serves to account for the transformation of these elements into higher complexes and the transition from one conscious state to the next.

\section{Other XVIIIth Century Associationists}

For about seventy years after the publication of Hartley's 'Observations' there was only one attempt at a thorough analysis of consciousness on the basis of association. But the influence of his work and of the earlier formulations of the theory was manifest in many directions. Thomas Reid and other writers of the Scottish movement, while they combated associationism as a doctrine, nevertheless paid due regard in their psychology to the laws of the association of ideas as formulated by Hume and Hartley. More notable was the influence of the theory upon a number of thinkers who applied the associative principles to the analysis of special topics. Among these writers, Tucker, Priestley, Alison, and Erasmus Darwin deserve special mention.

A larger group tacitly assume the results of the associational analysis or show its influence in their work.

1 Prop. LXXIII. 
The utilitarian doctrine, for example, with its empirical development of ethics, springs from the same attitude toward nature as associationism and proceeds upon the same underlying presuppositions. It is beyond the scope of our study to trace the obscure and implicit connections which abound in the literature of that time. Reference should be made, however, to the writings of SMITH, BenthaM, and the Belshams, who manifest the spirit of the association school in several outlying fields without adding especially to the psychological analysis itself. ${ }^{1}$

Abraham Tucker (I 705-I774), a lawyer, repeats the associational analysis of mind exhaustively, with some new features, in a voluminous work bearing the quaint title 'The Light of Nature Pursued' ( I 768), which seeks to derive the principles of morality from experimental data. His standpoint is more in agreement with Locke than with Hartley, whom he criticizes particularly for regarding the mind as merely a passive receiver of impressions. Tucker reverts to Locke's position in attributing ideas to reflection as well as sensation.

Association occurs with both classes of ideas. "From ideas thus received by sensation and reflection," he says, "there grows a new stock, framed up of these as of so many materials, by their uniting together in various assemblages and connections." 2 Tucker gives the generic

1 Adam Smith (1723-1790) in both economics and ethics; see 'The Wealth of Nations' ( 1776$)$, and 'Theory of Moral Sentiments' (1761). Jeremy Bentham (1748-1832) in jurisprudence and ethics; see especially his 'Principles of Morals and Legislation' (1789), and 'Table of the Springs of Action.' Rev. Thomas Belsham (1750-1829), an ardent admirer of Hartley, in philosophy and ethics. In his 'Elements of the Philosophy of the Mind and of Moral Philosophy' (180I) he endeavors to reduce the basis of association to pleasure (pp. 208-9). His brother, William Belsham (1752-1827), furnishes less systematic contributions in the same field: see his 'Essays, Philosophical and Moral' (I799), especially essays II, X, and XI. See also the anonymous work entitled 'Essay on the Nature and Existence of the Material World,' which appeared in $178 \mathrm{I}$.

2 Pt. I, ch. 9, art. I, 2d ed. 
name of combination to this juncture of ideas, which he says includes two separate modes, association and composition. Thus Tucker was the first to recognize explicitly the difference between a union without alteration of the components, and the sort of connection wherein the ideas so "melt together as to form one single complex idea." 1 The latter process, composition, or in modern terms fusion, was afterwards developed into the theory of mental synthesis or mental chemistry. Tucker's statement of this principle is perhaps his most important contribution to the association theory: "A compound may have properties resulting from the composition which do not belong to the parts singly whereof it consists." 2

Tucker considers simultaneous combination an earlier manifestation than successive combination. The rise of the latter he attributes to the fact that clusters of simultaneous ideas are generally too large to be taken in by the mind together; thus only a part of the clusters appear at first, but on account of their connection other parts or groups are immediately afterwards called up. ${ }^{3}$ There is an 'attraction' between ideas, so that the preceding idea generally determines what associate shall appear; ${ }^{4}$ and the association, once formed, cements the ideas together. Ideas bearing reference to some purpose in view tend in this way to appear in regular succession; and such a succession he terms a train." "Our trains once well formed, whatever suggests the first link, the rest follow readily of their own accord." ${ }^{\circ}$ As assemblages of ideas form trains, so trains become connected into "courses of thinking." 7 He notes, moreover, that often some of the middle terms of a train fall out as the result of frequent repetition-the doctrine of lapsed links. ${ }^{8}$

Reasoning, according to Tucker, is not a separate
1 lbid.
2 Ch. I2, art. I ; cf. ch. I, art. 2.
${ }^{3}$ Ch. I0, art. I.
4 Ch. 9, art. I4.
7 Art. I.
5 Ch. Io, art. 3.
8 Art. 13.
6 Art. 4. 
faculty, but is the "discerning of the agreement of two ideas between themselves, by their agreement with some third." 1 The mental processes usually attributed to the separate faculties of apprehension, judgment, and ratiocination, he believes, may be completely described in terms of perception, ${ }^{2}$ and there are in reality only two modes of perception-imagination and understanding, both of which are " acquired by use and practice, . . . the latter growing out of the former." 3 We need not follow him in his application of this analysis to moral principles.

JosePh Priestley (I 733-I804) began his career as a clergyman, but left this calling on account of a change in theological views. He became a student of Hartley's work and a follower of his theories. ${ }^{4}$ In I 775 he published an abridged edition of the 'Observations on Man,' to which he prefaced a series of three essays, defending and expounding Hartiey's theory of association. In particular he defends the view that sensation is the only source of ideas. ${ }^{5}$ He supplements Hartley's analysis by tracing out the elements of a number of very complex ideas, such as the notions of force, time, right and wrong, etc.

Priestley reiterates Tucker's view that mental phenomena are altered by fusion. As color-mixing, he says, produces apparently simple effects of color, so "from the combination of ideas, and especially very dissimilar ones, there may result ideas which, to appearance, shall be so different from the parts of which they really consist, that they shall no more be capable of being analyzed by mental reflection than the idea of white." ${ }^{6}$ A whole mass of ideas can so completely grow into one, that they

$1 \mathrm{Ch}$. II, art. I3.

2 Art. 36.

3 Ch. I2, art. I.

4 Priestley was for many years interested in chemistry, and is noted for having been the first to accomplish the separation of oxygen.

5 Essay 3. $\quad 6$ Ibid., 'Misc. Works,' III, p. 190, ed. of I818. 
appear to be only a single idea. Priestley abandoned Hartley's vibration theory; but on the other hand he assumes that mental phenomena are of the same nature as the brain states which underlie them; this materialistic assumption exposed him to much violent criticism, which was directed against Hartley as well. The odium theologicum was still very potent, and probably for this reason Priestley's support of Hartley hindered rather than helped the progress of associationism.

Archibald Alison (I 757-I839), a clergyman, is the author of a work on esthetics, entitled 'Essays on the Nature and Principles of Taste' (I 790), which was much studied during the early part of the nineteenth century. In it he traces out the feelings of beauty, sublimity, and the like, and attributes them to associations of ideational terms with sensations. Matter, he affirms, arouses sensations, not emotions; ${ }^{1}$ the latter arise only through the "exercise of the imagination." 2 Alison set himself the task of examining all varieties of experience that arouse the esthetic feelings in literature, painting, sculpture, etc., and endeavored to show that they are based on associated elements. He makes no explicit reference to Hartley in the 'Essays,' and quotes Locke only once, ${ }^{3}$ when he borrows a casual anecdote from him. But though he mentions writers of the Scottish school with approval, his own position is thoroughly associationistic, and he was largely instrumental in familiarizing students of art and general readers with that conception of mental processes.

The 'Zoonomia' (I 794) of ERASMUS DARWIN ${ }^{4}$ ( I 73 I1802 ) is an exhaustive treatise in several volumes on physiology and medicine. Though chiefly concerned with biological questions, it includes a psychophysical theory of experience (Pt. I) which is thoroughly associationistic. Darwin puts ideas and motion in parallel, and makes asso-

1 Essay II, ch. I, p. I26, Ist ed.

3 P. 2 IO.

2 I, ch. 2, p. $49 ; c f$. p. 410.

4 Grandfather of Charles Darwin. 
ciations of ideas the counterpart of associations of muscular movements. He attributes to the sensorimotor being four faculties-irritation, sensation, volition, and association,- - which give rise to four classes of ideas and movements; the fourth class is less fundamental than the others.

Each of the first three sorts of ideas and movements may be associated." "All animal motions which have occurred at the same time or in immediate succession become so connected that when one of them is produced the other has a tendency to accompany or succeed it." ${ }^{2}$ The same is true of ideas, which are never received singly, but always in combination: "those which belong to the same sense seem to be more easily combined into synchronous tribes than those which were not received by the same sense." ${ }^{3}$ We have the power of increasing the degree of combination by voluntary repetition of the ideas, or by repetition of the original sensation. ${ }^{4}$

These four writers fill the gap between Hartley and Brown. Tucker was the only one of the four who attempted a thorough analysis, and this marked a return to Locke rather than an advance. Yet they were instrumental in spreading the notion of association in scientific as well as popular circles. Tucker spoke to the preacher and moralist; Alison to the artist and man of letters; Darwin to the naturalist and physician; Priestley to the physical scientist. The attacks of the Scottish school also drew attention to the association concept and led to further study. But the charges of materialism and atheism made many hesitate to adopt the associational standpoint, or even to employ its most evident principles, till Brown, whose philosophy was free from any such odium, cleared it of the stigma.

1 Sec. IO.

3 I5, I, I.

2 Sec. 4 , art. 7.

4 Ibid., 2. 


\section{Thomas Brown's Standpoint}

Thomas Brown (I778-1820), who held the chair of moral philosophy at the University of Edinburgh, was a pupil of Dugald Stewart, through whose teachings he was grounded in the traditions of Reid and the Scottish school. Later he broke away from the psychology of this school, and in his 'Lectures on the Philosophy of the Human Mind' (I820) adopts a standpoint akin to the English movement. His analysis of consciousness is, in fact, a combination of the Scottish and associational viewpoints. With the former writers he regards mind as "a substance possessing certain qualities, susceptible of various affections or modifications, which, existing successively as momentary states of the mind, constitute all the phenomena of thought and feeling." 1 These modifications he attributes to perception, conception, memory, imagination, and rational processes.

But unlike the Scottish psychologists Brown does not consider the mental processes special faculties or powers of mind. He makes them, like Hartley, manifestations of the workings of association. Thus, perception is not "a peculiar mental power," but a result of " the power of association, by which one feeling suggests or induces other feelings that have formerly coexisted with it." 2 He prefers to call this power suggestion rather than association, a point which he argues at great length.

Our consciousness, he claims, is "far from indicating any process of association; and all of which we are conscious at the time of the suggestion itself is the mere succession of one feeling to another-not certainly of any prior process on which this succession has depended." 3 There is no ' union,' as the term association would imply, among the original sensations; and the 'union' of intel-

\footnotetext{
1 Lect. I, Vol. I, p. I3.

2 Lect. 25, I, p. 379.

3 Lect. 40, II, p. 92.
} 
lectual states consists merely in the fact that they succeed one another in accordance with the original coexistence or succession of sensations. ${ }^{1}$

Brown emphasizes particularly the fact of succession among ideas, and his use of the term suggestion is partly designed to exclude the notion of coexistence and union among them. The basis of suggestion he believes to be reducible to a single law, proximity; he does " not consider any influence distinct from that of the mere existence of the original feelings themselves in their state of proximity to be indicated by our consciousness, or at all necessary to the subsequent suggestions." 2

Before going further we should note a fundamental difference between Brown's standpoint and that of Hartley, which is really the basis of their disagreement as to the terms association and suggestion and of other differences which will appear. Hartley, we must remember, based mental association on certain supposed relations among the physical conditions underlying consciousness. Brown's analysis, on the other hand, was concerned solely with the mental phenomena themselves. He aimed to describe the sequence of ideas in purely mental terms, without reference to the physical concomitants of the process. It is not the psychologist's province, he insists, to consider the physiological happenings in the nervous system or elsewhere. Brown differs on this point not only with Hartley but with nearly all later associationists. His attitude is a natural result of his early training. Some writers have refused to consider him an associationist on account of his neglect of the physical side. Yet so rigidly and thoroughly does he carry out his principle of suggestion-which is nothing else but association with all physical reference removed-that he seems unquestionably to belong among the exponents of this doctrine. At the same time the consequences of this ultra1 Ibid., pp. 87-8. 2 Ibid., p. 9 I. 
psychological attitude are far-reaching. It alters not only the conception of the associative process, but the distinction between presentative and representative experiences. Other associationists regard ideas as revivals or faint copies of anterior sensory experiences; for Brown, representative phenomena constitute an entirely distinct class and may not properly be regarded as "mere sensations modified or transformed." 1 Not being derivatives, they are no more explicable than sensations: "We may see innumerable objects in succession; we may conceive innumerable objects in succession. But we see them because we are susceptible of vision; we conceive them because we have that susceptibility of spontaneous suggestion by which conceptions arise after each other in regular trains." ${ }^{2}$

\section{Brown's Laws of Suggestion}

As already stated, Brown regards suggestion as a succession based on some previous proximity. "All suggestion, as I conceive, may, if our analysis be sufficiently minute, be found to depend on prior coexistence, or at least on such immediate proximity as is itself, very probably, a modification of coexistence." ${ }^{3}$ But this fundamental principle he amplifies into three Primary Laws of Suggestion, namely, resemblance, contrast, and nearness in time and space, ${ }^{4}$ thus harking back to the original classification of Aristotle. His discussion of these laws is wholly by way of illustration and adds little to earlier analysis. The reintroduction of contrast as a separate form of association is a natural consequence of his standpoint: there is no need of reducing it to similarity and contiguity if we have no physiological facts to explain; and there is little use in attempting such a reduction by means of purely mental analysis.

1 Lect. 33, I, p. 5 I 7.
3 Lect. 35 , II, p. II.

2 Lect. 4I, II, p. 105.

4 Lects. 35-37. 
Probably the most important contribution of Brown to the association doctrine is his formulation of certain Secondary Laws of Association (or Suggestion). In these he seeks to enumerate the circumstances which " modify the influence of the primary laws, in inducing one associate rather than another." 1 They are nine in number:

(I) The relative duration of the original sensations: "The longer we dwell on objects, the more fully do we rely on our future remembrance of them." ${ }^{2}$

(2) Their relative liveliness: "The parts of a train appear to be more closely and firmly associated as the original feelings have been more lively." 3

(3) Relative frequency: "The parts of any train are more readily suggested in proportion as they have been more frequently renewed." 4

(4) Relative recency: "Events which happened a few hours before are remembered when there is a total forgetfulness of what happened a few days before." 5

(5) Their coexistence in the past with fewer alternative associates: "The song which we have never heard but from one person can scarcely be heard again by us without recalling that person to our memory." ${ }^{6}$

(6) Constitutional differences between individuals modify the primary laws: They give "greater proportional vigor to one set of tendencies of suggestion than to another." 7

(7) Variations in the same individual, "according to the varying emotion of the hour." 8

(8) "Temporary diversities of state," as in intoxication, delirium, or ill-health. ${ }^{9}$

(9) Prior habits of life and thought-the influence of inground tendencies upon any given situation, however new or irrelevant the experience may be. ${ }^{10}$
1 Lect. 37, II, p. 44.
5 Ibid.
9 P. 5 I.
2 Ibid.
6 Ibid.
10 P. 52.
3 Ibid.
4 P. 45 .
7 P. 46.
8 P. 50. 
According to Brown the primary laws " are founded on the mere relations of the objects or feelings to each other," ${ }^{1}$ while the secondary laws indicate the influence exerted by circumstances or conditions upon the particular application of the primary laws.

The first four of the secondary laws are summed up in a single statement: "When the two associate feelings have both (together or in immediate succession) been of long continuance, very lively, very frequently renewed in the same order, and that recently, the tendency to suggest each other is most powerful." 2 The fifth law might well have been included in this statement, and the remaining laws might readily have been summed up in another generalization.

\section{Brown's Analysis of Mental Phenomena}

Brown's departure from the Scottish faculty psychology is shown in his structural interpretation of mind. Rejecting the division into intellectual and active powers -into understanding and will-he regards all mental phenomena as states (or affections) of mind, and divides these states first of all into external and internal. ${ }^{3}$ The former are "the result of the laws both of matter and of mind-implying in external objects a power of affecting the mind, as well as in the mind a power of being affected by them "; the latter " result from the susceptibilities of the mind itself. . . . The affections of the one class arise because some external object is present; the affections of the other class arise because some previous change in the states of the mind has taken place." 4 The external affections are "so very simple as to require but little subdivision." The internal affections form two great classes: "our intellectual states of mind, and our

1 P. 53.

3 Lect. I6, I, p. 249.

2 Ibid., p. 53.

4 Ibid. 
emotions." 1 Brown regards the emotions as for the most part 'active,' but he is unwilling to class them specifically as active powers or states,-partly because our intellectual states are essential elements in the activity of the emotions, partly because some of the emotions "cannot with propriety in any case be termed active-such as grief, joy, astonishment . . . the feelings of beauty and sublimity," etc. ${ }^{2}$

Brown's examination of the various states is lengthy, and for the period in which he wrote it is very complete. But at times he is lacking in scientific sequence, and owing to his constant reiteration and his wealth of illustration it is difficult to grasp his analysis in its entirety: The main point of interest in his review of sensations, or external states of mind, is the distinction which he makes between the sensations proper of each sense, and the associated feelings of resistance and extension, which constitute our knowledge of the qualities of matter. ${ }^{3}$ Resistance in itself, and extension as known through resistance, are due not to touch, but to the muscles. ${ }^{4}$ Perception is " only another name ... for the result of [these] associations and inferences." "We shall see the importance of this analysis as developed by later writers.

His treatment of the internal states is closely bound up with the discussion of suggestion, to which he attributes them. As a result of his anti-physiological attitude he is led to treat of conception before he takes up memory, regarding the former as a simpler type of experience. Our memories, in fact, are " nothing more than conceptions united with the notion of a certain relation of time." " Certain circumstances, such as entering a friend's house, suggest that friend. ${ }^{7}$ This idea he regards as a conception; it only "becomes a remembrance when we combine with it this feeling of relation-the rela-
1 Ibid., p. $25 \mathrm{I}$.
5 Lect. 25, I, p. 382.
2 Ibid.
3 Lects. 22-25.
6 Lect. 4I, II, p. 107.
Lect. 23, I, pp. 345-7.
7 P. 104 . 
tion which constitutes our notion of time." 1 Conception itself is simple suggestion. ${ }^{2}$ Neither conception nor memory are voluntary acts of mind: ideas "arise uncalled; . . . what is termed voluntary recollection . . . is nothing more than the coexistence of some vague and indistinct desire with our simple trains of suggestion." 3 So too, imagination is not "a voluntary selection and combination of images," 4 but the result of simple suggestion: various complex conceptions "may exist together, forming one complex feeling, and . . . one part of this complexity may suggest one conception while another part suggests a different conception, that may in like manner unite and form one harmonizing whole," 5 which is an imagination.

This is followed by a discussion of habit, which (without any apparent reason) Brown makes coordinate with conception, memory, and imagination. Habit may be considered in two lights, as it "produces a greater tendency to certain actions, and as it occasions greater facility and excellence in those particular actions." ${ }^{\circ}$ The former aspect, the heightened tendency, he attributes to suggestion: "If feelings tend to produce other feelings in consequence of former proximity or coexistence, it would indeed be most wonderful if habitual tendencies were not produced." " His thought seems to be that when the same idea-and-act has occurred frequently in similar connections, it is on that account more likely to lead to the same succeeding idea-and-act. On the mere doctrine of chances one may well believe this; but his rejection of the physiological side debars him from using the additional argument which other associationists appeal to, namely, that the repetition itself produces a greater tendency to reinstate the sequence on account of the modifica- . tions in the brain state which it induces, whereby the
1 P. 108.
5 P. 127.
2 P. 104.
${ }^{6}$ Lect. 43, II, p. I4I.
4 Lect. 42, II, p. 125.
7 P. 144 . 
connection is rendered more close. Brown has already mentioned frequency as one of the secondary laws of suggestion, and the statement that habit produces a greater tendency is only a reiteration of this generalization.

More satisfactory is his attempt to describe the greater facility of performance produced by habit. In striving to perform a certain act for the first time, we make all sorts of mistakes, "in our ignorance of the particular muscles and particular quantities of contraction. . . . By frequent repetition, however, we gradually learn and remedy our mistakes. . . . At almost every repetition either some muscle is left at rest which was uselessly exerted before, or the degree of contraction of the same muscles is brought nearer and nearer to the desired point." I Brown does not attempt to show how the useless contractions fall out, but he might have done so without departing from his introspective standpoint. ${ }^{2}$ His view that we may "reduce the habit itself to the mere power of association," ${ }^{3}$ however, is rather a reversal of the ordinary associational position.

\section{Brown's Theory of Relative Suggestion}

Brown distinguishes two sorts of suggestion: simple and relative. Simple suggestion, as already noted, is the tendency of the mind, on the appearance of a certain experience, to call up some other idea by reason of their previous proximity. Perception and the representative processes just mentioned belong to the province of simple suggestion. Neither in perception as such, nor in con-

1 Pp. 144-5.

$2 \mathrm{He}$ would say that the proper contractions lead to the performance of the act, and hence to sensations corresponding to the previous idea, which is thus reinstated; while the inappropriate contractions do not reinforce the idea, and are therefore more likely to fall out.

${ }^{3}$ Lect. 37, II, p. 52. 
ception, memory, etc., do we attain the idea of a relation existing between different objects of experience. This idea of relation is due to relative suggestion.

Relative suggestion is "the tendency of the mind . . . by which, on perceiving or conceiving objects together, we are instantly impressed with certain feelings of their mutual relation." 1 These "feelings of relation are states of mind essentially different from our simple perceptions or conceptions of the objects that seem to us related, or from the combinations which we form of these in the complex groupings of our fancy." 2 They are due to "an original tendency or susceptibility of the mind, by which, on perceiving together different objects, we are instantly, without the intervention of any other mental process, sensible of their relation in certain respects." 3

Brown divides the relations so experienced into two general classes: relations of (I) coexisting, and (2) successive objects or feelings. Under coexistence he specifies position, resemblance, degree, proportion, and comprehensiveness or part and whole; ${ }^{4}$ under succession he mentions sequence (casual priority and posteriority), and causality (antecedent and consequent). ${ }^{5}$ The rational processes of judgment, reasoning, and abstraction he reduces to cases of relative suggestion." 6

In his treatment of relative suggestion Brown departs from the association standpoint. The idea of relation is, according to him, an entirely new experience; he does not attempt to derive it or in any way correlate it with past experiences, as he does in the case of simple suggestion.

Brown makes an important contribution to mental analysis in pointing out the distinction between our experience of related things and our awareness of the relation. This distinction brought to light a new problem, which later associationism was called upon to solve.
1 Lect. 51, II, p. 275.
4 Lect. 46 , II, p. 183 .
2 Lect. 45, II, p. I69.
5 Lect. 5I, II, p. 267.
3 Ibid.
6 Ibid. 
Brown's own solution is not associational: he goes over to intuitionism when he attributes our awareness of relations to an original tendency of the mind. Here again it is his ultra-psychological attitude that determines his answer. Had he been concerned with physiological correlates, he would have assumed some plausible process of nerve activity, taking place concomitantly with the rise of these new ideas of relation; or he might claim that the ideas of relation are not really new types of experience, but merely modifications of the experience of related sensations. Instead, he makes them something quite different from any other element of experience. ${ }^{1}$

According to Brown the complex mental states which are formed through simple and relative suggestion are not merely 'compositions,' but fusions as well. As we have seen, earlier writers, such as Tucker and Priestley, also conceived of complex experiences as being modified so that they become somewhat different from their constituent elements. Brown states this view very explicitly: "In this spontaneous chemistry of mind, the compound sentiment that results from the association of former feelings has in many cases, on first consideration, so little resemblance to these constituents of it, as formerly [existed] in their elementary state, that it requires the most attentive reflection to separate . . . the assemblages which even a few years have produced." 2 This notion of mental chemistry was taken up and elaborated by John Stuart Mill and other writers.

Brown's analysis is for the most part very acute, but its value is considerably impaired by his rambling style of presentation. His illustrations and many of his arguments are over-rhetorical. The lectures show plainly

1 The present writer considers the rise of 'awareness of difference' in experience the most difficult problem that confronts the association psychology. We shall see how later associationists have attempted to explain it.

2 Lect. Io, I, p. 156. 
that they were addressed to pupils rather than mature thinkers. There is also a constant tendency to emphasize the direct agency of Deity, which does not, however, impair the thoroughness of his insight into the connections of mental phenomena. His influence on later writers appears to lie especially in four directions: (I) in calling attention to the 'secondary' or quantitative laws of association; (2) in giving prominence to the muscle sense and experiences derived therefrom; (3) in calling attention to the experience of 'relation'; and (4) in emphasizing the chemical mode of composition as an analogy applicable to the phenomena of mental fusion. 


\section{CHAPTER IV}

\section{JAMES MILL AND THE LATER ASSOCIATIONISTS}

\section{James Mill}

THE division of the association movement into periods should not be regarded as sharp and absolute. In passing from Hobbes and Locke to Hartley, or from Hartley and Brown to the Mills, we find no great break. A gradual development and broadening of the fundamental conceptions and a progressive extension of the analysis has already been noted. The same is true in the transition to the later period. Yet there appear to be sufficient grounds for grouping the 'pure associationists' into two chronological periods.

The writings of the elder Mill mark the beginning of a new stage of development. The period examined in the preceding chapter is marked by a groping after fundamental terms, and by a somewhat desultory or at least unsystematic analysis. The writers of the later period assume the fundamental notions of association, and their task is to make the analysis more orderly and far-reaching. It must be remembered that the chief concepts of the association theory were now well known to English readers; that associationism constituted one of the dominant types of philosophy; and that systems of ethics, esthetics, jurisprudence, economics, and even history and theology had been formulated upon an associational basis, either avowedly or tacitly. ${ }^{1}$ The time was

1 By the writers mentioned in Chapter III-Tucker, Alison, Adam Smith, Bentham-and their followers. Among the numerous later 
ripe for a new analysis-not merely based on the principle of association, but conducted in that sequential way which association itself invites.

JAMES MiLL (I 773-1836), in early life a clergyman of the Scottish Church and later employed in the home office of the East India Company, undertook this work, and infused new life into the association movement. His 'Analysis of the Phenomena of the Human Mind' (1829) is the classic of nineteenth century associationism, as Hartley's 'Observations' is the classic of the eighteenth century. Taken in connection with the editorial notes of Bain and the younger Mill, and interpreted in the light of Bain's two volumes on psychology, it constitutes the most representative treatment of the association psychology.

James Mill accepts Hartley's conception of mental phenomena rather than Brown's. He gives due emphasis to the activity of the brain and nervous system, and makes free use of the physiological concomitants to explain and illustrate the principles of mental activity. But the influence of Brown's work is shown in many parts of his analysis, as well as by several specific references. ${ }^{1}$

Mill adopts a fundamental classification of mental data into sensations and ideas, which he considers " two classes of feelings," ${ }^{2}$ and begins with an investigation of sensation. Besides the traditional five senses he notices three other sorts of sensation-sensations of disorganization

writers may be mentioned Sir James Mackintosh (I765-I832) in ethics; John Austin (1790-1859) in jurisprudence; George Grote (1794-187I), who contributed to the annotated edition of James Mill's 'Analysis'; James Martineau (I805-1900) in ethics; E. A. Freeman (I832-1892) in history; Sir Henry J. S. Maine (18221883) in jurisprudence; William B. Carpenter (1812-1885) and Henry Maudsley (1835-1918) in physiology.

1 E.g., ch. I, § 7; see also references to Brown in preface to J. S. Mill's edition of the 'Analysis.' Page citations below are to this edition (London, 1878, $2 \mathrm{~d}$ ed.).

2 Ch. 2, p. 52. 
(physical pain), muscular sensations (which he carefully distinguishes from tactile), and sensations in the alimentary canal (corresponding roughly to what are now termed organic or systemic sensations).

The experiences derived from these senses are by no means simple. "We can not think of the sensation of color, without at the same time thinking of something colored-of surface or extension, a notion derived from another sense. ... Some of the things suggested by the sensations of sight, as extension and figure, are suggested so instantaneously that they appear to be objects of sight, things actually seen." 1 Our notion of any sense is really a very complex idea, including as ingredients (I) the idea of the organ, (2) the idea of the sensation, (3) the idea of the object of sensation, (4) the idea of synchronous order of the first two, and (5) the idea of a successive order of the third. ${ }^{2}$ Mill's discussion of sensation is very brief, touching only upon the general points needed further along in his analysis.

The distinction between sensation and idea is introduced by the notion of primary memory or the after-image: ${ }^{3}$ "After I have seen the sun, and by shutting my eyes see him no longer, I can still think of him. I still have a feeling, the consequence of the sensation, which, though I can distinguish it from the sensation, . . . is yet more like the sensation than anything else can be; so like, that I call it a copy, an image, of the sensation; sometimes a representation or trace of the sensation." " This copy or trace is conveniently called an idea; and for the process he coins the term ideation, analogous to sensation. ${ }^{5}$ Sensations and ideas are the "primary states of consciousness "; ${ }^{6}$ but the sensation is more fundamental

1 Ch. I, $\S 3$, pp. $2 \mathrm{I}-2$.

2 Ch. I, § p. I9.

$3 \mathrm{He}$ probably refers to both, and has in mind the passage from one to the other.
4 Ch. 2, p. 52 .
5 P. 53.
6 P. 62. 
than the idea, inasmuch as the second occurs " only when the first has previously existed." ${ }^{1}$

Mill does not accept the traditional view that ideas are always fainter than sensations, though he believes this to be usually the case. ${ }^{2}$ Some ideas are fainter than others-a condition which is due quite as much to the relative remoteness of the original sensation as to the relative vividness of that sensation; ${ }^{3}$ but it is difficult, he says, to compare the relative vividness of sensations, except when they are pleasurable or painful. ${ }^{4}$ This concluclusion is probably due to his confusing distinctness with intensity; he finds that some ideas have as great distinctness or prominence in consciousness as some sensations, and from this he concludes that they are in no degree fainter.

\section{James Mill's Conception of Association}

James Mill now passes to the problem of association. The order of occurrence of ideas depends on the order of sensations, which is conditioned only by "the order established among what we call the objects of nature." 5 Sensations occur in synchronous order and in successive order; and "it so happens that . . . most of those which are observed synchronously are frequently observed synchronously, most of those which are observed successively are frequently observed successively." 6 "Our ideas spring up, or exist, in the order in which the sensations existed of which they are the copies." " "This is the general law of the association of ideas, by which term ... nothing is here meant to be expressed but the order of occurrence." 8 Where sensations have occurred for the most part together, such as the smell, appearance, and contact of a rose, ${ }^{9}$ their
P. . 5.
6 P. 77.
2 Ch. 3 , p. 84.
7 P. 78 .
${ }^{3}$ P. 85.4 P. 84.
8 Ibid.
${ }^{5}$ Ch. 3, p. 71.
9 P. 79. 
ideas also spring up together; where they have occurred for the most part in succession, as in the repetition of the numbers one, two, three, etc., ${ }^{1}$ their ideas also arise in succession.

Mill's detailed exposition of the conditions of association is in striking contrast with the brevity of his preceding analysis. "A far greater number of sensations," he says, "are received in the successive than in the synchronical order; " and of our ideas, an infinitely greater number rise in the successive order. ${ }^{2}$ When we speak of the succession of ideas, we are not to suppose that any power resides in the earlier over the later; they are " only antecedent and consequent, with the additional idea that such order is not casual, but to a certain degree permanent." 3 Of two successive feelings, the suggesting and the suggested, the antecedent may be either sensation or idea, the consequent is always an idea. ${ }^{4}$ Often in an association, "the antecedent is of no importance farther than as it introduces the consequent. In these cases the consequent absorbs all the attention and the antecedent is instantly forgotten." 5 Thus, when we are listening to a conversation the sounds which we hear are obliterated in the thoughts to which they give rise. ${ }^{6}$

There are degrees in association just as there are degrees in sensations and degrees in ideas. Mill finds three conditions which modify the degree: An association is said to be stronger than another when it is (I) "more permanent," (2) "performed with more certainty," and (3) "performed with more facility." " "The causes of strength in association seem all to be resolvable into two: the vividness of the associated feelings, and the frequency of the association." 8 These two principles of vividness and frequency are Mill's substitute for Brown's secondary laws.
1 P. 80.
2 P. 8I.
3 Ibid.
7 P. 82.
4 Ibid.
5 Pp. 98-100.
6 P. IOI.
P. 82.
8 P. 83. 
After frequent repetition of an association, the ideas "sometimes spring up in such close combination as not to be distinguishable"; ${ }^{1}$ they "seem to run into one another, to coalesce, as it were, and out of many to form one idea; which idea, however in reality complex, appears to be no less simple than any one of those of which it is compounded." ${ }^{2}$ Thus, the idea of extension is derived from the muscular feelings that arise in connection with the movement of different parts of the body; ${ }^{3}$ and our ideas of external objects (for example, a tree) are formed from "the ideas of a certain number of sensations received together so frequently that they coalesce, as it were, and are spoken of under the idea of unity." 4 The simple ideas thus combined "are so intimately blended as to have the appearance, not of a complex, but of a simple idea." 5 Further, "some ideas are by frequency and strength of association so closely combined that they cannot be separated. If one exists, the other exists along with it, in spite of whatever effort we make to disjoin them." " For example, "it is not in our power to think of color without thinking of extension, or of solidity without figure." 7 Such associations he calls inseparable or indissoluble.

Mill examines Hume's three laws of association-contiguity in time and place, causation, and resemblancein the light of his own theory. Contiguity, he says, "must mean that of the sensations" which underlie the ideas ${ }^{8}$ contiguity in time " means the successive order," while contiguity in place "means the synchronous order." 9 But Mill has already shown that the ideas merely follow the order of the sensations, whether successive or synchronous; the law of contiguity thus reduces to Mill's more fundamental law of frequency. Causation is "the same with contiguity in time, or the order of
1 P. 90.
2 P. 9I.
${ }^{3}$ P. 92.
4 P. 93.
5 P. 92.
${ }^{6}$ P. 93.
7 Ibid.
8 P. 108.
9 Pp. I09-Io. 
succession." 1 Resemblance is noticed by us only because "we are accustomed to see like things together "; ${ }^{2}$ that is, we often experience at the same time a number of similar sensations-" "when we see a tree, we generally see more trees than one," etc. ${ }^{3}$-and resemblance is thus reduced to Mill's law of frequency. We shall notice presently J. S. Mill's wide disagreement with his father on this particular point. Association by contrast, according to James Mill, is due either to the fact that the contrasted objects are both deviations from a common standard (for example, a dwarf and a giant), or to the fact that they are experienced in succession (pain, followed by pleasurable relief from pain). ${ }^{4}$

Mill concludes by calling attention to the association of complex ideas together into a 'doubly compounded,' or 'duplex' idea. ${ }^{5}$ These duplex ideas (decomplex ideas in Hartley's terminology) may be of all degrees of complexity. "My complex idea of glass and wood and others compose my duplex idea of a window; "several such duplex ideas "united together compose my idea of a house "; and so on, in increasing complexity, till at length we reach the culmination of the series in "the idea called Every Thing." ${ }^{\circ}$

James Mill's account of the growth of mental complexity brings out a characteristic which runs through his whole analysis and differentiates him quite sharply from other associationists-namely, the mechanical view which he takes of the associative process. The association theory is in the nature of things mechanistic, inasmuch as it opposes on the one hand the casual or indeterministic hypothesis of experience and on the other hand the hypothesis of innate ideas or forms. It conceives of mind, or experience, as a series of mental states united into various complexes and successions, very much

1 P. I I0.

2 P. III.

3 Ibid.

?P. II4.

5 P. II5.

- Pp. II5-II6. 
as the atoms of the physical universe are united into material things and produce material events. Associationism, then, may properly be termed mechanistic, because it employs the material pattern for the explanation of mental phenomena. But material events follow chemical principles as well as physical; and most associationists have applied both concepts to mental synthesis. James Mill, however, ignores the chemical analogy entirely, and practically makes the physical-mechanical type his sole pattern for the laws of mental coexistence and succession. He does, it is true, notice the seeming coalescence of ideas into a complex experience which is apparently simple. ${ }^{1}$ And if the experience appears to be simple, he might consistently have affirmed, with J. S. Mill, that as an experience it is simple. But he does not admit this, and so loses the benefit of ' mental chemistry.' In the passage just mentioned he cites, as analogous to the coalescence of ideas, the coalescence of sensations when a color wheel of several sectors with various spectral colors is rotated rapidly, giving the sensation of white. From the present-day standpoint the sensation in this case is simple. To Mill it is only apparently so. ${ }^{2}$

\section{Ch. 3, p. 9 I.}

2 It is interesting to note how often the expressions 'as it were,' 'apparently,' 'seeming,' occur in this discussion. I believe James Mill's attitude is responsible for the widespread notion that 'pure' associationism (that is, the movement up to and including him) is essentially physical-mechanical, a mistake which even leading historians of the English psychology have shared. In preceding chapters attention has been called to passages in the works of earlier representatives of the school which show that they take a broader view and recognize a fusion of experiences after the chemical pattern. Since associationists generally, with the exception of James Mill and possibly Bain, hold this view, it seems proper to consider 'mental chemistry' an integral part of the association doctrine. ( $C f$. art. 'Associationism' in Baldwin's Dictionary of Phil. and Psychol., for the opposite view.) Bain studiously avoids the question; while he apparently agrees with James Mill, there is nothing in his analysis incompatible with mental chemistry. The term mechanistic is used above in the sense in which contemporary biologists apply it-to denote the type of process found in both chemical and physical activity. 
This narrowed viewpoint manifests itself throughout his analysis of the higher intellectual experiences, or higher complexes, as he terms them, which immediately follows the discussion of association.

\section{J. Mill's Analysis of Cognitive Phenomena}

The phenomena of consciousness are classed by James Mill as sensations, simple ideas which are their copies, complex ideas, and trains of ideas. In all complex ideas symbolism, or the process of naming as Mill calls it, is involved. ${ }^{1}$ Names are signs or marks attached to single sensations, clusters, and ideas; they are also marks which serve to introduce ideas or trains of ideas." "The name rose is the mark of a sensation of color, a sensation of shape, a sensation of touch, a sensation of smell, all in conjunction." 3 This is as near as James Mill comes to admitting an association of sensations. It is his equivalent for perception. He attributes this naming by clusters to motives of economy.

The naming of ideas follows the naming of the sensations of which they are copies; but there are also complex ideas "derived indeed from the senses but put together in arbitrary combinations." " These arbitrary clusters, which he terms 'mental' as distinguished from 'sensible' ideas, also receive names. Adjectives arise from subordinate distinctions among ideas, as for example when we characterize sounds as loud or low, harsh or sweet, etc. ${ }^{5}$ Verbs are particular kinds of adjectives, characteristic of motion and action. ${ }^{6}$ Mill analyzes in a similar way the minor parts of speech, and discusses predication, which he considers a device to mark the order of sensations and ideas. ${ }^{7}$ Besides the assignment
1 Ch. 4 , p. 128.
4 P. I38.
2 Pp. 128, I30, I34, I35.
5 P. 145 .
${ }^{3}$ Ch. 4 , § I, pp. I34-5.
7 P. I6I.
6 P. I5I. 
of names, as marks, to "clusters of ideas called objects," there are two other notable processes in naming: (I) Classification, or " generalizing those names so as to make them represent a class "; and (2) Abstraction, or "framing adjectives by which minor classes are cut out of larger." " These two important functions Mill regards as by-products of the naming process.

Conception is the process among ideas analogous to perception among sensations; it applies to clusters, not simple ideas. Thus we do not say, "I conceive red," or green; but we do say, "I conceive a horse," a tree, a ship; ${ }^{2}$ in such cases a number of simple ideas are "taken together' (con-ceived) in one experience. ${ }^{3}$ Conception, then, is not a new mental process; it merely serves to denote a complex idea to which a name has been given. In like manner, imagination is not a distinct 'power'; it is merely the term applied to "the manner in which ideas succeed one another in a train." 4

James Mill considers conceptions and imaginations as simpler types of experience than memory, which is " an idea and something more." 5 In this he is in agreement with Brown; though the general trend of his analysis follows Hartley's more nearly. In remembering, he says, "the mind runs back from the present moment to the moment of perception; that is to say, it runs over the intervening states of consciousness called up by association; . . . and in this case we associate them so rapidly and closely that they run, as it were, into a single point of consciousness, to which the name memory is assigned." 6 This is true whether the starting-point be a sensation, which we remember to have experienced before, or an idea which is remembered as a former sensation or idea.

This explanation of memory illustrates again the un-

1 Ch. 9, pp. 295, 294.

4 Ch. 7, p. 238.

${ }^{7}$ Pp. $329-35$. Compare Aristotle in the passage quoted in Chap-
2 Ch. 6, p. 233.

$5 \mathrm{Ch}$. Io, p. $32 \mathrm{I}$.

3 P. 234.

6 P. 33I. ter II. 
wieldiness of Mill's mechanical view of association. It is patent that we do not in the majority of cases actually 'run over' the intervening experiences-as the younger Mill takes pains to point out in a note on this passage. James Mill of course regards the process as syncopated to the utmost; but even so his description appears strained to his most sympathetic disciples; his difficulties are due (from the associationist's standpoint) to his unwillingness to admit the presence of transforming synthetic factors in the associative process.

As already noted, James Mill considers predication a mere variety of the naming process. Passing to the allied notion of belief, he subjects it to a minute analysis. The reason for this disproportionately close examination seems to have been the earnest controversy which had been going on since Hume's time regarding belief in causality and belief in the external world, especially by Thomas Reid, ${ }^{1}$ Dugald Stewart, ${ }^{2}$ and Thomas Brown. ${ }^{3}$ Mill saw that belief is a crux for the association doctrine. Hume and Brown had treated its psychological aspect very cursorily, and Hartley's discussion of assent (his equivalent for belief) was by no means thorough. Mill divides belief into three prime sorts: (I) Belief in events or real existences; (2) Belief in testimony; and (3) Belief in the truth of propositions. ${ }^{4}$ The first case, which he holds to be the most important of all, comprises (a) belief in present events (including i, existences present to the senses, and ii, those not present to the senses), (b) belief in past events, and (c) belief in future events. Belief in existences present to the senses (perception) includes something more than mere belief in present sensations-which is another name for having (or experienc-

1 'Enquiry into the Human Mind,' I764, ch. 2, and 'Essays on the Intellectual Powers of Man,' I785, II, ch. 20.

2 'Elements of the Philosophy of the Human Mind,' I792, I, ch. 3. 3 'On the Relation of Cause and Effect,' I818, pass.

4 Ch. 11, p. 344 . 
ing) the sensations. It involves, besides the present sensations, associated memories of tactile and muscular sensations, giving ideas of extension, distance, and resistance, and other sense memories "inseparably united one with another, and inseparably united with the idea of ourselves as having them." 1 Our belief in the physical objects + causing the sensations is a belief in causation. Mill resolves causation into an invariable connection of antecedent and consequent, and he resolves belief in causation into an inseparability which leads us to regard the complex experience as a unit. ${ }^{2}$ Belief in the existence of objects not present to the senses reduces to a case of testimony if we have never perceived these objects; if we have experienced them in the past and believe in their present existence, something more than memory is involved, namely, the belief that we shall experience them again if we are "in the same situation" 3 -which reduces to belief in the future.

Belief in past existences Mill resolves into memory or belief in testimony, as the case may be. Belief in the future, he finds, is due to indissoluble associations among our past experiences, which mark off the constant from the casual sequences, ${ }^{4}$ and which we term "the uniformity of the laws of nature." 5

Belief in testimony means belief in events as a result of testimony from others instead of our own experience; but the testimony itself is a present (or past) event, and belief in this has already been resolved into indissoluble association. $^{6}$

Belief in the truth of general propositions involves predication, or judgment, and this is shown to be merely an indissoluble association of names or marks belonging to two clusters of ideas." "To have two ideas, one a part

1 P. 349.

4 Pp. 363-8.

7 P. 388-90.
2 P. 352.

5 P. 384 .

3 P. 355.

6 Pp. 38I, 385. 
of another, and know that one is part of another, is not two things, but one and the same thing." 1

Belief, then, in any of its aspects, is a mere case of indissoluble association. ${ }^{2}$ Mill criticizes Locke's distinction between right and wrong belief: "Wrong belief is belief no less than right belief." Both proceed from association. The most we can say is that "when ideas are connected not in conformity with the connection of things, the belief is wrong belief." Custom, however, unites ideas more often in conformity with the connections among things than otherwise. ${ }^{3}$

\section{J. Mill: Motor and Affective Phenomena}

The remainder of the 'Analysis' may be summed up briefly. Ratiocination is association of the terms of propositions into a train. ${ }^{4}$ Reflection on any specific idea is merely "the having an idea, and knowing it," which are "one and the same thing." ${ }^{5}$ The "idea of reflection is simply the generalization of particular " experiences. ${ }^{6}$

James Mill attributes the distinction between intellectual and active powers of the mind to the fact that while some "sensations and ideas are considered merely as existing," others are "considered as not merely existing, but also as exciting to action." 7 The will he regards as "that peculiar state of mind or consciousness ... by which action is preceded." 8 It consists in "an idea of the thing willed," ${ }^{\circ}$ that is, of the action, associated with desire; and "the idea of the outward appearance of the action, ... excited by association, excites in the same way the idea of the internal feelings which are the immediate antecedent of the action, and then the action takes place." 10 "Whatever power we may possess over

1 P. 392.

$4 \mathrm{Ch}$. 12.

7 Ch. I6, II, p. I8r.

10 Pp. 378-9.
2 Pp. 369-77.

5 Ch. I5, Vol. II, p. I78.

${ }^{8}$ Ch. 24, II, p. 328 , th
3 Pp. 380-I.

- Ibid., p. 179.

9 P. 358 , 
the actions of our muscles, must be derived from our power over our associations," and this power "means nothing more than the power of certain interesting ideas, originating in interesting sensations, and formed into strength by association." 1

The affective consciousness Mill regards as a character of sensation. Sensations are indifferent, painful, or pleasurable; and this distinction runs through all the senses; the pleasures and pains of the "internal parts of the body," though they have no special names, "hold a great share in composing the springs of human action." 2 When anticipated as future, they become in certain cases motives. $^{3}$ "The idea of a pain or pleasure is not a pain or pleasure;" but this merely means "that the idea of a pleasurable or painful sensation is not a sensation." 4

Thus James Mill succeeds in ridding his psychology of any distinct 'affective' element, as he has rid it of a distinct 'active' element. Every experience is resolved into sensations and ideas, combined into groups, or following in trains, by the single process of association; and the principle of association itself is reduced to its simplest terms-the tendency of ideas to group themselves or succeed one another after the manner of their originals. His analysis is the most thorough of any up to his time, and the most systematic in its passage from point to point. It is also the most rigidly associational-and, as has been indicated, it holds to a very narrow type of associationism. Unsatisfactory in many points even to those predisposed in favor of the theory, it nevertheless furnished them with a complete survey of the field; and thus it naturally became the starting-point for later work. The writers who followed Mill adopted much of his analysis, and that which appeared faulty or strained served only to stimulate more careful examination. 


\section{John Stuart Mill's Law of Association}

John Stuart Mill (1806-1873), the son of James Mill, was connected with the East India Company till the age of fifty; he was at the same time engaged in editorial work and other writing, and in the later years of his life devoted himself chiefly to study and literature. His psychology is closely linked to that of his father, his own original work being chiefly in the field of logic. He was a more critical thinker than the elder Mill, and saw difficulties where the latter was content with a plausible explanation.

J. S. Mill was impressed with the force of some of the objections to associationism raised by William Hamilton $^{1}$ and others, and realized the weakness of certain parts of the 'Analysis'; he accordingly amended the theory in several respects. We are fortunate in having his views presented in critical annotations to James Mill's masterpiece, which he edited in connection with Alexander Bain (1869). The reasons for his emendations are thus made clear. He does not hesitate to bring out incisively the points in which he differs with his father. The chief of these, already alluded to, is his broader conception of the associative process, which he pictures as a 'chemical' union instead of a merely 'physical' conjunction; there are also many points of difference in the analysis itself, especially in connection with the intellectual processes. Besides the notes to his edition of the 'Analysis,' his psychological views are found in his 'Logic' (1843), and in his 'Examination of Sir William Hamilton's Philosophy' (I 865).

A chapter in the 'Logic,' on the Laws of Mind,'

${ }_{1}^{1}$ The historical note on Association and the discussion of its principles by Hamilton have been referred to in Chapter I. Though himself a follower of the Scottish school, Hamilton's work was of great value to the later associationists and stimulated them to review the underlying principles of their doctrine.

2 Bk. VI, ch. 4 . 
presents his conception of association very clearly, though his views were modified somewhat in later years. ${ }^{1}$ The subject-matter of psychology, he declares in this chapter, is the determination of the laws according to which one mental state succeeds another. ${ }^{2}$ Two of the most general (laws are as follows: (I) "Whenever any state of consciousness has once been excited in us, no matter by what cause, an inferior degree of the same state of consciousness, a state of consciousness resembling the former but inferior in intensity, is capable of being reproduced in us without the presence of any such cause as excited it at first." 3 This defines the nature of ideas in relation to sensations. (2) "These ideas; or secondary mental states, are excited by our impressions or by other ideas according to certain laws which are called Laws of Association." 4

There are three such laws: "The first is that similar ideas tend to excite one another. The second is that when two impressions have been frequently experienced (or even thought of) either simultaneously or in immediate succession, then whenever one of these impressions or the idea of it recurs, it tends to excite the idea of the other. The third law is that greater intensity in either or both of the impressions is equivalent, in rendering them excitable by one another, to a greater frequency of conjunction." 5

It will be noticed that the first is the familiar law of Similarity; the second is Contiguity, which Mill combines with Frequency or Habit; the third is the law of Intensity. Mill rejects the law of Contrast absolutely; in a note to the 'Analysis' he declares that " black does not remind us of white more than of red or green; if light

${ }^{1}$ Quotations are from the 8 th edition-the last revised by the author.
2 Loc. cit., $\$ 3$.
4 Ibid.
3 Ibid.
5 Ibid. 
reminds us of darkness, it is because darkness is the mere negation, or absence, of light." 1

In a later work J. S. Mill postulates four laws instead of three: (I) Similarity and (2) Contiguity, stated practically as before, but without the reference to Frequency. (3) The law of Frequency, stated in a somewhat modified form: "Associations produced by contiguity become more certain and rapid by repetition. When two phenomena have been very often experienced in conjunction, and have not in any single instance occurred separately either in experience or in thought, there is produced between them what has been called Inseparable, or less correctly Indissoluble Association." 2 (4) When an association has acquired this character of inseparability ... not only does the idea called up by association become in our consciousness inseparable from the idea which suggested it, but the facts or phenomena answering to these ideas come at last to seem inseparable in existence." 3

Mill differs with his father on the question of Similarity, making it the first principle of association. Similarity is not reducible to mere frequency of experience, for we experience unlike things together more frequently than many like things, yet they do not suggest one another in the same degree as do like things. ${ }^{4} \mathrm{He}$ goes rather to the other extreme, assigning frequency a role in connection with contiguity but not with similarity. It is interesting here to note Mill's use of one of his canons of induction to account for inseparability of association. In the 'Examination' he omits the law of intensity, which he seems to think deducible from frequency under the law of Inseparable Association. Special emphasis is laid on this notion of inseparable association, to which he attaches an important epistemological role

1 Vol. I, p. 126.

Boston.

2 'Exam.,' ch. II, Vol. I, p. 235 ; cf. ch. 6, p. 83, ed. of 1865, ${ }^{3}$ Ibid.

4 'Anal., I, p. III ff. 
in the fourth law. In criticism of the term indissoluble he urges that associations which have become for the present inseparable may nevertheless be dissolved in time. ${ }^{1}$

Mill holds that the laws of association are supplemented by certain laws of oblivescence, the principal one of which he states as follows: "When a number of ideas suggest one another by association with such certainty and rapidity as to coalesce together in a group, all those members of the group which remain long without being especially attended to, have a tendency to drop out of consciousness." ${ }^{2}$ They may even "disappear from consciousness as completely as if they had never formed part of the series." ${ }^{3}$ By this law of lapsed links, taken perhaps from Tucker, he is able to account for the limitations of memory without resorting to the elder Mill's questionable hypothesis that all intervening states actually pass rapidly through consciousness each time we have a recollection.

J. S. Mill's view of the compounding of experiences is most clearly stated in his 'Logic.' Certain of our complex ideas, he says, are generated from simple ones; they do not consist of them. For, "the effect of concurring causes is not always precisely the sum of the effects of those causes when separate, nor even always an effect of the same kind." 4 In psychology, as in the physical sciences, there are two distinct types: "The laws of the phenomena of mind are sometimes analogous to mechanical, but sometimes also to chemical laws. When many impressions or ideas are operating in the mind together, there sometimes takes place a process of a similar kind to chemical combination. When impressions have been so often experienced in conjunction that each of

1 This qualification meets the objection which might otherwise be raised to the term inseparable.
2 'Exam., I, 317.
3. Anal.,' I, Io6.
4. Loc. cit., § 3 . 


\section{J. S. MILL'S LAW OF ASSOCIATION}

them calls up readily and instantaneously the ideas of the whole group, those ideas sometimes melt and coalesce into one another, and appear not several ideas but one." 1 Our idea of an orange really consists of certain ideas of color, form, taste, smell, etc., because by examination we can perceive all these elements in the idea. But we do not perceive, in the visual perception of the shape of an object, " that multitude of ideas derived from other senses, without which . . . no such visual perception would ever have had existence; nor in our idea of Extension can we discover those elementary ideas of resistance derived from our muscular frame, in which . . . the idea originates. These, therefore, are cases of mental chemistry, in which it is proper to say that the simple ideas generate, rather than that they compose the complex ones' another rapidly it is proper to say that they generate white, not that they are white.

J. S. Mill files two caveats in connection with the application of the notion of mental chemistry. First, when we see that some complex idea may have been generated in this wise from simpler elements, we should not assume at once that it actually has been-that the complex phenomenon has been satisfactorily explained: we must employ the canon of Difference as well as the canon of Agreement, and show that it could not have been brought about otherwise. Second, even if the association theory be proved, "we should not be the more enabled to resolve the laws of the more complex feelings into those of the simpler ones." ${ }^{3}$ The generation of one class of mental phenomena from another does not supersede the necessity of an experimental study of the generated phenomena and their laws. ${ }^{4}$
1 Ibid.
2 Ibid.
3 ' Logic,' loc. cit.
4 Ibid. 


\section{J. S. Mill's Analysis of Belief}

J. S. Mill is concerned with association as a logician rather than as a psychologist, and he does not attempt to apply it systematically to the higher complexes as his father did. We need not stop to examine the minor emendations which are suggested in his notes on the 'Analysis,' since he is in general agreement with Bain's view, which will be discussed presently. But it is of interest to follow his analysis of Belief, which on account of its relation to judgment attracts his special attention in the 'Logic' and elsewhere.

Predication is not a mere case of naming, as the elder Mill declared; it is something more than the mere association of predicate with subject. Predication " expresses a belief that a certain coexistence or sequence of sensations or ideas did, does, or under certain circumstances would take place; and the reverse of this when the predication is negative." 1 Belief itself "is always a case either of memory or expectation." ${ }^{2}$ It is the element which distinguishes memory from imagination, and expectation from mere conception. ${ }^{3}$ Belief "is more than an inseparable association; for inseparable associations do not always generate belief, nor does belief always require as one of its conditions inseparable association " certainly is not an indissoluble association, for then "an opinion once formed could never afterwards be destroyed or changed." 5

There seems to be, then, some distinctive element in belief. Mill agrees with Bain that "what constitutes belief is the power which an idea has obtained over the will "by association. "We believe a thing when we are ready to act on the faith of it-to face the practical con-

1 'Anal.,' I, p. I64.

3 Ibid.; cf.' 'Exam.,' ch. I8, II, p. 97.

2 Ibid., p. $4 \mathrm{I} 8$.

5 P. 404.

4 Ibid.

6 'Anal.,' I, pp. 402-3. 
sequences of taking it for granted; and therein lies the distinction between believing two facts to be conjoined, and merely thinking of them together." ${ }^{1}$ "But when there is a difference in the effects there must be a difference in the cause: the association which leads to action must be, in some respect or other, different from that which stops at thought." 2

It is at this point that J. S. Mill differs with Bain, and questions the sufficiency of the associational analysis of belief: "I can perceive no escape," he says, "from the opinion that the distinction [between our representation of an imaginary thing and our belief in the reality of a represented thing] is ultimate and primordial. There is no more difficulty in holding it to be so than in holding the difference between a sensation and an idea to be primordial. It seems almost another aspect of the same difference." 3 And in his 'Logic,' also, he questions whether mental chemistry is adequate to explain the generation of belief.4

Mill's theory of belief plays an important role, as might be expected, in his epistemology. In two chapters of the 'Examination' he discusses at considerable length the psychological basis of our belief in the external world and mind. The external world reduces, psychologically, to a "permanent possibility of sensation." ${ }_{5} \mathrm{My}$ own mind reduces to " the permanent possibility of feeling," including internal feelings, thoughts, emotions, etc., as well as the sensations of my outward senses "; ${ }^{6}$ it is a consequence of memory.

Belief in the future enters as an important element into

1 P. 403.

2 P. 404. Compare the pragmatic doctrine of today.

$3 \mathrm{Pp}$. 412-3. An explanation of the relation between sensation and idea rests, as Hartley pointed out, on physiological grounds. It is difficult to see how physiological data can serve to explain the sui generis character of belief.

4 Pt. VI, ch. $4, \S 3$.

${ }^{6}$ Ch. 12, pp. 253-4.

5 'Exam.', ch. II, esp. p. 243. 7 'Anal.,' I, p. 229. 
our idea of causation. Mill defines a cause as an unconditional as well as invariable antecedent; it is not merely one that always has been followed by a given consequent, but one which we believe always will be so followed. ${ }^{1}$ But our idea of cause includes another element, still more important than expectation-namely, the idea of effort. This latter datum is " derived from the action of our muscles," which always "has to contend against resistance, either that of an outward object, or the mere friction and weight of the moving organ; every voluntary motion is consequently attended by the muscular sensation of resistance, and, if sufficiently prolonged, by the additional muscular sensation of fatigue." ${ }^{2}$ By constant association this experience is generalized, so that savages and children conceive inanimate causes as overcoming re-sistance, and this becomes their notion of power. While "we outgrow that belief," still our mind "interposes between the antecedent and the consequent an abstract entity to express what is supposed common to the animate and the inanimate agency," and "this purely subjective notion . . . is power." 3

Mill assigns an important role to attention in connection with voluntary activity. Attention, produced by highly pleasurable or painful experiences, tends to prolong the experience so characterized, to strengthen it, and to render it more distinct. ${ }^{4}$ When such an idea is associated with a muscular act, this intensification "has a specific tendency to excite the act when the idea is that of a pleasure, but when it is the idea of a pain has a specific tendency to prevent that act." 5 The power of the attention over the will, then, is not arbitrary, but an instance of the laws of association. This application of attention to the problem of volition, which Mill does not fully work out, is an important contribution to the theory of the

1 'Logic,' Bk. III, ch. $5, \S 6$.

3 Pp. 47-8. ${ }_{4}$ 'Anal.,' II, 372. 2 'Exam.,' ch. I6, II, p. 47. ${ }^{5}$ P. 380. 
will from the associational standpoint, since it brings association to bear on conative phenomena in a new way, supplementing Hartley's general analysis.

Mill bases logic on the data of psychology, but declares that "logic is not the theory of thought as thought, but only as valid thought." 1 The so-called laws of thought (identity, contradiction, and excluded middle), which determine its validity, may or may not be "an original part of our mental constitution." Whether they "are laws of our thoughts by the native structure of the mind, or merely because we perceive them to be universally true of observed phenomena," he says, "I will not positively decide; but they are laws of our thoughts now, and invincibly so." 2

The distinguishing features of J. S. Mill's work are (I) his emphatic reinstatement of mental chemistry as an operation attending certain associations, especially fusion; (2) his thorough analysis of belief, and his assertion that it contains an original element, not to be identified with sensation or idea, nor attributable to association; (3) his logical insight into many difficulties and shortcomings of the earlier associational analysis, his fair and incisive criticisms of these, and his many hints at more consistent solutions.

It is to be regretted that his psychological analysis is so detached and incomplete; but this disadvantage is scarcely felt if we take his system in connection with that of his father, amending the latter in accordance with his suggestions. Furthermore, we have a thorough analysis of consciousness by his contemporary and coworker Bain, whose point of view coincided in the main with John Stuart Mill's.

1 'Exam.', ch. 20, II, p. 145.

2 'Exam., ch. 2I, II, p. 180; cf. 'Logic' Bk. II, ch. 7, § 5. 


\section{Alexander Bain's Conception of Association}

AleXander Bain (I8I8-1903) for many years held the chair in logic at the University of Aberdeen, but is better known for his contributions to psychology. His book on logic is overshadowed by J. S. Mill's great classic, just as the latter's fragmentary psychology is dominated by Bain's exhaustive two-volume treatise. Bain's chief book on psychology appeared as two separate works, thefirst entitled 'The Senses and the Intellect' (I855), the second, "The Emotions and the Will' (1859); they were twice revised by the author ( $3 \mathrm{~d}$ ed. 1875). These two works, really one, embody Bain's conception of mind in a full and thorough analysis whose chief instrument is the associative principle. Some additional points and many side-lights are found in his notes to J. S. Mill's edition of James Mill's 'Analysis' (I869), and in his 'Mind and Body' (I866), his 'Mental Science' (I868), which is mainly an abridgment of his two first works, and his 'Logic' (1870). These later works and the revised editions of his earlier volumes show the influence of Herbert Spencer's evolution philosophy and Charles Darwin's theory of biological evolution in several respects; but Bain's psychology is essentially pre-evolutionary. His best piece of analysis is his treatment of the intellectual processes in terms of association, in his first volume.

Bain distinguishes at the outset between three sorts of mental phenomena: ( I ) feeling, including "pleasures and pains, emotion, passion, affection, sentiment"; (2) "volition, or the will, embracing the whole of our activity as directed by our feelings; " and (3) "thought, intellect, or cognition." " Intellect "includes such functions as memory, reason, judgment, and imagination." ${ }^{2}$ It implies three facts: (I) "Discrimination, or sense of dif-

1 ' S. and I.,' 3d ed., Intr., ch. I, § 2.

2 Ibid., § 3. 
ference, shown by our being conscious of one sensation as more intense than another," etc.; (2) "Similarity, or sense of agreement;" (3) "Retentiveness, commonly understood by the familiar names memory and recollection; this power is essential to the operation of the two former." 1

Discrimination involves an important mental principle - the Law of Relativity: "As change of impression is an indispensable condition of our being conscious, or of being mentally alive to feeling and thought, every mental experience is necessarily two-fold. We can neither feel nor know heat, except in the transition from cold. In every feeling there are two contrasting states; in every act of knowledge two things are known together." ${ }^{2}$ In his first edition Bain combines the first two factors together as "sense of agreement or of difference," and limits this phenomenon to intellect. The extension of discrimination to feeling and consciousness in all its forms, under the law of relativity, is an effect of Spencer's influence. It does not fit especially well into Bain's treatment of the laws of assóciation, as L. Ferri points out. ${ }^{3}$

The third power, retentiveness, has two aspects: "the persistence or continuance of mental impressions after the withdrawal of the external agent," and "the power of recovering, or reviving, under the form of ideas, past or extinct sensations and feeling of all kinds, without the originals, and by mental agencies alone." ${ }^{4}$ It is a striking feature of Bain's psychology that he dispenses with any treatment of memory as such; the nervous function of renewal is discussed briefly in one place, ${ }^{5}$ the revival of sensations is alluded to under several senses, and the subjective phenomena of memory are treated mainly

1 Ibid.

2 'S. and I.,' § 6; cf. 'Logic,' Intr., § 3.

3 'Psychol. de l'assoc.,' p. I38.

4 ' $\mathrm{S}$. and I.,' Bk. II, prelim.

5 ' $\mathrm{S}$. and I.,' Intr., ch. $2, \S 25$. 
under the associative principle of contiguity. ${ }^{1}$ The other "intellectual functions" of imagination, judgment, and reason are similarly subsumed as forms of association.

In his first edition Bain considers association as simply the revival or reappearance of past states of mind by mere mental operations. " The process " is subject to fixed laws . . . termed Laws of Mental Association, Suggestion, or Reproduction," which are " four in number, two being simple and fundamental, and two complex." $3 \mathrm{He}$ names these principles Contiguity, Similarity, Compound) Association, and Constructive Imagination.

In his third edition he links the law of contiguity with retentiveness, and the law of similarity with sense of agreement. The third law, which he terms Complicated Reproduction as well as Compound Association, and which seems to be derivative, he links with sense of difference or discrimination. Bain suggests no special basis for the fourth process, which involves "the applications of the intellectual forces to form new constructions, the Creative or Inventive faculty of the mind"; he is not disposed to treat it as a separate law. ${ }^{4}$ This difference of treatment is a result of his attempt to incorporate the Spencerian principle of relativity into his analysis. Following the same plan, in the third edition he elevates discrimination to an important position at the outset and relegates it later on to a subordinate place under the law of contrast. This uneven treatment shows that his attempt is only partially successful - that he has not reconstructed his analysis thoroughly to accord with the new view, as should have been done in the interests of consistency. The four laws given in the first edition represent Bain's own standpoint.

(I) The Law of Contiguity, which is " the law of association proper, of adhesion, mental adhesiveness, or

1 Bk. II, ch. I.

${ }^{3}$ Ibid.
2 'S. and I.,' Bk. II, prelim., $\$ 6$.

4 'S. and I.,' 3d ed., Bk. II, prelim. 
'acquisition," is stated as follows: "Actions, sensations, and states of feeling, occurring together or in close succession, tend to grow together, or cohere, in such a way that, when any one of them is afterwards presented to the mind, the others are apt to be brought up in idea." 1 This law applies first of all to groups of muscular movements, and to the feelings which we have of such movements. It is the basis of our coordination of movements, and of our idea of a movement when the latter does not actually take place, a type of intellect or thought which appears at an early stage. In like manner sensations arising from the same sense group themselves into objects of sense, and give rise by association to ideas, though this usually occurs in the higher senses only. A later form is the grouping of sensations from different senses and of sensations with movements, which gives rise to perception and ideas of objects of perception. These 'object-experiences,' again, may be associated with emotions (sublimity, etc.) or with movements (volition). The law of repetition, according to which the strength of an association is increased by its frequent renewal, is implied in the law of contiguity. ${ }^{2}$

Bain believes that most cases of association are successive-all, in fact, " except complex and coinciding muscular movements, and the concurrence of sensations through different senses at the same moment." ${ }^{3}$ "The features of a landscape can be conceived only by successive movements of the mind, as it can be seen only by successive movements of the eye." 4 In this way he sets aside in large measure the problem of simultaneous association and the question of fusion.

(2) Bain's other fundamental principle is the Law of Similarity or Agreement: "Present actions, sensations, thoughts, or emotions tend to revive their like among

1 'S. and I.', Ist ed., Bk. II, ch. I, § I.

3 Ibid., § 58 ; cf. 'M. S.,' I 12 .

2 Ibid., § I.

4 Ibid. 
previous impressions." Under the first law "the new action or the new image was supposed precisely identical with the old, and went simply to reinstate and to deepen an impression already made"; the second law applies to cases "where the identity is only partial." ${ }^{2}$ In the first case the reinstatement is sure, here it is doubtful, and the problem is what degree of similarity will produce association. When two experiences are alike in one respect and dissimilar in many, it is possible to detect the similarity in some cases and not in others. Faintness and diversity are impediments to the revival, ${ }^{3}$ and familiarity a help, ${ }^{4}$ under this law. The rational processes of abstraction, induction, deduction, and analogy are instances of association by similarity.:

(3) Bain's third principle is the Law of Compound Association; "Past actions, sensations, thoughts, or emotions are recalled more easily when associated, either through contiguity or similarity, with more than one present object or impression." " This is not a new principle; the reinstatement according to the two fundamental laws merely becomes " more easy and certain" where "several threads, or a plurality of links or bonds of connection concur in reviving" one and the same previous mental

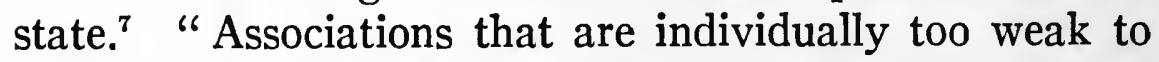
operate the revival of a past idea, may succeed by acting together." 8

Bain's exposition of this principle is scarcely satisfactory; his instances are for the most part complexities which have been already associated, rather than separate experiences-or the association is traced to frequency rather than concurrence. He does show, however, that trains of thought are directed into one rather than the other of two conflicting lines by the relative number of
1 Ch. $2, \S \mathrm{I}$.
2 Ibid., § 2.
4 \$9.
$5 \S 34$.
3 § 4.
7 Ibid.
8 Ibid.
6 Ch. $3, \S \mathrm{I}$. 
the favorable elements in the present experience as well as their strength. ${ }^{1}$

In his first edition Bain reduces Aristotle's law of Contrast or Contrariety to a combination of contiguity and similarity, together with an element of emotion which serves to impress the contrast upon us. Black and white, for example, are both colors, or modes of light; having become coupled in popular language, they tend to suggest one another by contiguity; while in many instances of contrast one quality is painful and suggests the other as a relief from this. ${ }^{2}$ In the revised edition he makes contrast "the reproductive phase of the first law of mind -relativity or Discrimination," 3 while admitting that contrast may also arise in many cases in the ways just stated.

(4) The fourth principle, Constructive Imagination, is stated as follows: "By means of association the mind has the power to form new combinations or aggregates, different from any that have been presented to it in the course of experience." 4 This operation is variously known as Imagination, Creation, Constructiveness, and Origination or Invention; it is the process whereby we put together new forms of mental imagery. Bain affirms that "the intellectual forces operating in these creations are no other than the associating forces already discussed; the new combinations grow out of elements already possessed by the mind, and brought forward according to the laws above laid down. ${ }^{5}$

\section{Bain's Derivation of Mental Phenomena}

Bain reduces all the intellectual processes to instances of one or other of these laws or forms of association. In

1 \& 4 .

2 Ibid., § 18.

3 'S. and I.', 3d ed., ibid.; cf. 'Mental Sci.,' Bk. II, ch. 3, § Io. 4 'S. and I.,' 3d ed., Bk. II, ch. 4, § I. 
general, perception and memory result from the principle of Contiguity, generalization and all forms of reasoning result from the principle of Similarity or Agreement; complex experiences of objects are consolidated and habitual trains of thought are formed in accordance with the principle of Compound Association; while imagination and invention result from the principle of Constructive Association. "The principal distinction between memory and imagination lies in the setting of the respective ideas: ideas of memory have a place in the continuous chain of our remembered life; ideas of imagination correspond to nothing in that chain-or rather, they are consciously combined from different ideas of memory taken out of their memory-setting and aggregated under a special motive." 1

Knowledge is identical with affirmation and belief. Its essential elements are, (I) in the case of a single thing known, "we must be conscious of it as differing from some things and as agreeing with others"; (2) in the case of affirmations, at least two things are noticed, and "the couple must be farther viewed as coming under a third property," such as coexistence, succession, etc.; (3) "into these affirmations there must enter the active state or disposition termed belief, or disbelief." 2

Belief is essentially a part of the active side of mind. "Preparedness to act upon what we affirm is . . . the sole, the genuine, the unmistakable criterion of belief." 3 In its primitive form it is primitive credulity and spontaneous activity-the impulse to accept experience without question and to act upon it; but even early in experience there appear contradictions, which produce depressing emotional effects. Owing to these contradictions, belief in its developed form implies " as a necessary element some cognizance of the order of nature." ${ }^{4}$ In a

1 'Em. and Will,' 3d ed., ch. on Belief, § 29.

2 Ibid., ch. Consc., $\$ 26 .{ }^{3}$ Ch. Belief, $\$ 2$. 
word, belief proper is "innate credulity tempered by checks." ${ }^{1}$ Our beliefs are strong in proportion (I) as "we work as strongly for the means as we do for the end" (motor test), and (2) as we are elated "by attaining the means to a given end," or depressed "by a prognostic of calamity "-emotional test."

Contrary to J. S. Mill, Bain finds no new and unanalyzable element in belief; he is able to reduce it to a case of association. His position is virtually in agreement with that of the elder Mill, except that he makes noncontradiction the test of belief: we assume that the uncontradicted is true-not merely that which has been incessantly repeated. ${ }^{3}$

Bain's analysis of the distinction between subject and object, between the internal and external worlds of experience, forms an interesting contrast with J. S. Mill's. He finds that these two sides are separated in experience by three independent criteria: (I) Objects are characterized by "movement . . as contrasted with passive sensation" which characterizes the subject. (2) "Definite feelings connected with definite movements " characterize the object, in contrast with "feelings independent of our movements (subject)." (3) "Experience common to all (object), as against experience special to each (subject). ${ }^{\mathbb{2}} \quad$ The fundamental experience connected with movement of objects, in the first criterion, is " that peculiar sensibility that we term the feeling of resistance," which he attributes to the muscle sense. The second criterion forms the demarcation between sensation and idea. The third he regards as "one of the handiest tests to distinguish reality from illusion." 5

We noticed that Bain places the active side of mind ahead of the intellectual in his opening analysis. This order has peculiar significance in his system. Perhaps

$1 \S 2$ I. $2 \S 5$.

4 Ibid., ch. Consc., $\S 28$.

5 Ibid.

$3 \S 22$. 
the most important feature in his treatment of the elementary facts of psychology is the prominence he accords to motor phenomena, starting with the notion of contractility and sensibility, and examining all forms of spontaneous and instinctive activity in connection with the feelings that accompany them. His theory of volition hinges on this relation.

The primitive fact of mind on its motor side is the original tendency of the organism to spontaneous movements. $^{1} \quad$ For the passage from spontaneous to voluntary activity, it is necessary (I) that certain movements, or groups of movements, be capable of isolation from all others; and (2) that there be some special excitement, especially by what may be termed mental stimulants or ideas. $^{2}$ The link between feeling and action in primitive life is the law of self-conservation: pleasurable stimuli tend to incite greater activity, while painful stimuli tend to check activity. ${ }^{3}$

The special stimulus to voluntary activity is directive, and consists in an ideal "purpose or aim." 4 Ideas come under voluntary control by the hindering effect on movements of certain thoughts and the furthering effect of others. ${ }^{5}$ The sense of voluntary power arises in the consciousness of effort, which is the consciousness of expenditure of energy in the struggle against obstacles; its growth is due to exercise and fatigue: the repetition of chance conjunctions of movements with ideas which are favorable to the coordinated activity generates an association (law of contiguity), while irrelevant accompanying movements only hinder the consolidation till by chance they are omitted and the obstacle to complete coordination is overcome. ${ }^{6}$ Ideas so joined with coordinated activity are known as motives or ends.

1 'Em. and W.,' Bk. II, ch. I, prelim.

$2 \$ \$ 3,4$.

3 'S. and I.,'Bk. I, ch. 4, § 26.4 ' Em. and W.' Bk. II, ch. I, §6. $5 \S 8$.

6 Ibid., ch. $2, \S \S \mathrm{I}, 2$. 
Motives admit of a variety of classifications, the most fundamental division being into ideas concerned with the promotion of pleasure and those concerned with the warding off of pain. ${ }^{1}$ Conflicts in motives arise from the joint presence of two or more motives that tend toward different lines of activity; deliberation is the check or pause during this conflict, and resolution marks its termination. ${ }^{2}$ The moral instincts are habits of control which arise according to the laws of association, aided by social education; ${ }^{3}$ the notions of duty and conscience depend at first on punishment and the fear of punishment, which are later superseded by a subjective control-the former stage is the slave conscience, the latter the citizen conscience. $^{4}$

Bain regards volition as a mental phenomenon, but not as a fact of consciousness. The elements in consciousness corresponding to volition are either intellectual or emotional; deliberation, desire, and belief, as facts of experience, are ideas. ${ }^{5}$

Emotions, according to Bain, are complex manifestations of feeling. The direct external stimulus, which is the prominent physical element in sensation, is lacking in emotion, and in its place we find the "outward manifestations or diffused wave of effects." " This tendency of the aroused currents to diffuse themselves is a characteristic of all feeling, but in the case of emotion it is more extended and definite than in the simpler pleasure or pain reactions. $^{7}$ Associations founded on feeling are the slowest to form and require most repetition $;^{8}$ on the other hand the complex feelings or emotions aroused by association attain a greater intensity or volume and subside more gradually than ideational associations. ${ }^{9}$ Bain analyzes the emotions as developments of primitive pleas-
1 Ch. 5.
4 Ch. Io.
8 § 16.
2 Ch. 7.
5 'Em. and W.' ch. Consc., $\$ 6$ note.
3 Ch. 9.
7 Ibid., § 3 .
${ }^{9}$ Ch. 3, \& 3 . 
ure and pain; the chief types are love, anger, and fear, the lowest form of love being sympathy, which differentiates into the social, sexual, and parental emotions, etc.

To sum up the main points in Bain's position. (I) The key to his psychology is found in the relation which he assumes between experience and motor impulse. Previous writers regard sensation as an effect or consequent of stimulation. Bain not only accepts this view, but makes the further assumption that sensation, or its nervous correlate, is accompanied by a direct motor tendency of some sort, and that this motor impulse is more pronounced the stronger the feeling element in the experience.

(2) Discrimination, the elemental fact of intellect, is an original element in all experience, for consciousness itself implies change, and change involves primitive discrimination. This theory was borrowed from Spencer after Bain's work first appeared, and is not thoroughly. incorporated into his analysis in the later editions.

(3) The revival of impressions without renewal of the external stimuli, resulting in ideas, is a fact explicable in physiological terms, and its psychological formulation appears in the Law of Association. All varieties of intellectual experience and all trains of thought result from discrimination and revival according to the associative principles of contiguity and similarity. This is brought out in a very searching analysis.

(4) Motor coordination and voluntary control result from the association of ideas with motor impulses according to the same laws. Chance unions and repetitions of favorable unions guide the coordinations into the proper channels. 'Volition' is not a fact of consciousness, however; the consciousness of effort, deliberation, desire, and belief are ideas, not a new type of experience.

(5) The emotions are traceable to complications of primitive feeling, motor impulse, and discrimination. 
(6) The fundamental facts of consciousness thus appear to be $(a)$ primitive feeling-sensation, as pleasure, pain, or neutral; $(b)$ discrimination, or relativity of consciousness, which includes sense of similarity; and $(c)$ associative revival, in the form of ideas. No other elements are needed, except the laws of the physical organism.

\section{Culmination of Pure Associationism}

Bain develops his analysis along rigidly associational lines. Even belief, in which J. S. Mill finds an irreducible element, is traced to associative principles. He emphasizes the sequential character of consciousness; with few exceptions all experiences are successive, and consequently he finds no cases of simultaneous association. Thus he avoids dealing with the question of coalescence and mental chemistry. Apparently he accepts, with James Mill, the mechanical view of association - or at least does not accept the 'chemical analogy.' The elder Mill, however, believes in simultaneous association, which makes the mechanical character of his theory apparent, whereas there is nothing in Bain's analysis inconsistent with 'mental chemistry' if his few instances of simultaneous experiences should necessitate the extension of association to synchronous intellectual experiences.

Bain follows Hartley in laying stress on the nervous system and its functions. A long chapter is devoted to details of anatomy and physiology of brain, nerves, sense organs, and muscles. In this he appears to have set a pattern for many recent psychological treatises. His analysis of sensation is as full as James Mill's is brief, and he is a forerunner in this respect of the modern experimental movement.

Bain's work marks the culmination of the 'pure' associationist movement. The introduction of the conception of evolution into science wrought a change in the problem 
of mental growth, involving a reconstruction, or at least a restatement, of the notion of association. Bain's relation to this new trend in psychology will be discussed in the next chapter.

Before passing to the last phase of associationism we should notice briefly three other writers who belong to this period.

SAMuel BAmEy (I79I-r870), a writer on psychology, logic, and economics, in his 'Letters on the Philosophy of the Human Mind' (I855-I863) vigorously attacks the 'faculty' interpretation of mind. His empiricism leads him to question the Berkeleyan theory that distance perception is an inference. ${ }^{1}$ According to Bailey it is rather an associative experience of the same sort as the union of sensory data in other perceptual experiences.

John Daniel Morell (I8I I-I89I) developed an empirical system of psychology in two works, 'Elements of Psychology' (1853) and 'Introduction to Mental Philosophy' (1862). While adopting the associational standpoint in the main, he was largely influenced by Herbart. According to Morell similar ideas 'blend,' 2 while the term association applies to the sequence of ideas. ${ }^{3}$ The strength of an association, according to Morell, may in every case be stated as " equal to the amount of the action and reaction of the associated ideas." 4

James Sully (b. r842) belongs in the main to the Scottish movement, but lays great emphasis on the associative process. In his 'Outlines of Psychology' (I884), while adopting the 'faculty' psychology, he accords first place to association under the laws of mind. ${ }^{5} \mathrm{He}$ discusses the laws of association at considerable length, ${ }^{6}$ following Bain's treatment in the main.

1 'Review of Berkeley's Theory of Vision,' 1842.

2 'Intro.,' Pt. III, ch. 3.
3 Ibid., ch. 4.
${ }_{4}$ Ibid., p. 177.
5 Pp. 29-36.
6 Pp. 227-75. 
Sully's later work, 'The Human Mind' (1892), devotes more space to experimental and psychophysical results, but his general standpoint remains the same. $\mathrm{He}$ is not influenced by the evolution doctrine. In this work Sully adopts the notion of mental chemistry, ${ }^{1}$ and follows Bain in his general treatment of association. Sully formulates a new law of association, which he calls the Law of the Dominant Element: "Where associative cohesion of two or more psychical elements is strong, the characters of dominant elements tend to be distributed over the whole compound." ${ }^{2}$

1 Vol. I, p. 190. 


\section{CHAPTER V}

\section{EVOLUTIONARY ASSOCIATIONISM}

\section{The Evolution Concept in Psychology}

BaIN occupies a peculiar position in psychology. He had worked out his analysis along pure associational lines and had published his results while still under the influence of the older world-view, which held to the permanency of biological species. The theory of fixed organic types carries with it the view that the mental constitution of each species is also fixed and changeless; hence the only sort of mental growth to be considered is the development of experience which arises from the action of the environment on the individual. The debate between 'nativists' and 'empiricists' seemed to resolve itself into a question whether the 'original constitution' with which each individual begins life is in the nature of structure (innate ideas, mental forms, etc.), or of dynamic conditions (laws of association, etc.). The nativists provided the new-born infant not with actual mental currency, but with drafts payable to bearer at sight; the associationists started him off in life with neither money nor drafts, but merely with an introduction to the bank, and compelled him to work his way to mental wealth according to the laws of associational economics.

Just as Bain was publishing his first volume, Herbert Spencer issued in its earliest form his work on 'Psychology' ( 1855 ); and in the year in which Bain's second volume appeared Charles Darwin published the 'Origin of Species' (1859), and Spencer was beginning to outline 
his evolution philosophy. The effect of the evolution concept on psychology was to reveal a possible intermediate position between the two conflicting schools. The individual biological organism, as even the ancients had observed, starts life with certain organs already formed in embryo and ready to function at birth; but according to the evolution theory the form of these organs is the result of a gradual process of modification and increasing complexity which occurs in race history. Similarly the individual mind may be pictured as starting in upon its independent career at birth with certain innate grounds of experience, which are likewise the result of a gradual formative process operating through actual experience in race history. This application of the evolution theory to psychology gave the a priori school a nominal victory, since its contention was literally substantiated; but empirical psychology came off with the real honors, since its protest against 'innate forms' was validated in the wider field of race history.

Adopting the evolution view, other factors besides association might be introduced into an experience psychology. Such biological concepts as plasticity and fixity, rudimentary appearances and vestigial remnants, chance and determinate variation, the lapsing of intermediate links, etc., translated into psychological language, have a wider importance when applied to the growth of the mind in the race than when limited to the individual. The relation of sensation to idea and the interplay of sensation and motor impulse require description along broader lines, in terms more analogous to the language of biology. The whole science of social psychology, including social data and social transmission, comes into being or at least attains maturity. On the other hand, these factors might easily be passed over. The association psychology. might be transferred bodily to the new world-view with scarcely an alteration, by a mere change of emphasis at certain 
points from the development of individual experience to the evolution of experience types.

The latter was what actually occurred in Bain's case. Though he adopted the evolution theory and revised his two earlier volumes in accordance with it, there are few changes of fundamental importance in the later editions of these works; while many of the changes which he did make, notably those due to his acceptance of the doctrine of relativity, were not directly due to the requirements of the new view. Although Bain adopts the evolution view in all but his first works, his system does not bear the marks of having been vitally affected by it. He stands by the older ' mechanical' viewpoint. His conception of association and its principles is based on the analogies of the physical sciences, rather than on biological analogies.

Spencer and Lewes, though one was born only two years later and the other a year earlier than Bain, both belong to a later generation in thought. They had assimilated the notion of evolution before undertaking their analysis of mental phenomena. Their psychology is the historical successor of the older associationism; but it re-examined the empirical standpoint and interpreted association in terms of evolution. They attempted a new analysis of consciousness and broadened its foundation to include many principles borrowed from the biological field. The evolution psychology, as worked out by Spencer and Lewes, is based essentially on the biological analogy. It is 'mechanistic' only in the widest sense of the term-not physical, like the associationism of James Mill and Bain, nor chemico-physical, like that of the other earlier associationists, but bio-chemico-physical. However we interpret their theory of being, their psychology is based on laws derived from the objective sciences, rather than on laws of a new and peculiar type; the pattern of these laws is found in the organic sciences 
first of all, and only secondarily in the laws of the inorganic world.

\section{Herbert Spencer's Psychological Standpoint}

Herbert Spencer (1820-1903), a civil engineer in his younger life, relinquished this calling in 1847 for philosophy and science; he conceived about $185^{8}$ the notion that all cosmic phenomena constitute an evolution from " an indefinite, incoherent homogeneity to a definite, coherent heterogeneity." Abandoning practically every other work he devoted forty years to the formulation of the laws of this evolutionary process and to elaborating their details in biology, psychology, sociology, and ethics.

Spencer's 'Principles of Psychology ' 1 being part of his larger 'System,' its starting-point is naturally the phenomena of organic life already dealt with in the preceding volumes on the 'Principles of Biology.' Nervous activity is a particular mode of motion and conforms to the physical laws of integration. "The actions of all organic beings, including those of our own species, are known to us only as motions." 2 When we study our own actions, however, there lies before us a class of facts absolutely without any perceptible or conceivable community with the facts revealed as nervous activity; the phenomena of consciousness are truths of which the very elements are unknown to physical science. Objective observation and analysis fail us, and subjective observation and analysis must supplement them. The changes which have been expressed in terms of motion have now to be expressed in terms of feeling. ${ }^{3}$

1 First ed., 1855, in one volume; 2 d ed., 1870 , essentially rewritten, in two volumes; $3 \mathrm{~d}$ ed., enlarged, 1880 .

2 'Pr. of Psychol.,' 3d. ed., Pt. I, $\S 7$.

3 Ibid., \$ 4I. In this and other passages cited, Spencer's own language is partly quoted and partly paraphrased. Full quotation is impracticable on account of the elaborate qualifying clauses introduced which are not essential to the present discussion. 
Thus at the outset Spencer thrusts aside the materialistic hypothesis. According to him the two series, neural change and feeling, though absolutely different in sort, bear a quantitative relation to each other when all other things remain the same; this relation he expresses in terms of direct proportion, not according to the formula of Weber's Law. ${ }^{1}$ The ultimate unit of consciousness is ' little else than a nervous shock,' ${ }^{2}$ using that term in a' subjective sense-not as molecular motion. Starting with this primordial element of consciousness, "the countless kinds of consciousness may be produced by the compounding of this element. with itself and the recompounding of its compounds with one another in higher and higher degrees-so producing increased multiplicity, variety, and complexity." It is probable that "all the unlikenesses among our feelings result from unlike modes of integration of this ultimate unit." 3

Spencer reduces the elements of which mental phenomena are composed to "two broadly-contrasted kinds -feelings and the relations between feelings." " The term feeling as he uses it is equivalent to any definite experience or state of consciousness. He divides feelings into three main classes according to their source: (I) Centrally initiated feelings, or emotions. All others are peripherally initiated, and are termed sensations; but they differ according as they originate in nerves whose endings are within the body or at its outer surface. The former give (2) entoperipheral feelings, which, though not peripheral in an anatomical sense, are physiologically peripheral, since they do not imply outer agencies. The latter give (3) epi-peripheral feelings, which are peripheral in every sense of the term, and imply outer agencies as stimuli. ${ }^{5} \quad$ Feelings of all three classes are di-
1 \& 47.
$2 \S 60$.
3 Ibid.
$4 \S 65$.

$5 \S 66 ; c f$. $\S$ II2. These three classes correspond roughly to the recent division into interoceptors, proprioceptors, and exteroceptors respectively. 
vided into primary and secondary, by the criterion of vividness. ${ }^{1}$ The primary feelings are those vivid states of consciousness which we know as sensations and emotions; the secondary are the faint states of consciousness which we know as remembered sensations or ideas of senations, and remembered or ideal emotions. ${ }^{2}$ Vivid feelings have a tendency "to cohere with the faint forms of all preceding feelings like themselves"; such combinations are known as ideas, and are the units of knowledge. ${ }^{3}$

The relations between feelings are due to " the passage from one apparently-uniform state [of feeling] to another apparently-uniform state, implying the momentary shock produced by the commencement of a new state." 4 They occupy no appreciable part of consciousness, since they disappear if we take away the terms which they unite. ${ }^{5}$ The relations between feelings may be classified as relations of coexistence, sequence, and difference, ${ }^{6}$ but they reduce in the last analysis to relations of difference and no-difference. ${ }^{?}$

The secondary or faint feelings may be regarded on the physiological side as revivals of corresponding primary states. ${ }^{8}$ Spencer finds that feelings of the different classes are revivable in proportion as they are relational. ${ }^{9}$ Visual sensations are the most revivable on this account, auditory come next, etc. ${ }^{10}$ "The revivability of a feeling varies with its strength," and "with the number of times it has been repeated in experience." 11 Relations are more revivable in general than feelings. ${ }^{12}$ Among other laws of revival, Spencer finds that present feelings of extreme vividness interfere with the revivability of past feelings, especially of feelings of the same order; for instance, a present visual sensation interferes with the revival of a visual image, ${ }^{13}$ and in like manner presented relations
1 Ibid.
2 \$ 49.
5 \$ 65.
6 \$ 89.
$9 \$ 97$.
10 Ibid.
$3 \$ 73$.
7 \$ 93.
$11 \$ 99$.
$4 \$ 67$.
$8 \S 96$.
12 \& 105. 
hinder the representation of other relations, but in a lesser degree. ${ }^{1}$

Summing up, Spencer divides states of consciousness into two classes-feelings and cognitions, the latter being states which correspond to the relations of feelings. Feelings consist of (I) presentative feelings, or sensations; (2) presentative-representative feelings, embracing a great part of what we commonly call emotions; (3) representative or ideational feelings, namely, the ideas of the two first classes of feelings; and (4) re-representative feelings, the most complex states of all, which include the higher sentiments, such as justice, etc. Cognitions fall into four corresponding classes, in which consciousness is occupied with relations of the feelings of these respective sorts. $^{2}$

\section{Spencer's Interpretation of Association}

The phenomenon which has been treated up to this point as nervous revivability and coherence, may be regarded from another aspect as association. According to Spencer, cohesions may be otherwise described as associations, and, other things equal, revivability varies as associability. " "On the one hand, we know feelings to be associable only by the proved ability of one to revive another," and "on the other hand, the revival of any feeling is effected only through the intermediation of some feeling or feelings with which it is associated. Hence, the conditions that favor revivability are those that favor associability." 4 As already noted, this revivability or associability is in proportion as the states in question are relational. Emotions being less relational than sensations, they are less revivable or associable than sensations; and of the latter the ento-peripheral are less relational, revivable, and associable than the epi-peripheral.
$1 \S$ I07.
$2 \S 480$.
3 §III.
4 § II2. 
Epi-peripheral feelings, which are sensations due to external stimuli, even when they occur together or in succession only a few times become linked in such a way that the vivid or the faint form of one arouses the faint forms of the rest. ${ }^{1}$

Association involves two problems: (I) the association of feelings, both vivid and faint; and (2) the association of the relations between feelings. ${ }^{2}$

As regards the association of feelings, Spencer believes that its only mode is the " cohering of each feeling with previously-experienced feelings of the same class, order, genus, species, and, so far as may be, the same variety." 3 In other words, the only direct association of feelings is the association of some present sensation or emotion or idea with preceding feelings like itself. All other associations of feelings are indirect and are due to the association of relations. The direct association of a sensation with its idea, that is, the phenomenon of revival, is automatic; it is " not an act of thought that may or may not take place, but constitutes the very recognition of each feeling." 4 Neurologically, "it answers to the re-excitation of the particular vesicle or vesicles which, when before excited, yielded the like feelings before experienced." ${ }^{5}$

Association of relations follows the same law as the association of feelings: Every relation, on being presented to consciousness, associates itself with like predecessors; ${ }^{6}$ that is, each recalls its own class and subclass of relations. ${ }^{7}$ Thus, when a sensation occurs in a relation of coexistence with another sensation (as when we see two things simultaneously), not only is the sensation in question automatically associated with its corresponding idea, but the relation of coexistence also automatically classes itself with relations of coexistence in general. ${ }^{8}$ Coexistence, especially of the visual type, is the most relational,
1 Ibid.
$5 \S 116$.
$2 \S$ II3.
3 II 5.
$7 \S$ II9.
4 Ibid.
${ }^{8}$ Ibid. 
and hence the most associable relation; ${ }^{1}$ " any coexisting positions visually presented are immediately associated in thought with the cluster of coexisting positions similarly related to us." ${ }^{2}$ Relations of sequence are associable into simple combinations with considerable facility, though with less facility than coexistence; and there is considerable associability of coexistence with sequences. ${ }^{3}$ The association of relations "leads by perpetual repetition to indissoluble connections in consciousness, which govern our thoughts absolutely." 4

Spencer concludes that "knowing a relation, as well as knowing a feeling, is the assimilation of it to its past kindred; and knowing it completely is the assimilation of it to pass kindred exactly like it." 5 The association of coexistent or successive feelings, in fact, is due to the association of coexistent or successive relations, since it is the result of an association of spatial or temporal relations; and this is true not only of simple feelings and their relations, but also of any plexus of relations among many feelings. ${ }^{6}$

This is the basis, then, of the so-called law of Association by Contiguity. When we analyze it, contiguity resolves itself into likeness of relation in time or space or both. $^{7}$ In other words, according to Spencer the association of one experience with another is the revival of an experience corresponding to the given one, in the form of an idea; and the association of relations among experiences is the revival of relations like those involved in the given experience. Unlike experiences, though contiguous, are associated only through the revival of like experiences, or through revival of the temporal and spatial relations which constituted the basis of their contiguity in some earlier experience.

It is important to notice here a change in terminology
$1 \S$ I I8.
2 \& II9.
$5 \S$ I20.
6 Ibid.
3 I I8.
4 Ibid.
7 Ibid. 
introduced by Spencer which, though slight, radically altered the complexion of the association problem for him. What Spencer calls relation of feelings, is precisely the phenomenon which associationists generally have called association; and what he terms association and reduces to the fact of automatic revival, is classed by preceding writers as an original datum of the mental life (idea). His predecessors regarded ideation not as a form of association, but as one term in the associative process.

From Spencer's standpoint the leading task of psychology is to account for ideational revival. Assuming that the primitive data of psychology are feelings, which are due to direct action of stimuli on the nervous system, in what manner are revivals (faint copies of these originals) produced by central excitation without direct action of the original stimuli? This is Spencer's conception of the association problem. For his predecessors the problem was to account for the unity and complexity of experience. Assuming that the data of experience are sensations and their copies (ideas), how do these data come to be united into simultaneous 'complexes' and into successive 'trains'? The concept of association was the instrument used to solve the difficulty.

While Spencer by means of his revival theory explains perhaps more satisfactorily than earlier writers the physiological grounds of the ideation process, he does not throw much new light on the problem of complex experiences. He merely assumes an additional principle of union (which they included under association) in the guise of relations of feelings. ${ }^{1}$ This union of the rela-

1 It is difficult to understand just what Spencer means psychologically by his relations of feelings-whether he would regard them as 'data of experience,' like sensations, or 'mental forms,' such as Kant postulated. His physiological explanation of their occurrence is clear enough, but his discussion of their mental character seems vague. (See $\$ \S 65,67,70-4$.) 
tional type is quite distinct from revival, nor does he analyze its laws as fully as some of his predecessors.

In fact, Spencer overlooks what most associationists consider the fundamental problem of psychology. Take any ordinary state of consciousness in the adult human experience; we find that it consists in a complex of sensations and ideas; their ' unity' as a single present experience is a joining together (a conjunction, relation, or association) of some sort, or a multiplicity of such joinings, according to the associational view. The chief problem, according to these writers, is what produces this unity of consciousness, rather than how certain of the constituents come to be revivals of past experiences or of past unions. The repetition of an experience, whether sensation or idea, leads to the successive renewal of certain elements which belonged to former similar experience but which do not appear in the present experience at the outset; they become joined to it or succeed it because they were formerly united to its like, either coexistently or successively (law of contiguity).

How comes it, then, that coexistent or successive elements are experienced together in one complex, unitary experience? This is the fundamental problem of the associationists. Brown simply assumes this unification as a fundamental and inexplicable fact; Hartley endeavors to show the physiological accompaniments of the process. But whatever the solution, the question is a crucial one for any empirical psychology. Spencer's postulate of relations of feelings affords the empiricist little direct help, though his theory of revival helps considerably by implication.

Important in its bearing on the law of association is Spencer's discussion of coexistence and succession. "Psychical.life is distinguished from physical life by consisting of successive changes only, instead of successive and simultaneous changes. . . Though a visual 
impression makes us nascently conscious of many things, yet there is always some one thing of which we are more conscious than of the rest. . . Though the images of other things are all the while being impressed on the retina and are producing changes there, yet these are not appreciated internally-are scarcely more than physical changes - do not undergo that coordination with others which constitutes them psychical changes. . . . While the outer strands of changes which constitute the thread of consciousness are indefinite and loosely adherent, there is always an internal closely-twisted series of changes, forming what we may consider as consciousness proper." 1 Psychical changes, then, are relatively speaking serial, "and in proportion as they assume that most developed form constituting rationality they cohere into a seemingly-single succession of states. Though these states are physiologically composite, and were once psychologically composite, yet, to the extent that they have become consolidated elements of thought, they may rightly be regarded as severally simple." 2

Spencer formulates three laws governing the degree of associability of experiences, which he bases on characteristics of the underlying physiological processes.

Vividness: "The connection formed between two feelings or ideas that occur together or in succession is strong when they are vivid and feeble when they are faint." (2) Repetition: "Repetition of the relation between two states of consciousness, presentative or representative, strengthens their union." (3) Decreasing gain: "For some time recurrences of a sequence go on appreciably increasing the readiness with which the antecedent excites the consequent; but the increase gradually becomes less and less appreciable." 3

To sum up, Spencer regards association as the revival of similar experiences. To this type he adds another
$1 \S$ I80.
2 Ibid.
$3 \S 250$. 


\section{I30 EVOLUTIONARY ASSOCIATIONISM}

form of union, the relation of experiences, which is the juncture of contiguous experiences. In the higher manifestations of consciousness this contiguity tends more and more to the form of succession, with corresponding loss on the side of coexistence.

\section{Derivation of Higher Mental States}

The derivation of the higher mental states is examined by Spencer in Part IV of his 'Psychology,' under the title of Special Synthesis. He starts with reflex action as the lowest form of psychical life-the "most nearly related to physical life "; ${ }^{1}$ it is the sole form observed in the lowest animal species, and constitutes the lowest type of mental process found in higher organisms. Reflex action is specially characterized by simultaneity: as in the case of physical transformations, "a great number of these simplest nervous changes go on quite independently in the same organism at the same moment." We find them occurring in ourselves without consciousness. ${ }^{2}$

The next higher form, instincts, includes compound reflex actions, ${ }^{3}$ in which the diffused simultaneous changes are transformed into concentrated serial changes. ${ }^{4}$ In its higher forms, instinct is probably accompanied by a rudimentary consciousness. ${ }^{5}$

Memory arises when the stimulus is so complicated that the nervous center cannot receive all the impressions at the same instant; it follows that the different impressions, being severally supplanted by one another, "will each of them consist of an incipient or faint form of that nervous state which would have accompanied the actual motor change had it occurred. But such a succession of states constitutes remembrance of the motor changes which thus become incipient-constitutes a memory." "In conjunction with this motor memory there
1 \& I92.
4 \& 195.
2 Ibid.
5 Ibid. 
occurs in the organism at the same time and by the same process a memory of those combinations of impressions which it receives through the senses. "Of the impressions produced by adjacent objects during the movements of the organism, each is apt to make nascent certain other impressions with which it has been connected in experience - calls up ideas of such other impressions; that is, causes a remembrance of the attributes previously found in connection with the perceived attributes. As these psychical states have in their turns been connected with others, they tend to arouse such others; and thus there arises that succession of ideas, partly regular, partly irregular, which we call memory." 1

There is no hiatus, according to Spencer, between instinct and reason; rational action, like instinctive action, is an adjustment of inner relations to outer relations. In reason, however, "the correspondence is between inner and outer relations that are complex, or special, or abstract, or infrequent." 2 Consequently, the direction of association or union is more determinate. Each experience comprised in a complex group resembles previous complex experiences in some ways, "yet it has presented some attributes which they did not present, and has not presented others which they did present." Hence, when such a complex group appears, "the ideas of one or more unperceived attributes will be aroused "; that is, they will appear as nascent states of consciousness-they are said to be inferred..$^{3}$ This is typical of all forms of rational process.

"Beginning with reasoning from particulars to particulars - familiarly exhibited by children and by domestic animals-the progress to inductive and deductive reasoning is similarly unbroken, as well as similarly determined. And by the accumulation of experiences is also determined the advance from narrow generalizations

1 Ibid.

2 § 203.

$3 \S 205$. 
to generalizations successively wider and wider." ${ }^{1}$ Classification, naming, and recognition are special types of inference, all based on the idea of likeness or similarity. ${ }^{2}$

"Other things equal, the cohesion of psychical states is proportionate to the frequency with which they have followed one another in experience." ${ }^{3}$ This Law of Frequency supplies an explanation of the so-called forms of thought and of our ideas of space and time, if it is supplemented by the law that habitual psychical successions entail some hereditary tendency to such successions -which, under persistent conditions, will become cumulative in generation after generation. ${ }^{4}$ These predetermined internal relations constituting our ideas of space and time and the laws of thought, though independent of the experiences of the individual, are not independent of experiences in general: they have been determined by the experiences of prior-existing organisms. ${ }^{5}$

Spencer traces the higher development of feeling and of will in much the same way. Volition arises as follows: When the automatic actions become so involved, so varied in kind, and severally so infrequent, as no longer to be performed with unhesitating precision, action is delayed, and there is constituted a state of consciousness called deliberation, which, when it finally issues in action, displays what we term volition. ${ }^{6}$

Our differentiation between subject and object rests, according to Spencer, on ten separate criteria. Subjective states (I) are relatively faint; (2) they are successors in time or copies of the objective; (3) they are changeable by volition in their qualities, (4) in their simultaneous order, and (5) in their successive order; (6) they form parts of a faint aggregate never known to be broken, which (7) is partially independent of the vivid aggregate, (8) with laws partly derived from the 
other, partly peculiar to itself; (9) their antecedents are always traceable; and (10) they belong to a whole restricted to what we call memory. ${ }^{1}$

Objective states, on the other hand, are vivid, original, not changeable by volition, and form parts of a vivid aggregate with laws that originate within it. They have antecedents that may or may not be traceable, and they belong to a whole of unknown extent. ${ }^{2}$

The emotions, whether faint or vivid, belong to the faint aggregate, but they have the peculiar character of affecting the vivid aggregate by exciting muscular contraction. ${ }^{3}$

The faint aggregate, taken as a whole, is termed the mind. The body is a special part of the vivid aggregate which coheres with mind in various ways and is regarded, now as belonging to the vivid aggregate, now as belonging to the same whole with the faint aggregate. The rest of the vivid aggregate, which has no such coherence with the faint aggregate, is the not-self. ${ }^{4}$ The idea of power is a result of the experience of resistance, which the vivid aggregate arouses, ${ }^{5}$ and this experience of resistance is the primordial, the universal, the ever-present constituent of consciousness; it exists even in the lowest orders of creatures, and comes to be the general symbol for that independent existence implied by the vivid aggregate. ${ }^{6}$

The differentiation into subject and object is not complete until quite late in the scale of evolution. Even in low stages of human evolution self-consciousness is very incomplete; the child and the savage continue to speak of themselves objectively.

\section{Spencer's Relation to Earlier Writers}

Comparing Spencer's analysis as a whole with that of the earlier British writers, we find that it proceeds accord-
$1 \S 458$.
2 Ibid.
$5 \S 465$.
' § 466; cf. 347-8.
3 \$§ 460-I.
$7 \S 475$ p.
4 \$ 462. 
ing to the same associational method. The more complex states are traced back to simpler states, of which they are associative aggregates; the higher manifestations of mind are regarded as unions (associations and relations) of lower forms of manifestations, very much as Hartley and the Mills regarded them. The evolution factor brings in a certain change of interpretation of the process. Spencer regards the more fundamental unions as having taken place far back in the scale of organic life, resulting from the first in certain permanent changes in the physical organism; such physical modifications appear even prior to experience in individuals belonging to later generations, and consequently many complex mental states occur at the very dawn of individual experience.

Thus the meaning of repetition of associations is broadened, and the law of frequency or habit acquires a phylogenetic as well as an ontogenetic interpretation. The main problem remains substantially the same-to account for repeated successions and higher complexities according to the principle of association; but granting the validity of this principle, its application to the growth of the individual mind as actually observed becomes more plausible. It had been urged as an objection to the association theory that the comparatively few experiences of any individual are inadequate to account for the development of the space and time notions and of the rational functions without magnifying preposterously the permanent effects of each particular association. But granting evolution and the hereditary transmission of associative effects in organic structure, the law of repetition is no longer strained, and the process appears at least perfectly plausible.

An important effect of the evolution concept, as we have seen, is to correlate psychology more closely with biology. From this viewpoint Brown's ultra-psychological analysis of consciousness appears to omit factors which 
would aid decidedly in explaining the process of association. For what persists phylogenetically is modification in the form of organic structure, not experiences themselves. Hence, to understand the growth of consciousness in the individual as well as the race, the psychologist must study more closely the development of nerve structure and the fundamental laws of nerve physiology. This side of the investigation is prominent in Spencer's work. He has quite as much to say concerning nervous function and types of motor activity as concerning states of consciousness; and that without in any wise identifying the two, or 'deducing' consciousness from neural or molecular changes.

In short, the transformation of the analysis brought about by the evolution view affects the details, the distribution of emphasis, and the terminology, without modifying any of the essential factors or laws of association. The principle of association remains an effective workinghypothesis; its psychological meaning is practically unaltered. The individual peculiarities of Spencer's analysis of the association process are quite distinct from his evolution standpoint.

The chief features of Spencer's psychology, so far as they concern us here, may be summed up as follows: (I) His theory of the relativity of consciousness. Consciousness appears only with changes in stimulation. This is an extension of the observed fact that a longcontinued stimulation is less and less attended to. ${ }^{1}$

(2) His classification of the phenomena of consciousness (or mental life) into feelings and relations of feelings, and the identification of association with revival. Spencer, we have seen, regards the passage from one conscious state to another as a datum of mental life, though

${ }^{1}$ Like his hypothesis that "all motion is rhythmical" ("First Princ.' Pt. II, ch. Io, $\$ 82$ ), it appears to be an induction extended far beyond observation. 


\section{EVOLUTIONARY ASSOCIATIONISM}

not a feeling. This relation of feelings corresponds, in a way, to the relativity of consciousness regarded as a function of the stimulus. When the passage is from sensation to revived idea, that is, from a vivid experience to its faint copy, he terms it association, or revival. He thus distinguishes two sorts of union-relation and revival.

(3) Relations of feelings reduce to coexistence, sequence, and difference-or, in the final analysis, to relations of difference and no-difference. While in early experience coexistent states are more relational than successive, as the mind becomes more complex experience tends more and more to the successive, and less to the coexistent type of contiguity. Association or revival, whether of feelings or relations, proceeds by similarity or assimilation of the present to similar past experiences.

(4) Spencer mentions three laws of the degree of associability - vividness, repetition, and decreasing gain.

(5) Consciousness is classified into feelings and cognitions, the latter including states based on relations of feelings. Spencer's analysis of complex and higher conscious states is based $(a)$ on certain differences in their elementary constituents (external and internal stimulation, revival) and (b) on the inheritance of the effects of association and relation. The motor element he regards as the physical concomitant of mind, not as an element or sort of consciousness.

(6) Spencer leaves entirely out of his discussion the problem of ' mental synthesis.' He does not reject it, but it seems to lie outside of his scope. ${ }^{1}$ In the first place, he regards mental association and relation in their higher stages as phenomena of succession, which would obviate the problem. And second, his psychology, being part of a larger system of philosophy, is concerned mainly with quantity and quantitative relations, and only slightly with 
differences of sort. ${ }^{1}$ Spencer's ' unity of composition' of mental phenomena ${ }^{2}$ is an extension to the realm of mind of the primordial 'indefinite homogeneity' which characterizes the cosmos. "Compound impressions," he says, "continually approach in their apparent characters to simple impressions;" their elements eventually become distinguishable from one another only by analysis. ${ }^{3}$ Whether this mental analogue of physical 'integration' has any qualitative meaning, he does not say. His statement of the process is much like James Mill's, but the notion of integration apparently has some real significance, and certainly does not tally with Mill's mechanical conception of mental composition.

\section{The Psychology of G. H. Lewes}

GeORge HeNRy Lewes (I8I 7-I878), a writer in many fields of literature, editor for some time of the Fortnightly Review, and domestic helpmate of the novelist Mary Ann Evans ('George Eliot'), is known in philosophy and psychology by his 'Biographical History of Philosophy' (r 854-6), ${ }^{4}$ his ' Physiology of Common Life' (I859-60), and a series of volumes entitled 'Problems of Life and Mind' (I874-9). ${ }^{5}$ This last work develops

1 When I see a red rose, I have a peculiar qualitative experience of 'redness.' Spencer seems to regard this qualitative phenomenon as peculiar to subjective psychology,-an interesting fact, but of no more scientific value than the dot over an $i$ in the statement of one of Newton's laws.

$2 \S 380$.

3 \$ 169.

4 Revised editions to 1880 .

5 The first series of the Problems, Vols. I and II, with subtitle 'Foundations of a Creed,' includes Introduction, Psychological Principles (Psy. Pr.), and six Problems. The second series, Vol. III, entitled 'The Physical Basis of Mind,' with the serial title subordinate, contains four Problems (I-4). The third series (posthumous), embracing Vols. IV and V, takes the serial title again, and contains four Problems; the subtitle of Vol. IV is "The Study of Psychology, from the problem discussed-Vol. V has no subtitle. In citing this work the volume (from I to V), problem, 


\section{I38 EVOLUTIONARY ASSOCIATIONISM}

in detail his views of the nature of mind and his system of psychology. The final volume was never revised by the author; it is not arranged in proper sequence and contains many redundancies. But it is quite readable and complete with the exception of the last Problem; this was written shortly before the author's death and is merely a sketch.

Lewes is an acute and logical thinker, and his 'Problems' carry the associational analysis to its historical culmination. One could only wish that he had written a briefer statement of his position in one or two volumes, taking up the analysis in a single, orderly sequence with less discussion and fewer illustrative examples. The inner consistency and force of his system would then have appeared to better advantage, and Lewes would probably have exerted a greater influence on the development of psychology in England. ${ }^{1}$ The fact remains that Lewes's system has not been noticed to the extent of Bain's or Spencer's, although it seems to deserve greater attention on the part of psychologists on account of its striking adaptation of the traditional English position to the new results of biological research and to the evolution theory.

Besides several notable advances in the manner of performing the mental analysis and some improvements in nomenclature, Lewes makes two original contributions to the analysis itself. In the first place, he lays special emphasis upon the social side as a factor in mental evolution; and second, in place of the usual distinction between sensations and ideas, he adopts a threefold division into sensations (or feelings), images, and ideas (or

and section are given. Section numbers run through each 'problem' separately.

1 Lewes would probably have been more carefully studied, in spite of his prolixity, had not the general trend of psychology during the next decades been away from associationism. See Chapter VIII. 
conceptions), attributing a special symbolic character to the third.

(I) Lewes's conception of the special importance of social phenomena for mental science is traceable to Auguste Comte. But in opposition to Comte he insists that we must treat psychology as an independent science. The data of psychology, he affirms, are contributed by biology and sociology. The biological data furnish the starting-point of both animal and human psychology: The sociological data appear only in the human sphere and form the basis of the human intellectual and moral life, as distinguished from the animal sentient life. ${ }^{1}$ Such diverse phenomena as folk-customs, traditions, arts, tools, science-lore, literature, depend on the system of intellectual signs known as language; and language exists only as a social function. ${ }^{2}$

(2) The primary form of sensibility, which Lewes calls feeling, ${ }^{3}$ includes sensibility resulting from external stimulation (special sensations, the 'sensations' of earlier psychologists), and sensibility due to systemic stimulation (systemic sensations or emotion). A reproduced feeling constitutes an image. But when the image has lost its original value and has become merely a sign or symbol of some feeling different from itself, it then becomes an idea or conception. ${ }^{4}$ This triple division he also borrows from Comte, ${ }^{5}$ though the third element is found implicitly in most of the associationists. ${ }^{\circ}$ The manner in which the image is transformed into the idea and the role of ideas

1 'Probs.,' Vol. I, Psy. Pr., § I.

2 Ibid., § 10.

3 V, Prob. 2, §§ 3-5. $\$ 7$.

4 I, Psy. Pr., §§ 44, 64-5, 25; V, Prob. 4, §§ 26-8; V, Prob. 2,

$5 \mathrm{~V}$, Prob. 3, note following $\$$ I4.

6 It is to be regretted that Lewes did not work out more fully and consecutively his distinction between image and idea. $\mathrm{He} \mathrm{em}$ phasizes the striking difference in their associative value ('logic'), but his discussion of the nature of symbolic experience is scattered about in various parts of his work. 
in psychological evolution will be examined presently. The important point here is that Lewes regards ideas or conceptions as essentially a social product and instrument; they are signs, whose objective expression is language.

While Lewes agrees with Spencer in laying special stress on physiology and biological evolution as a basis of explanation for psychological phenomena, he does not go to Spencer's length of regarding the biological standpoint as furnishing the only scientific element in psychology. He endeavors to maintain an equilibrium between the objective and subjective sides of the science, and puts forth an earnest plea for introspection as an instrument of research. ${ }^{1}$ He claims that what the data of introspection lack in quantitative exactness they make up for in possessing the highest degree of certainty; the results of external observation or objective analysis, on the other hand, though preeminently exact, lack this element of surety or conviction. ${ }^{2}$

\section{Association and Logical Grouping}

Lewes starts with sensibility, which he uses as a general term for the material of psychology. The psychical organism evolves from 'psychoplasm,' or 'sentient material.' The psychoplasm is ever fluctuating; it is constantly being renewed, and these movements constitute the function of sensibility. ${ }^{3}$ Sensibility is the internal factor, to which corresponds, on the physiological side, "the successions of neural tremors variously combining into neural groups "; ${ }^{4}$ it includes both consciousness and subconsciousness. ${ }^{5}$

There are three fundamental laws of sensibility: (I)

1 IV, Prob. I, $8 \S 50-I, 62-6$.

3 I, Psy. Pr., §6; cf. III, Prob. I, \$60.

2 Ibid.

4 I, Psy. Pr., $\S 6 ; c f$. V, Prob. 2, § 33.

5 I, Psy. Pr., $\S 33$; cf. III, Prob. 3 , $\S 50-2$. 
Interest: "We see only what interests us, know only what is sufficiently like former experiences to become, so to speak, incorporated with them-assimilated by them." 1

(2) Signature: Every feeling "has its particular signature or mark in consciousness, in consequence of which it acquires its objective localization, i.e., its place in the organism or in the cosmos." ${ }^{2}$ Signature is Lewes's term for the individuality or specific identity of each particular sensation or experience.

(3) Experience, or registration of feeling: "Through their registered modifications, feelings once produced are capable of reproduction, and must always be reproduced, more or less completely, whenever the new excitation is discharged along the old channels." 3

Sensibility becomes organized into definite mental states along with the evolution of the physical organism, and in modes best described by reference to the corresponding biological processes. In physiological reaction we find a threefold process-stimulation, coordination, and discharge; the psychological equivalents of these are sensible affection, logical grouping, and impulse. ${ }^{4}$ The sensible affection includes, as we have seen, sensibility resulting from both external and systemic stimulation. ${ }^{5}$ But " no reaction on a stimulation can be called forth without revival of residua of past stimulations." ${ }^{6}$ These revival states or images arise according to two fundamental processes, irradiation and restriction, whose laws may be stated on the physiological side as follows: (I) Irradiation.-Every wave impulse is irradiated and propagated throughout the system. (2) Restriction.-

\footnotetext{
1 Psy. Pr., § $9 ; c f$. V, Prob. 2, §§ 74-6.

$2 \mathrm{I}$, loc. cit.; cf. V. Prob. 3, §§ I17-8.

3 I, loc. cit.; cf. V, Prob. 2, ch. 4.

4 V, Prob. 2, § 33.

5 I, Psy. Pr., § 28.

${ }^{6} \mathrm{~V}$, Prob. 2, § 35.
} 
Every impulse is restricted, and by its restriction a group is formed. ${ }^{1}$

Revival states, or reinstatements, are due physiologically to the irradiative tendency, by which any given neural process tends to re-excite those processes which formerly were excited in conjunction with it, or which are anatomically linked with it. ${ }^{2}$ On the subjective side this means that a sensation formerly connected with the given sensation may be reproduced with fainter energy as an image. ${ }^{3}$ Physiologically, the irradiative tendency is limited by the definite pathways of discharge cut by previous stimulations-the law of restriction; ${ }^{4}$ on the psychological side this means that the given sensations will tend to re-excite certain groups of fainter feelings of previous impressions, so that they are grouped into a judgment or perception. ${ }^{5}$

Irradiation and restriction work together in the process of Reinstatement, whose law is as follows: "Every mental state will be reinstated whenever the conditions of its production are reproduced; and the reinstatement will be more or less complete according to the more or less perfect reproduction of the original conditions." " The directly excited feeling (sensation or presentation) is distinguished by its greater vividness from the indirectly excited or reproduced feeling (image or representation). The former is fitly considered real, because it has objective reality (res) for its antecedent stimulus; the latter is ideal, because its antecedent is a subjective state. ${ }^{7}$

Association, according to Lewes, is a special form of the process of Reinstatement. Reinstatement is grouping; association is " the grouping of groups which are not connected by any necessary anatomical links. Processes which depend on the native mechanism, although dependent on the connection of groups, are not called asso-
1 Ibid., § 36.
2 I, Psy. Pr., § 37.
5 I, Psy. Pr., § 38.
6 V, Prob. 2, \& 8 .

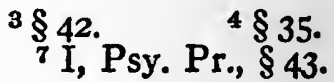


ciative processes. Association is acquisition." 1 Without discussing the laws of this restricted type of association at all systematically, Lewes refers his readers to Bain's exhaustive analysis, which he accepts in the main. He notes, however, two phenomena of association which Bain fails to take properly into account: (I) "The enormous influence of the emotional factor . . . in determining the reinstatement of images and ideas." (2) "The influence of obscure organic motors, manifested in the sudden irruption of incongruous states-the orderly course of association being burst in upon by images and ideas having none of the normal associative links." 2

It is not clear why Lewes restricts the meaning of the term association to such narrow limits. He goes even further than Spencer in this respect. Spencer limits the term to revival by similarity. Lewes makes it a sort of adventitious revival; he harks back to Locke's notion of a connection "wholly owing to chance or custom." His broad treatment of the process, however, fully warrants us in considering Lewes an associationist, in spite of his peculiar restriction of the term. Historically, association corresponds closely to what Lewes calls grouping, or logical process. And this logic, or grouping of elements, enters fundamentally into his system, as we shall see; it begins at the lowest and simplest states and follows through to the highest and most complex.

The grouping or coordination of experience can be understood only when interpreted as part of the entire reactive process, whose three terms on the psychological side are affection, grouping, and impulse. The grouping process is of significance only as it leads to some new or more integrated form of impulse and activity. And just as grouping determines impulse, so it is determined

1 V, Prob. 2, §94. In this passage Lewes accepts Spencer's conception of 'association,' not the wider connotation of earlier writers.

2 Ibid., § 95 . 
by affective data. The modifications of neural structure caused by past impressions are what determine the specific neural grouping; on the subjective side it is the residua of former experiences that determine the specific mode of grouping in any instance.

Grouping, then, depends not only on the stimulus at the present moment, but also on the entire condition of the organism as determined by its past history-in other words, it depends on the self, as determined by the individual's whole past experience, as truly as on the given presentation." "When once a neural group, however complex, has been formed, it operates like a simple unit, and enters as such into the combination of other groups." So, on the subjective side, sensations which were originally independent are " brought into such convergence by intermediate links that they now coalesce and act together without the need of such intermediation "; for example, visual and tactile sensations combine to form "an intuition of form and size of an object; but these having coalesced, and the intuition being effected, we no longer need the intermediate process." 2 This is the simultaneous aspect of grouping.

The serial aspect is more important. In accordance with the law of irradiation, "one excitation of the sensorium sets going associated excitations, the associations rising out of prior modifications." ${ }^{3}$ This results in a series of images and ideas, whose specific course is determined according to the law of restriction. Restriction operates in accordance with two distinct factors: the specific revival depends (I) on the harmony of the image to be revived with the ground-tone of feeling or mental predisposition at the time, and (2) on the energy of the image. ${ }^{4}$ This grouping of experiences in serial order is

1 I, Psy. Pr., § 9-law of exp.; V, Pr. 2, §§ 42, 77, 166-72.

2 V, Prob. 2, § I36.

3 V, Prob. $2, \S 42$.

4 Ibid., I02. 
what Lewes terms the logical process, or in brief, logic. As a psychological process, logic is "not simply the process of reasoning, but that which is common to reasoning and to all other modes of combination belonging to mental states. This common process is coordination, or grouping of neural elements." 1 One mental state thus determines its successor, and is included in it. ${ }^{2}$

All experience, even its lowest forms, involves coordination. On the physiological side, this process of coordination results from the tendency of stimuli to general irradiation and restriction of such irradiation by previous modifications of structure to more or less habitual paths. On the mental side, therefore, the experience grouped with the given experience would be one that had been contiguous to it in some past primary experience. And since the associated element is always a revival-a reinstatement, not a mere copy ${ }^{3}$ - only the law of contiguity would seem to apply; in other words, the law of similarity would appear to have no place in association. Lewes is apparently mistaken in believing that he agrees with Bain in this part of his analysis, since the latter admits both contiguity and similarity as associative principles. $\mathrm{He}$ differs with Bain still further in assuming an association by contrast. ${ }^{4}$ It should be noticed, however, that Lewes admits these principles only as laws of 'casual' association, not of the general logical process.

While he does not expressly admit that the synthetic process yields anything really new in chemistry or in

$1 \mathrm{~V}$, Prob. 3, §2. Lewes uses the term neural element here and frequently elsewhere to denote the primitive, unanalyzable element of experience.

2 Ibid.

3 V, Prob. 4, $\S 8$.

4 V, Prob. 2, \$§ 100-I.

5 Possibly Lewes would have reduced these "groupings of groups which are not connected by any necessary anatomical links" to irradiation and restriction also, and attributed all association to contiguity, had he repeated for himself Bain's analysis. 


\section{I46 EVOLUTIONARY ASSOCIATIONISM}

mental grouping, ${ }^{1}$ several passages show that Lewes recognizes a qualitative variation; he concedes that the effect of mental synthesis is, in appearance at least, similar to what chemical synthesis appears to be. Causation, he says, is of two sorts: the effect may be "the resultant of its components, the product of its factors "; or, in cases of cooperation of things of unlike kinds, the effect is an emergent, that is, it is 'qualitatively unlike' the causes." Quality is a primary fact of feeling which enters into every subjective synthesis; ${ }^{3}$ and no matter how much we strive to reduce psychology to quantitative terms, " no variation of undulations will really correspond with variation in color, unless we reintroduce the suppressed quality which runs through all color." 4

\section{Lewes's Analysis of Mental Phenomena}

Lewes attributes not only the higher types of experience, but all definite experience, including sensation itself, to the grouping or logical process. "A sensation is a group of neural tremors." " Given the hypothetical simple element underlying experience, which he calls a neural tremor, such tremors are grouped into definite sensations by the irradiative tendency which unites to them the residua of past tremors." A perception is "the synthesis of all the sensations we have had of the object in relation to our several senses "; 7 this includes secondary elements (images) as well as primary (sensations).

The application of the grouping principle to space perception is typical: extension is perceived as a continuum, he says, inasmuch as by irradiation " there is a necessary

${ }^{1}$ See I, Psy. Pr., $\S 88$.

3 II, Prob. 2, § 31 .

2 II, Prob. 5, $\S 65-6$.

5 V, Prob. 2, § 35 ; cf. I, Psy. Pr., § 24.

4 III, Prob. $3, \S 5$.

6 As already noted, the term neural tremor is used subjectively.

7 I, Psy. Pr., § 25. 
blending of the discrete points, a fusion of the similar tremors." 1 And the observed temporal unity of consciousness admits of explanation in the same way, the serial order of conscious experiences being the result of serial irradiation. ${ }^{2}$

A remembered sensation is something more than a repetition of the sensation: the repetition of the stimulus causes in addition a stimulation of residua, which furnish ' an escort of other states.' ${ }^{3}$ Memory differs from perception in the character of this escort: in memory the escort is of states constituting the field of personal experience, in perception the escort lacks that definite personal character. ${ }^{4}$ Memory is a grouping of image elements as they occurred in the past. Imagination differs from memory in that its personal escort has reference to the present or future, not to the past. ${ }^{5}$ In plastic or constructive imagination the image elements are grouped in new ways. ${ }^{6}$ "Images, although reproductions of perceptions, possess a property not possessed by perceptions, namely, that of facultative reproduction, which enables them to be abstracted from the sensible order of presentation, and combined and recombined anew." 7 Emotions are to be regarded under two aspects-as sensations and as impulses which guide action; under the former aspect "they belong to the systemic more than to the special affections, but are complexes of both." 8

All the above-named forms of grouping belong to the logic of feeling, or to its subdivision, the logic of images. The grouping of ideas, or symbols, or conceptions, constitutes the logic of signs. ${ }^{9}$ In the mode of grouping known as logic of images, the image becomes the representative

1 Psy. Pr., § 35 .

2 Ibid., $\$ 36$.

$3 \mathrm{~V}$, Prob. $2, \S 82$. This 'escort' corresponds to what William James later called the "fringe of consciousness."
4 Ibid., $\$ 87$.
7 I, Psy. Pr., §64.
$5 \S 92$.
8 V, Prob. 3, § I54.
$6 \$ 93$.
๑ I, Psy. Pr., § 25. 
of its sensation; it is a sort of substitute, but a substitute which is more or less equivalent to the thing signified.'

With the growth of organization " these images may be replaced by signs which have no trace of the sensations signified "; ${ }^{2}$ they are substitutes of sensations, not reinstatements. $^{3}$ This higher type of reproductive states Lewes calls ideas, as distinguished from images. ${ }^{4}$ Words are signs of this sort; the auditory symbol horse has no likeness to the visual or other sensations which the idea symbolizes-it may not even awaken a visual image of the horse; yet such verbal symbols "operate quite as effectually as the images.". ${ }^{5}$ Verbal symbols (language) arise as a result of social intercourse-they could not have arisen without it. ${ }^{6}$ For this reason and also because a high degree of nervous organization is requisite for the production of words, language belongs solely to the human species. ${ }^{7}$

Ideas, with all their substitutive and symbolic value, could never have developed $a b$ initio in an individual's single lifetime. But according to the evolution theory they are not innate in the older sense-rather, they are con-nate. ${ }^{8}$ The advent of language introduces a new factor into the environment-namely, the social medium. ${ }^{9}$ In the higher stages of mind, where ideas exist, we find a social as well as a physical environment, an ideational as well as affective self. ${ }^{10}$

Ideas group themselves according to the same principles as images. Serial groupings of ideas constitute thought, or the logic of signs. Since ideas are general

1 Ibid.; V, Prob. 2, § I37; Prob. 4, §28.

2 V, Prob. $2, \S 137$.

$3 \mathrm{~V}$, Prob. $4, \S 26$.

4 Ibid. This gives still another meaning to the much-defined term idea. It would seem more in keeping with historic usage to make idea the generic term, including imagery and thought as its species; thought would be the symbolic type of ideation.

5 V, Prob. 2, § I37. ${ }_{6}^{6}$ I, Psy. Pr., §§ Io, 54, 63; V, Prob. 4, ch. 6. 7 Ibid.

9 Ibid., $\S \S$ Io, 57. 8 I, Psy. Pr., $\S \S 57,60 ; c f . \S 8$. 10 V, Prob. 2, §§ I68, I7I-2. 
and flexible, while images and perceptions are always particular and fixed, ${ }^{1}$ we are able in thought to pass rapidly and easily from one term to another, in a way that would be impossible were it necessary to translate each idea into a specific image. ${ }^{2}$ It is this use of the general symbol that constitutes the superiority of the human over the animal mind. ${ }^{3}$ The logic of signs enables man to act with reference to more distant ends, as the symbols become further removed from direct correspondence to sensations; ${ }^{4}$ whereas, the ' reasoning' of animals is always in terms of sensations and images. ${ }^{5}$ 'Associations' in the narrower sense are generally symbolic, whence the phrase association of ideas. ${ }^{6}$

The developed processes of thought form the intellect, or rational functions, or reflection. ${ }^{7}$ All these processes - judgment, induction, deduction-are reducible to the ' logic of signs '; ${ }^{8}$ they culminate in the laws of thought, which Lewes focuses into a single principle of equivalence ${ }^{9}$ - an affirmative counterpart of the criterion of certitude which Spencer states in negative form as the inconceivability of the contrary.

The consciousness of volition includes two factors according to Lewes: ( $\mathrm{I}$ ) the feeling of effort in attention, which is reducible to muscle sensations; ${ }^{10}$ (2) an innervation feeling, due to the irradiation of the outgoing motor impulse back toward the center. ${ }^{11}$ But the consciousness attending volition is merely an incidental feeling linked

${ }^{1}$ I, Psy. Pr., § 25; V, Prob. 4, § 27. ${ }^{2}$ V, Prob. 4, §6I ; cf. chs. 5, 6. 3 Ibid., $\$ \S 45-8$.

5 V, Prob. 4, $\S \S 40-4$.

4 I, Psy. Pr., § 27.

6 V, Prob. 2, \$94.

7 In several passages Lewes makes discrimination the fundamental fact of intellect; he appears to use the term to denote the selective or restrictive effect of grouping. Though he does not explicitly say so, he apparently applies the term discrimination to the subjective aspect of 'restriction' and sclection to its objective or neural aspect. (See I, Psy. Pr., § I7; III, Prob. 4, §§ 5I, 53; V, Prob. I, §§ I04, I5I.)

8 II, Prob. 2, chs. 2-4.

$10 \mathrm{~V}$, Prob. 2, § I57.

9 II, Prob. 2, chs. 4, 5.

11 V, Prob. 3, §§ 82-9I, esp. 87. 
with it; - the motor side of subjective phenomena is impulse or action, rather than feeling. The grouping or coordinating process is the guide which controls the impulse, and thereby regulates conduct. In the broadest view of psychology "the significance of mental phenomena is their relation to conduct." 1

\section{Lewes's Contributions to the Problem}

The main features of Lewes's psychology, in so far as they bear on the association problem, may be summed up as follows: ( I) He takes the concept of biological evolution from Darwin and Spencer, and carries it out on the psychological side more fully than they.

(2) He interprets the laws of nervous irradiation and restriction in mental terms, under the single law of Reinstatement, which serves to account at once for $(a)$ the distinction between primary and secondary feeling, or sensation and image, and for $(b)$ the grouping or associative function of mental phenomena, which he terms logic.

(3) The grouping tendency accounts for all complex forms of experience, from sensation upwards, the only datum not attributable to grouping being the hypothetical underlying element, the neural tremor.

(4) The tendency to use part of a complex experience as a sign for the whole, which is a general phenomenon of mental activity, evolves to a higher form in the human mind. In man arbitrary associated elements (ideas) come to be used as symbolic signs for sensations and images which they in no wise resemble. This symbolism and logic of signs arises out of social intercourse, for which words and language afford a convenient, flexible, and adequate medium.

(5) Images are individual, concrete, specific-ideas are 1 Ibid., § 15. 
general, abstract. The sequence of ideas, or logic of signs, is therefore more facile and more adaptable than the logic of feeling or the logic of images. Ideas and ideational processes constitute the intellectual side of the mental life, and intellect is its highest form.

(6) An established group, which has become a single experience (intuition), is characterized by a higher degree of belief, conviction, certainty, than a group in the making (inference); intuitions of sensations and images (called perceptions) are distinguished from intuitions of ideas (conceptions); and inferences of sensations and images (memories, hallucinations, imaginations) are distinguished from inferences of ideas (judgment, reasoning).

(7) Lewes applies the term association in an unusual way to that special sort of grouping in which the elements are casually brought together by contiguity, similarity, or interest. Grouping in general, which he calls logic, proceeds by the revival of identical elements in the form of images, the revival operating from one element to another according to the principle of contiguity only. He applies Bain's treatment of association in general to his own 'casual associations.'

To appreciate the breadth of Lewes's viewpoint we should also note several other points which bear on our problem only slightly. (I) His conception of the cooperation of organism and environment in experience. The present stimulus and the self due to one's entire past experience work together; any given experience is a resultant of these two factors. (2) His extension of the nervous arc concept to psychology. Feeling or affection, logic or grouping, impulse or action, are the mental equivalents of the three sides of the nervous arc; they form the psychological spectrum, whose combination constitutes mentality. (3) His endeavor to give proper weight to both the subjective and objective sides of psy- 
chology - to the method and data of introspection as well as to the method and data of external observation. (4) His demarcation between external sensations and the systemic sensations. This distinction deserves special notice on account of the prominent role which he assigns to the latter.

To grasp Lewes's system as a whole requires considerable effort. His style is prolix and his development is not always systematic. $\mathrm{He}$ is careless of detail, inconsistent on some points, and obscure in his treatment of others. Yet upon close examination he proves to be the most consistently associational of all psychologists. Lewes deserves far more study than has been accorded him by recent writers; and especially does he deserve the attention of genetic psychologists. Those who wish to know at first hand the evolutionary associationism at its best, should read his final volume. ${ }^{1}$ Though not a complete exposition, it contains most of the essential points of his psychology, and corrects many of his earlier inconsistencies.

\section{Other XIXth Century Associationists}

Among the many writers whose psychology shows the influence of Spencer and Lewes, the following may be cited as most closely related to the association movement.

JoSEPH JoHN MURPHy (I82 7-I 894), though a believer in innate intelligence, lays stress on association, which he holds to be a racial growth. In his 'Habit and Intelligence' (r869) he declares that association enters into every mental process except the most elementary; ${ }^{2}$ " a complete treatise on the laws of association would be nothing less than a complete treatise on psychology." 3 The laws of association, however, while they would ac-

1 'Problems of Life and Mind,' Vol. V.

2 Vol. II, p. 54. 
count for the origin of thought, would not account for our belief that a thought corresponds to an external reality. ${ }^{1}$ This and other complex phenomena of consciousness depend on a principle of organizing intelligence. $^{2}$

W. $K$. Clifford (I845-I879), in his 'Lectures and Essays,' devotes an essay to 'Some of the Conditions of Mental Development,' in which he maintains that "the first indication of consciousness is a perception of differences." 3 The essay on 'Body and Mind,' which is based on the hypothesis of parallelism, and his volume on 'Seeing and Thinking' (I879) also show the influence of the association psychology.

The contributions of Francis Galton (I822-I9II), whose numerous studies on mental heredity are based on the standpoint of Spencer and Lewes, will be discussed in connection with the recent experimental work on association. ${ }^{4}$
1 P. 152.
2 P. 54 .
3 Vol. I, p. 97
4 Chapter VIII. 


\section{CHAPTER VI}

\section{SUMMARY OF ENGLISH ASSOCIATIONISM}

\section{Development of the Association Concept from Hobbes to Hume}

THE analysis of mental processes which the English school carried out is a logical result of their philosophical attitude. These writers employed the empirical method in philosophy. They were concerned in demonstrating that all knowledge is derived from experience-that it occurs without the mediation of innate ideas which were supposed by their opponents to exist in the mind prior to experience. To establish their contention it was necessary to analyze the character of experience and show that knowledge can be accounted for in terms of empirical data alone. Assuming that impressions due to external stimuli give rise to sensations of a definite character, how do these sensations become organized into knowledge?

What struck these writers most forcibly at the outset of their psychological analysis was the observed fact that one experience succeeds another with a certain degree of regularity. In such sequences, moreover, the prior experience does not vanish entirely before the succeeding one begins to appear; there is a union of some sort between the two members of the sequence. This fact of union, according to the associationists, constitutes the basis of organized experience and knowledge. They applied the term association to the process.

The aim of the English school was to account for all the facts of conscious life, excepting the crude material (sensation), as the product of the operation of association. 
Thus their chief problem was to analyze the complex data of consciousness into elementary experiences, and to show how these elements are combined together by means of the associative factor. In connection with this analysis of experience they endeavored to formulate the laws of the associative process. itself. A chronological study of the movement indicates how the analysis grew clearer with each writer, and how at each step the association process gained in importance. At first a mere incident in the sensationist theory, it at length became the sole means of explaining all the great variety of experience that lies beyond sensation.

HoBBES represents the crude sensation psychology. He adopts sensation as the basis of all experience. Every other mental process is derived from it. Imagination and memory, in particular, are regarded as 'decadent' sensations. The order of succession among representative experiences follows the order of the original sensations, but inasmuch as a sensation may have been followed sometimes by one sensation, sometimes by another, the order of representative experience is not always unequivocal. The sequence, he says, may be unguided or inconstant, or it may be regulated by desire. Beyond recognizing that habit is an important determining factor he attempts no real analysis of association. Thus when he passes to the higher intellectual processes or experiences he has no weapon of attack against the nativists; their assumption of innate ideas seems quite as acceptable to introspection as his assumption that abstract ideas are decadent sensations. In many cases ideas appear to bear no resemblance to sensations, and their derivation from that source may well be challenged.

Hobbes's theory may be as plausible as Descartes's or even more so, but it provides no means for refuting the theory of innate ideas. Yet in spite of its inadequacy, Hobbes's analysis accomplished one important result. It 


\section{I56 SUMMARY OF ENGLISH ASSOCIATIONISM}

set the pattern for an empirical conception of mind, and following the lines which he marked out the role of association came naturally into greater and greater prominence.

LOcke sought to meet the difficulty of accounting for the higher intellectual processes by emphasizing reflection and treating it as coordinate with sensation in the forma-, tion of experience. We have two sources of experience: the outer and the inner-sensation and reflection. Now the strength of the nativist position lies in the difficulty of deriving certain of our higher experiences from bare sensation, and when Locke supplements sensation with reflection he suggests an answer to the nativist objection. His own position is not strictly empirical, for in place of innate ideas he merely substitutes a native faculty or power-reflection. And this involves a concession to nativism which Hume held to be needless. But Locke's explanation of complex experiences opens the way to an empirical solution through the associative process. He is thus really responsible for the transition from sensationism to associationism. One is hampered in the attempt to determine Locke's attitude by the vagueness of his conception of reflection. Yet this very vagueness is of the utmost importance historically, for it drew attention to the weakness of this portion of Locke's psychology, and led to the extension of the association principle to account for complex and derivative ideas, which Locke attributed to reflection.

It is remarkable that historians have generally overestimated Locke's contribution to successive association, and at the same time have ignored his stress on the union of simultaneous experiences. For reflection, in one of its aspects, is the means of combining a number of simple experiences into a single compound experience. Simultaneous association, which Locke attributes to the faculty of reflection, is therefore an essential factor in his scheme 
of mental analysis. On the other hand, he regards successive association as a hindrance to right thinking, a habit to be uprooted by careful exercise in the 'voluntary' supervision of our trains of thought.

BERKELEY's analysis is very incomplete, but his theory of space perception furnished empirical psychology with a valuable asset. In demonstrating that distance or depth is not a sensation but an element added to the visual data, he indicated how psychological analysis might break up apparently simple experiences into more primitive data. If perception itself is an associative union of elements, why not imagination and thought? This implied query was taken up by later writers, who applied the principle of association to account for the welding together of elements into the higher intellectual experiences.

HumE sought to clarify Locke's analysis by abandoning reflection as a separate source of experience. He admits only two varieties of experience, sensation and ideation (to use our present terms); and of these, ideation is merely a faint replica of sensation. But he recognizes the need of accounting for those ideas and images which differ so widely from sensation that they cannot be directly traced to that source. To explain their existence he relies on association, which he submits to a more careful analysis than any of his predecessors, with $=$ results not far from those of Aristotle.

Hume's chief interest is to explain the succession of ideas, rather than to account for their complexity and transformations. He attributes the causal connection of logical thinking to habitual association, but his treatment of simultaneous association is limited to a few suggestions.

\section{Contributions of Hartley and Brown}

With Hartley the association psychology first assumes a definite form. He gathered together the hints 


\section{I58 SUMMARY OF ENGLISH ASSOCIATIONISM}

which were scattered through the writings of his predecessors, and wove them into a sightly fabric. His power of analysis carried him to the root of the problem. As a physician he saw the need of relating psychology to physiology. And his scientific training impelled him to reduce the mental side to the simplest and fewest terms possible.

Hartley starts with a dualism of matter and mind. Stimulation of the sense organs results in brain vibrations which are accompanied by sensations, though not to be regarded as physical causes of the latter. ${ }^{1}$ Ideas are attributed to fainter vibrations of the brain substance which occur when the vestiges of former vibrations are stimulated. The mental side, then, is reduced to two terms, sensations and ideas, which in the last analysis are data of the same type, characterized by a stronger and fainter degree of intensity respectively. They are correlated with activities of the physical organism.

But if sensations are traceable to external stimulation, what is the nature of the physical activity lying at the basis of ideas? Investigation shows that it is not external-that it originates within the brain itself. In the first instance it is a sensory brain impulse which excites to a fainter degree the traces of previous sensory impulses. Following this, an ideational impulse may also stimulate other traces and thereby give rise to other ideational impulses. Thus the physical basis of an idea is either a sensory brain state or an ideational brain state.

Regarded from the mental side, this passage from sensation to idea or from one idea to another is the process of association. A sensation or an idea (or, Hartley adds,

1 Since he expressly rejects any causal connection, this is distinctly a theory of psychophysical parallelism. (It would be interesting, by the way, to know how far Hartley's theory of brain vibrations is responsible for the modern pseudo-scientific talk of sympathetic mental vibrations!) 
a muscular movement) is able to induce another idea or another muscular movement, provided the latter term of the sequence has in the past occurred frequently in conjunction with the former term. The meaning of the law is understood when we examine the physiological side of the process. If several sensory brain processes have occurred many times in conjunction, then the recurrence of one induces a fainter repetition of the others, and these faint stimulations may in turn lead to faint repetitions of other sensory processes which have formerly occurred in conjunction with them. Thus Hartley's law of association is really the statement in psychological terms of a fundamental physiological process.

There is no very marked distinction in Hartley's theory between successive and simultaneous association. Experiences which have occurred simultaneously as sensations may be associated successively as ideas. And we may credit him with holding the converse also-namely, that when sensations have occurred frequently in immediate succession, their ideal counterparts may be simultaneously associated in the form of a compound idea. ${ }^{1}$ Each of the two modes yields an important datum. Succession. explains the rise of ideas (or images, as we should call them); and simultaneous association explains their complexity and deviation from the original sensations.

It is fully in keeping with Hartley's physiological trend that he does not regard resemblance as a factor in association. The physiological basis of the idea is the same brain process as that which formerly accompanied the sensation, only fainter. Hence, a stimulus induces by association not similar processes, but a renewal of either the same processes or contiguous ones. Contiguity is the sole criterion of what alternatives are open to association, while frequency or habit measures the strength of the

${ }^{1}$ He does not explicitly state whether the original association of sensations is serial or simultaneous. 


\section{I60 SUMMARY OF ENGLISH ASSOCIATIONISM}

associative tendency in given instances and determines the result as between these alternatives.

We should notice that Hartley indicates two fruitful directions in which the alialysis of experience may be carried out by the use of association, though he does not himself proceed very far with either. These are (I) the motor aspect of consciousness, including volition. $\mathrm{He}$ indicates the relation of voluntary muscular movements to sensation and ideas in his general formulation of the associative law. (2) The derivation of thought and reasoning from imagery proper. The transition from imagery to abstract thought is approached from several sides: in his account of the origin of complex ideas, in his study of verbal association, and in his analysis of belief. The weakness of some parts of his analysis and its incompleteness in dealing with the more complex experiences was in itself a stimulus to further study. In particular, the vagueness of his explanation of belief incited his successors to a minute analysis of its nature.

There seems abundant reason for according Hartley the title of founder of the association school, since he was the first to adopt the associative principle as the fundamental operation of psychology. The consistency and deep-reaching character of his investigation certainly entitles him to be regarded as the typical representative of the earlier period of associationism, when the principle itself was new and required elaboration before it could be effectively applied to the more intricate phenomena of mental life.

The effect of Hartley's constructive work appeared first in other sciences. The principle of association was seized upon by students of ethics, esthetics, logic, jurisprudence, and biology, and applied to their several spheres. Associationism appeared to be ' in the air' during this period, much as evolutionism was in the air a century later. It would be difficult to determine how far Hartley was re- 
sponsible for this radiation of the movement and how far it is due to the combined influence of the whole body of empirical thinkers from Hobbes onward. ${ }^{1}$ The contemporaries and successors of Hartley must have derived their well-rounded notion of association mainly from him, since most of them assume it without independent analysis; and their broad treatment is not to be found in the earlier authorities. Yet it would not be fair to ignore two other tendencies of the time, for which Hobbes and Hume are responsible respectively.

The social contract theory, which held sway in the latter part of the eighteenth century, and was undoubtedly suggested by Hobbes's conception of the state, led to views regarding society which were quite favorable to the association psychology. The two theories are indeed quite independent and belong to entirely different spheres of thought. But their world-view is similar. Each is a mechanistic notion, opposed on the one hand to supernaturalism and belief in irreducible complexes, on the other hand to racial evolution. According to the social contract view, society is not an unanalyzable, divinely ordained composition; neither is it a growth by means

1 Writers of the I8th century were not careful to cite their authorities. It is not difficult to discover the sources which influenced them when the suggestions led to polemic; they are frank enough in naming their antagonists. But they do not usually deem it necessary to mention the sources whence their own standpoint was derived. In the present instance the search would lead us too far into problems of textual analysis. The writer believes, however, that present-day psychologists give too little weight to Hartley's influence on his contemporaries, just as they attribute too little importance to his original contributions to association.

Psychologists have had to rely largely on histories written by philosophers for their estimates of the association movement. The importance of Locke, Berkeley, and Hume bulks large in philosophy, while Hartley is a 'mere psychologist.' The present volume seeks to correct the misplacement of emphasis in this particular instance. It is desirable that all historical questions which concern psychology be re-examined from a psychological standpoint and that a history of psychology be written which shall counteract the errors into which our histories of philosophy have undoubtedly fallen in tracing the development of these problems. 


\section{I62 SUMMARY OF ENGLISH ASSOCIATIONISM}

of internal forces. It is an artificial union of human elements. And according to the earlier association theory human experience also is not an unanalyzable supernatural product nor a real development and transformation. The association of experiences is rather a mechanical reconstruction of elements into somewhat more intricate and complicated forms. Thus the two theories harmonized with each other and together constituted a tendency of thought during this period.

Again, the Kantian philosophy, which is traceable to a reaction from the conclusions of Hume's philosophy, drew attention to various aspects of Hume's analysis and brought association into prominence. Kant's disciples in Britain were strenuously endeavoring to advance beyond Hume's empirical view of mental phenomena. But the very strife itself served to familiarize the general reader with the notion which was popularly called the 'association of ideas.'

From philosophy and jurisprudence, then, as well as psychology, came influences which turned British thinkers in the direction of associationism. The work of such writers as Tucker, Priestley, Alison, and Erasmus Darwin in applying the association doctrine to special sciences has been noticed in an earlier chapter.

THOMAs BRown's position is peculiar, since he rejects the connection between psychology and physiology, which lies at the basis of Hartley's system. Moreover, his application of the association. doctrine to intuitional psychology is unusual. The Scottish school in general seek to distinguish each separate mental faculty carefully from every other, while the associationists endeavor to unite all mental phenomena into one class. Brown is an introspectionist, but he nevertheless endeavors to bring the so-called mental faculties together, and this by means of the principle of association. He rejects the notion that association accomplishes the union of mental 
terms; for introspectively we find no connecting linknothing but the fact of succession; and his standpoint forbids him to search for a connection outside of consciousness. For this reason he abandons the term association and substitutes Hobbes's term suggestion. But in general his view of the associative process conforms to Hartley's. The associated or suggested image is for Brown not a revival of the old sensation; it is a new experience. We can not explain it; we can only describe its appearance in consciousness by asserting that it is 'suggested.' But suggestion itself is based on the contiguity or contrast of similar experiences in the past.

Brown's attempted union of associationism with intuitionism was historically unsuccessful. It aroused the suspicion of both schools. This and his tedious prolixity lessened the influence which his system deserved on account of its exhaustive investigation of mental processes. He was the first to distinguish clearly between the primary and secondary laws of association-between the different sorts of union and the factors which determine its quantitative variation. In particular, his analysis of the secondary laws is remarkably complete, and his formulation of them is thorough, not to say redundant. He emphasized the 'mental chemistry' aspect of simultaneous association and his attitude seems to have influenced John Stuart Mill in adopting that view.

\section{The Two Mills and Bain}

James MrLl viewed the human mind as a species of machine. It is set going by outside forces (sensory stimuli), and proceeds to operate as a physical mechanism. The machinery of the mind is the associative process, and the elder Mill conceives of this as acting like a physical force, mechanically. $\mathrm{He}$ makes no attempt to correlate the mental processes with the brain 


\section{I64 SUMMARY OF ENGLISH ASSOCIATIONISM}

processes as Hartley did, though his appreciation of the function of nerves and brain is clearly indicated and his attitude toward physiology is far more sympathetic than Brown's. His analysis of consciousness is introspective and in this he follows Brown. But his conception of association is totally different from the latter's. Brown regards association as a means of transforming simple experience into complexes, which differ in kind from their components. James Mill rejects the notion of transformation. He holds that the sole function of association is to bind experiences together, and that the complex states contain all the original elements intact. In successive association the passage from thought to thought is so rapid that often certain intermediate steps escape attention; in simultaneous association certain elements may be so obscure as to remain unnoticed, but the intermediate terms and the obscure elements are there nevertheless, and it only requires analytic examination to bring them to light.

An instance of such analysis is found in James Mill's examination of the notion of belief, which he finds associated with a host of different mental factors according to circumstance, but which is itself nothing more than an indissoluble association between the factors. Belief, or indissoluble association, is in fact a cardinal point in James Mill's system. In his view association does not reconstruct or modify the material, but it cements the separate elements together with a strong force, and by repetition this union at length becomes indissoluble. The complex fact appears to be simple; only psychological analysis proves that it is made up of a weft of elementary strands or a succession of separate steps.

This view of association enabled James Mill to analyze the higher mental processes, such as conception and reasoning, with better success than his predecessors. A concept is a cluster of ideas, reasoning is the association of 
the terms of propositions. Each of these mental phenomena seems to be a single thing, but by psychological analysis it is shown to be really a composition. Taken in its entirety, Mill's analysis was far more thorough than any previous attempt, and his psychology is the first complete system worked out on an associational basis. Other associationists, however, raised strenuous objections to his instrument of research, and no one protested more vigorously than his own son.

JoHN STUART MILL was essentially a logician, and saw the logical fallacy of using introspective analysis to over-• throw the validity of introspection. If introspection declares a certain experience to be simple, how can another introspection prove this introspection to be false? The way out of the difficulty appears plain enough to the younger Mill. It involves merely abandoning the mechanical view of association for the chemical analogy. According to him, association produces experiences which are really unitary, in the sense that they are not separable into parts by introspection. Introspection does not break the experience up into elements, as the elder Mill supposed, but it does reveal the elements which the act of association has brought together to form this new product. Association does more than unite-it transforms.

This revised view of the nature of association involved a restatement of nearly all of James Mill's analysis. But the restatement was not so difficult as might be imagined. In most cases the results could be accepted as they stood with merely the qualification that what James Mill considered ingredients in a complex experience are really its antecedents - that the resulting experience is not so much * a complex state as a derivative state, which is introspectively as simple as it appears. Thus the perception of an orange or the concept horse are really simple, though derived from primitive elements. This line of argument 
enabled the younger Mill to transform his father's system completely without duplicating the analysis. He accomplished the astonishing feat of giving to the world a psychology resting on a basis of his own construction, while using practically the entire superstructure which his father had built up on an altogether different foundation.

This procedure, while it resulted in a powerful system of psychology, proved a source of historic weakness. Later writers naturally regarded James Mill's original work as the principal element in the joint product. They have underestimated the value of J. S. Mill's reconstruction. James Mill's 'mechanical' interpretation of association came to represent associationism to the average student's mind, and the 'chemical' interpretation was generally considered a foreign branch grafted upon it; it was treated as something contrary to the genius of pure associationism. In the present volume the aim has been to show how mistaken is this attitude toward the theory on historical grounds as well as logically. The chemical view or something akin to it was held by many associationists before and after J. S. Mill, and these included some of the most vigorous analysts. The chemical interpretation belongs quite as much to the genius of associationism as James Mill's mechanical interpretation.

John Stuart Mill's greatest difficulty arose in accounting for belief. He inclined to the opinion that it contains some distinctive element which renders it primordially" different from both sensation and ideation. In this of course he abandons the pure associational standpoint rather unnecessarily; for it was open to him to study the genesis of the element peculiar to belief and trace it so far as possible to familiar sources, as he attempted to do in the case of complex ideas. But the younger Mill's special interest was in logic rather than psychology. He was concerned only in correcting the logical fallacies in his father's psychological method and in outlining a psy- 
chology which was fitted to serve as a basis for his own scheme of logic.

BaIN's psychology is notable for its abandonment of introspection. He emphasizes the physiological concomitants of mental processes as Hartley had done; and in this he presents a sharp contrast to the Mills and Brown. But his physiology is far in advance of Hartley's, for the science had made vast progress during the intervening century. Brain activity was no longer conceived of as mechanical vibration, and the notion of diffusion of nervous impulses had arisen to account for the emotions. When physiology is emphasized it almost inevitably results in giving prominence to the motor side of the mental life. Thus Bain starts with sensibility and contractility of muscle as his two primary data, and a leading factor of his psychology is his study of impulsive and instinctive activity, the sense of effort, and other internal forms of motor phenomena. Moreover, Bain brings out a new connection between the mental and motor sides. Every sensation, he says, is accompanied by a tendency to movement, which grows in strength with the increased intensity of feeling. The motor tendencies of sensation being a legitimate object of psychological study, Bain's attitude justifies the investigation of physiological processes by association psychologists. In Hartley the reference to brain activity is rather an analogy brought in from another science. With Bain it admits of translation into psychological terms, and thus interpreted it forms an integral part of psychology.

The associative process is a fundamental element in Bain's system. He restates its laws and uses it as an instrument of research in every part of his analysis, especially in treating the intellectual processes; for association means revival of past mental states, and this revival always has an implied reference (if not an explicit one) to the restimulation of some trace of former brain ac- 
tivity. The coordination of motor impulses into definite, specific movements results from the association of ideas with these motor elements and from the coordinated grouping of such ideas. And the crowning motor phenomenon, volition, is only the final step in this associative and coordinating process. In his later works Bain adopts Spencer's principle of relativity, but not his genetic system of mental organization. Had the advent of the evolution theory been delayed, it would seem as though Bain must have been the model for empirical analysis during the next generation. But events moved quickly, and almost before the revised edition of Bain's psychology was written it had passed into history. Bain's treatment of the motor side, indeed, had a marked influence on later writers. But his association theory was out of touch with the thought of the age. Evolutionists felt the need of a thorough re-examination of association in connection with the new theory, in which growth meante real transformation; while the opponents of evolution had no sympathy whatever with the association psychology. Bain therefore appears as the last of the 'pure' associationists. Those who follow him belong to another regiment, and march under another banner.

\section{Spencer and Lewes}

The change in standpoint which the evolution concept introduced was further-reaching than one is apt to realize. It gave a totally different meaning to the world's history and thoroughly transformed the whole group of sciences which deal with life and human activity. We conceive today of a gradual perfectioning of organic forms from the dawn of life onward. We trace the progress of humanity from a state of ignorance and bestiality upward, instead of starting with an original condition of mental and moral perfection as pre-evolution thinkers 
interpreted the beginnings of history. The legal, ethical, social, and religious institutions of mankind acquire a new meaning when we view them as a growth and as real progress. Even the study of language is transformed; it is no longer a science of mechanical inflections. Comparative philology shows how sounds have been transformed and how inflections have grown up; language is an evolution from crude beginnings by a quasi-vital process.

With this concept of ' real growth' in the air, it was difficult to regard the human mind from the old standpoint. The mind could no longer be conceived of as a tabula rasa at the birth of each individual, inasmuch as each individual inherits the entire race-history of his biological organism. The sense organs, nerves, and brain exhibit progress from species to species, and the mental life exhibits a distinct gradation of levels among the different species. Thus the vague phrase 'mental endowments' came to have a definite and scientific meaning. The human individual at birth, if he has inherited no actual experiences, has at least inherited certain organic. capacities which make his experience, from the outset, different from those of the lower animals. Pre-evolutionary associationism was based on a mechanistic conception of experience; association was viewed as a mechanical or chemical process. It now became necessary to interpret association after the pattern of organic processes.

It has been urged by certain writers with some show of reason that the term associationism cannot properly be applied to the transformed doctrine; and one must grant that the term no longer holds without qualification. But the historian finds two reasons for retaining the old designation: First, the new school is a direct outgrowth of the older associationism-its historical successor. The two schools dovetail together; they belong historically to 


\section{I70 SUMMARY OF ENGLISH ASSOCIATIONISM}

the same movement and therefore deserve to be grouped together under the same name. Second, in the newer psychology the notion of association, though somewhat altered, still remains a dominant factor in the explanation of mental processes.

In SPENCER's evolutionary psychology the nervous functions play a more prominent role than even Bain accorded them. Spencer does not identify experience with neural activity as some of his critics claim. ${ }^{1}$ But he makes these physiological processes the pattern for the correlated psychological processes. He first investigates the processes of nerve physiology, and then translates them directly into psychological processes. The physical and mental being two sides of the same unknown reality, the laws of the former hold for the latter by merely substituting a different set of terms.

There are two prominent facts in the nervous life which interest psychologists: nerve impulse and nervous. revivability. On the mental side the corresponding facts are feeling and assaciation. Spencer formulates the conditions of nervous revival and transforms these conditions into laws of mental association. He differs with other associationists, however, in distinguishing between the act of inducing an associative mental state, which is for him the phenomenon of mental association, and the relation between the inducing and induced state, which he terms relation of feeling. The former experience is based on the neural phenomenon of revival or coherence; the latter is attributed to the shock which accompanies the passage from the old state to the new. His predecessors do not regard the 'relation' as a separate element of consciousness, nor as a distinct physiological phenomenon. For them the revival or production of the second experience

${ }^{1} \mathrm{He}$ applies the term 'nervous shock' to the primitive form of experience, but in other respects he distinguishes the two sides very carefully. The word 'shock' itself is scarcely impeachable from the introspective standpoint. 
carries with it the relation or union of elements and is part of the act of association; they recognize but one factor in the experience.

Spencer's theory on this point has led to a study, by William James and other writers, of the feelings of relation which accompany these relations of feeling. What interests us here, however, is that for Spencer the chief problem of association is the nature of the relations between feelings, as indicated by the physiological process involved. Spencer finds that every relation associates itself with similar relations experienced in the past, just as feelings associate themselves with similar past feelings. Hence, for Spencer the primary fact or law of association is similarity. Contiguity is subordinate; it is merely a repetition of the succession or coexistence which held among the original sensations. He finds, moreover, that consciousness as it grows complex tends more and more to take on the form of succession, while coexistence belongs rather to the physical side. ${ }^{1}$ The degree or strength of associability among experiences depends on their vividness, on the amount of repetition, and on a third principle which he calls the law of decreasing gain.

Thus far Spencer conforms to the older associationism in spirit, in spite of his unusual interpretation of association. But his evolutionism appears when he transfers the nervous integration which underlies experience from the individual organism to the sphere of race history. The more fundamental nervous coherences are not formed in the lifetime of any individual; they are too deeprooted for that. Biology indicates that, like all structures of the body, they have been gradually built up through many successive generations. Thus a difficulty of the older associationism was met. Many thinkers had questioned whether the well-nigh indissoluble associations

1 Physical events are both simultaneous and successive according to Spencer. 


\section{I72 SUMMARY OF ENGLISH ASSOCIATIONISM}

which empirical psychologists find in experience could be built up through the comparatively few repetitions of similar experiences that occur during an individual's infancy. Doubt was thus cast upon the empirical solution. But the evolutionists argued that nervous structure is inherited, and that the anatomical connections which underlie association are built up in large measure prior to actual experience. Hence, they held that the conditions underlying association are inherited by the indi-t vidual, though experience itself is not innate. The empirical position was confirmed by comparative neurology, which demonstrated that the underlying nerve structure involved in association has been gradually built up in the animal series.

Spencer is responsible for bringing associationism into accord with the Darwinian biology. But Spencer was not a trained psychologist. In reading him one feels his lack of sympathy with the psychological standpoint. In his writings mental phenomena appear to be merely biological processes clothed with a borrowed garment for modesty's sake. Psychology is treated as a child under tutelage, whose parent-science must always be consulted in matters of importance.

It is to LEwEs, then, that we must turn for a sympathetic exposition of the revised theory. He believes mental phenomena to be worthy of study for their own sake; and his psychology, though based and rooted in physiology, is a mature science capable of holding property in its own right. Lewes reasserts the claim of introspection, which Spencer had abandoned almost altogether, as an instrument of research. He is also unique among associationists in emphasizing the social data of psychology, which he believes to be chiefly responsible for the tremendous growth of mind in man beyond other species.

Lewes denotes the primitive element of experience by 
the term neural tremor, and regards sensation as a grouping together of these elements, while the higher types of experience are due in turn to groupings of sensations. This process of grouping, which Lewes also terms the logical process, is the association principle of earlier writers. But, like Spencer, he restricts the term association to one aspect of the grouping process: with him association is a purely adventitious grouping-one which has no basis in the connate mechanism. This would seem to exclude many important types of connection, such as the primitive spatial grouping of experiences. It harks back to Locke's view that association is a fortuitous or customary conjunction. The groupings which have a connate basis are more essential in Lewes's psychology than those which are brought about during the individual's lifetime. For the sake of historic unity, however, we may include all aspects of his so-called 'logical process' under the traditional term association.

Lewes considers associations of sequence more important than those of coexistence, but gives the latter greater weight than Spencer had attributed to them. Simultaneous associations tend to become fixed, and the resulting complex group operates like a single unit. Thus the perception of objects as unitary experiences arises when several different sense-data combine. Lewes does not adopt the chemical analogy in describing these unions, like John Stuart Mill. But he lays emphasis on the transforming character of fusion, which gives a qualitative tinge to experiences.

Serial grouping or association also is responsible, according to Lewes, for some of the varieties observed in experience. It leads in the first place to the rise of imagery. When a large number of sensations are stimulated together, they cannot all be reinstated with their prior associations to the fullest extent; as a result, some are suppressed and only occur incipiently. Such incipient 


\section{74 SUMMARY OF ENGLISH ASSOCIATIONISM}

reinstatements are representations or images. But a further step occurs: these images may be replaced by experiences of another sort, which bear no trace of the original sensations. Such experiences Lewes terms ideas; they include words and other associative factors which serve as signs for the image, though they do not resemble it.

Not merely the sensory and image-producing mechanism, but even the physical basis of ideas is too fundamental to have been wholly developed within the individual's lifetime. All these mechanisms are connatethat is, they are due to a structure which has evolved phylogenetically. Ideas, according to Lewes, are a social product, and their physical basis could only be evolved by generations of social life. The association of ideas is much readier and easier than the association of images, inasmuch as ideas are more general-in other words, less concrete and less specialized-than images. Association of ideas (in this technical sense) constitutes the intellectual side of experience, and hence the associational analysis accounts for intellectual phenomena as readily as for sensation and imagery.

Substitute the historic term 'association' for Lewes's grouping or ' logical process,' and his psychology proves to be thoroughly associational; it carries out the associational analysis more completely than any of the preceding attempts.

Lewes suggests a plausible relation between sensation and affection, in the distinction which he carefully makes between external and systemic senses. $\mathrm{He}$ adheres to Spencer's treatment of instinct and impulse, which points to a psychophysical correlation between the motor side of the organism and experience; this results in a psychological concept of conduct, embodying the highest aspect under which mental phenomena may be viewed. It corresponds closely to the more recently adopted term behavior. 
It remained only to apply Lewes's principles in a systematic manner, in order to construct a complete associational psychology. But this was never accomplished. Later British writers, such as Sully, Ward, and Stout, - based their analysis on a modified intuitionism, while the experimental laboratory movement initiated by Fechner and Wundt in Germany brought to light a new method - of research, and treated association as a minor factor to be investigated and analyzed psychophysically. Thus the work of the association school remained incomplete when the movement came to an end. The systematic study of the human mind along the lines indicated by Spencer and Lewes, which should have crowned their work, was never undertaken. As a result the world today appraises the association psychology only through the fragmentary attempts at analysis belonging partly to a bygone unscientific age, partly to the rudimentary stage of the evolution era.

\section{Estimate of English Associationism}

The work of the English school as a whole extended along three different lines: (I) The formulation of cer- tain laws according to which mental association proceeds. (2) The analysis of every sort of mental phenomena with a view to reducing them all, even the most complex, to the workings of the associative process. (3) The application of these results to the sciences of humanity, in an attempt to build up systems of ethics, logic, epistemology, jurisprudence, sociology, esthetics, and education in accordance with empirical principles.

(I) The first of these problems was recognized as important by many writers besides the associationists. Formulations of the laws of association were attempted by various psychologists not at all identified with the English school. ${ }^{1}$ On the other hand we find considerable ${ }^{1}$ See Chapter IX. 


\section{76 SUMMARY OF ENGLISH ASSOCIATIONISM}

diversity of opinion within the school itself regarding these laws. As one would expect, the associationists made a more careful and thorough study of the associative principles than other schools. Nevertheless their discovery and formulation is not an achievement for which the association school can claim entire credit.

(2) The attitude toward the second problem is more characteristic of the school. Where others accepted certain mental powers as innate, or viewed certain experiences as simple data, the associationists sought to reduce mental function and structure to the lowest possible terms; they analyzed complex experience into simpler elementary data, joined together into real or apparent unity by the associative processes. ${ }^{2}$ In some cases the peculiarities of a given writer's view may be due to his philosophical standpoint. In other cases they appear as legitimate psychological alternatives.

With the progress of anatomy and physiology and the formulation of the broader biological laws, came the reconstruction of certain psychological interpretations along the line of better organic analogies. In all this the associationists played a leading part. The chief contribution of the school to the historical development of psychology consists in their analysis of complex and higher mental states into simpler and more fundamental. Their work in this field, however incomplete, is of lasting value.

(3) To study their third problem, the application of associative principles to other sciences, would carry us too far beyond the scope of this history. It should be emphasized, however, that the extension of associational principles to the various fields of mental and social science is an inevitable consequence of adopting the association standpoint. In fact, it was the search for empirical data adequate to account for the humanistic sciences that 
really led most of these thinkers to adopt the association psychology. In all these sciences the association of ideas appeared to be the most adequate principle available for explaining the working of human mind. It would be scarcely correct to attribute utilitarianism and other phases of the empirical movement entirely to the influence of the association psychology; rather, the empirical trend of thought which originated with Locke manifested itself both in the association psychology and in allied, congruous movements in other sciences.

The motive which underlay the association movement was an endeavor to explain mental phenomena on an empirical basis. The system arose out of the attempt to combat the notion that certain ideas are innate-implanted in the mind at birth. But in the course of time the standpoint of both nativists and empiricists shifted. The nativists abandoned their theory of ready-made ideas, and claimed merely that the forms of experience are due to the intellect. The empiricists on the other hand were forced to admit that the primitive data of experience undergo transformation as they unite into complex forms.

A typical branch of nativists follow Kant in holding that the data of sensation are arranged by the mind itself in certain forms of time and space; these forms are native to the mind, but do not constitute experience-they do not of themselves appear in consciousness save in connection with the data furnished from without. The later associationists, on the other hand, hold that the temporal and spatial forms are themselves built up in connection with experience; they insist that the only 'native' data are the physiological dispositions of the brain which modify sensory impressions and transform them into a countless variety of central stimulations; the diversity of experience depends on the differentiation of these physio- 
logical processes and not on any power native to the mind.

The adoption of the evolution theory had little direct effect on either of these positions. It only served to make the process of mental development more comprehensible, inasmuch as the underlying basis of association, whether mental form or physiological disposition, was now seen to have evolved through generations of individual lives, instead of being a character of the individual organism.

The nativist position rests on the assumption that mind is a substance or entity. The associationists regard each individual mind as consisting of many unit experiences, which are so firmly bound together in simultaneous groups and in one long train, that they constitute a unitary consciousness. By scientific examination (so-called ' introspective analysis') the elementary units may be attended to separately and their derivation and synthesis may be accounted for, the grounds of their rise, combination, and diversification being stated in terms of the physiological processes which accompany them. ${ }^{1}$ Because it sought to split consciousness up into elementary states and laid special emphasis on the physiological basis, the association psychology has sometimes been termed a "psychology without a mind." It should be remembered, however, that the chief exponents of associationism recognized fully the unitary character of consciousness; the only basis for such criticism is that they regard the 'self' as a product of experience and not as the substantial and underlying basis of consciousness.

To sum up: ( I ) A cardinal point in the English move- + ment is its hearty recognition of the psysiological basis of experience and its constant reference to the nervous functions in explaining the development of experience.

1 Brown alone refused to consider these physiological laws a proper topic for psychology and merely stated the observed principles of psychological association. 
(2) Mental association is accepted as the instrument whereby experience is fashioned into complex forms and serial trains; this associative process is viewed as depending on certain characteristics of brain activities. (3) Further, associationists generally recognize that a transformation occurs as a result of the associative union of experiences-that the product of such union is often qualitatively different from its elements. Some writers consider this a departure from the pure associational standpoint; but we have found that the theory in some form was accepted by practically all the English associationists except James Mill. It is in fact no more a departure from the genius of the associational analysis than recognition of qualitative diversity among the original sensations themselves. ${ }^{1}$ These three postulates, together with the primitive datum of sensibility, constitute the working material of the association school.

We have observed how persistently these principles were used by the English writers in their attempt to explain all the phenomena of mental life. That the analytic examination was not carried out more systematically and completely was due to the fact that the associationists were one and all busily engaged in strengthening their foundations. Even Spencer and Lewes were forced to reconstruct the bases of their system in order to bear the added weight of the new evolution concept.

This task completed, it remained the duty of others to systematize the science along the lines laid down. But meanwhile the experimental laboratory method, starting

${ }^{1}$ It is interesting to note certain recent attempts (e.g. that of Professor E. B. Holt in his contribution to the 'New Realism') to derive the qualitative differences in sensation and other experience from homogeneous primitive units. The present writer believes that the 'mental chemistry' analogy furnishes a more plausible ground of explanation. Qualitative modification (or 'transformation') may be regarded as a primitive 'mental function,' of the same order as sensibility, revival, and association. 


\section{I80 SUMMARY OF ENGLISH ASSOCIATIONISM}

in Germany, was beginning to supersede the method of pure self-observation. Psychophysics, with its emphasis on quantitative results, came more and more into the foreground.

The quantitative measurement of mental phenomena gives greater precision than mere subjective analysis. But the two modes of investigation in reality supplement each other. Introspective analysis of the traditional associational type, united with quantitative measurements obtained by the newer experimental methods, have yielded notable results, as will be shown in a later chapter. ${ }^{1}$

1 Chapter VIII. 


\section{CHAPTER VII \\ CONTINENTAL ASSOCIATIONISM}

\section{French Associationism; Condillac}

THE principle of mental association was duly recognized by many writers of the Scottish and German movements. But in no case was it elevated by them to a commanding position in psychology. In France, however, we find a group of thinkers who developed a system along lines somewhat similar to the English school, in which the fundamental factors were sensation and association. While these French thinkers were influenced in some degree by the English movement (notably by Locke) their system was really worked out independently and presents individual characteristics of its own.

Marin Cureau de La Chambre (i594-i669) employed the phrase "l'union et la liaison des images" some years before the publication of Locke's 'Essay.' The expression occurs in his work 'Système de l'âme'" which appeared in r664; Locke's chapter on Association of Ideas was inserted only in the I 700 edition of his Essay. There is no reason to suppose, however, that Locke had seen Cureau de La Chambre's work or that he was even indirectly influenced by it.

Nicholas Malebranche (I638-i7i5), a follower of Descartes, went a step further than Cureau de La Chambre. In his 'Recherche de la vérité' (I674), after attempting to explain the causes of association between ideas and the brain traces, he examines the association

1 Bk. IV, ch. 2, art. 9I. The reference is from Hamilton; the writer has been unable to consult the original. 
between several of these traces. The psychophysical connection is based upon three laws: (I) The nature or will of the Creator; (2) Simultaneous occurrence of the two phenomena; (3) The will of man. ${ }^{1}$

The association between different brain traces rests upon the second of these grounds-simultaneity. ${ }^{2}$ Traces which were imprinted on the brain at the same time become associated. Some traces are associated naturally; others in a purely arbitrary way. ${ }^{3}$ Moreover, the traces may or may not be associated with emotions. Those ideas which are necessary to the preservation of life are always associated with emotion, as for example the idea of a precipice and the danger of falling into it, are associated with the idea of death and with an emotion disposing us to flee. ${ }^{4}$ It appears, then, that Malebranche regards simultaneity as the primary law of association.

At this period and till about I750 the Cartesian philosophy held full sway in France. The suggestion of Cureau de La Chambre and Malebranche was not elaborated. These writers are the sole representatives of the precursory stage of French associationism.

The first systematic attempt to develop an associational psychology was made by Condillac in 1746 . Paralleling the English movement we may treat the work of Condillac and his contemporaries as the second stage of the French movement. It corresponds chronologically and. in phase of development to the second English period, represented by Hartley and Brown.

Etienne Bonnot de Condillac (I715-1780) was a voluminous writer whose thought was largely influenced by Locke. He admits having no knowledge of English, and apart from an occasional second-hand reference to Berkeley (whose name he misspells) he appears to have

1 'Rech.,' 8th ed., Livre II, Pt. I. ch. 5, pp. 279-8r.

2 P. 291.

3 This passage may have influenced Locke.

4 P. 292. 
had no knowledge of the English development succeeding Locke. He owes nothing to Hume, though the 'Treatise' was published before Condillac's first work. ${ }^{1}$

Hartley's Latin ' Conjecturae ' came out (it is believed) in 1731 and the 'Observations' appeared in 1749 , the former I5 years before Condillac's first psychological work, and the latter 6 years before his chief production. But Condillac was obviously as unfamiliar with Hartley's system as with Hume's. His own psychology was built up independently and in many features is quite distinct from the English interpretation of association.

Condillac's system of psychology is developed in two works, 'Essai sur l'origine des connoissances humaines' (I746) and 'Traité des sensations' (I754). The 'Essai' seeks to demonstrate that all our knowledge is due to the association of material derived from the senses. The 'Traité' examines the growth of knowledge as more and more varieties of sense material are presented.

The plan as well as the title of the 'Essai' is obviously suggested by Locke's work. Condillac examines in turn the various kinds of ideas, and endeavors to explain them upon an empirical basis.

The 'Traité' is more original in design, and may be regarded as Condillac's chief contribution to psychology. It is a curious blending of scientific analysis and imagination. In order to show that the growth of experience is determined solely by sensation and association, Condillac imagines a statue, organized internally like a human being and endowed with a soul, but lacking at the start any idea whatsoever. He assumes that the statue's senses are opened up one by one and notes the effect of each successive addition in enlarging its field of knowledge. ${ }^{2}$ However artificial the design of the book may seem, it at

1 See Dewaule: 'Condillac et la psychologie anglaise contemporaine,' p. 5.

2 'Traité,' pp. 49-50. 
least serves to emphasize Condillac's chief thesis-that no a priori factor is concerned in the growth of mental powers and experiences.

Two other works of Condillac should be noted, 'L'art de penser' (I780), and his posthumous 'Logique' (I780). These follow the same line of thought as the 'Essai.' The 'Penser' is in fact little more than a recapitulation of the 'Essai,' with modifications due to some change in standpoint. The 'Logique' may be regarded as a summary of his psychology.

Condillac's psychology is sensationistic and associationistic. He attributes the source of all experience to the senses. Complex experiences are due to the combination of sensory data by association. Our task is to discover "what is the origin of our cognitions [nos connoissances], what are their data, by what principle they are put into effect, what instruments we employ, and in what way we should make use of them. I have found, it seems to me, the solution of all these problems in the association [liaison] of ideas, either with signs or with one another." 1

Locke had distinguished two sources of experiencesensation and reflection. Condillac rejects the latter, on the ground that reflection is either essentially sensation itself, or else it is a channel through which the sensory material flows, rather than an independent source of experience. $^{2}$ The material of our experiences consists wholly in sensations and mental operations upon them. ${ }^{3}$ There are two species of mental process: operations of the understanding and of volition. ${ }^{4}$

The fundamental operations of the understanding are reduced to perception and three special phases of perception: consciousness, attention, and memory (réminiscence). Condillac regards consciousness as awareness of an impression, which is equivalent to perception. At1 'Essai,' p. 8. $\quad 2$ 'Traité,' p. I3. 3 'Essai,' p. 19. $\quad{ }^{4}$ P. 36. 
tention occurs when a certain cognition appears to be the only perception of which we are aware. ${ }^{1}$ Memory is the association between present perceptions and earlier experiences. $^{2}$ The course of this association is facilitated by the use of signs, and particularly by conventional signs, which have only an arbitrary relation to our ideas. ${ }^{3}$ These signs, which constitute language, enable man to awaken the ideas with which they are connected. ${ }^{4}$ They serve in this way to exercise the mental operations and to develop experience. In particular, associations with the past are built up and the mind becomes less dependent upon the objects which affect the senses. ${ }^{5}$ The exercise of attention in connection with memory develops a special variety of operation called reflection, ${ }^{6}$ which enables us to direct the attention according to our desires. ${ }^{7}$

In similar fashion Condillac takes up certain modes of reflection: discrimination, abstraction, comparison, composition and decomposition of ideas, the judgment process (which includes the double operation of affirmation and denial), reasoning, and conception. The 'understanding' itself is nothing but the entire group of these mental operations, ${ }^{8}$ which rest one and all upon the association of ideas.

Nowhere does Condillac attempt a systematic classification of the laws of association. Dewaule, who has made a careful study of his writings, finds allusions to five laws: Contiguity, Resemblance, Intensity, Frequency or Vividness, and Inseparability. ${ }^{9}$

As a broad general analysis of the contents of experience, Condillac's scheme is more thoroughly empirical than Locke's and compares favorably with that of Hartley and the later British associationists. Studied in
1 P. 54 .
2 P. 52.
3 P. 75.
4 P. 86.
5 P. 88.
6 P. 89.
7 P. 92.
8 P. I16.

9 'Condillac et la psychologie anglaise contemporaine,' I892, p. 100. The references cited for these laws are 'Traité,' Pt. I, ch. 2, pp. $68,82,85$; Pt. II, ch. 3, pp. $207,303,309$. 
detail, however, it is lacking in the concreteness which characterizes these thinkers. The application of association in specific cases is asserted rather dogmatically, with no attempt to demonstrate by illustration. The important operation of judgment is disposed of in a single paragraph, and reasoning is scarcely more satisfactorily treated. Condillac's program is excellent, but he fails to carry it out in such a way as to carry conviction. The reduction of experience to a sensory basis, which is even more characteristic of his system than his associationism, is not within the scope of the present work. His treatment of association, while thorough-going in intention, is superficially carried out and is unsatisfactory as a contribution to psychological analysis.

\section{Bonnet and Helvétius}

With Condillac may be placed a group of writers whose analysis is more or less influenced by his writings but depends upon other sources as well. The works of Hobbes, Locke, and Berkeley were becoming more generally known on the Continent; the leading points of their systems had permeated French thought, which had become receptive to the empirical attitude through the teachings of a group of political and philosophical writers in France and French Switzerland.

The epoch-making Encyclopédie belongs to this group of writings. Edited by Diderot and d'Alembert, it comprises 17 volumes, the joint product of many contributors. The project was launched in $\mathrm{I} 745$, and the volumes appeared successively from I75I to I765. The psychological contributions are not particularly striking. The association of ideas is treated in a short article by Abbé Claude Yvon, in the first volume (I 75I); it merely describes the traditional conception of Aristotle and Locke.

Julien Offray de La Mettrie (I 709-I 75I), a writer 
of the same period, deserves passing mention. A thorough-going materialist, he seeks to demonstrate the mechanistic nature of human activity, in a work appropriately entitled ' L'homme machine' (1 748). From certain evidences of bodily activity after death he denies the historic conception of a 'soul' which is released from the body at death. His own conception of the mind is given in an earlier work, 'L'histoire naturelle de l'âme' ( 745 ). Claparède cites him as using the notion of association to explain the formation of ideas. ${ }^{1}$ The present writer is unable to find any passage in either of these works which expressly employs the association principle.

Of far greater significance are the writings of Bonnet and Helvétius, which belong to this period.

Charles Bonnet (r720-1793), a Swiss, published anonymously in 1754 a work entitled 'Essai de psychologie,' which he later acknowledged and reprinted among his collected writings. His larger work, 'Essai analytique sur les facultés de l'âme,' appeared in I 760 . The latter work is confessedly influenced by Condillac. Bonnet states that he had independently conceived the idea of using the simile of a statue and had already written two chapters when he heard of Condillac's 'Traité ' and read it, revising his plan somewhat to conform with Condillac's treatment. Whether the 'Essai de psychologie ' was influenced by Condillac's earlier work is uncertain. It offers more striking suggestions of Hartley, yet not sufficient to indicate a careful study of the 'Observations on Man.' We may venture the hypothesis that Bonnet had read Hartley's ' Conjecturae,' which appeared anonymously about I73r. Bonnet's emphasis on nerve fibers, the conciseness of his style, and the anonymity of his earlier work lend color to this view.

The distinctive feature of Bonnet's work is his attempt

1 'L'association des idées,' p. 16. 
to explain mental phenomena in physiological terms. Like Hartley, he regards experience as due to the activity of fibers in the brain. "All our ideas depend ordinarily. upon movements or vibrations which are excited in certain parts of our brain." 1 Association is a kind of sympathetic vibration. The recall of ideas, he says, is due apparently to "a modification of the motor force of the soul, which acts on the fibers or on our spirits [sur les esprits] and arouses in them movements similar to those which objects generate." ${ }^{2}$ The mind is usually affected by several ideas at the same time; when one of these reappears it ordinarily awakens some of the others which formerly accompanied it. Memory, imagery, and in fact all mental operations admit of a mechanical explanation. ${ }^{3}$ "Certain tones, certain movements, arouse one another because they have frequently occurred in succession. From these repeated successions there is generated in the machine [i.e. the organ of thought] an habitual disposition to perform a certain series of tones [suite d'airs] or a certain series of movements more readily than any other series." 4 The more often such movements are reproduced, the more readily does the mind reproduce them. ${ }^{5}$

The mechanism of association is explained more fully in the 'Essai analytique.' Each brain fiber is affected by a certain object and is set in movement in a specific fashion. This creates in the fiber a disposition or tendency to move in a certain manner rather than another. Since the entire fiber is affected by the object, if it receives some new sort of impression it will yield to this impression, but with regard to the dispositions which it has received from previous impressions. This modification due to the past, serves to arouse the memory of the sensation connected with the vibration of the fiber. " "It

1 'Essai de psychologie,' ch. 4. The present writer is responsible for translation of quotations in this chapter, unless indicated.

${ }^{2}$ Ibid. $\quad{ }^{3} \mathrm{Ch} .5$. $\quad{ }^{4} \mathrm{Ch}$. 6. $\quad .5 \mathrm{Ch}$. 63. ${ }^{6}$ 'Essai anal.,' 2 I. 
is possible," he declares, "that two sensory fibers which touch at but a single point, may set each other mutually into vibration if both have previously been set into vibration by [the same] object." 1

Bonnet's relation to Hartley is indicated by these passages. Impressions are due to vibrations of brain fibers, which leave dispositions. These dispositions cause changes in the effects producing new stimuli, and the re-echoing of old modes of vibrations thus brought about are the basis of memory, imagination, and general ideas. His physiological standpoint leads him to emphasize habit and what we would now call 'neural set' or disposition, more than Condillac or the English writers of the same period. But this principle of retention is insufficient by itself. The actual working of mind in its higher operations is based upon the principle of association, which Bonnet interprets as a principle of neural mechanism.

Claude Adrien Helvétius ${ }^{2}$ (I 7I 5-I 77I), whose ancestors were originally a German family of physicians called Schweitzer, is chiefly important as the connecting link between the earlier and later periods of the French movement. His writings add little or nothing to empirical psychology. But his home was the center where gathered a group of young thinkers, including Cabanis and Destutt de Tracy, who imbibed the sensationist tradition and later formed a politico-psychological school known as idéologues, or ideologists. After the death of Helvétius his wife, Mme. Anne Catherine Helvétius, continued her salon, and at one time during the Revolution the ideologists played a prominent part in governmental affairs.

Helvétius's psychology is found in two works, 'De l'esprit' ( $175^{8}$ ) and 'De l'homme, de ses facultés intel-

1 Ibid.

2 The name is spelled without accent in some early editions of his works and may be properly so spelled in English. 
lectuelles, et de son éducation' (posthumous). In neither is the principle of association developed. The sensory basis of all experience is the corner-stone of his system. The mind possesses two faculties or 'passive powers '-the faculty of receiving different impressions from external objects, and the faculty of preserving the impressions which these objects make upon us. ${ }^{1}$ The former capacity he terms physical sensibility. The capacity to preserve impressions-called memory-serves merely to continue our sensations in weakened form. ${ }^{2}$ In other words, sensibility produces all our ideas, since to recollect (ressouvenir) is only to have feeling (sentir). This groundwork suggests Hobbes's influence. But Helvétius asserts rather his obligation to Locke, claiming that his views are similar to the latter's. He shows also the influence of Hume, to whom he refers explicitly.

Proceeding from this fundamental position, Helvétius holds that the development of mind in the individual depends far more upon education and environment (circonstances) than upon any inborn gift of nature. ${ }^{3}$ Our mentality, virtue, genius, are all the product of instruction. ${ }^{4}$ All false judgments on our part, he declares, are the effect of either passion or ignorance. ${ }^{5}$ In ethics he is a forerunner of utilitarianism, holding that uprightness consists in actions which are useful to society. ${ }^{\circ}$

The psychology of Helvétius is sensationistic and aims at a thorough empiricism. It fails in the latter because the author has found no specific principle-association or other-to account for the differentiation of mental states. As a result his examination is largely speculative. He vehemently denies the accusation of materialism raised against him. It would appear that his explanation of

1 'De l'esprit,' Disc. I, ch. $\mathbf{r}$.

3 Ibid., Disc. III.

5 'De l'esprit, I, chs. 2, 3 .
2 Ibid.

4 'De l'homme', sec. I, ch. 7.

6 Ibid., II, ch. 5. 
the mind-body relation is too fragmentary to either refute or substantiate the charge.

\section{The Ideologists}

The ideologist movement may be regarded as a third stage in the French development. It corresponds to the English development under the Mills and Bain, though somewhat earlier in point of time. This movement was the direct outcome of Mme. Helvétius's salon. Destutt de Tracy, one of the leading members, was the adopted son of the Helvétius couple. Cabanis was their warm friend; he and Condorcet married sisters of General de Grouchy. Other frequenters of the salon were Sieyès of the republican Directory, Volney, Roederer, Daunou, and Ginguené-all prominent in revolutionary politics and in the world of letters. After the downfall of Robespierre this circle played a leading part in constitution making. When Napoleon came into power he shrewdly fostered their literary activity while gradually suppressing the political influence of the school. The result is seen in the works which began to appear, embodying the doctrines of the group in various fields of thought.

Antoine Louis Claude Destutt de Tracy (i754r836) furnished the psychological basis of the system in his five-volume 'Eléments d'idéologie' (I80I-I8I5). His system is merely a restatement of Condillac, of whom he believed himself to be the very last disciple. ${ }^{1}$ Destutt de Tracy reduces the mental faculties or operations to four, which give rise to corresponding kinds of perceptions: sensations, memories, judgments, and desires. The last three are all derived from sensations. In his analysis sensation is more important than association. Like Condillac (and in some degree Bonnet) he takes for granted the liaison of mental states without analyzing the process.

1 'Eléments,' art. 'Condillac.' 
Pierre Jean Georges Cabanis (I757-I808) emphasized the physiological side more fully than Destutt de Tracy. In his chief psychological work, 'Rapports du physique et du morale de l'homme' (I802) he examines the nature of the sensory process. Ideas, he asserts, arise not merely from sensations due to external objects, but from visceral dispositions and dispositions from other internal organs. ' With him the point of emphasis is the source of experience, which he places outside the mindin objects or bodily conditions which serve as stimuli. The manner in which the sensory material is woven together into complex experiences he does not seem to have regarded as a specific psychological problem.

Curiously enough the most distinctive contribution to the association psychology during this period was by one who later adopted a voluntaristic standpoint. M. F. P. G. MAINE DE BIRAN (I766-I824) emphasizes especially the motor factor in experience, and the role of habit in modifying experience. While still associated with Destutt de Tracy and Cabanis he wrote his 'Influence de l'habitude. sur les facultés de penser' (1802), in which he expressly mentions Condillac and Bonnet as his models.

According to Maine de Biran, the most widespread faculty among living creatures is that of receiving $\mathrm{im}$ pressions - a term which he prefers to sensation. ${ }^{2}$ Our impressions are either active or passive. Pleasure, pain, warmth, cold, etc. are passive-we have no power to modify them directly. But when we move, we have active impressions. This latter form of impression he calls movement, in distinction from feeling (sentiment), which is his general name for passive impressions. Both sorts are included under perception. Maine de Biran distinguishes between memory as active revival, and imagination which is passive. ${ }^{3}$ Movements are the cause of

1 'Rapports,' Mem. II, § 4.

2 'Influence de l'habitude,' p. I3. 3 P. 72. 
active phenomena. On this basis he divides his own work into the examination of passive and active habits.

Movements and passive impressions, according to Maine de Biran, are combined in a common center. Even those perceptions which are apparently the most simple are due to the combination of still more elementary data. ${ }^{1}$ This brings him to an examination of the principles of association. In addition to the laws of simultaneous and successive association he formulates a third principle, the law of signs and of the things signified: "When one of several impressions associated in a series or simultaneous group serves as sign [i.e. symbol] of the total perception, the latter . . . often attracts only the most superficial attention." ${ }^{2}$ In other words, the symbol-a word or verbal thought-becomes the prominent factor in the experience, while the objective perception is barely noticed.

Summing up the influence of habit on memory, he states the following laws: (I) Through repetition the succession of movements becomes more ready, tends to pass unperceived, finally becomes automatic. (2) The succession of modifications, feelings, or ideas evoked by articulation grows now weaker, now stronger, according to the prominence of the symbol and transitoriness of the object signified. (3) The succession of symbols and ideas comes to be interwoven in a species of chain, whereby recall becomes more facilitated, more certain, more easy of interpretation. $^{3}$

The influence of Maine de Biran is seen in the writings of PIERRE LAROMiguitre (I 756-r837), whose chief work, 'Leçons de philosophie,' (2 vols., I 8I 5-1837), bears the subtitle 'Essai sur les facultés de l'âme.' Laromiguière regards sensation not as a mental faculty, but as furnishing the material upon which the mind acts. Distinguishing like Maine de Biran between the activity
1 P. 134.
${ }^{2}$ P. 174.
3 Pp. $397-8$. 
and passivity of mind, he holds that sensation is merely the passive or receptive capacity. There are two fundamental faculties, understanding and volition. Understanding includes three subordinate faculties: attention, comparison, and reasoning. Volition includes desire, preference, and freedom, which correspond in a manner to the faculties of the understanding.

Laromiguière's empiricism is shown in his rejection of innate ideas. He finds four classes of ideas: (I) sensory ideas, (2) ideas of the mental faculties, (3) ideas of relations, and (4) moral ideas. The principle of association is not expressly developed in any of his writings.

\section{Later French Associationism}

The influence of Hartley, the Mills, and Bain was felt in the later development of the French empirical psychology, and produced a distinctly associationistic trend in the works of Mervoyer and Taine. These writers represent the fourth stage of the French movement.

Pierre Maurice Mervoyer (I805-ca. I866) ${ }^{1}$ is the best exponent of associationism in France. His 'Etude sur l'association des idées' (r864) acknowledges the influence of Locke, Hume, Hartley, J. S. Mill, Spencer, and Bain. The general analysis of the work follows Bain. Singularly he fails to mention James Mill, though apparently familiar with his views. Human knowledge, he

1 Mervoyer was born at Esquennoy (Oise) September 22, 1805, and was graduated at Paris with the degree of licencié-ès-lettres. He went to America, where he taught for several years. In December, 1852, he was appointed to the chair of English in the Lycée of Pau. In October, 1854, he was transferred to the Lycee of Auch, and in October, 1855, to the Lycée of Douai, where he remained till his retirement in 1866. From 1864 to 1866 he was given leave of absence on account of ill-health. The writer has made every effort to trace his subsequent history without result. The serious state of Mervoyer's health and the fact that he ceased to write makes it probable that he died soon after his retirement in 1866. 
holds, depends altogether upon two great principles: the law of continuity, and the law of resemblance. ${ }^{1}$ The former is objective, the latter subjective. These two laws account for the genesis of sensory ideas, movements, and feelings of movement.

The law of continuity (which is equivalent to contiguity) accounts for the association of sensations. Not merely sensations of the same sort or those from the same organ are associated, strengthened, and amplified by repetition; but sensations of different origin are united so closely in the process of internal elaboration, that there issues from the combination an idea which though complex appears simple at first sight. ${ }^{2}$

If the law of continuity is of major importance in perception, the law of resemblance is preeminent in the higher mental processes. Without resemblance neither language nor science could arise. Communication itself depends upon resemblance-the application of the same word to similar precepts and ideas. Reasoning, in both its deductive and inductive forms, depends upon the same principle. Mervoyer lays stress upon latent or unconscious association, which molds and perfects our habitual acts and spontaneous adjustments. ${ }^{3}$

The distinctive features of Mervoyer's analysis are: (I) His thorough-going associationism. (2) Reduction of the principles of association to continuity (or contiguity) and resemblance. (3) Identification of the former with objective processes, while the latter is regarded as a distinctively subjective operation. (4) The application of association to sensations and other simultaneous combinations as well as to ideas. (5) Extension of the associative principle to movements and subconscious operations.

The influence of the association psychology in France is seen in a number of other writers. Th. Simon Jouffroy

1 'Etude,' ch. I.

${ }^{2} \mathrm{Ch} .4$.

3 Ch. I2. 
in philosophy and Claude Bernard in science owe much to James Mill and Hartley respectively. Taine and Ribot, leading psychologists of the second half of the I 9 th century, accept the laws of association as fundamental principles of mental activity, though Ribot at least does not assign them an exclusive role like Mervoyer.

Hippolyte Adolphe Taine (I828-I893) may be regarded as the culmination of the French association movement. In his work 'De l'intelligence' (1870) the traditional method of introspective analysis dominates. Experimental psychology had not yet begun to exert its influence. Taine is an associationist rather than a sensationist; a thorough supporter of the new brain physiology; a believer in the future of experimental research whose beginnings in Weber, Helmholtz, and Fechner he utilizes freely. ${ }^{1}$

Taine's starting-point is the notion of mental signs, which he attributes to Condillac. "A sign is a present experience which suggests the idea of a possible experience." ${ }^{2}$ The suggestion operates through association. When we stand in a city square at night the vague sensation of moving spots may suggest to us a throng of human individuals walking about. The perception of an event or object may arouse the conception of another event or object. Among the many classes of signs one species is especially noteworthy: a name is a sensation or image which arouses in us an image or group of images. In certain cases the second image or group is not actually aroused; the name then becomes a substitute for the group.

The peculiarity of Taine's presentation is that he starts with the analysis of the symbolic data of experience. Imagery is treated next, and sensation is taken up only

${ }^{1} \mathrm{He}$ is more widely known as the author of a valuable 'History of English Literature.'

2 'De l'intelligence,' ch. $\mathrm{I}$. 
after these have been disposed of. His discussion of the data of experience concludes with an examination of the physical basis of experience. The second part of his work deals with the various sorts of experience in a somewhat unsystematic way. This latter portion is primarily epistemological, and is open to the same criticism as the works of Locke and Hume from the standpoint of psychological analysis.

Taine devotes a chapter to the laws of association of ideas. $^{1} \quad$ Ideational experience rests upon the capacity of sensations to be revived even after long intervals. The actual renewal depends both upon certain characteristics of the original sensations themselves and upon special circumstances which lead to their revival in the form of images. The capacity of a sensation for revival depends upon ( $\mathrm{I}$ ) our degree of attention to it (whether voluntarily or involuntarily) at the time of its original appearance; and (2) the frequency of its occurrence. Its revival at any specific moment depends upon the laws of (r) contiguity and (2) similarity. But Taine points out that sensations (and consequently images also) are not detached experiences. One sensation passes imperceptibly over into another; there is no clear line of demarcation. Hence, when an image begins to be recalled through similarity or contiguity, the entire experience to which it belongs is likely to be revived. Accordingly, the laws of contiguity and similarity may be reduced to a single law: the tendency of sensation (and imagery) to revival. This tendency insures the successful completion of an image which has begun to appear, which is accompanied by attention, and which has been strengthened by repetition.

The precise meaning of Taine's general law is not clear. His exposition, here as elsewhere, is unfortunately neither detailed nor systematic, though extremely suggestive. One is reminded of Hamilton's Law of Redintegration. 
And yet Taine's fundamental law seems less satisfactory and convincing than Hamilton's when taken at its face value, though it carries further and explains association better if restated in terms of neural activity. Taine himself holds to the double-aspect interpretation of the mindbody relation. ${ }^{1}$ One may regard the revival process as an irradiation of the nerve current into neighboring brain centers, renewing the traces left there by former impressions, and thus ' reviving' experiences which are either similar to the present experience, or which on former occasions affected brain centers adjacent to it. ${ }^{2}$ If this is Taine's real meaning (which is only conjectural), his law is far more in keeping with contemporary views than Hamilton's. As actually stated and illustrated it is merely a third principle supplementing similarity and contiguity.

The conception of mental chemistry is formulated more adequately by Taine than by the English associationists. It is embodied in three general laws of sensation.

Similarity: Two sensations which separately yield no consciousness may, when they appear in immediate succession, form a total sensation which is perceived by consciousness. (2) Analysis: A sensation which is not consciously decomposable, and which is apparently simple, is a compound of successive and simultaneous sensations which are themselves compound. (3) Quality: Two sensations which are of the same nature and which differ only in size, arrangement, and number of elements, appear to consciousness as mutually irreducible and endowed with absolutely different special qualities. ${ }^{3}$

Taine's analysis of sensations yields little apart from these three laws. It is interesting to note that he starts with the sense of hearing, to which he apparently at-

I Pt. I, Bk. IV, ch. 2.

2 Compare Lewes's notion of irradiation and his law of reinstatement.

${ }^{3}$ Pt. II, Bk. III, ch. 2. 
taches greater importance than to sight or the other senses. ${ }^{1}$ He limits his discussion to the five traditional senses, ignoring James Mill's alimentary sense; the muscle sense is included under touch.

The synthetic part of Taine's work is disappointing to the psychologist. His interest being primarily epistemological, he confines himself almost wholly to the intellect, leaving out of account the emotional and active phases of mental life. The perception of the external world is most adequately examined. Taine goes beyond J. S. Mill's definition of matter as the permanent possibility of sensation; matter is also, he points out, the necessary presupposition of sensation, since our experiences depend upon stimulation by objects in the external world. ${ }^{2}$

We may class Taine's psychology as a pure associational system, carried out with some degree of thoroughness on the side of analysis, but inadequate on the synthetic side. Soon after his work appeared the experimental movement in psychology began to attract attention in France. Later empirical writers abandoned the older analytic method for laboratory research. During the transition period the voluntaristic movement and a priori analysis held sway. As in England, the old association psychology was suddenly checked, to be replaced in a short time by a different type of association study.

In concluding this survey of the French sensationassociation movement, reference should be made to Ribot, whose historical work was mentioned in the first chapter. Theodule Armande Ribot (i 839-I903) belongs more properly to the experimental school, but shows his appreciation of French sensationism and English associationism and recognizes their affinity with the newer method of laboratory research. His historical work 'La psychologie anglaise contemporaine' (1870) was designed to inform

1 Condillac starts with the sense of smell.

2 Pt. II, Bk. II, ch. I, $\$ 6$. 
French thinkers concerning the English association psychology. That his interest is distinctly psychological is shown by the fact that his survey begins with Hartley, where the philosophical historian would have given prominence to Locke and Hume.

Ribot's original contributions to psychology are mainly in the experimental and pathological fields. As editor of the Revue philosophique for many years, he fostered empiricism in philosophy and psychology, using his influence against $a$ priori methods in both fields. Just as Taine has given us one of his ablest histories of English literature, so Ribot's history of English associationism is the most sympathetic and discerning examination of the movement that has appeared.

\section{Italian Contributions}

The association movement exerted far less influence in Italy than in France. The study of psychology was in abeyance in the Italian states during the I8th century and the early part of the Igth, and only began to be effectively pursued when United Italy approached the threshold of realization. Italian psychology prior to the experimental awakening caused by Weber and Fechner is almost negligible.

One work, which appeared in the I8th century, shows a distinct leaning toward associationism. It is an essay by Francesco Maria ZaNotti (I692-I777) entitled 'Della forza attrativa delle idee.' Zanotti originally published this under a French pseudonym of Marquis de la Tourry, and dated it I747. The actual date of publication is uncertain: it is included in Zanotti's 'Opere scelte.'

Zanotti follows Hume's conception of a subtle force which serves to bind ideas together. His treatment is highly imaginative and somewhat fanciful. He pictures 
the attractive force among ideas as a sort of electric phenomenon; its influence extends to the connection of propositions into syllogisms. The theory is not worked out in detail and is vague to an extreme. It is part of a general cosmology, which starts out with a discussion of corporeal or material forces (forza de' corpi), and attempts to carry the analogy of these forces into the realm of mental phenomena and finally into the sphere of nonexisting things (' forza attrativa delle cose che non sono'). The work of Zanotti met with little success and bore no fruit.

Pasquale Galluppi (I770-I846) is the only other Italian writer who seems to have been greatly influenced by associationism. His 'Elementi di psicologia' (I 834), the second part of his philosophy, while combating the sensationism of Condillac and Bonnet, attaches considerable importance to the association of ideas. Galluppi recognizes seven elementary mental faculties: internal sensibility, external sensibility, the analytic faculty, imagination, synthesis, desire, and will. Imagination (or imagery) is subject to the following principle: "A past perception returns whenever part of it returns." Contiguity is thus taken as the chief law of association of ideas, and is made to account for the succession of imagery and trains of thought. Memory in the strict sense is a subordinate and non-elementary faculty. Galluppi emphasizes the role of habit or repetition in producing facility of performance. He also insists that vocal utterances play a leading part in the formation of ideas.

The list of 'faculties' is sufficient indication that Galluppi's system is by no means strictly associationistic. The analytic function is regarded as equal in importance to synthesis. Attention, one variety of analysis, is as fundamental as association. Galluppi's system may be regarded as a protest against Kantian rationalism, and 
as an attempt to keep the empirical psychology alive in Italy. He is at most an echo of the association movement.

The historical work of LUIGI FERRI (I826-I895) has already been mentioned. ${ }^{1}$ This volume, written originally in Italian ('Sulla dottrina psicologica dell' associazione,' I878), was later expanded and translated into French under the title of ' $\mathrm{La}$ psychologie de l'association depuis Hobbes jusqu'à nos jours' (I883), and was awarded distinctive honors by the French Academy of Moral and Political Sciences. While he portrays the association system with fairness, Ferri does not accept its principles, and in the second part of his book he subjects it to a drastic critique.

Ferri is an adherent of intuitionism and distinguishes between the lower and higher capacities of mind. The lower or sensory capacities build up complex phenomena by association; but the underlying principle of association is coexistence and succession-not resemblance. The principle of similarity (or resemblance) is fundamentally a sense of relation, and belongs to the higher capacities or functions of the mind. Syntheses, which are based upon resemblance, are operations of the understanding, and are utterly distinct from sensory associations.

The work of Ferri was an important factor in preventing the spread of associationism in Italy. He combated with some success the positivistic philosophy of R. Ardigò, whose psychology was akin to the association school.

On the whole, the English movement affected Italian psychology but little. The Cartesian and German rationalistic methods were dominant in the earlier period and the voluntarism of Maine de Biran exerted some influence in the rgth century. The positive philosophy of Comte, which minimizes the study of psychology, had many disciples. While it supported empiricism in science, the positivistic movement was concerned mainly with the

1 Chapter I. 
physical sciences and sociology. The association psychology was unable to secure a foothold in Italy.

\section{German Contributions}

In Germany the pure association psychology found no disciples. Rational and $a$ priori methods were generally in the ascendent until the experimental laboratory movement began to make itself felt. The Aristotelian laws of association received considerable attention in the 18 th century. In the first half of the I 9 th century Fries, Herbart, Beneke, and others developed systems in which association played an important part.

An early instance of the use of the principle of association is found in BenEDict SpINoza (1632-I677), who applies it in his 'Ethics' (1674) to the theory of emotion. G. W. L. LeIBNITZ (I646-I7I6) made no use of the principle, but it has been pointed out ${ }^{1}$ that he recognizes the occurrence of association by contiguity. Johann August ERnesti (I 707-I 781), in a work entitled 'De mente humana' (I734), gives three laws of recall: (I) Similarity; (2) Part and whole; (3) Simultaneity. It will be noticed that succession is omitted from the list, as well as Aristotle's principle of contrariety. The second and third laws are but slightly differentiated; for the law of part and whole means that the part tends to recall the whole of which it is a part, and this is usually a simultaneous experience of all parts.

Johann Nic. Tetens (I738-1807) also attaches considerable importance to the associative process. In his 'Philosophische Versuche über die menschliche Natur' (I 777) he states that ideas are renewed by one another (I) according to their previous connection, and (2) according to similarity. ${ }^{2}$ This principle, which is virtually

1 Frenzel, B., 'Der Associationsbegriff bei Leibnitz,' pp. 94-5.

2 § 3 , p. 107. 
a restatement of the laws of contiguity and similarity, he regards as a significant principle of mental activity, but not the sole connective principle. It applies to phantasy only, not to sensation; and it is not a mode of linking ideas into new series. The psychology of Tetens is more nearly related to the Scottish school than to associationism.

During the quarter century from I770 to I795, for some reason which is not clear, the laws of association were made the subject of several apparently independent studies in Germany. Hamilton cites some of these in his Note on the History of Mental Association. ${ }^{1}$ Their chief significance is the influence they apparently had in directing the attention of later psychologists toward the association doctrine. They are mainly of the doctorate thesis type and contribute little to the theory. We need only cite them by title: Mich. Hissmann, 'Geschichte der Lehre von der Association der Ideen' (I777); C. G. Bardili, 'Ueber die Gesetze der Ideenassociation und insbesondere ein bisher unbekanntes Grundgesetz derselben' ( I 778); A. J. Dorsch, 'Ueber die Ideenverbindung und die darauf gegründeten Seelenverstände' ( 1788 ); Johann August Goerenz, a work cited by Hamilton as 'Vestigia' (I79I); ${ }^{2}$ and Johann Gebhard Ehrenreich Maass, 'Versuch über die Einbildungskraft' (I792).

How far these studies stimulated opposition to the rationalistic psychology of Kant and his successors is uncertain. They at least indicate a tendency toward empirical methods, which first manifested itself in J. F. Herbart and more clearly in Johannes Müller and E. $\mathbf{H}$. Weber, leading through them to the development of experimental psychology and laboratory research, in which Germany took the lead at the start.

1 Reid's 'Works,' Note D**.

2 The present writer has not been able to find this work or identify its full title. 
Even before Herbart, the empirical method was adopted by JAKOB FrIEDRICH FrIES (I 773-I 843), whose psychological analysis (like Hume's) was merely an adjunct to his epistemology. The principle of association is employed as an explanation of mental phenomena in his 'Neue oder anthropologische Kritik der Vernunft' (1807). Fries extends the principle of association not only to ideas but to all inner or mental activities. Experiences of every sort are strengthened when they are linked together. ${ }^{1}$ The associative process, rather than a mental faculty of apperception, accounts for degrees of attention in consciousness.

\section{Herbart and Beneke}

Of far greater significance for empirical psychology is the work of JoHANN FrIEDRICH HERBART ( I 776-I 84I). His 'Lehrbuch der Psychologie' (I8I6) marks an epoch in German psychology. Herbart's interest was more pedagogical than philosophical; consequently in his concept of mind he emphasizes growth and plasticity instead of adhering to a rigid scheme of innate mental powers. Opposed to Kant's a priori treatment, doubtful as to the division of mind into separate faculties, Herbart regards experience as resulting from the clash of elementary data, which strive to rise above the threshold of consciousness and which modify one another in the struggle. For Herbart, association is a subordinate phenomenon; the opposition of impressions and their mutual resistance is the primary fact of experience.

Experiences are made up of simple elementary impressions (Vorstellungen). These elementary data are in some cases not in mutual opposition, as for example a tone and a color. In most cases, however, they resist one another wholly or in part, and as a result one exerts an 
inhibitory influence upon the other. The amount of inhibition undergone by each member of the group may be expressed by a mathematical formula. If one member is very weak it may be submerged below the threshold of consciousness, to rise later if the opposing force is withdrawn. The stronger members of the group are likewise inhibited to some extent, but remain above the threshold. The content of consciousness at any moment is the resultant of these opposing forces, together with the synthesis of such elements as are not in opposition.

The change of stimulation and inner activity from moment to moment produces a continual variation in the total content of consciousness, some elements increasing in strength, others diminishing; some rising from an unconscious state to consciousness, others falling below the threshold of consciousness. The data which are repressed and submerged below the threshold are not wholly destroyed, but remain as tendencies, somewhat in the sense of the modern Freudian notion of subconscious data. The total consciousness at any moment, then, is due to the balance of forces in the elementary impressions which are striving against one another. The composition of experience is the result of this opposition and of the interplay of non-opposing data. Thus we find two processes operating to bring about complex experiences-integration or complication (Complexion), and fusion (Verschmelzung). Complication is the synthesis of noncontrasted data, fusion is the result of partial suppression of factors which nevertheless enter as components into a unitary experience.

Experimental investigation has since demonstrated the falsity of Herbart's mathematical formula. His work was based on hypotheses which have not been borne out. He did not take sufficient account of the neural activity which produces impressions. Nevertheless his conception of 
elementary data and their mutual interworkings was suggestive and stimulated experimental research.

In a similar way Herbart's treatment of association was the starting-point of experimental investigation of that problem. He dismisses as matters of slight importance the association of ideas according to temporal and spatial grouping and according to resemblance and contrast. "Rather we may mention here the varied complicated course which reproduction often takes; for example, he who finds coals and ashes in a forest thinks immediately of burning wood which (farther backward) may have lain dry in the forest; then (forward) of men who may have camped there and who may have set fire to it. But how came the men there? (This question goes backward.) What has become of them? (Forward.) What fire might have originated had a storm arisen? (Sidewise into the region of possibility.)"1 This suggests the inquiry into the various types of relation which enter into association and their relative frequency-a problem which began to occupy the attention of experimental psychologists some seventy-five years later.

Herbart emphasizes the antagonism of mental data rather than their association. But in his treatment of the development of concepts and judgments his standpoint is almost identical with that of the associationists. Collective impressions of the same individual in many attitudes are formed by the grouping together of many separate impressions. These lead to the formation of judgments, which are successive associations of concepts. A judgment, according to Herbart, is never a simultaneous association (an integration or fusion), since in this case the subject and predicate would not be held separate but would merge into an individual unit. ${ }^{2}$ The

p. 72 ,

I'Lehrbuch der Psychologie,' art. 92. Trans. by M. K. Smith, 2 Art. I8I-2. 
fluctuations between different mental states, however, bring about successive associations which are frequently of the nature of judgments. Words, on account of their symbolic nature, are especially fitted to serve as subjects in the judgment. Ideas develop in the individual through a continuous application of successive association as found in judgment. The definition and demarcation of general concepts is not reached through the separation of integrated experiences, but through the fixed connection of each individual element in the integration with certain other groups of data already formed.

In brief, Herbart stands with the association school in emphasizing the interaction of mental data. Concrete experiences are due to this interworking rather than to the synthetic action of specific faculties or powers of mind. He parts company with the school in regarding the antagonism of mental data as a more important factor in the formation of experiences than association.

FRIEDRICH EDUARD BENEKe (I 798-I 854) stands in closest relation to associationism of all German writers. His psychology is presented in several works: 'Erfahrungsseelenlehre als Grundlage alles Wissens' (I820), 'Psychologische Skizzen' (2 vols. 1825, I827), 'Pragmatische Psychologie' (I832), 'Lehrbuch der Psychologie als Naturwissenschaft' (1832), and 'Die neue Psychologie' ( 1845 ). Like Herbart he seeks to explain mental states by the interworking of elementary data rather than by the activity of mental powers.

In the 'Lehrbuch' Beneke recognizes three fundamental types of mental occurrences: (I) The production of sensations and perceptions as a result of impressions or stimuli from without. (2) The production of new capacities within the mind, which exist first as tendencies (Strebungen) and later rise above the level of consciousness. (3) The association of capacities and stimuli into more or less stable groups. An experience which has oc- 
curred for a time and has disappeared from consciousness, continues to exist in an unconscious state as a trace (Spur). These traces are not directly known, but are observed through their reproductions. ${ }^{1}$ The reproduction of traces in consciousness is the result of association. But according to Beneke the older association theory was defective in attributing the basis of association to the relations of similarity, simultaneity and sequence, spatial contiguity, causality, contrast, etc. For almost every idea has at one time or another been associated with countless other ideas and in all of these relations.

The problem, then, is to account for the specific connection in a given case-why the association proceeds according to one relation rather than another, and why a certain idea is aroused rather than any one of a thousand others. $^{2}$ Beneke accounts for this by the following law, which he regards as the basal principle of association: "Starting from any stimulated mental phenomenon, the variable elements are always carried over to that other phenomenon which is most firmly united to it or identical with it." 3

This law enables us to compare the relative strength of the various associative criteria. Simultaneous elements are stronger than those whose association rests upon sequence; consequently the association of the properties of a thing (simultaneity) is usually stronger than an association of cause and effect (sequence). Similarity is reducible to likeness and difference, both of which elements occur simultaneously. Contrast is likewise resolvable into some basal similarity and acts through this principle of association. ${ }^{4}$

Regarded as a complete explanation of experience, Beneke's theory is open to challenge. He neither adopts the neural basis nor substitutes a system of mental forces like Herbart. From the standpoint of our present study,

1 'Lehrbuch,' pp. 22-8.

2 P. 86.

${ }^{3}$ P. 9 I.

4 P. 92. 
it is to be noted that Beneke regards the principle of association as one of the fundamental factors in the production of experience. Stimulation, mental energy, association of the product of these two-these are the underlying factors in the development of consciousness. Beneke's primary law of association differs widely from the traditional formulations. It is in fact little more than a paraphrase of the physical principle that a body moves in the line of least resistance. The chief significance of his formula lies in its emphasis on the interaction of mental data. Both Beneke and Herbart stand with the association school in this, against the faculty psychology of the Scottish school and against the doctrine of innate ideas. With them belongs a later writer, Karl Fortlage (1806-188I), who contributes little, however, to the subject of the present study.

\section{Transition to the Experimental Movement}

The transition to the contemporary mode of investigating psychological problems is marked by three writers, Müller, Weber, and Lotze. Johannes Peter Müller (r80I-I858) propounded the doctrine of specific nerve energies, which revolutionized the theory of sensation and perception. In his 'Handbuch der Physiologie des Menschen' (1833-40) he brought forward the hypothesis that the kind or quality of sensation which results from stimulation is determined, not by the mode of the stimulus, but by the character of the sense organ. This led to a discussion of alternative hypotheses-that the specific quality of sensation depends upon the sensory nerve or upon the character of the brain center to which the nerve impulse is carried. Recently physiologists have suggested that specific qualities may be the result of the various patterns into which elementary impulses are combined to form sensation. The theory may be regarded 
as a physiological echo of the older associationism. The main effect of Müller's work was to stimulate the experimental investigation of sensation. This impetus was further assisted by ERNST HeINRICH WebER (I 795-I878), whose researches on the relation of stimulus to sensation were the starting-point of psychophysics.

HermanN Lotze (1817-188I), whose interests were both philosophical and psychological, may be mentioned here for the doctrine of local signs propounded in his 'Medicinische Psychologie' (1852). According to this theory each point of a spread-out sense organ bears a stamp or hall-mark of its own, by which the sensations arising from its stimulation are identified and attributed to the proper place of origin on the surface of the body. The perception of space relations is due to these local signs, and their grouping together results in the perception of extended surface. The doctrine of local signs opens a possible line of psychological explanation for simultaneous association. Lotze himself was skeptical of the association theory, however, and regarded investigations into the laws and modes of association as a profitless task.

On the whole, German empirical psychology contributed little to the traditional association problem. The opponents of the rational psychology, which dominated in Germany, made use of the association principle; but they did not regard it as a cardinal point of psychology. Some emphasized the physiological processes which underlie mental states; to others the conflict of mental data appeared even more significant than the synthetic principle.

Their work as a whole shows a trend toward experimental study of the data of experience; and this led in due time to a shift of interest in psychology from introspective analysis to laboratory research. The contemporary development of psychology may be regarded as the 
direct outcome of this movement. Fechner and Wundt are the historical successors of Herbart and Beneke, through the medium of Lotze, Müller, and Weber.

The experimental movement, starting in Germany, spread to France, America, England, and other countries. By comparison with its more exact results, the introspective generalizations of the English and Scottish schools were seen to be meager and defective. The study of association by this new method, once begun, went forward with surprising rapidity. The leading results of these investigations are described in the next chapter. 


\section{CHAPTER VIII}

\section{EXPERIMENTAL STUDIES OF ASSOCIATION}

\section{Beginnings of Experimental Investigation}

Several influences combined to bring an end to the association movement. (I) The Scottish 'faculty psychology' obtained a foothold in England as well as America. In 1838 William Hamilton brought out an edition of Thomas Reid's 'Works' with notes of his own which showed considerable sympathy with Reid's system. Later James Sully's 'Outlines of Psychology' (r884), a combination of the Scottish and English standpoints, was welcomed as being more in touch with popular conceptions than Bain's system. Sully emphasizes the faculties or 'operations' of feeling, knowing, and willing, rather than the more elusive operations of association and attention.

(2) The $a$ priori method of Kant and his followers, brought over from Germany, gained ground in Britain and led to a type of psychology in which speculative analyses of the cognitive processes were dominant. This tendency is seen in James Ward's article on 'Psychology' in the Encyclopedia Britannica, Ninth Edition, and later in the writings of G. F. Stout. ${ }^{1}$ The application of the rationalistic method to the association problem is illustrated by an article published in Germany in $1872-3$ by Max Schiessl on the influence of association on the act of knowledge. ${ }^{2}$ Schiessl reaches the conclusion that any

1 'Analytical Psychology,' I896, and later works.

2 Untersuchungen über die Ideenassociation und deren Einfluss auf den Erkenntnissakt. Zsch. f. Phil. u. Kr., 61, 62. (Page references to articles cited in this chapter will be found in the Bibliography at the end of the volume.) 
idea can be associated with a given idea by means of a third idea. This result, though sufficiently broad, affords us no real help in understanding the associative process.

The same method of treatment is found in several English discussions of the association problem. F. $\mathrm{H}$. Bradley, examining the thought process in 1887 , finds association inadequate to account for its connections and sequences. The underlying motive for the flow of thought is the end or purpose determined beforehand. ${ }^{1}$

(3) The associational analysis had gone as far as it could by the sole use of the introspective method. Something corresponding to the laboratory investigations used in chemistry and physics was needed to determine the relative strength of the associative processes. When these investigations were actually under way, they suggested new experimental problems. Association thus came to be viewed not as the fundamental process of human mind, but as one among several processes, each complex and interwoven in the total manifestations of consciousness.

This experimental treatment of the association problem may be regarded as the logical outgrowth of associa-, tionism, since it took up the investigation at the point reached by the English psychologists and followed in even more rigid form the empirical methods which characterized this school.

The experimental studies and theoretical discussions of association problems which have appeared in the 40 years since 1879 are so numerous that it would be impossible to do justice to them all in this volume. We shall merely indicate the general trend of contemporary investigation and thought which grew out of the association movement. Most of this work followed a few definite lines.

1 Association and thought. Mind, I2.

An earlier analysis of the same general type is R. Flint's paper on the role of association in the genesis of moral ideas. Mind, 1875, I. 
The first investigation of association from the experimental standpoint was published in 1879 by FrancIs GaLtoN (I822-I9II) in the second volume of Brain, under the title of 'Psychometric Experiments.' Galton maintains (I) that ideas present themselves to us through association with some object newly perceived or with some idea already before us; (2) that only such associated ideas as are germane to the topic before us become fixed and vivified by attention. His experiments deal with several problems connected with the first of these two points.

Galton's method at first was to allow free play to thought for a brief period of time, and then to direct his attention to the traces of thoughts still lingering. During a walk he observed the objects which presented themselves successively and afterwards endeavored to recall and associate them so far as possible. This part of the experiment brought no striking results.

His next experiment was on reaction time and was the precursor of considerable work in that field. Galton's procedure was to select at random some word written on paper, pressing a stop-watch when the word was perceived. When two other ideas were associated successively with this word the watch was stopped and the time noted. The results showed the rate of association to be 50 words per minute, or $\mathbf{I} .2$ seconds for a single association. ${ }^{1}$

Galton further examined the tendency to repeat the same associations, later called the perseverative tendency. Out of 505 associated words only 289 were different; $33 \%$ of the words used occurred once, $23 \%$ twice, $21 \%$ three times, and $23 \%$ four times. ${ }^{2}$ As regards recency, he found that $39 \%$ of the associations could be traced to boyhood and youth, $46 \%$ to the period of manhood, while only i $5 \%$ were of recent date. ${ }^{3}$
1 Brain, 1879, 2, 153.
2 P. 154 .
3 P. 157. 
Finally, Galton distinguished three distinct sorts of associations: (I) Associations based upon the sound of the word rather than its meaning; (2) Sense-imagery, or ideas aroused by the meaning of the word presented; (3) Histrionic associations, which picture the performance of an action, bringing in the appropriate situations; ${ }^{1}$ the last type includes what we now call kinesthetic elements. Galton closes the paper with remarks emphasizing the nimbleness of thought and the recurrence of the same ideas in trains of thinking. ${ }^{2}$

In Wundt's psychological laboratory at Leipzig the problem of association was taken up quite early. MARTIN TRAUTSCHOLDT published the results of elaborate investigations $^{3}$ in the first volume of Philosophische Studien (1883). The experiments upon which this paper was based were performed in the Leipzig laboratory in 1880 .

Trautscholdt re-examined Galton's problem on the reaction time of association, with much more exact procedure. He made use of the newly devised Hipp chronoscope, which records time in roooths of a second $(\sigma)$. The association reaction time was found to vary between $I 896 \sigma$ and II $54^{\sigma}$ for his four subjects, the association time proper being $706 \sigma$ to $874^{\sigma}$. These figures are remarkably close to Galton's results.

Repeating Galton's investigation upon the recency and recurrence of associations, Trautscholdt found the following:

Repeated: Once Twice Thrice 4 times $\begin{array}{lllll}\text { Dating from childhood and youth } & 13 \% & 7 \% & 9 \% & 10 \% \\ \text { "“ " manhood } & 26 & 5 & 7 & 8 \\ \text { Of recent date } & \text { II } & \text { I } & 3 & 0\end{array}$

1 P. I59.

2 About the same time appeared some papers on association by Solomon Stricker, entitled 'Studien über die Association der Vorstellungen' (1883), which have not been accessible to the present writer.

3 Experimentelle Untersuchungen über die Association der Vorstellungen. 


\section{Effects of Repetition and Lapse of Time}

HeRManN EbBinghaus (1850-1909) investigated in I885 the strength of association as determined by repetition and lapse of time. ${ }^{1}$ To insure the equivalence of all his material he used nonsense syllables instead of words with meanings. The syllables used consisted of two consonants with a vowel sound between. About 2300 different combinations were used, omitting those which form actual words. The syllables were grouped into series of various lengths. In learning any series the syllables were pronounced aloud at a given rate $(0.4 \mathrm{sec}$.) with ictus on every third or fourth. A series was always gone through from start to finish, and each series was repeated over and over till the subject was able to give it correctly on presentation of the first term. The number of repetitions required to learn a series was found to depend upon the number of terms in the series, as follows:

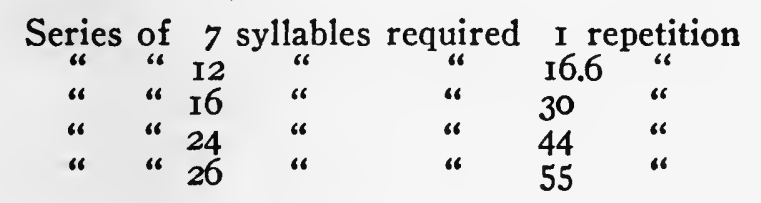

A second problem was the retention of the learning effect. Taking r6-syllable series, Ebbinghaus found that if they had not been previously learned, an average time of 1270 seconds was required for memorizing; if they had been repeated 8 times, then 24 hours later only II 67 seconds were required to memorize,-a saving of IO3 seconds; and for more repetitions a greater saving of learning time was obtained, as follows:

1 'Ueber das Gedächtnis.' 


\section{Number of} repetitions

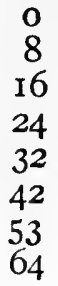

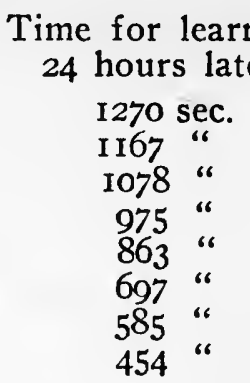

Time saved

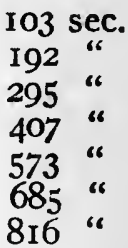

Tests were also made of learning completely the same material on a number of successive days, to determine the saving of time due to the previous practice. The results were as follows:

\begin{tabular}{|c|c|c|c|c|c|c|c|}
\hline In series of 12 syllables a saving of & $5.5 \mathrm{r}$ & & on & 2nd & & & day \\
\hline & 3.5 & “ & 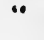 & 3 rd & "• & and & $\because$ \\
\hline & 2.5 & 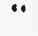 & “ & 4th & "• & 3 rd & $\bullet$ \\
\hline & 2. & "• & $"$ & sth & "• & $4^{\text {th }}$ & •" \\
\hline & 0.5 & “ & 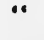 & 6 th & “ & 5th & • \\
\hline In series of 24 syllables a saving of & 21.5 & •• & • & 2nd & • & Ist & $\bullet$ \\
\hline & 10. & “ & $\bullet$ & 3rd & 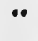 & and & 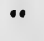 \\
\hline & 5. & •• & "• & ath & •• & $3 \mathrm{rd}$ & " \\
\hline & 3. & “ & $\because$ & 5th & 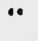 & 4th & “ \\
\hline & I. & “ & $\bullet$ & 6 th & •• & $5^{\text {th }}$ & $\bullet$ \\
\hline In series of 36 syllables a saving of & 32. & "• & •" & and & "• & Ist & •• \\
\hline & 12. & •• & • & 3 rd & •• & 2nd & $"$ \\
\hline & 3.5 & “ & 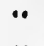 & 4th & 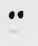 & 3rd & •• \\
\hline & 3. & "• & "• & 5th & "• & 4th & $\bullet$ \\
\hline & I. & 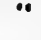 & 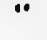 & 6th & " & 5 th & "日 \\
\hline
\end{tabular}

Ebbinghaus's investigations served as model for numerous later researches. They were repeated on a more elaborate scale in 1893 by G. E. MülLER and F. Schumann. ${ }^{1}$ Nonsense syllables were used, as in the earlier experiment; the letters were attached to the surface of a rotating kymograph drum, before which was placed a screen with a slit so that only one syllable was visible at any time. Various conditions of rhythm, attention, and breathing were examined, and variations were introduced in the methods of learning and relearning.

${ }^{1}$ Experimentelle Beiträge zur Lehre des Gedächtnisses. Zsch. $f$. Psychol., 6. 
In 1894 John A. BeRgSTRöm studied the relation of interference to the practice effect of associations. ${ }^{1}$ The material in this experiment consisted of picture-cards, which were to be dealt into piles, each pile to contain cards bearing the same picture. He found that the increase of strength in an association was less marked if other, alternative associations had recently been made with the same stimulus, - that is, if during the practice period different positions were assigned to the various piles. The interference effect, however, wears off with time. The conclusion is reached that the diminished effect of practice is due to the persistence of the earlier associations and not to a fading away of the later associations. The nervous discharge does not drain off into one channel (following the all-or-none law), but tends to radiate out in all directions, the amount being inversely proportional to the resistance.

E. A. KIRKPATRICK investigated the relative strength of visual, auditory, and motor material in recall, and the relation between associative recall and recognition. ${ }^{2}$ The material used consisted of series of 30 disconnected words. Objects were recalled better than written names, and the latter better than spoken names. The power to recognize appeared to be nearly double that of recall.

Another phase of this problem was attacked by ALFRED Jost. $^{3}$ He sought to determine whether, given a certain number of repetitions of the material, the associations are better established by performing them all at the same sitting or by distributing the repetitions over a number of days. The material consisted of nonsense syllables joined in series, the series being learned in various distributions of practice time.

Jost's results indicate that a distribution of the repeti-

1 Amer. J. of Psychol., 6.

2 Experimental study of memory. Psychol. Rev., 1894, I.

3 Die Associationsfestigkeit in ihrer Abhängigkeit von der Verteilung der Wiederholungen. Zsch. f. Psychol., I897, I4. 
tions over a lengthy period is more favorable than concentrating them into one day, but that it is more economical to learn the material as a unit than piecemeal. $\mathrm{He}$ formulates the two following principles, which are known as Jost's Laws:

I. If two associations are of equal strength but of different age, a fresh repetition increases the value of the older more than of the newer.

2. If two associations are of equal strength but of different age, the older decreases less with the course of time.

MARY W. Calkins ${ }^{1}$ compared the relative strength of frequency, vividness, and recency in promoting association. She found differences according as the material is presented through eye or ear. Using visual numerals, frequency predominates, while vividness and recency are about equal; with auditory numerals recency and frequency are most potent and in about equal degrees.

In later experiments ${ }^{2}$ Calkins found that in recalling material which has been serially presented, the first part of the series is most often recalled and the last part has some slight advantage over the middle of the series. She also found far less tendency than Galton had reported to form associations harking back to childhood experiences. Where Galton placed these at $39 \%$, Calkins obtained only I4.7\% with college students and $33.4 \%$ with old and middle-aged persons.

G. E. Müller and A. Pilzecker published in I 900 an elaborate investigation on memory, ${ }^{3}$ using the $\mathrm{Eb}$ binghaus nonsense syllables. The method of right and wrong cases was employed, the syllables being given in pairs. They found that where the number of correct

1 Association. Psychol. Rev., 1894, I; I896, 3. Association. Psychol. Monog., 1896, No. 2, pt. 2.

2 A study of immediate and delayed recall. Psychol. Rev., I898, 5.

3 Experimentelle Beiträge zur Lehre vom Gedächtnis. Zsch. $f$. Psychol., Ergbd. I. 
answers is equal for old associations and those recently learned, the reaction time is longer for the old. Their experiments confirm both of Jost's laws.

The influence of simultaneous association upon the reproductive process and recognition was investigated in I9IO by ERNST MEYER. ${ }^{1}$ His experiments included variations in the number of repetitions of the association, the influence of remoteness, and the effect of retroactive inhibition. Meyer concludes from his results that apperception is facilitated by simultaneous association. Incidentally his results confirm Jost's law that older associations decrease in strength less rapidly than fresh ones.

MARK A. MAY has shown ${ }^{2}$ that the preparatory 'set' of attention exerts considerable influence on the direction taken by association. Some factors in the set are inhibitive, others facilitative. The set may inhibit all but the right (or desired) association, without facilitating the latter. In his experiments the preparatory set shortened the association time on the average from ro to 25 per cent.

HARvey Carr has investigated the progress of animals in learning two alternative motor associations at the same time. ${ }^{3}$ He placed white rats in a maze with two alternative paths, one of which was blocked in any given trial: The rats formed permanent associations in the course of time, even with an interval of 35 seconds between successive trials. In a later study ${ }^{4}$ the path chosen by the rat was blocked in $80 \%$ of the trials, a buzzer signal being given either before or after the animal discovered the error, or simultaneously with the discovery. It was

1 'Ueber die Gesetze der simultanen Assoziation und das Wiedererkennen.'

2 The mechanism of controlled association. Arch. of Psychol., I9I7, No. 37.

3 Length of time interval in successive association. Psychol. Rev., 1919, 26.

4 Carr and Freeman: Time relationships in the formation of associations, Psychol. Rev., I919, 26. 
found after training that the rats had learned to associate the signal with the act of turning, even when the signal had hitherto been given only simultaneously with the turning and was now given before the animal discovered his error. Both investigations indicate a capacity in these animals to form mutually exclusive associations at the same time.

\section{Reaction Time of Association}

Galton's attempt to time the associative process was repeated under more exact laboratory conditions by Wundt's pupils.

James McKeen Cattell carried out in the Leipzig laboratory in 1887 a series of experiments on the reaction time for various mental processes, including perception, recognition, discrimination, and association. ${ }^{1}$ In the association experiments the stimulus consisted of printed words exposed in connection with a timing apparatus. The subject pronounced the first word associated with the stimulus; the lip movement of the response marked the end of the reaction and measured the time automatically. The association time was found to vary within wide limits according to the type of association involved. For one subject the relation of class to member (e.g. river-Rhine) averaged $727 \sigma$; while the relation of whole to part where the objects were exhibited in pictures (e.g. ship-sail) averaged only $358 \sigma^{2}$ In later experiments with untrained subjects much longer association times were found.

TH. ZIEHEN in 1898 found the reaction time of children far longer than that of adults. ${ }^{3}$ Moreover the

1 Experiments on the association of ideas. Mind, $1887,12$.

Psychometrische Untersuchungen. Philos. Studien, 1888, 3, 4.

2 Philos. Studien, I888, 3, 4. (See Table III, infra. p. 248.)

3 Ueber Ideenassoziation des Kindes. Samml. v. Abh. a. d. Geb.d. päd. Psychol. 
time varies in children according to the kind of relationship involved; purely verbal associations are quickest of all.

The reaction times of conscious associations and those without conscious accompaniment were investigated in IgOI by A. MAYer and J. ORTh. ${ }^{1}$ They found that ' unconscious' associations are quicker and occur more frequently.

In the same year the reaction times for various parts of speech and verbal forms and the association of one part of speech with another (e.g. substantive with verbinfinitive) were investigated by Thumb and MARBE. ${ }^{2}$ The same problem was examined more precisely by FrIEDRICH SCHMIDT, ${ }^{3}$ who found that the reaction times for various forms of the verb are longer than for the other parts of speech.

Subsequent investigations of association time have generally been concerned primarily with differences of individual types, which will be discussed presently. ${ }^{4}$ Recently Tolman and JoHnson ${ }^{5}$ studied the effect of feeling tone on association time. They found that unpleasant words used as stimuli tend to lengthen the reaction, while pleasant verbal stimuli tend to shorten it slightly.

\section{Association and Apperception}

WILHELM WUNDT'S (I832-I920) contributions to the investigation of association are exceedingly important, but they are for the most part indirect. He set many

1 Zur qualitativen Untersuchung der Association. Zsch. $f$. Psychol., 26.

2 Experimentelle Untersuchungen über die psychologischen Grundlagen der sprachlichen Analogiebildung.

3 Experimentelle Untersuchungen zur Associationslehre. Zsch. f. Psychol., 1902, 28.

4 Sec. 6 of this chapter.

$5 \mathrm{~A}$ note on association-time and feeling. Amer. J. of Psychol., I9I8, 29. 
experimental problems, which his students worked out. These are mentioned elsewhere in this chapter. Wundt's personal contributions are more difficult to estimate. In his monumental work, the 'Grundzüge' 1 he devotes most of the section on association to the description and discussion of experimental results.

A characteristic feature of his theoretical treatment is the distinction between association and apperceptive connection. The latter he regards as a higher sort of connection, based upon association. In apperceptive connections the 'apperceptive' function operates; a feeling of activity is subjectively present, and the connection is determined (objectively) not merely by the idea aroused, but by the entire previous development of consciousness. Wundt classifies the two types as follows:

Associations

Fusions

Assimilations

Complications

Assimilative Memory Associations

Successive Memory Associations
Apperceptive Connections

(Complex Apperceptions)

Synthetic Apperceptions

Analytic Apperceptions

Synthetic-analytic Apperceptive

Processes

Apperceptive-associative Stream of Thought

Since apperceptive connections rest on association, Wundt holds that all changes of ideas, so far as they are not due to direct sensory stimulation, depend ultimately upon the associative process. ${ }^{2}$

Walter B. Pillsbury in 1897 investigated experimentally the relation between association and the selective process involved in apperception. ${ }^{3}$ The material consisted of typewritten words into which misprints were introduced. He finds that apperception represents a higher intellectual stage than association; but both of

1 'Grundzüge der physiologischen Psychologie' (Ist ed. 1874, 5th ed. I902-3).

2'Grundzüge,' Vol. III. Section on Association.

3 A study of apperception. Amer. J. of Psychol., 8. 
these processes are abstractions. The first concrete manifestation of consciousness appears in assimilation, which completes the process or act of perception. Pillsbury concludes that many forms of intellectual connections which psychologists usually treat as distinct types really involve the same factors. Hence if the prevailing schemes of mental classification are to be retained, they must be justified on other than psychological grounds.

WARNER FITE distinguishes ${ }^{1}$ between association as a physiological process, and apperception as a form of mental activity. "Physiological links cannot bind together psychical states." 2 If we examine the two principles of contiguity and similarity, we find that the former admits of a physiological interpretation, while the latter does not. On the other hand, association by similarity cannot be expressed in any known terms. It is therefore, he concludes, due to the apperceptive function of consciousness.

\section{Mediate Association}

In I889 Hugo MüNSTERBERg (I863-1916) published the first of a series of studies or ' Beiträge', 3 dealing with various points of psychological theory on the basis of laboratory experiments. Münsterberg endeavors in one of these papers to reduce association not merely to contiguity but to actual simultaneity. According to his view apperception consists of a number of simultaneous associations. The association of ideas is always based on these earlier simultaneous occurrences-not upon the succession of experiences.

This hypothesis is supported by an experiment pub-

1 The associational conception of experience. Phil. Rev., 1900, 9. Contiguity and similarity. Ibid.

2 Op. cit., p. 292.

3 'Beiträge zur experimentellen Psychologie.' 
lished later ${ }^{1}$ in which series of letters were presented simultaneously and afterwards reproduced. With series of 7 letters the letters were always reproduced correctly and in the correct order. With longer series errors occurred, especially in the order. The letter-memory test was supplemented by an experiment in mental arithmetic. The errors and transpositions occurring in this work were more numerous, according to Münsterberg, than would have occurred if it had been possible to associate the material successively. This raised the problem, for some time warmly debated, as to the existence of 'mediate' association,- that is, whether mental data may be linked together through unconscious terms.

In a later study ${ }^{2}$ Münsterberg finds no evidence of association by means of unconscious mediating terms. But between the onset of an external stimulus and the resulting central excitation there is an unconscious interval in which intensifications and inhibitions based on associated simultaneous excitations may be as effective as though they were conscious. His observations indicate that there is no fundamental difference between a perceptual process of this sort and its ideational reproduction.

EDWARD W. SCRIPTURE arrived at the opposite conclusion from Münsterberg in an investigation conducted in the Leipzig laboratory and published in $1891-2 .^{3}$ Scripture exposed series of cards, on some of which were printed a German word and a Japanese word in Japanese script. To each of these cards corresponded another card containing the same Japanese script and a Japanese word in Latin letters. The cards were shown in order, first one series, then the other. Afterwards one of the words in

${ }_{1}^{1}$ Die Association successiver Vorstellungen. Zsch. f. Psychol., $1890, \mathbf{r}$.

2 'Beiträge zur exper. Psychologie,' I892, Heft 4.

3 Ueber den associativen Verlauf der Vorstellungen. Philos. Studien, 7 . 
Latin letters (either German or Japanese) was shown without the Japanese script, and the subject was instructed to mention the word which occurred to him in association with it. In many cases the correct word of the other series was mentioned. Since the subjects were unfamiliar with the Japanese script, Scripture concludes that the associations are effected by means of an unconscious mediating term. He states the principle that an unconscious mediating element (i.e. one not perceived) may have sufficient strength to produce later a conscious recollection of the experience of which it formed part. ${ }^{1}$

The problem of mediate association was re-examined in 1894 by William G. SMith ${ }^{2}$ in the Leipzig laboratory. Both words and nonsense material were used, each single word or group of letters being shown on a separate card with some symbol which was to furnish the basis for a mediating association. The author finds no satisfactory evidence for mediate association in his own results, though admitting the possibility of the process under other experimental conditions.

Another investigation of the same problem was reported about the same time by $\mathrm{H}$. C. HowE, ${ }^{3}$ one of Titchener's students. In this study two sorts of material were used: (I) auditory presentation of words associated in pairs with nonsense syllables; (2) visual presentation of words associated with colored patterns. Here again the results do not confirm the hypothesis of mediate associations, only one case being noted in 557 auditory tests and two or three only in $96 \mathrm{I}$ visual, which is well within the limits of chance.

WUNDT, summing up the evidence in $1894,{ }^{4}$ accepts

1 P. 135.

2 'Zur Frage der mittelbaren Association.'

Mediate association. Mind, N. S., 3.

3 'Mediate' Association. Amer. J. of Psychol., I894, 6.

4 Sind die Mitglieder einer mittelbaren Association bewusst oder unbewusst? Philos. Stud., ro. 
the doctrine of mediate association, but concludes that the mediating factors are always present in consciousnessthey are always at least dimly perceived.

Gustav Aschaffenburg, in a series of experiments extending over several years, ${ }^{1}$ finds traces of mediate associations, or associations in which the mediating term is vague and becomes conscious only later. His experiments show that associations of this type are quite rare; however.

Mediate association was investigated again in rgor by G. CoRdes. ${ }^{2}$ The material consisted of cards with printed words. His results bring out a distinction between (I) ideas immediately aroused and (2) ideas aroused through association with these. If the latter are complex, so that part of (I) is also part of (2), we have an apparently mediated association. Hence he concludes that mediate association is merely a special case of a two-term association.

HENRI PIÉRON in 1903 reviews the previous work on the subject ${ }^{3}$ and concludes that the reported experiments, which may easily be verified, seem to demonstrate the occurrence of mediate association.

FrIEDRICH KIESOW, experimenting on ' free' associations in $1905,{ }^{4}$ finds reason to believe that the mediating factors are not unconscious but are merely unobservedthat is, not attended to.

Some of the fundamental problems of association were re-examined experimentally in I9I 2 by FRANZ NAGEL. ${ }^{5}$ His results lead him to deny the existence of mediate

1 Experimentelle Studien über Association. Psychol. Arb., 1895, I ; I897, 2 ; I902, 4. I7.

2 Experimentelle Untersuchungen über Association. Philos. Stud.,

3 Association médiate. Rev. philos., 56.

4 Ueber sogenannte 'frei steigende" Vorstellungen. Arch. f. d. ges. Psychol., 6.

5 Experimentelle Untersuchungen über Grundfragen der Assoziationslehre. Arch. f. d. ges. Psychol., 23. 
association. The problem is still unsettled; it seems to involve a question of interpreting the notion of 'mediation.'

\section{Association Tests and Mental Diagnosis}

The association of ideas found practical applications in abnormal psychology and criminology. Attempts were made to differentiate types of insanity by the types of association which they yield and the length of association time. It was further sought to determine whether an accused person had guilty knowledge of a crime, by the length of association time in the case of certain leading or significant words, and by the kind of associations made with these words as compared with the associations following non-significant stimulus words.

The first work in this direction seems to have been that of EMIL KRAEPELIN, who in I 883 published a paper on the significance of associations in mental disease. ${ }^{1}$ Two other early papers by Kraepelin may be referred to here-one on the effect of practice upon the duration of associations, ${ }^{2}$ the other on the effect of drugs upon simple mental processes. ${ }^{3}$

The earliest systematic contribution to diagnostic association tests seems to have been an investigation in 1900 by ARTHur Wreschner, ${ }^{4}$ on the associations of a feebleminded patient.

A study of Frances A. KeLLOR, ${ }^{5}$ which appeared in rgor, showed that the range of ideas in criminals is much smaller than in normal individuals, and that logical con-

1 'Experimentelle Studien über Associationen.'

2 'Ueber den Einfluss der Uebung auf die Dauer von Associationen,' I889.

3 'Ueber die Beeinflussung einfacher psychischer Vorgänge durch einige Arzneimittel,' I892.

${ }^{4}$ Eine experimentelle Studie über die Association in einem Falle von Idiotie. Allg. Zsch. f. Psychiat., 57.

5 The association of ideas. Ped. Sem., 8. 
nections are less frequent. W. voN BEcHTEREW reported in 1903 certain experiments on criminals. ${ }^{1}$

The diagnostic value of association in cases of mental disorder was examined exhaustively in a series of researches by C. G. Jung and his co-workers, E. BLEULER, FR. RICKLIN, and others. ${ }^{2}$ Jung and Ricklin first studied the normal course of association, determining the relative number of associations of each type, the tendency to perseveration (repetition of the same association), egocentric tendencies, predilection for certain grammatical forms, etc. These normal results were compared by WEHRLIN with the associations of imbeciles and idiots, which were found to consist in the main of very rudimentary and primitive types. Many associations were merely crude illustrations or cases of far-fetched superordination.

Jung examined an epileptic and found his associations similar in some points to the normal, in others to the subnormal type. In normal individuals it was found that the quality of the stimulus word exerts a marked influence upon the reaction time of association. Words which arouse an intensive feeling-tone in the subject require a longer time to complete the association.

A later paper of the series discusses the relation of the association process to consciousness. Bleuler insists upon the importance of subconsciousness in mental life. The study of unconscious processes he asserts to be especially useful in psychopathology, where they indicate symptoms of a fundamental character. Most brain processes, he says, are void of consciousness. Only those attain consciousness which are functionally connected (associated) with the Self. ${ }^{3}$

1 Experimentell-psychologische Untersuchung von Verbrecher. J. f. Psychol. u. Neurol., 2.

2 Diagnostische Associationsstudien. J. f. Psychol. u. Neurol., I904, 3, 4; 1905, 5, 6; I906, 7, 8; 1907, 9, 10, II; 1910, I6.

3 A general summary in English of this work is given by Jung in Amer. J. of Psychol., 1910, 21. 
The diagnosis of specific situations by association tests was investigated by MAX WERTHEIMER ${ }^{1}$ in I904 and 1905. The problem was to determine experimentally, if possible, whether a certain fact is known or unknown to the individual examined. Supposing, for instance, that a burglary has been committed and several suspected persons are apprehended, can we determine by differences in their associative reactions which of them possess information vitally connected with the crime-such as the interior arrangement of the building, or known details of the robbery?

In the experiment certain of the subjects were shown a picture representing the locality of the 'crime.' They were told to examine the picture carefully, familiarize themselves with it, and in the ensuing association tests to endeavor to conceal their knowledge of the scene. A second group of subjects were similarly treated with another scene radically different from the first. The test consisted of (I) a series of non-significant stimulus words, (2) a series significant of that one of the two scenes with which the subject was not acquainted, (3) a series significant of the scene which the subject had studied, (4) another 'normal' series. The words used in series 2 with one group of subjects were used in series 3 with the other group, so that in every case the words significant of the knowledge which it was sought to conceal followed those pertaining to the unknown. scene. In this way the ' unknown' and 'known' associations of the two groups of subjects were open to mutual comparison. The associations were free; the stimulus words were printed on cards and given short exposures, the association times being measured with a Hipp chronoscope.

The results for 6 subjects showed in every case a longer

${ }^{1}$ Psychologische Tatbestandsdiagnostik. (With J. Klein.) Arch. f. Kriminalanthrop., 1904, 15.

Experimentelle Untersuchungen zur Tatbestandsdiagnostik. Arch. f. d. ges. Psychol., 1905, 6. 
reaction time for the 'known' than for the 'unknown' material-the difference in 3 subjects amounting to nearly $50 \%$. The associated words also showed characteristic differences. In the series containing significant words there were more frequently meaningless associations, perseverations, and significant responses to non-significant stimulus words.

Numerous investigations have since been made on the diagnostic significance of association. W. STERN published a series of papers ${ }^{1}$ by himself and his pupils on the psychology of testimony. YERKES and BERRY, experimenting in the Harvard laboratory, ${ }^{2}$ found a marked shortening of reaction time for 'significant' stimulus words.

In I909 A. WIMmer sought to differentiate feebleminded from normal children on the basis of the type of their associative responses. ${ }^{3}$ He found that among normal children the characteristic types of response are concrete images and memories, while among the feebleminded responses of the memory type rarely appear and those of the indeterminate or symbolic type are most frequent.

R. R. RusK ${ }^{4}$ confirms Wreschner's findings that the speed of association bears no relation to age and has little value as a criterion of intelligence. He finds, however, that the degree of perseveration, or persistent repetition of the same response, varies inversely with age and also with intelligence.

A standardized test for differentiating the insane from the normal was devised in I9IO by KENT and RosANOFF. ${ }^{5}$

1 'Beiträge zur Psychologie der Aussage,' 1903-6.

2 Association reaction method of mental diagnosis. Amer. J. of Psychol., 1909, 20.

3 Ueber Assoziationsuntersuchungen besonders schwachsinniger Kinder. Monat. f. Psychiat. u. Neurol., 25.

4 Experiments on mental association in children. Brit. J. of Psychol., 3.

5 Study of association in insanity. Amer. J. of Insan., 67. 
It consists of 100 selected stimulus words. Applying the test they found that normal subjects tend to give one or other of a small group of common reactions. In some cases insane patients gave $50 \%$ of individual responses. The total results showed an average of $6.8 \%$ individual results for normal persons and $26.8 \%$ for the insane.

The same problem was taken up in I9I I by LAY and MenzeRATH, ${ }^{1}$ who found characteristic differences in the associative responses for each psychopathic type.

The Kent-Rosanoff test-words have been used in many investigations. EASTMAN and Rosanoff applied them to the diagnosis of mental retardation, ${ }^{2}$ and found that the responses of the feeble-minded are characterized especially by (I) frequent failures to give any reaction whatever; (2) an excess of non-specific reactions; (3) prevalence of certain types of individual reactions. The RoSANOFFS ${ }^{3}$ later applied the same tests to normal children, who were found to have more individual reactions than adults and more failures to react at all. They conclude that a definite correlation exists between association and mental capacity. These results have been confirmed by Woodrow and Lowel.. ${ }^{4}$ Finally, Mitchell and the ROSANOFFS ${ }^{5}$ compared the types of reactions in negro and white children and noted in the negroes a further departure from the (white) adult standard than among white children.

F. Lyman Wells used the Kent-Rosanoff tests in examining the general characteristics of free associations. ${ }^{6}$

1 'L'étude expérimentale de l'association des idées dans les maladies mentales.'

2 Association in feeble-minded and delinquent children. Amer. J. of Insan., 1912, 69.

3 A study of association in children. Psychol. Rev., I9r3, 20.

4 Children's association frequency tables. Psychol. Monog., I9I7 (No. 97). 26.

5 A study of association in negro children. Psychol. Rev., 1919,

${ }^{6}$ Articles in Psychol. Rev., I9I1, 1912, I919 (see Bibliography, pp. 316-17). 
He found that a certain range of reaction time appears typical of any given individual. His normal subjects showed two contrasted types of temperament, distinguished by marked differences in reaction. He found also characteristic differences among psychotic patients.

The Kent-Rosanoff tests have been extended by WooDWORTH and WELLs. ${ }^{1}$ A number of other association tests either new or elaborated are reported in the same monograph. Among them are cancellation tests, addition tests, subtraction tests, opposites tests, and directions tests.

MABEL V. LoRING carried out an investigation ${ }^{2}$ on types of response with a list of 10,888 stimulus words of various lengths and including various parts of speech. She found that in English the adjective-noun association gives a shorter reaction time than the noun-adjective; the time increases with length of stimulus word.

H. HUBER ${ }^{3}$ compared the responses of educated with those of uneducated persons, and men with women; he observed in each case some difference in association types. There are also differences according as the stimulus is presented visually or auditorily.

Arthur H. SutherLand re-examined the problem of medico-legal diagnosis by association in $1913 .{ }^{4}$ He questions the diagnostic value of free association tests so far as they have been worked out at present. In his opinion the results obtained from their use should be regarded as suggestive but not conclusive. Failures to react are due to a large number of factors; sex traumata may be one factor, but they are not the source of variability. More valuable for practical purposes than single reactions, he believes, is the study of association trains.

1 Association tests. Psychol. Monog., I9II (No. 57).

2 Methods of studying controlled word associations. Psychobiol., I9I8, $\mathrm{I}$.

3 J. f. Psychol. u. Neurol., 1918, 23.

4 'Critique of word association reactions.' 
A similar conclusion is reached by $\mathrm{H}$. W. Crane, ${ }^{1}$ who re-examined the applications of the association-time method to the determination of guilty knowledge of crimes. His results, based on an extensive research, are wholly negative.

\section{Miscellaneous Investigations}

E. TANZI reported ${ }^{2}$ in 1888 some instances of association occurring within his own experience, which led him to accept the traditional association view. He follows James Mill in reducing mental data to sensation plus association.

In the same year the problem of mental synthesis was examined by Fr. PAULHan. ${ }^{3}$ In every compound mental state there is something which is lacking in its elementsnamely, the order of these elements, their mutual relations, and the general results which follow from these relations. Neither similarity nor contiguity can explain mental activity. The association doctrine, therefore, is insufficient to explain the growth of mind; it must be supplemented by a more fundamental process-organization. The law of system or orderly synthesis, according to Paulhan, is a primary factor in mental development.

In I889 J. ANDRADE examined the role of association in the formation of abstract ideas. ${ }^{4}$ He concludes that the underlying concepts of mechanics are built up by association of ideas; but once formed, these ideas go beyond their subjective origin and become the foundation of metaphysics.

ROBERT ARDIGò, following Tanzi, treats association as

1 A study in association reaction and reaction results. Psychol. Monog., 1915, 18 (No. 80).

2 'Intorno all'associazione delle idee. Riv. di filos. scient., 7.

3 L'associationisme et. la synthèse psychique. Rev. philos., 25.

4 Du rôle de l'association des idées dans la formation des concepts métaphysiques du mécanisme. Rev. de mét., 7 . 
a species of physiological process. ${ }^{1}$ Mental dynamics is the source of the association of ideas. No sensation or representation is simple and lasting. All representations are constantly undergoing change. The associative process has three modes: (I) A sense of need which may result in voluntary satisfaction. (2) A physiological operation which leads to satisfaction without voluntary activity. (3) A morbid persistency or tension which leads to activity. Ardigò emphasizes the active factor in association. Integration is regarded as merely a byproduct of the operation.

The experimental investigation of association was inaugurated in France by B. BouRDON. In a preliminary discussion $^{2}$ he points out that the classical theories of association have relied too much upon subjective analyses; psychologists have not sufficiently examined the nature of the association phenomenon itself. He suggests the term société des phénomènes, which emphasizes the English use of the word 'association' in the sociological sense. A society, or social grouping, depends upon resemblance; the most important sort of similarity in the social realm is similarity in quality.

Bourdon followed this in 1893 with an elaborate experimental investigation, ${ }^{3}$ which seems to have been planned independently of the researches mentioned in earlier sections of this chapter. Using the method of free association, a word was pronounced by the experimenter and the successively aroused associations were recorded. The results were examined with a view to determining the relative frequency of different kinds of association, the degree of persistence (perseveration) of

1 Lo sforzo associative e la dinamica mentale. Riv. di filos. scient., $1889,8$.

2 Les résultats des théories contemporaines sur l'association des idées. Rev. philos., 1891, 31 .

3 Recherches sur la succession des phénomènes psychologiques. Rev. philos., 35 . 
specific associations, the homogeneity of the material, and other characteristics. In a later investigation ${ }^{1}$ Bourdon examined the relation between recognition, discrimination, and association, and reached the conclusion that the processes of recognition and association are more closely related to each other than either of them is related to discrimination.

While most recent discussions of association have been confined to cognitive material, Georges Dumas applied the concept in I89I to emotions. ${ }^{2}$ Accepting the general view of the association school, he regards the associative process as a tendency rather than a dynamic factor. In emotional phenomena this tendency holds, though the relation is not of the logical or syllogistic type.

In I894 JOSEPH JASTROW investigated the community of associations among different individuals. ${ }^{3}$ A word was written on the blackboard and shown to a class of students, who were instructed to write the first 5 words which occurred in association with it. Jastrow found considerable uniformity in the first association and an increasing variety in the later terms of each series. He found no appreciable differences in association between men and women, except a tendency to different types of association.

Theodate L. Smith investigated in 1896 the influence of motor factors on association. ${ }^{4}$ In one series of experiments nonsense syllables were used, but the subject was required to count aloud during their exposure, in order to eliminate contractions of throat and mouth muscles corresponding to the syllable. In another series the material consisted of the printed characters of the deaf-mute alphabet. Here the subject was required to

1 Observations comparatives sur la reconnaissance, la discrimination et l'association. Rev. philos., I $895,40$.

${ }^{2}$ L'association des idées dans les passions. Rev. philos., $3 \mathbf{I}$.

3 Community and association of ideas. Psychol. Rev., I.

4 On muscular memory. Amer. J. of Psychol., 7. 
reproduce the positions of the hand for each letter (so far as he was able) at the end of each series of 5 or ro letters.

No general quantitative results were obtained, but incidentally a striking fact was brought out. The nonsense syllables were exposed not successively but in groups of Io, each group being exposed for 20 seconds. The subjects were allowed to use their own method of learning. It was found that those who 'studied' each syllable before proceeding to the next, and perused the series through only once, were freer from errors than those who read the series through several times, the errors increasing with the number of 'perusals.'

Reference should be made here to WIIFRED LAY's monograph on 'Mental Imagery,' ' which emphasizes the role of association in arousing images. Also to an incidental result of CALKINs's investigation, ${ }^{2}$ which indicates a tendency of the mind to group unconnected stimuli in one way or another. "Fully three-tenths of the images [obtained in the experiments] are fairly forced into some sort of relation." 3

In I900 E. HALÉVY, using the a priori method of analysis, compared the sensationistic and intellectualistic interpretations of psychology. Associationism, the most widely accepted form of sensationism, is based on two varieties of data: (I) states of consciousness, whose elements are sensations, and (2) the laws of association of ideas. These fundamental hypotheses Halévy finds to be mutually contradictory, which leaves the presumption in favor of intellectualism.

A monograph by AMY E. TANNER ${ }^{5}$ is of special interest

1 Psychol. Monog., 1898 (No. 7).

2 Memory and association. Psychol. Rev., I898, 5.

3 P. 460.

4 De l'association des idées. Bibl. du Congrès int. de philos., Sec. I.

5 'Association of ideas,' 1900. 
as presenting the attitude of the 'functional' psychology toward the association process. She regards images not as 'entities' but as taking form (or growing) out of a shapeless mass. Association from this standpoint is not a joining together of static, structural data, but a functional or formative process.

This view was developed as the result of an elaborate experiment in which Miss Tanner acted as subject. She set out to make abstracts of the courses in her high-school curriculum, most of which were in branches that had not been studied since her school days. The material offered a set of data which had not been learned originally with any reference to the present problem, and which were now revived after a lapse of several years. The nature of the revival and of the association process was studied as the experiment progressed. The results indicate that associations grow up gradually; in the first stage their character is indefinite.

Alfred Binet (I857-I9II), on the basis of experiments performed on two children, ${ }^{1}$ finds instances of sudden and complete breaks in trains of thought, which the laws of association do not account for. This injection of a new 'theme' into consciousness he believes to be due to an unconscious directing and organizing force in our mental constitution, comparable to "the vital force which directs the physicochemical properties, molds the form of beings, and guides their evolution." 2

The associations involved in the simple arithmetical processes were investigated in 1906 by CHARLES $\mathrm{E}$. BROWNE. ${ }^{3}$ In multiplication the associations were found to be largely of the motor and auditory types. Subtraction operates through the same associative laws that are effective in addition, which are derived in turn from the

1 'L'étude expérimentale de l'intelligence,' 1903.

2 P. 108.

3 Psychology of the simple arithmetical processes. Amer. J. of Psychol., I7. 
conditions of counting. Division depends upon multiplication, but tends to free itself from this basis and to develop a specialized type of immediate association.

ARTHUR WREschner made an exhaustive experimental study of several problems of association during the years r900-1903 (published as a monograph, 1907-r909). ${ }^{1} \mathrm{He}$ defines association as the causal process by which one experience is reproduced through another. The question of the relation of consciousness to association is thus avoided.

Wreschner's experiments deal with such problems as (I) the influence of the form and control of the stimulus word upon the time of reaction, (2) individual differences in reaction time, (3) response by repetition of stimulus word and perseverative associations (repetition of earlier responses), (4) identical responses by different subjects, (5) effect of different modes of presenting the stimulus, (6) effects of practice on association. His results are too detailed to be discussed here. Wreschner's classification of association types is given later in this chapter. ${ }^{2}$

SHEPARD and FogelSANGER ${ }^{3}$ find cases of inhibited associations which are apparently not explicable on theories of drainage or division of the nerve impulse. The inhibition seems due to the mutual interference of two simultaneous impulses. The authors conclude that inhibition is a more important factor in all association than is generally realized.

The phenomenon of perseveration has been re-investigated by William S. Foster. ${ }^{4}$ He challenges the view that the recurrence of a former response is due solely to the fact of the idea having once before been present in consciousness. This would imply a spontaneous recur-

1 Die Reproduktion und Assoziation von Vorstellungen. Zsch. f. Psychol., Ergbd. 3.

2 P. 255.

3 Studies in association and inhibition. Psychol. Rev., I913, 20.

4 On the perseverative tendency. Amer. J. of Psychol., I9I4, 25. 
rence of mental content. There is, he concludes, no spontaneous activity in the nervous system.

\section{Laws of Association: Similarity and Contiguity}

The classic laws of similarity and contiguity have been submitted to experimental study. This new mode of treatment was forecast by WILLIAM JAMES in a critical and constructive article ${ }^{1}$ published in 1880 , which emphasizes the physiological factor in association. James points out that the historic association school and the Herbartian movement, while differing in theoretical basis, agree in almost every other respect in their interpretation of association. Thought, according to both schools, works under mechanical conditions. These conditions determine the order in which the mental content is presented. James himself accepts this view. He reduces the laws of contiguity and similarity to one: complete association by contiguity. The quantitative laws he increases to four: habit, recency, vividness, and emotional congruity. These laws explain the reason why one representation rather than another appears at a given time in consciousness. The arousal of the associated thought depends in every case upon the activity of adjacent nerve tracts. This physiological interpretation is maintained in James's 'Principles of Psychology,' ${ }^{2}$ which appeared ten years later.

By way of contrast may be mentioned an article by V. BROCHARD ${ }^{3}$ which also appeared in 1880 . Brochard distinguishes between two types of association: (I) Mechanical connection, based upon contiguity, which is prevalent in animals. (2) Perception of resemblances, which operates only in man.

1 The association of ideas. Pop. Sci. Mo., 16.

2 Ch. I4.

${ }^{3} \mathrm{La}$ loi de similarité dans l'association des idées. Rev. philos., 9. 
JAMEs WARD in his Britannica article, ${ }^{1}$ which was written in $1884-5$ and appeared in 1886 , reduces the two forms of association to contiguity, since similarity means identical elements in different settings. The fundamental problem, according to Ward, is how the new complex of presentations was integrated in the first place. This integration he explains by movements of the attention, which depend first on intensity and finally on interest. Thus in the last analysis the associative process reduces to successive contiguity.

Having limited the scope of association in this way, Ward finds the need of another term to denote the more fundamental operation which is traditionally known as association. In a later discussion ${ }^{2}$ he proposes the term assimilation for this broader process. Assimilation he regards as the 'fusing' process which occurs in all association. Assimilation may occur among presentations even when there is no contiguity between them-when therefore no association can take place.

J. MaRK BaLdwIN distinguished in I 889 between the laws and forms of association. ${ }^{3}$ The primary law of association is correlation; the secondary laws are contiguity and resemblance. Baldwin discusses the two forms of association (coexistence and succession), and finds that coexistence, or simultaneous occurrence, is a condition of the presented objects, not of the resulting experiences. Hence, succession is the one true form of contiguous reproduction.

ALFRED LeHMANN conducted an experimental investigation ${ }^{4}$ in $1888-9$, designed to determine whether resemblance or contiguity is the real basis of association. The experiments were concerned with the recognition of the pitch of musical tones. From the results obtained he

1 Article 'Psychology,' Encyclopedia Britannica, 9th ed., Vol. XX.

2 Assimilation and association. Mind, N. S., 1893, 2 ; 1894, 3.

3 ' Senses and Intellect.'

4 Ueber Wiedererkennen. Philos. Stud., 5. 
concludes that contiguity is the more fundamental mode; resemblance furnishes only a 'formal' sort of association.

HaROLd HöFfding disputes Lehmann's conclusions. ${ }^{1}$ Recognition, or identification of presentations, he claims, depends upon association by similarity. The transition is not through identical but through similar elements. The fundamental law of association is the part-whole relationship.

Ch. Dumont seeks to reduce contiguous association to resemblance, and at the same time to demonstrate that the converse reduction is impossible. His discussion, ${ }^{2}$ which appeared in I895, deals chiefly with abstract notions and relies on the method of $a$ priori dialectics. It is cited by way of contrast to the empirical method which was gradually becoming prevalent.

ARThur Allin, ${ }^{3}$ by the method of exclusion, makes contiguity the fundamental type of association. After an examination of perception he rejects the 'recognition' theory of perception, which rests on association by similarity. He concludes that resemblance is not a true mode of association. He also denies Helmholtz's view that perception is an unconscious inference, and reduces apperception to a specialized sort of perception, which arises through the activity of interest, attention (Aufmerken), and observation (Bemerken).

EDMOND GoBLOT ${ }^{4}$ also considers contiguity the primary form, but suggests that the term contiguity is open to misapprehension since it emphasizes spatial nearness. The fundamental fact of association, actually, is temporal proximity. Association by resemblance may be reduced

1 Ueber Wiedererkennen, Association und psychische Activität. Vjsch.f. wiss. Philos., I889, 13; 1890, 14.

${ }_{2}$ De la ressemblance et de la contiguité dans l'association des idées. Rev. de mét., 3.

3 'Ueber das Grundprincip der Association,' 1895. 46.

${ }^{4}$ Sur la théorie physiologique de l'association. Rev. philas., 1898, 
to temporal contiguity, which suggests the possibility of a strictly physiological explanation of association.

KARL Deffner, ${ }^{1}$ a pupil and follower of Lipps, divides associations into two sorts: association by similarity and experiential (habitual) association. Association by similarity he regards as the more important type. He believes association to be the cause of the sequence of ideasnot merely the manner in which they follow one another. It is a natural characteristic of mind to pass from one excitation to a similar excitation. Thus association is to be interpreted as a mental power or psychical disposition.

Theodor ZIEHeN, on the other hand, experimenting on children, finds no clear evidence of association by resemblance. $^{2}$ The connection is frequently through certain common parts of the ideas, whereupon the remainder is recalled through contiguity.

Edward B. Titchener in his ' Outline of Psychology,' published in 1896, regards the fundamental classes of associations as (I) simultaneous and (2) successive. The traditional laws of association are only forms of association. Actually the ideas themselves do not associate, but only the elementary processes of which they are composed. In his 'Textbook' ${ }^{3}$ he points out that the elements of a perception may never have been together in consciousness before, while in the case of an associated idea the elements have already many habitual connections. There is no essential difference between an idea and an association of ideas; but practically our ideas come to us ready-made, while our associations may be frequently new.

Of the two sorts of association Titchener considers

1 Die Aehnlichkeitsassociation. Zsch. f. Psychol., 1898, I8.

2 Ueber Ideenassoziation des Kindes. Samml. v. Abh. a. d. Geb. d. päd. Psychol., I8g8, r, pt. 6; 1900, 3, pt. 4, p. 63.

3 'Textbook of Psychology,' I9I0, p. 390. 
simultaneity by far the more important. This is emphasized in his statement of the general law of association: "Whenever a sensory or imaginal process occurs in consciousness, there are likely to appear with it (of course in imaginal terms) all those sensory and imaginal processes which occurred together with it in any earlier conscious present." 1 Titchener lays special emphasis on the functions of clearness and attention in association.

In a series of experiments published in $1910,{ }^{2} \mathrm{WIL}-$ Helm Peters examined associations of similarity by means of reaction time, repetition of stimulus, etc. $\mathrm{He}$ finds that association according to similarity is not due to awareness of the similarity. It is due rather to the partial perseveration of the reproduced perception. This perseverative tendency radiates out and brings about the reproduction of partly similar ideas in the neighboring reproductive material.

Marcel Foucault ${ }^{3}$ investigated the problem by the use of both nonsense syllables and words. He reaches the conclusion that contiguity alone creates new associative bonds between experiences.

A. WoHLGEMUTH ${ }^{4}$ objects to the employment of verbal material in these investigations, since it emphasizes succession over simultaneity. His material consisted of colors and figures of different shapes. He concludes that all associations are due to simultaneous occurrence of the two experiences or simultaneity of the second experience with the after-sensation of the earlier. The more the members of a group are apperceived as a whole, the stronger is their association with one another.

1 'Text-book,' p. 378 .

2 'Ueber Aehnlichkeitsassociation.'

3 Etude expér. sur l'assoc. de reassemblance. Arch. de Psychol., I9II, IO.

${ }^{4}$ Simultaneous and successive association. Brit. J. of Psychol. I9I5, 7. 
On the other hand, Sven Froeberg presents results ${ }^{1}$ which indicate that simultaneity is not necessary for association. An association may be formed between two experiences of which the first has passed out of consciousness before the second appears.

Some slight departures from the traditional conception of association should be noted. Henri PIÉRon formulates a fundamental law of association, ${ }^{2}$ in which system and repetition serve as criteria instead of contiguity: "Two states which have coexisted in consciousness so as to form two parts of the same systematic grouping, tend to attract each other, so as to form an analogous grouping, whose strength is greater according as the former grouping was more coherent and according as these states have been more frequently united in the same system."

W. Poppelreuter ${ }^{3}$ views retention as due to a series of registers, the first being in the receptor, the next in the primary center, and so on. He believes that the immediate basis of reproduction lies not in the sensation or its after-effects but in the apprehension (Auffassung) of these registered data. The laws of association, accordingly, are really laws of apprehension.

WALTER S. HUNTER ${ }^{4}$ calls attention to the fact that association not only gives rise to ideas and images, but may often arouse experiences in a sensory form-a phenomenon denied by earlier psychologists from Hartley on. He restates the principle of association as follows: "If $\mathrm{A}$ and $\mathrm{B}$ are experienced together in space or time, and if later one is experienced either in sensory or in

1 Simultaneous vs. successive association. Psychol. Rev., I9I8, 25.

$2 \mathrm{La}$ conception générale de l'association, etc. Rev. philos., 1904, 57.

3 Versuch einer Revision der psychophysiologischen Leh"e von der elementaren Assoziation u. Reproduktion. Monat. f. Psychiat. u. Neur., 191 5, 37 .

4 A reformulation of the law of association. Psychol. Rev., 1917, 24. 
imaginal form, it tends to arouse the other either in sensory or in imaginal form." 1

\section{Classifications of Association}

A number of schemes for classifying the various types of association have been suggested as a result of the experimental investigations of the problem.

The earliest was published in 1883 , by MarTIN Trautscholdt, ${ }^{2}$ a pupil of Wundt's, and has been adopted by the latter in successive editions of the 'Grundzüge.' (See Table I.)

An elaboration of the historic classification, proposed in $\mathrm{I} 885$ by $\mathrm{R}$. WAHLE, ${ }^{3}$ should be mentioned here, though not based on experimental work. He divides contiguous associations into six classes, with resemblance forming a seventh, and an eighth class (contrast) which is a mixture of the two. (Table II.)

Catteli and Bryant ${ }^{4}$ devised a scheme of classification in 1889 , based on Cattell's experiments mentioned above; the authors indicate at the same time the relative frequency of each kind of association. (Table III.) The first figure in each case represents the percentage of the given type of association when the stimulus word is a concrete noun. The second figure is the percentage for associations where the stimuli are abstract nouns. In a few cases no association whatever was made, or the word was misunderstood, or the nature of the relation is not evident. It appears that concrete nouns give rise more frequently to objective than to logical associations (5I: 46); while with abstract nouns logical associations

1 P. 190.

2 Experimentelle Untersuchungen über die Association der Vorstellungen. Philos. Stud., I.

${ }^{3}$ Bemerkungen zur Beschreibung und Eintheilung der Ideenassociation. $V j s c h . f$. wiss. Philos., 9.

$\checkmark$ Mental association investigated by experiment. Mind, I4. 
TABLE I.-TRAUTSCHOLDT, $1883^{1}$

I. External

A. Simultaneous $\left\{\begin{array}{l}\text { I. Part-Whole }\left\{\begin{array}{l}\text { a. Assoc. of Whole to Part } \\ \text { b. Assoc. of Part to Whole } \\ \text { c. Assoc. of Parts }\end{array}\right. \\ \text { 2. Assoc. of Independent Ideas }\end{array}\right.$

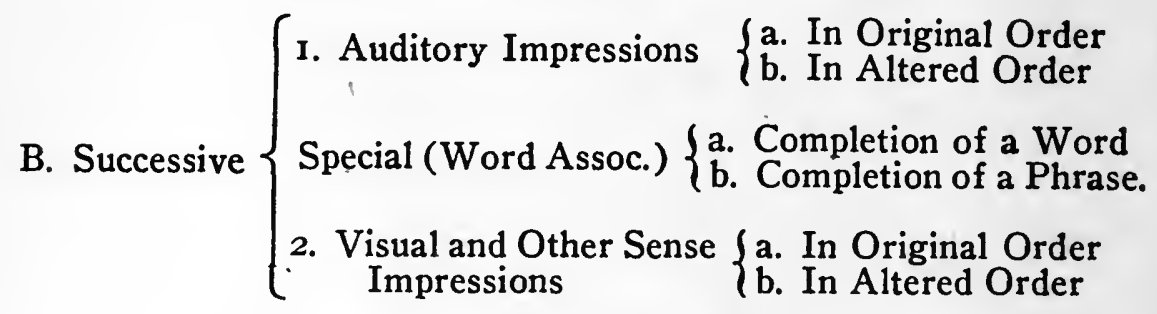

II. Internal

I. Superordination and Subordination $\left\{\begin{array}{l}\text { a. Assoc. of More General } \\ \text { b. Assoc. of More Specific }\end{array}\right.$

2. Coordination $\left\{\begin{array}{l}\text { a. Assoc. of Similar Impressions } \\ \text { b. Assoc. of Contrasted Impressions }\end{array}\right.$

3. Relations of Dependence $\left\{\begin{array}{l}\text { a. Casuality } \\ \text { b. Finality (Purpose or End) }\end{array}\right.$

TABLE II.-WAHLE, I $885^{2}$
I. Simultaneity
2. Immediate Succession
5. Whole-Part Relationship
3. Contiguity in Space
4. "In Same Place"
6. Causality, Finality, etc.
7. Resemblance
8. Contrast

are vastly preponderant $(80: 6)$. Associations attached to proper names are much the same as associations to concrete nouns, while associations to verbs and adjectives agree substantially with associations to abstract nouns.

Three different schemes of classification proposed in r 892 are shown in tables IV-VI. OFFner holds that successive ideas actually associate, and do not require the

1 Experimentelle Untersuchungen über die Association der Vorstellungen. Philos. Stud., I ; compare Wundt, 'Grundzüge,' 5th ed., 1913, Vol. III, p. 549.

2 Bemerkungen zur Beschreibung und Eintheilung der Ideenassociation. Vjsch. f. wiss. Philos., 9. 
TABLE III.-Cattell and Bryant, I889 ${ }^{1}$

I. Objective $\begin{cases}\text { A. Coexistence } & \begin{array}{l}\text { Coordination IO-O } \\ \text { Whole to Part 34-0 } \\ \text { Part to Whole I-O }\end{array} \\ \text { B. Succession } & \left\{\begin{array}{l}\text { Forward 4-5 } \\ \text { Backward 2-I }\end{array}\right.\end{cases}$

II. Logical $\begin{cases}\text { C. Specification } & \left\{\begin{array}{l}\text { Correlation I0-33 } \\ \text { Specialization I9-31 } \\ \text { Generalization 3-8 }\end{array}\right. \\ \text { D. Causation } & \left\{\begin{array}{l}\text { Final (Forward) I3-4 } \\ \text { Efficient (Backward) I-4 }\end{array}\right.\end{cases}$

TABLE IV.-OFFNER, $1892^{2}$
I. Assoc. of Simulta- neous Ideas A. Pure Simultaneous

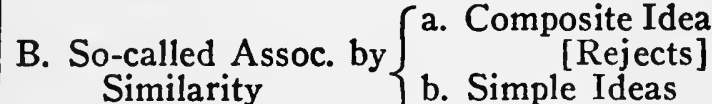 b. Simple Ideas
[Rejects]
C. So-called Assoc. by Contrast [Rejects]
D. Part-Whole, Subordinate-Superordinate [Based on Similarity]

II. Assoc. of Successive Ideas

presence of a mediating idea simultaneous with each of them. KraEPELIN's scheme is based in part on work with abnormal subjects; Calkins's is based on laboratory experiments upon normal subjects.

Gustav AschaFFEnBURG sought to determine the classification of associations in connection with the experiments already described. ${ }^{3}$ Three methods were used; (I) timed associations, (2) untimed, (3) successive associations written down by the subject. Some 4000 experiments were made on 17 persons. In addition to the

1 Mental association investigated by experiment. Mind, I4.

2 Ueber die Grundformen der Vorstellungsverbindungen. Philos. Monatsh., 28.

3 Experimentelle Studien über Association. Psychol. Arb., I895, I; 1897, 2 ; 1902, 4. 
TABLE V.-KRAEPELIN, I892 1
I. External $\left\{\begin{array}{l}\text { I. Spatial and Temporal Coexistence } \\ \text { 2. Verbal Reminiscence } \\ \text { 3. Assonance }\end{array}\right.$
II. Internal $\{$ I. Coordination and Subordination
2. Predication

TABLE VI.-CALKINS, 1892-6 2

I. Total or Concrete $\{$ a. Without Appreciable Persistence Assoc. of Objects $\{\mathrm{b}$. With Persistence

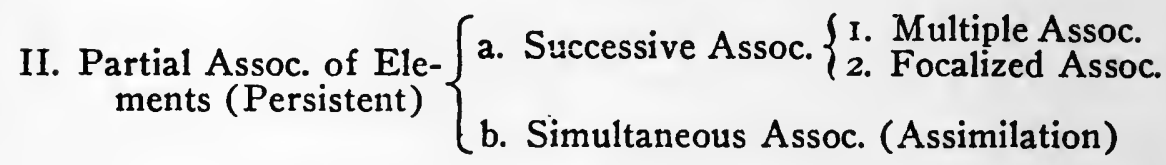
[Rejects Association by Similarity]

'internal' associations (by similarity) and 'external' associations (by contiguity and frequent repetition) which Trautscholdt adopted as basis of classification, Aschaffenburg finds two other fundamental types of response: (I) associations through the mere sound of the stimulus word, and (2) cases where the stimulus serves only to provoke a responsive reaction, such as a repetition of the stimulus word or of some previous word, or the production of some meaningless reaction. Associations of the latter class occur in less than $4 \%$ of the cases. This classification is shown in Table VII.

JUNG and RICKLIN ${ }^{3}$ proposed a scheme based upon their examination of normal and abnormal subjects, which Jung later revised (Tables IX A-B). The schemes offered by Edouard Claparede, Felix Arnold, and PaUl Sollier are the result of their studies of the his-

1 'Ueber die Beeinflussung einfacher psychischer Vorgänge durch einige Arzneimittel.'

${ }^{2}$ A suggested classification of cases of association. Philos. Rev., $1892, \mathrm{r}$.

Association. Psychol. Monog., 1896, No. 2.

3 Diagnostische Associationsstudien. J. f. Psychol. u. Neurol., 1904, 3. 


\section{TABLE VII.-AsChAFFENBURG, $1896^{1}$}

I. Immediate Association

tory of association and their critique of earlier classifications (Tables VIII, X, XI).

WRESCHNER, whose extensive experimental investigations have already been referred to, ${ }^{2}$ proposed a classification which shows the influence of the earlier schemes and is suggested by his own experiments. (Table XII.)

WeLLs's scheme, like Kraepelin's and Jung's, is based to a considerable extent upon pathological material. (Table XIII.)

It has been remarked by more than one writer that the various schemes of classification proposed appear to rest upon logical rather than psychological foundations. Those who reduce the two laws of similarity and contiguity to a single general principle of Reintegration, regard the so-called rational or conceptual associations

$$
1 \text { op. cit. } 2 \text { P. } 240 .
$$



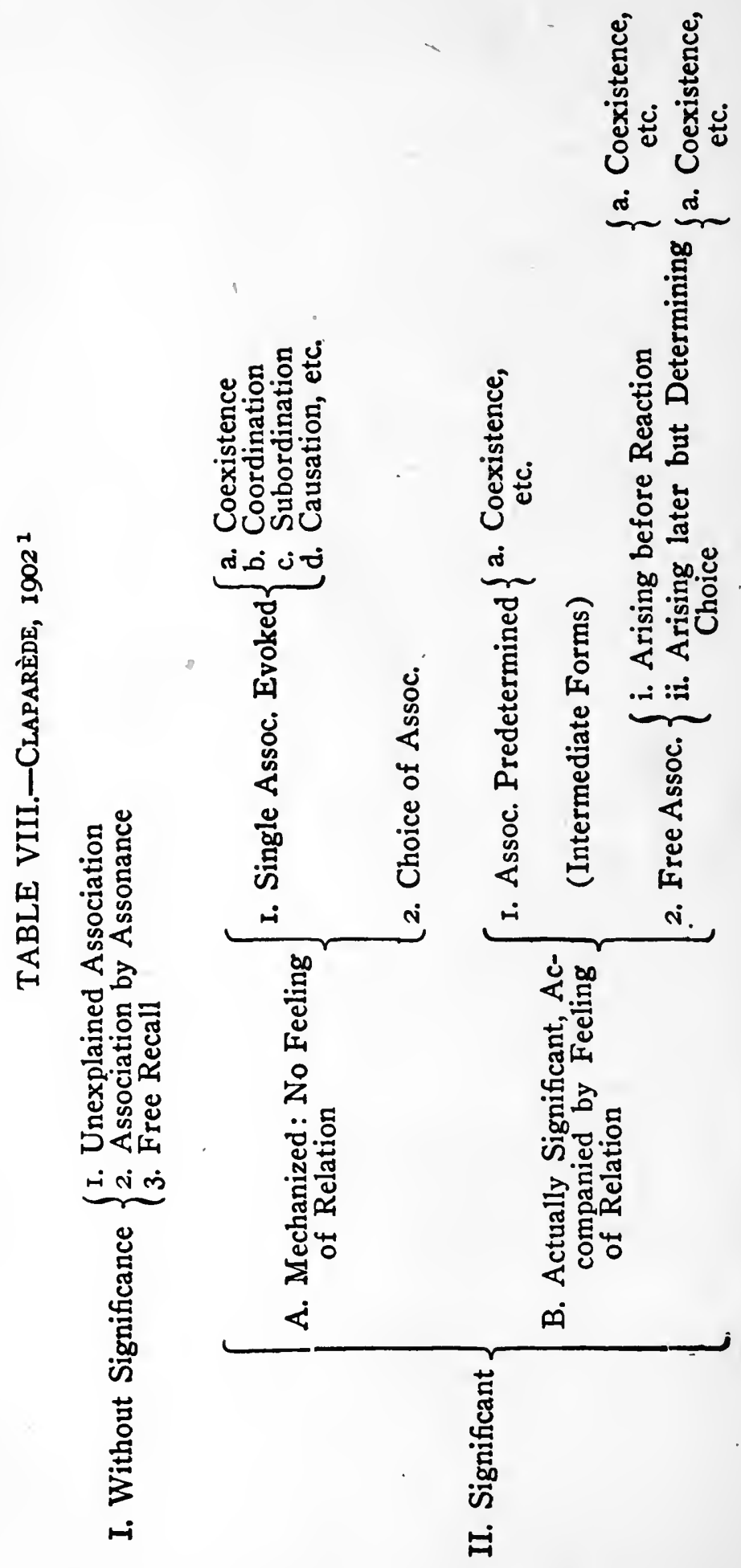

도융 屯ै
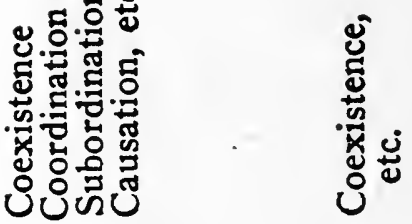

동 ป

.

近

낭

芒 
TABLE IX A.-Jung AND RICKLIN, $1904^{1}$

I. Internal $\left\{\begin{array}{l}\text { I. Coordination } \\ \text { 2. Predication } \\ \text { 3. Causal Dependence }\end{array}\right.$

II. External $\left\{\begin{array}{l}\text { I. Coexistence } \\ \text { 2. Identity } \\ \text { 3. Speech-motor Type }\end{array}\right.$

III. Sound Reactions $\left\{\begin{array}{l}\text { I. Completion of Word } \\ \text { 2. Assonance } \\ \text { 3. Rhyme }\end{array}\right.$

IV. Residual Group $\left\{\begin{array}{l}\text { 1. Mediated Reaction } \\ \text { 2. Meaningless Reaction } \\ \text { 3. Errors. } \\ \text { 4. Repetition of Stimulus }\end{array} \mid\right.$ Word

Characteristic Types $\left\{\begin{array}{l}\text { A. Perseverations } \\ \text { B. Egocentric Reactions } \\ \text { C. Repetitions } \\ \text { D. Linguistic Relations }\end{array}\right.$

TABLE IX B.-JUNG, ${\text { I } 907^{2}}^{2}$

I. Coordination

2. Subordination and Superordination

3. Contrast

4. Predication: Personal Judgment (e.g., prick-hurt)

5. Ordinary Predication

6. Relation of Verb to Subject or to Object

7. Place, Time, Means, End, Substance, etc.

8. Definition

9. Coexistence

Io. Identity

II. Verbal-motor Association

12. Formation of Words (Compounds, etc.)

13. Completion of a Word

14. Assonance (Rhyming)

15. Defective Reactions

1 Op. cit.

2 Associations d'idées familiales. Arch. de psychol., 7. 
TABLE X.-ARNOLD, 19061
A. Development of a Psy- chophysical Disposition
2. Interconnection (as System)
3. Impulse to Pass On
1. Development $\left\{\begin{array}{l}\text { a. Fusion } \\ \text { b. Assimilation } \\ \text { c. Complication }\end{array}\right.$
4. Disposition of the Whole as a Trace

B. Recall $\left\{\begin{array}{l}\text { I. A-Phenomenon, due to }\left\{\begin{array}{l}\text { a. Fusion } \\ \text { b. Assimilation } \\ \text { c. Complication }\end{array}\right. \\ \text { 2. B-Phenomenon, Free Revival }\end{array}\right.$

TABLE XI.-SOLLIER, $1907^{2}$

I. Constitutional

(Static, Anatomical)

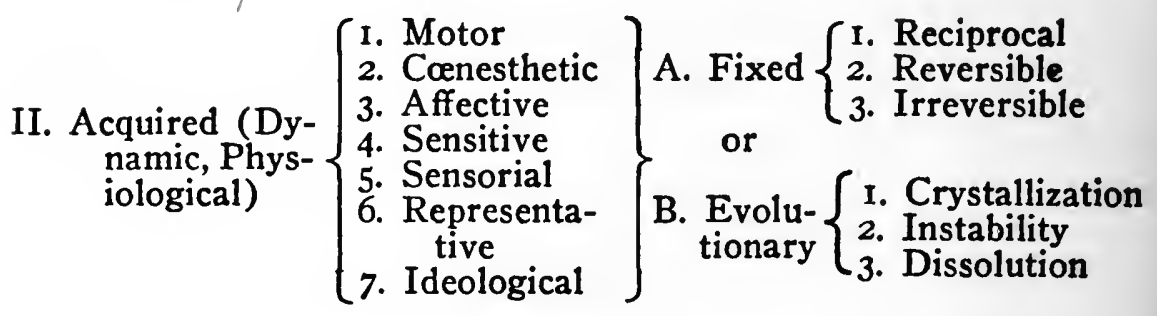

1 'Psychology of association.'

2 'Essai sur l'association en psychologie.' 
TABLE XII.-WRESCHNER, I907-9 ${ }^{1}$

I. Verbal $\left\{\begin{array}{l}\text { I. Auditory or Visual Similarity } \\ \text { 2. Completion of Word }\end{array}\right.$

II. Significant $\left\{\begin{aligned} & \text { A. Perceptual } \begin{array}{rl}\text { I. Spatial, and Whole-Part } \\ \text { 2. Temporal }\end{array} \\ & \text { B. Conceptual } \begin{array}{l}\text { I. Contrast } \\ \text { 2. Similarity } \\ \text { 3. Synonym } \\ \text { 4. Subordination } \\ \text { 5. Specification } \\ \text { 6. Cause } \\ \text { 7. Effect } \\ \text { 8. Other Relations }\end{array} \\ & \text { C. Connections }\left\{\begin{array}{l}\text { I. Spatial or Temporal } \\ \text { 2. Predication }\end{array}\right.\end{aligned}\right.$

III. Manifold Relations

IV. Mediated Associations

V. Unidentifiable

TABLE XIII.-WeLLS, $191^{2}$

I. Egocentric $\left\{\begin{array}{l}\text { a. Reactions of Modification (e.g., flower-pretty) } \\ \text { b. Response is Proper Noun } \\ \text { c. Stimulus Interpreted as Proper Noun } \\ \text { d. Response Involves Pronoun } \\ \text { e. No Response; or Repetition of Stimulus }\end{array}\right.$

2. Supraordination (Individual-Genus)

3. Contrast

4. Miscellaneous $\left\{\begin{array}{l}\text { a. Causality } \\ \text { b. By Name } \\ \text { c. Coordination } \\ \text { d. Subordination } \\ \text { e. Coexistence } \\ \text { f. Identity (Synonyms) }\end{array}\right.$

5. Speech Habits $\left\{\begin{array}{l}\text { a. Language } \\ \text { b. Completing or Compounding of Words } \\ \text { c. Pure Sound } \\ \text { d. Syntactic Changes }\end{array}\right.$

1 Op. cit.

2 A preliminary note on the categories of association reactions. Psychol. Rev., 18. 


\section{TABLE XIV.-Proposed Classification}

I. Simultaneous or Immediate Associations

II. Mediated or Successive Associations

III. Non-associative Responses (Perseverations, etc.) and Inhibitions

as due to previous experiences involving actual contiguity. In other words, not merely similarity and contrast, but causal relations, coordination, etc., may be regarded as 'contiguous' associations so far as experience is concerned. The separation of associations into corresponding classes is merely a classification of the relations existing between the objective data that are brought into associative relation-not a distinction of associative processes.

L. Duprat ${ }^{1}$ declares that the categories assigned to association constitute a false system of classification. The proper scheme is etiological; it should recognize as causes the various currents of imagery and thoughts whose sources are our permanent ideo-affective dispositions.

So far as the mental process of association itself is concerned, we seem limited to some comparatively simple classification. The present writer sees no reason for adopting a more elaborate scheme of associative relations than the one offered in Table XIV.

In this scheme only three types of association are recognized, the first two being the familiar forms of simultaneous grouping and succession. In the third type there is no real association between the present stimulus and the response; the stimulus idea serves merely to establish sensory or ideational connections with some irrelevant idea, or to arouse some characteristic (usually egocentric) mental state. Failures to react ('inhibitions') may be included in the third class.

According to this interpretation the various 'logical'

1 Assoc. mentale et causalité psychologique. Rev. philos., I913, 25, 


\section{CLASSIFICATIONS OF ASSOCIATION}

types of association (causation, etc.) would represent specific attitudes of the individual, built up by repeated experiences on his part. The relative frequency of the various types of connection would measure the intellectual development of the individual in each specific type of thought; the reaction time of any particular type may be regarded as a measure of the 'immediateness' or ' directness' of that variety of connection.'

1 One line of research more or less germane to our topic has not been discussed in this chapter. The 'conditioned reflex' is really a case of motor association. Investigation of this phenomenon was started about 1900 by J. P. Pawlow and has been carried on by his pupils in Russia and by S. Morgulis, J. B. Watson, and others in America. In a personal letter to the writer Dr. Edwin B. Holt remarks that Pawlow's law of the conditioned reflex is "nothing but a corrected form of the physiological matter that Hartley tried

$>$ to express with the formula that when two 'brain-cells' are simultaneously excited they tend to acquire an associative connection."

The writer feels that the conditioned reflex belongs to the present and future of association psychology rather than to history. For a summary of earlier work, see Yerkes and Morgulis, Psychol. Bull., 1909, 6, 257-273; and Morgulis, J. of Animal Beh., 1914, 4, 362-379. 


\section{CHAPTER IX}

\section{NATURE AND LAWS OF ASSOCIATION}

\section{The Nature of Association}

THe problem of associationism in so far as it concerns psychology is twofold: (I) To discover the nature of the association process and formulate its laws. (2) To apply these laws to concrete experiences in order to account for all varieties of mental phenomena excepting only the primordial data.

Given sensations and the associative process, the association psychologists sought to explain all other phenomena of consciousness as modifications of the sensations by the operation of association. The present chapter will outline the conception of the associative process as finally worked out by the association school. The next chapter will sketch the typical analysis of the association psychology in its attempt to account for mental phenomena according to associative principles.

Nature of Association.-The associationists agree in regarding as fundamental the union or association of experiences, but they interpret in various ways the operation by which this union is brought about. Three radically different views may be distinguished, and one of these admits a twofold interpretation, so that four different conceptions of the association process are actually held;

f (I) Some writers regard association as a force operating upon the data and (so to speak) driving them into sequences or compressing them into unitary experiences! (2) Others discard the notion of a force which works upon sensations in a physical manner, and regard association 258 
as a mere fact of sequence or conjunction of experiences.

(3) Intermediate between these two extremes lies the view adopted by most associationists: according to this view association, though not a force, is nevertheless a directing and uniting process. (a) This process is regarded by some as analogous to the mechanical type of grouping which occurs in physical phenomena. (b) Others hold that the union entails a modification of the constituent elements as occurs in chemical combinations; the process of association according to these writers involves transformation as well as union.

I. Association as a force.-Aristotle's view belongs to the first type. Throughout his discussion in the historic 'De Memoria' passage ${ }^{1}$ two terms constantly appear: the verb $\varkappa \imath v^{\varepsilon} \dot{\omega}$ (to move or work or stimulate) with its derivatives, which applies to the antecedent state in a successive pair; and yiyvopa (to be engendered or brought to life), which applies to the consequent. In this interpretation the conception of an operating force is implied; there is some power in the antecedent to arouse or revive a new state. But the consequent has already followed the same antecedent-it is quickened rather than engendered. The state which is aroused is a past experience which has lain dormant within us; the force of the antecedent operates to waken this dormant material-to bring it up into actual experience. According to Aristotle's conception, then, association is a force inherent in mental states, which operates upon the quiescent remains of former experiences, stirring them into new life and activity.

Hobbes is the only modern writer who adheres to this view. His language is remarkably similar to Aristotle's. The antecedent moves, in the old English sense of a motor force; the consequent is begotten. But the term 'be-

1 The references in this chapter are generally cited in the preceding discussion and will not be repeated. 
gotten' proves to be rather a figure of speech than a biological analogy, for the consequent is always some experience that has previously followed the antecedent more or less frequently, the association having originated at first in a succession of sensations. In several places Hobbes speaks of the associative process in terms which imply merely the fact of sequence; one idea is said to suggest another; the second idea follows the first. Without the context this would indicate quite a different conception of the process. But in view of his language elsewhere we may conclude that he does not intend by these expressions to imply, like Brown for instance, the absence of ' force' in the process; the 'suggestion ' or 'sequence' is always to be interpreted in line with his general theory, which involves active 'motivation.'

2. Association as sequence.-The opposite type of interpretation is set forth most logically by Thomas Brown. Brown not only repudiates the notion that association is a force: he expressly denies that there is any conscious union or connection between the experiences which follow one-another. Only the fact of sequence is given in consciousness. One idea succeeds another because the same ideas have previously occurred in the same order, and this ultimately goes back to the original proximity of the sensations corresponding to these ideas. According to this view the mind has merely the power to 'call up ' an idea which some time previously followed the idea now present; the first idea then gives place to the second, just as it did before. But in neither case is the second idea joined to the first.

In deference to common usage Brown refers this sequence to the associative power of mind; but he avoids using the term association as far as possible, because this would imply a union between the mental states, which he expressly denies. The term suggestion, which lacks this implication, is preferred by Brown and is more frequently 
employed in his writings. Brown makes no attempt to explain the process of suggestion on physiological grounds, his view being apparently that mental habit alone determines the direction of the flow of thought. That is, the only mental power involved in suggestion is the power of habit. The frequent repetition of any given succession, $a-b$, makes it easier for the mind to pass from $a$ to $b$ than from $a$ to $c$, if the latter sequence has occurred less frequently in the past. Brown's zeal for a purely introspective psychology will not permit him to go beyond this in his search for causes.

Brown stands practically alone in this interpretation of the associative process. Other writers who use the term suggestion either regard it as synonymous with association or restrict it to a subsidiary kind of succession. Thus Berkeley admits that one idea may 'suggest' another owing merely to their prior coexistence-that is, apart from any similarity or other ' necessary connection' between them. In the main, however, Berkeley attributes association to some perceived connection between ideas; special stress is laid in his psychology on the unitary combination of simultaneous experiences. Tucker also uses the term suggestion in describing the steps of successive association, but he regards the succession of ideas as an active process, and in discussing simultaneous association. he holds that an actual transformation of material is brought about.

3. Association as a process.-The great majority of writers on association adopt a view intermediate between the two extremes held by Hobbes and Brown. They maintain that the succession and simultaneous appearance of mental data actually involve a union of some sort, but they do not believe in the existence of a potent force in consciousness which effects the synthesis. Thus Hume calls the associative process a 'gentle force' within the ideas themselves, which commonly brings about their 


\section{NATURE AND LAWS OF ASSOCIATION}

union but which does not always prevail. He seems to regard it as a principle of attraction rather than a force. By this means thoughts are bound together, imagination joins together elements which were originally distinct, and sense impressions are grouped together into unitary experiences.

Locke regards some ideas as naturally connected, others as connected by chance or custom, still others as capable of combining together into a compound idea. Here the emphasis is upon the capacity of the elements themselves to combine, not upon a potent force distinct from the elements. According to Berkeley, as we have seen, ideas are combined together; one idea suggests another which is habitually connected with it. Gay asserts that moral acts have commonly an element of pleasure or pain annexed to them, and that they become inseparably united with these affective experiences. Among the French writers, Condillac, Bonnet, and Destutt de Tracy regard association as an operation or process.

None of the analyses prior to Hartley's attempted to picture very definitely the nature of the associative union. Hartley's theory of correspondence or parallelism between mental and physical phenomena led to more precise statements concerning the effect of the associative process on the mental data.

In consequence of Hartley's attempt to correlate mental and physical phenomena, two opposite interpretations of the associative process arose, which follow the analogy of physics and chemistry respectively.

a. Association as a' mechanical' process.-Hartley's position is exceptional. His general attitude is parallelistic. He conceives association to be a general process which extends to muscular movements as well as ideas and sensations. Nevertheless he uses-the physical analogy rather than the chemical: the product of asso- 
ciation is a 'cluster' of elements; the complex experience which results from association, however closely consolidated it be, is always resolvable into its original elements. He does not assume that a transformation takes place in the data as a result of the synthesis.

Among later psychologists James Mill is the foremost exponent of the mechanical conception of association. According to him the qualitative changes resulting from the synthetic process are only apparent; in reality the elements remain unaltered, however complex their grouping. The associative union may be so strong as to be practically indissoluble. But it is analogous to the cementing together of material substances. The original data maintain their identity; in thinking, the mind passes over the entire series, though often so rapidly that many of the constituents are not reccgnized. The act of association involves cohesion and compression, but not transformation.

Bain and Spencer are able to avoid the question of qualitative change, since they confine association practically to the succession of experiences. The problem of transformation arises only in the synthesis of simultaneous data. Where one experience succeeds another the two are not synthesized into a complex unit. If a series of stimuli follow one another very rapidly (as in Spencer's notion of elementary 'nervous shocks') they may be regarded as forming one complex stimulus rather than a successive series. The origin of qualitative differences between experiences in such cases is part of the general problem of the 'quality' attribute of consciousness; it is not a result of mental association. Thus while neither Bain nor Spencer insist on the mechanical interpretation of the associative process, we may class their theories along with James Mill's. All three regard association as an active process, which unites elementary data without transforming them. 


\section{NATURE AND LAWS OF ASSOCIATION}

b. Association as a 'transforming' process.-Tucker was the first to call attention explicitly to the transformation which the elementary data of experience undergo in the process of association. In certain kinds of composition of mental data the elements coalesce, melt together, fuse. The compound is a 'new stock'; it may have properties which do not belong to the parts singly. If any of its elements drop out the cluster or train thereby becomes still further modified. The scope of transformation is thus far-reaching. It affects all experiences in the adult human being.

Brown adopts this conception and elaborates it. $\mathrm{He}$ attributes the complexity of experience to a "spontaneous chemistry of mind." As a result of the transformation which takes place during grouping, our compound experiences often bear little resemblance to their constituents. As we have seen, Brown refuses to consider successive association as a process of either the physical or chemical type. Owing to his rejection of physiological inquiry his conception of the associative process belongs in a class by itself. At the same time his analysis played a prominent part in developing the theory of ' mental chemistry.'

To the younger Mill belongs the credit of incorporating the doctrine of mental chemistry, or qualitative transformation, into the 'orthodox' association psychology. J. S. Mill views association as a generating process, whereby one idea brings another into being, and a group of elementary experiences, joined together, are melted or fused into a compound state which is qualitatively different from its constituents. His exposition of the 'chemical' interpretation of association is perhaps the best statement of this view.

Lewes adopts substantially the same standpoint. He speaks of the coalescence, blending, and fusion of elements in the associative complex. He regards the result of simultaneous association as a resultant or emergent, 
which is qualitatively unlike the elements. Among the French associationists Taine may be cited as an adherent of the view.

Typical interpretation.-All four interpretations of the associative process manifest the spirit of empiricism and are reconcilable with the association psychology, but the first two are least characteristic. The crude conception that an external force binds experiences together is confined to the earlier stages of the analysis, while Brown's categorical denial of the associative nexus arises from his indisposition to take account of the physiological processes which accompany consciousness-an attitude in which he stands alone.

The two views which interpret association as a mental process are most typical of the school. In the act of 'associative synthesis,' elementary mental data combine or coalesce into complex experiences. According to certain writers, this coalescence is a mere grouping, in which the constituents remain unaltered though so closely bound together that often they cannot be detached save by the greatest effort. The complex unity is so condensed, so syncopated, that its parts are indistinguishable and the whole may appear to be qualitatively different from its elements. According to others, coalescence involves an actual transformation of the elements. They melt together or fuse; they become transformed. The compound experiences, like the products of chemical synthesis, take on new qualities which are not present in the elements. These two standpoints are quite antagonistic. One follows the 'mechanical,' the other the 'chemical ' analogy. Neither is more typical of the association movement than the other. But the 'chemical' interpretation seems to furnish a more adequate account of the qualitative differences actually observed in experience. ${ }^{1}$

${ }^{1}$ It is also not incompatible with the general system of any associationist, except James Mill. 


\section{Role of the Nervous System}

The Nature of Mind.-The relation of neural processes to the act of association is variously interpreted by associationists according to their different theories of the nature of mind. It is by no means easy to understand the views of the earlier writers, owing to their constant use of figurative language and physical analogies. These pictures doubtless served to enlighten their contemporaries; but it is difficult to translate them into modern terms without suggesting anachronistic interpretations based upon recent scientific discoveries.

Mind was generally regarded as a substance. Priestley identified it with material substance, while Berkeley went to the other extreme and reduced matter to mental substance. With these exceptions the associationists hold that mind is something ' substantial ' though distinct from material substance. Yet their analogies are drawn for the most part from the world of matter. Locke's famous allusion to the tabula rasa irresistibly suggests a wax tablet or stencil on which impressions are permanently traced. Similarly Descartes, from another point of view, likens the memory traces to creases in a sheet of paper 'which has been folded in certain places.

These expressions need not be regarded as anything more than metaphor. The writers of that period seem really to consider the mind as something entirely different from wax or paper, which merely served to illustrate its properties; they may even have held that mental substance resembles material substance only in the capacity to retain or register permanent impressions. There is, indeed, good evidence for this interpretation. The writers of the $I 7$ th and $I 8$ th centuries generally regard extension, impenetrability, resistance, etc., as distinctively characteristic of matter. According to their view these qualities are wholly absent from mental substance. The 
corresponding differential character of mental substance is thought. Even Hartley, despite his insistence on neural vibrations, made no attempt to reduce sensations to phenomena of motor activity.

Physiological Basis of Association.-The relation between mental and material phenomena was conceived in many ways, which may be grouped under three general attitudes: (I) Brown ignores the question altogether. He is interested solely in the interrelations of mental facts, and refuses to consider their physical basis or correlate. Similarly, Berkeley, going to the extreme of identifying the physical with the mental, finds no problem of relationship to solve; and Priestley, taking the opposite extreme of materialism, is in much the same situation. None of these writers is concerned with the physiological concomitants of association. They represent widely different metaphysical standpoints, but psychologically they belong in the same class.

(2) Other writers, especially in the earlier period, assume that a definite relationship of some sort exists between the two 'substances,' but do not attempt to determine the character of this relationship precisely. Hobbes, Locke, Berkeley, and Hume, for example, all distinguish between the stimulus and neural processes on the one hand and the mental or inner states on the other; but they pass directly from one to the other without explaining the nature of the transition.

(3) Later writers not only assume a correspondence, but attempt to explain the relationship generally in one of two ways-parallelism or interactionism. According to the parallelistic view, of which Hartley is the most logical exponent, the two series of phenomena, the mental and physical, proceed simultaneously in corresponding phases, but do not exert any influence upon one another. According to the interaction view, physiological phenomena actually produce the states of consciousness, and 
certain phases of consciousness-namely, acts of volition -produce changes in the motor nerves and muscles. Bain is the typical exponent of this view. He emphasizes not only the neural accompaniment of conscious states, but the motor impulse resulting from consciousness. The reaction process consists of a sensory nerve impulse which determines the conscious state, the latter in turn determining the motor activity.

We should note that the line of demarcation between the 'mechanical' and 'chemical' interpretations of association corresponds rather closely tor that between the interaction and parallelistic theories.

(a) Those who regard mental phenomena as causally initiated by physical and physiological activity, usually interpret the association of mental material as depending directly on the relations and connections of physical phenomena. Since physical particles group themselves together in various forms without undergoing any real qualitative change, it is assumed that the resultant mental elements act in the same way. The apparent qualitative changes in experiences due to association are only apparent; they disappear under close analysis, just as the apparent changes which take place in physical particles when these are grouped together disappear if viewed under the microscope.

(b) On the other hand, those who regard physical and mental as two parallel series, or as two different aspects of the same phenomena, are inclined to treat the union of mental facts as an event sui generis. While admitting that a certain correspondence exists between physical relationship and mental association, they insist that mental synthesis, like every other primitive mental datum, can only be described in psychological terms. According to this view mental association involves the direct relation of one experience to another. It is an operation in which the mental material alone is concerned; or at least 
it admits of description in subjective terms. Hence, a parallelistic or double-aspect interpretation of the mindbody relation almost inevitably postulates some sort of transformation of the material as an outcome of the synthesis, in order to account for the qualitative differences actually observed in consciousness. ${ }^{1}$

It would not be correct to assert that all writers who accept the notion of transformation are parallelists or adherents of the double-aspect view, nor that all who reject the notion of transformation are interactionists. Often the relation between mind and matter is not stated with sufficient precision-in some cases it is not analyzed clearly enough to be, correlated with the given explanation of the associative process. But the general trend is toward this pairing of standpoints: interactionism with mechanical union of the associated mental material, and parallelism with transformation of associated mental data.

While parallelism and interactionism represent two radically distinct philosophic positions, the problem which they raise is of little importance for psychological analysis except in the way just indicated,-namely, to distinguish between the 'grouping' and 'transformation' conceptions of association. Whether or not a causal relation exists between neural processes and conscious experiences, it is on all sides admitted that the two proceed pari passu -that changes in the one are accompanied by changes in the other, either simultaneously or alternately. The important problem for psychological analysis is to discover what sort of physical events-in other words, what sort of physiological processes-correspond to mental processes, especially in sensation and association.

The associationists generally, beginning with Hartley, describe the brain activity which accompanies or precedes

1 This is the present writer's view. The reader should guard against possible unconscious bias in the historical interpretation given here. 


\section{NATURE AND LAWS OF ASSOCIATION}

sensation as a vibration or current of some sort-either physical, or chemical, or electrical. The neural process corresponding to mental association is interpreted as a combination effect of these currents. Hartley's explanation was precise and thorough-going, but the science of physiology was still in a rudimentary stage and his interpretation fell to pieces when subjected to criticism. There are no brain vibrations such as he assumed; and the integration of nervous processes is a far more complex affair than he supposed.

James Mill recognizes fully the importance of the neural processes for psychology, but he pays little attention to physiological details in the 'Analysis.' The younger Mill merely accepts Bain's treatment.

The two evolutionary writers, Spencer and Lewes, lay far more emphasis on neural activity than their predecessors. Spencer attempts to interpret mental phenomena in terms of their nervous correlate, and bases mental association on the process of integration which successive nerve impulses undergo. Spencer's view is not materialistic, since he does not identify the two series. According to him they are quantitatively but not qualitatively related; they increase or decrease proportionally, and at the same time they manifest differences of sort.

Lewes carries out the physiological interpretation as consistently as Spencer, but lays more stress on the introspective side. Where Spencer's analysis is forbiddingly formal and mathematical, Lewes interprets the data with a more sympathetic touch. The three sides of the nervous arc, according to Lewes, give rise respectively to an affective process, a grouping process, and an active process; these correspond in consciousness to feeling, logic, and impulse respectively.

Lewes's interpretation of the grouping process (association) is well in line with modern theories regarding the nature of nervous integration; he indicates most clearly 
of all the school the neural meaning of association. Had Lewes lived a few years longer he might have extended his analysis so as to include a physiological explanation of the quantitative laws of association.

Typical interpretation.-Taking the association movement as a whole, we find that the physiological basis of association becomes interpreted more and more precisely with the growth of knowledge of the nervous system and its processes, while the attempts to explain the nature of consciousness or mental substance remain as vague in later writers as in Hobbes and Locke. Till the very close of the movement nerve physiology was not sufficiently developed to account in neurological terms for the various modes of association or its intensity variations. The associationists in general conceived the mental process of association as depending in some way upon the conjunction of separate nerve impulses or upon the spread of the nerve impulse from one region to another in the brain. How these complex neural processes are related to the mental process of association is variously interpreted.

Physiology of Ideation.-The neural basis of ideational states was a problem of special interest to the earlier associationists. From the time of Hume there were persistent efforts to explain the relation between sensation and ideation in physiological terms. Brown alone, the rigid introspectionist, held that the memory image and other forms of ideation are original data, that they constitute a type of experience sui generis like sensation, and are not reducible to the latter. According to the other associationists, the memory image is aroused by a faint re-excitation of the same neural process which originally aroused the corresponding sensation. Their conception of the nature of the physiological process concerned in ideation varies somewhat.

Hartley, for example, attributes ideation to certain fainter vibrations which occur in the small particles of 


\section{NATURE AND LAWS OF ASSOCIATION}

the brain substance, while Spencer assumes that the particular vesicle previously stimulated in a sensory experience is stimulated anew. In the main, however, their conceptions are substantially the same. A sensory impulse produces some disturbance in the brain, the effect of which does not disappear entirely when the neural activity ceases. In some way or other a trace is left in the brain substance, and this trace may be aroused to activity by some internal stimulus. The consciousness which accompanies or results from this re-excitation of former traces is an ideational experience. Hobbes calls it a 'decaying sensation.' Later writers, on the other hand, emphasize the wealth of new material which such ideational experiences add to the mental life.

The earliest form of the association problem was to account for the rise of memory images and their succession. Why certain experiences are recalled, why others refuse to appear when desired, why a train of thought takes just the course it does rather than a hundred other possible lines-these are the prominent features of the problem for Aristotle and his successors down to Locke, and even later.

Among the psychological associationists, however, the emphasis is shifted to another aspect of the problem. The phenomenon of revival seems less important to these writers than the production of new and more complex types of experience.

The process of 'arousing ideas,' like the process of ' exciting sensations,' was conceived by the English school and their French sympathizers as intimately related to some definite kind of neural process. The explanation of the phenomenon of re-excitation became for them primarily a physiological problem. The problem of association, on the other hand, was to account for the way in which mental data of any and every type are consolidated into unitary experiences or are joined into a continuous, 
unbroken chain. Granting that some neural process always accompanies mental association, the later associationists were concerned chiefly with the introspective aspect of the associative process and the resulting mental data. They made little attempt to determine the precise nature of the physiological process which accompanies conscious experience.

The typical view of the school seems to be that sensory excitation leaves some disposition, trace, or modification in the brain substance, and that upon occasion this trace, being stimulated in some other way, may revive or renew the former process in a somewhat fainter degree. The connection between the 'inadequate' stimulus and the revived neural process would constitute the physiological explanation of successive association.

\section{The Modes of Association .}

In examining the characteristics of association two general problems appear: (I) The fundamental modes of association and their application to various classes of mental data: and (2) The associative laws, qualitative and quantitative, according to which new experiences arise.

Modes of Association: Succession and Simultaneity.One would expect empirical psychologists, who were seeking to account for experience in terms of elementary data, to recognize two modes of grouping, the successive and synchronous. As a matter of fact, many of the associationists recognize only one of these forms.

With the exception of Aristotle the earlier writers generally ignore simultaneous association. ${ }^{1}$ Their attention is directed solely to the manner in which one experience

1 Properly speaking this mode should be called "association of simultaneous impressions," and the other mode "association of successive impressions." The abbreviated phrases are sanctioned by general usage. 


\section{NATURE AND LAWS OF ASSOCIATION}

gives rise to another. The fact that they did not observe the grouping of elements which occur simultaneously at a given moment indicates the superficial character of their analysis. These writers are interested only in explaining the orderly succession of ideas. This is the chief problem of association according to Plato, the Stoics, Epicurus, Carneades, Augustine, Vives, and even Descartes.

Aristotle, with his usual acumen, notes the simultaneous occurrence of sensations in fusion. ' Later writers generally failed to notice the relation between this type of grouping and the successive association which they discuss in connection with memory. Like Aristotle, Hobbes lays chief emphasis on successive association, but alludes also to simultaneous association, which according to him takes place between two imaginations.

The change of view began with Locke. Locke emphasizes the synthetic union of simultaneous data, which he classes into two separate forms-composition, and juxtaposition. He does not apply the term association to this process, however, but confines association to the succession of ideas. Locke regards successive association as rather a casual sort of connection, whereas simultaneous grouping depends upon the 'necessary' connections between ideas; hence the latter mode is far more important in experience than the former. Hume's problem was epistemological; he sought to discover the nexus between cause and effect in physical phenomena, and as a result of his analysis he reduces the causal 'bond' to a mere habitual sequence of experiences. Thus for Hume the successive mode of association is all-important, and like Hobbes he makes only passing references to simultaneous grouping.

Hartley lays equal emphasis on both modes, as does Berkeley. Priestley and E. Darwin also consider the two ${ }^{1}$ In 'De Sensu,' loc. cit. surs $28 \mathrm{n} .1$ 
equally important. On the other hand, the writers of this period who apply the associational analysis to special fields are inclined to lay greater emphasis on the grouping of coexistent elements. Tucker, for example, in attempting to account for the moral judgment, finds it due to a synthesis of several elementary experiences which occur simultaneously, and the same is true of Alison's analysis of the esthetic judgment. So too Gay dwells on the association of pleasure and pain with simultaneous sensory data.

Brown returns to the earlier conceptions of association, emphasizing almost wholly the succession of experiences. Relying entirely upon introspection, he is unable to observe any uniting 'bond' between simultaneous experiences, whereas the succession of experiences is clearly open to observation. This is in keeping with Brown's rejection of the physiological basis of consciousness.

In the later phases of associationism both simultaneous and successive association were duly recognized, but emphasis was generally laid upon the latter. This is partly a matter of terminology. A number of writers expressly limit the term association to the successive mode and apply some other term to simultaneous grouping. J. S. Mill alone seems to give no preference to either form. James Mill notices both modes, but believes that successive association occurs more frequently. Bain considers succession the chief form.

According to Spencer, coexistence is the important fact in the physical world and serial order the prominent feature of the psychical life. We must remember, however, that Spencer uses the term association in a narrow sense, and that he recognizes another form of connection, namely, relation between feelings. The latter mode includes simultaneous complexes of mental data.

Lewes's attitude is like Spencer's in this respect. He considers the serial order of experiences more important; 


\section{NATURE AND LAWS OF ASSOCIATION}

but he introduces a new term, grouping, to cover the fact of simultaneous union. In such groupings the whole aggregate of simultaneous elements may act as a unit; and this is just what the earlier writers meant by association.

Among the earlier French writers the distinction between simultaneous and successive modes of association was not noticed. Bonnet seems to recognize only succession. Maine de Biran and Taine recognize both simultaneous and successive association.

Typical interpretation.-If we consider the fundamental conception, rather than the particular terminology of the various writers, we find that all the associationists from the time of Hartley admit the union of simultaneous elements in consciousness as well as the succession of experiences. Some of them use different terms, such as composition and association, or grouping and association, to denote the simultaneous and successive modes respectively; while others use the same term, association, to cover both classes of facts. The latter is quite in accord with the history of the term, which was originally used to express the fact of union rather than any particular mode of union.

There has been a tendency among recent critics of the association movement to restrict the school too closely on this point. It has been commonly assumed that pure associationism recognized only the successive mode of grouping. This error is due to taking certain writers as typical of the whole movement. The spirit of associationism seems clearly to involve both modes. Mental life includes synthetic experiences as well as trains of experiences. The associational attempt to explain experience in empirical terms calls for recognition of both types of union. While some writers ignore one mode or the other, wholly or in part, a broad view of the movement will take account of both simultaneous and successive group- 
ing. Both are synthetic processes-modes of joining together or associating mental data.

Association of Sensations. - Observation early indicated that sensations are not subject to control in the same way as ideas. They are not called forth ' at will'; their succession does not follow the same governing principles as their mental 'copies.' On this account several writers assume that sensations are not associated together at all. It was clearly established that they do not follow the mental principles of successive association. But sensations do coexist and the associationists are divided on the question of including this coexistence under the simultaneous mode of mental association.

Aristotle, we have seen, recognizes the occurrence of association among sensations. He holds that two separate simultaneous sensations are impossible, whether in different senses or from the same sense; where two sense impressions occur together they fuse $(\mu \imath \chi \theta \tilde{\eta}, \mu \imath \chi \theta \tilde{\omega} \sigma \tau \nu)$ into a single unit through a unitary principle of the soul. Hobbes does not treat the problem at all. According to Locke, the mind unites ideas as they are found in nature and also in artificial ways. Inasmuch as he uses the term idea broadly to include sensations, this would seem to involve the perceptual unity of sensation elements as well as the formation of ideational complexes. Berkeley declares definitely that different sense impressions unite into objects, such as an apple, a book, and the like. In Hume we find only a passing reference to association among impressions; and this union he holds takes place only through resemblance, not through grouping of contiguous impressions.

Hartley places the association of sensations upon exactly the same footing as association of ideas and association of movements. Indeed, he bases association of ideas upon the previous association of the sensations from which they were originally derived. James Mill, follow- 


\section{NATURE AND LAWS OF ASSOCIATION}

ing Hartley in part, holds that sensations appear in clusters. These clusters of sensations do not form an actual unity, but each cluster acts as a unit through its association with a name. Erasmus Darwin admits the association of data from the same sense and from different senses. While he calls the resulting experiences 'ideas. of sensation' it is evident that the word idea is here used in the older meaning of 'experience.'

On the other hand, Brown does not admit that any grouping of sensations occurs which is similar to the association of ideas. According to Brown a sensation may suggest an idea, but the idea is a new fact, not a revival of some former sensation; he finds therefore no ground for attributing association of ideas to a similar associative process among the original sensations. J. S. Mill agrees with Brown to the extent of regarding sensations and ideas as primordially different. He has nothing to say concerning the grouping of sensations, but considers association an important factor in motor phenomena.

Bain follows Hartley in attributing association equally to actions, sensations, and states of feeling. According to Bain all intellectual processes are instances of association.

Spencer's analysis is especially clear on this point. $\mathrm{He}$ declares that sensations cohere with memories of ideas, forming unitary percepts; the external sensations in particular become linked together into perceptual units.

According to Lewes sensation itself is a group of neural tremors. These neural tremors are the simplest data of consciousness; all other data of consciousness are the result of a uniting process ('logic') by which these neural tremors are grouped together into sensations, and sensations in turn are grouped into perceptual and other complex units.

Typical interpretations. - We find, then, that most of the associationists, either explicitly or by implication, 
extend the associative process to sense data. This is somewhat obscured by their language. Some limit the term 'association' to successions of experiences, or still more narrowly to successions of ideational data; but even these writers recognize for the most part that some mental act of synthesis takes place among sensations and that by this synthetic process the isolated sense impressions are brought together into unitary states of consciousness. ${ }^{1}$

As noticed earlier in this chapter, the character of this union is interpreted in two radically different ways. According to James Mill perception is a mere juxtaposition of sensations; the blending is only an appearance; the character of the elements remains unaltered by the synthetic process. According to Tucker, Brown, J. S. Mill, and Lewes the process is one of actual fusion; ${ }^{2}$ the elementary sensations are transformed as a result of the union; just as in the case of chemical action the compound is found to possess properties or qualities which are lacking in its constituents. Either interpretation is in conformity with the spirit of the association school. ${ }^{3}$

Other Modes: Revival and Relation.-Before leaving the subject we should notice a classification of the modes of association by certain writers along different lines. This takes account of the apprehension of relations as well as objects. Brown, for example, distinguishes between simple and relative suggestion; the latter type calls forth feelings of relation. For, as Brown remarks, the awareness of relations between things carries us one step beyond the awareness of related things.

Spencer draws a somewhat different distinction, which is nevertheless based upon the same mental phenomenon.

1 The synthesis of sensations is always simultaneous-never successive. The recent extension of successive association to sensation by Hunter is a distinctly new departure. (See Chapter VIII, p. 246.)

2 The concept originated with Tucker, but he did not apply it specifically to sensation.

3 The latter seems to accord better with the results observed in introspection. 


\section{NATURE AND LAWS OF ASSOCIATION}

He finds two modes of grouping: revivability and relatedness. Certain feelings (or elementary experiences) are more closely related than others, and the degree of revivability of an experience is proportionate to its degree of relatability. The fact of relatedness itself is what most writers call association.

Other writers make a similar distinction somewhere in the course of their analysis. The revival of simple sensations in the form of memories or ideas is not exactly the same process, they would assert, as connecting together various clusters of elementary experiences. Thus we find two modes of association assumed by a number of associationists - revival and relation-a scheme which appears to transect the division into simultaneous and successive.

It is possible that closer examination would demonstrate these modes to be virtually the same as succession and simultaneity; for revival is a phenomena of successive association, and ' relation of experiences,' where it differs from revival or calling up former experiences, seems to depend on the simultaneous occurrence of experiences that are related. Many associationists do not admit this correspondence between the two schemes of classification-especially those who hold (with Spencer) that experiences group themselves chiefly in a serial order. On the other hand, it might be maintained by the adherents of simultaneous association that this mode at times includes both revival (memory) elements and relations.

Lewes's attitude seems to represent the best solution of the 'relation' problem along associational lines. As the nerve impulse irradiates from center to center it leads to the reinstatement of former experiences; each impulse may itself be complex, and this natural grouping of simple impulses into a complex unity depends upon the relations of the earlier sensory stimuli. 
While the problem of relativity is of considerable importance to philosophy, the distinction which it involves seems a matter of minor importance in the psychological analysis. Those writers who consider ideational experiences a renewal of sensations or of ideas already experienced would regard all successive association as belonging to a single type. According to this view an idea is a sensory experience repeated with a lesser degree of intensity. The relatedness is the fact of union, whether that union be successive or simultaneous.

One phase of the problem remains over, for which the associationists find no satisfactory solution: ${ }^{1}$ How do we become aware of relations between things? Brown first brings out clearly the difference between awareness of related things and awareness of their relations; and Bain makes one of the chief characteristics of intellect a 'sense of difference,' or discrimination. When two sensations, one of which is larger, brighter, louder, heavier, etc. than the other, occur together, the two, according to Bain, give rise to an appreciation of the fact of difference. ${ }^{2}$ Here we have a new primordial datum in the mental life, and its relation to the other data (sensation and association) is not clearly worked out by any of the associationist writers. Possibly a purely associational and psychophysical explanation might be devised to cover the phenomenon, just as the difference-tone in music appears as a third element accompanying two simultaneous tones. Or it may be that, like the qualitative differences among sensations, this 'perception of difference' is a new sort of fact, characteristic of consciousness. It is in any case a defect of the associational analysis that no definite solution is attempted. If the 'sense of difference' is a brand-new experience, it involves a modification of asso-

1 In the opinion of the present writer, who is otherwise most sympathetic to the association movement.

2 This is apparently the basis of the view lately proposed by Professor Woodbridge and others, that consciousness is relative. 


\section{NATURE AND LAWS OF ASSOCIATION}

ciationism. If not, the origin of discrimination should in some way be accounted for in empirical terms. ${ }^{1}$

\section{The Laws of Association}

The associationists observed certain regularities in the succession and grouping of experiences, and on the basis of these uniformities they formulated their laws of association. Most of these writers, however, fail to distinguish clearly between the kinds of relation and the degrees of relationship - that is, between the qualitative and the quantitative aspects of association. As a result two sorts of 'laws' are often confused, as when J. S. Mill combines the two heterogeneous classes into a single set of associative principles. In reality the means of association and the amount of associativeness constitute quite separate problems. One problem is to discover what relations exist between the data associated together; the second is to determine the quantitative factors which measure the strength of this relation. Brown and others after him distinguish between primary and secondary laws on this basis. But this does not indicate the real nature of the distinction. Indeed it may be questioned whether the so-called secondary laws are not first in importance. Recent experimental work certainly emphasizes the quantitative aspect of association far more than the qualitative. Historically the reverse is true; the kinds of relationship play the more important role in the development of associational analysis. They were the first to be analyzed and became the starting-point of the association psychology.

Kinds of Relation: Qualitative Laws of Association.Aristotle's formulation served as basis for all later

1 The present writer would regard discrimination as a fundamental 'operation' of consciousness, like sensibility, association, and transformation. 


\section{THE LAWS OF ASSOCIATION}

analyses. Of his three relations, similarity, contrast, and contiguity, the first and third are accepted by a majority of writers. The law of contrast was recognized by a few of his successors, but was generally considered subordinate. In the end J. S. Mill disposed of the principle altogether by pointing out that a thing reminds us no more of its opposite than of any other among the many possible alternatives.

The relation of contiguity is divided by some writers into spatial coexistence and temporal succession. This distinction does not exactly correspond to the simultaneous and successive modes of association; for it is quite possible to maintain that coexistent sensations are recalled successively or that the memories of successive sensations are grouped into an instantaneous unitary experience. The distinction between coexisting experiences and successions of experiences is important for the process of association, but only as regards the present experience. The principle of contiguity seems sufficient to cover the relationship between present ideational experiences and their original sensory source.

The Law of Contiguity is generally stated in substantially the following terms: "A sensation or idea tends to recall other experiences which formerly occurred in close proximity to it." The Law of Similarity is generally formulated as follows: "An experience tends to recall experiences which resemble it."

The two relations of similarity and contiguity are typical of the association standpoint, and are generally coupled together. Certain writers, however, emphasize one at the expense of the other, or reduce one to terms of the other. Thus Spencer makes likeness the sole basis of association and reduces contiguity to "likeness of relation." More commonly, resemblance (similarity) is subordinated to contiguity. In particular, such writers as Hartley, who consider the idea a renewal of sensation, 


\section{NATURE AND LAWS OF ASSOCIATION}

argue that similarity is merely the identity of certain elements in present and former experiences, and that what is renewed is certain contiguous elements from the former experience which do not at the outset form part of the present state. Thus when a perfect stranger, Jones, recalls to us our friend Smith, it is because certain of Jones's features, movements, or other characters are identical with those of Smith, and the remaining characters of Smith are recalled as memory images through the relation of contiguity.

Hamilton, in his 'Metaphysics' (Lecture 3I), attempts to reduce the relations of contiguity and resemblance to one principle without showing favor to either. He propounds the general law of Redintegration (more euphoniously called Reintegration) to cover the process as a whole. In the same way Lewes formulates the general principle of Reinstatement, which implies contiguity and either identity or similarity. Lewes's conception of the relationship is appropriate for writers who emphasize the physiological basis. It is not a suitable term for unions of simultaneous sensations when these sensations are grouped together to form a perceptual experience. The latter is ' association by contiguity,' but it does not involve reinstatement or reintegration.

The French writers generally recognize contiguity and similarity as distinct laws of association. Condillac is believed by Dewaule to use both principles. They are explicitly recognized as distinct forms by Bonnet, Mervoyer, and Taine. Bonnet alone attaches greater importance to the principle of resemblance (similarity).

The typical standpoint of the association school would seem to make the relation of contiguity dominant. (I) Sensations tend to call up their corresponding ideas; and these ideas arouse certain contiguous data-experiences or experience-elements which either coexisted with the corresponding experiences or succeeded them when 
they occurred previously. (2) Similarly, ideas which have been aroused through this process of association tend in their turn to arouse other ideational states or elements which coexisted with them or succeeded them in some prior experience. (3) Sensations which occur contiguously-that is, either simultaneously or in immediate sequence-tend to unite into single experiences or unbroken chains of experience. Thus the law of contiguity may be regarded as the basis of the association psychology in its attempt to explain the nature of complex experiences and account for the course taken by trains of thought.

Degrees of Relation: Quantitative Laws of Association.-As early as Aristotle the role of habit in the associative process was noted. From the time of Descartes and Hobbes nearly every writer on association emphasized this factor. Locke, though he gave little heed to the qualitative relations, attempted a searching quantitative analysis. He finds four factors which determine the degree of association: attention, repetition, habit, and the pleasure-pain accompaniment of the original experience. Hartley emphasizes the importance of frequent repetition in determining the actual course of association, and other writers of this period dwell on one or other of Locke's factors.

Brown was the first to distinguish clearly between the intensity factors and the quality factors in association. With his usual minuteness he formulates, under the name of ' secondary laws,' nine principles which determine the degree of association. Not all of these principles are really independent. But at least six may be treated as fairly distinct factors. These are Duration, Intensity, Frequency, and Recency of the original impressions; Constitutional Tendencies and Present Condition of the individual experiencing them.

The first four factors are concerned with specific expe- 


\section{NATURE AND LAWS OF ASSOCIATION}

riences. Their laws may be stated as follows: "One experience tends to bring up another earlier experience more readily according as the latter $(a)$ remained longer in consciousness [Duration], (b) was more intense [Intensity], (c) has occurred more frequently [Frequency], and $(d)$ has occurred more recently [Recency]."

The two remaining factors are concerned with the experiencing individual. Their laws may be stated as follows: "The strength or degree of any given associations varies $(a)$ with the individual's constitutional tendencies, and $(b)$ with his present psychophysical condition."

The Mills and Bain leave the individual factors out of account and reduce the experience factors to twoFrequency and Intensity. There is really no great discrepancy between their view and Brown's; long duration is much the same as frequency of repetition; recency is a separate factor, but since lapse of time decreases the effectiveness of an impression, the recency factor may be grouped with intensity if we adopt a physiological interpretation.

None of these writers seem to have recognized Locke's pleasure-pain factor. Lewes stands alone among later writers in emphasizing its importance. He also renews Brown's reference to individual differences, maintaining that the direction of association depends on the individual's whole past. Spencer, who accepts the two laws of Repetition and Vividness, adds a new principle which he calls the law of Decreasing Gain. "An association gains less strength by each additional repetition." This is a phase of the law of Repetition (or Frequency), rather than a distinct principle.

Typical interpretation.-The typical attitude of the school toward the quantitative principles is probably that of Lewes. Other writers either confuse these laws with 
the qualitative (as for example, Bain), or consider them of secondary importance. The best interpretation of the ' associative' connection of experiences would regard the process as a spreading of consciousness to contiguous experiences. The important problem is: In what direction will the spreading occur? What factors in the present experience or in the traces left by past experiences determine this direction?

Four distinct factors are noted by one or other of the association writers: (I) Original intensity and progressive fading of intensity; (2) Repetition, including length of duration; (3) Hedonic accompaniment; and (4) Personal equation of the individual, based on heredity and general environmental conditions. These may be grouped together in a single statement: The degree of potency of a present experience to associate with itself a former element of experience depends on the intensity, duration, and hedonic tone of that element, and on the present condition and life history of the individual under consideration.

The recent experimental investigations of association have confirmed the importance of original intensity and repetition, and tend to regard recency as a distinct factor.

\section{Typical Interpretation of the Associative Process}

We may now sum up the typical interpretation which the school as a whole gave to association as a mental phenomenon and attempt a representative formulation of its laws.

The most workable view of the nature of association seems to be that which regards it as a process whereby mental phenomena combine or coalesce into more complex unities. The 'mind' is conceived as made up of a vast number of elementary 'impressions' bound together by the process of association. 


\section{NATURE AND LAWS OF ASSOCIATION}

Both the impressions and the associative relations between them are dependent in some way upon physiological processes which occur in the nervous system. The nature of this psychophysical relationship is problematic; the most self-consistent interpretations are those which deny causal interaction between mind and brain-process; the two series are regarded as concomitant, independent, and yet parallel phenomena, or as two aspects of a single reality. ${ }^{1}$

The elementary impressions are of two sorts, sensational and ideational data. Their fundamental distinction is based upon the character of the corresponding neural processes. The sensory data of experience depend upon stimulation of the organs of sense; the ideational data depend upon central excitation of the brain substance, ideational experience taking the same form as earlier sense impressions of the same regions. This act of 'arousing' ideas is one manifestation of the associative process.

The associative act includes two distinct modes, successive and simultaneous grouping. The former welds the elementary data together into a unitary train of experiences; the latter binds them into complex unitary groups. The complex experiences resulting from simultaneous association are qualitatively different from their constituents; the union is analogous to chemical combination, in which the elements lose their identity in a higher type of unity-it involves fusion rather than mere juxtaposition.

Association proceeds according to two different sets of principles, qualitative and quantitative. The qualitative laws account for the kind of union which occurs in any given case. In the broadest sense there are two sorts

1 The present writer may possibly be biased in this appreciation of the associational position by his own view of the relationship, which is the 'double-aspect' hypothesis. 
of relation, similarity and contiguity; that is, the elements are either similar in quality, or else they occur near together in space or time; in the case of ideational elements they are such as have previously been experienced together as sensations. Close analysis, however, reduces the qualitative laws to the single principle of contiguity, for the 'similar' experiences consist in reality of identical elements accompanied by certain contiguous elements which are dissimilar.

The quantitative principles of association account for the selection of one rather than another of the entire set of possible groupings in any given case. The grouping depends upon (I) the original intensity and recency of the impression; (2) frequent repetition and length of duration, (3) the hedonic accompaniment of the experience, and (4) the general heredity and life history of the individual.

It will be seen from this summary that the common conception of associationism, and the descriptions of the movement given generally in our histories and encyclopedias, are defective in several respects:

(I) The common view limits association to successive grouping, whereas the more representative writers of the school include under the term simultaneous grouping also.

(2) There is a widespread notion that the associative process is limited by the English school to ideational elements-that it accounts only for the flow of thought. This error is due to a confusion between the original and modern uses of the term 'idea.' The more typical writers conceive the process as including the union not merely of representative elements, but of sensory data as well; many writers extend the term (quite legitimately) to include motor phenomena also.

(3) It is commonly supposed that 'pure' associationism conceived of the associative union as a mechanical compounding. As a matter of fact, the chemical analogy 


\section{NATURE AND LAWS OF ASSOCIATION}

was accepted by many representative associationists. This notion enabled them to accept the evidence of introspection at its face value, and at the same time to analyze mental compounds into the elementary data out of which they are assumed to have arisen genetically. 


\section{CHAPTER X \\ THE ASSOCIATIONAL ANALYSIS OF MENTAL STATES}

\section{Fundamental Concepts}

THE examination of the associative process was not the only problem of the associationists. Quite as important was the task of accounting for the origin of all derivative mental phenomena in terms of association, which was conceived as operating upon certain primordial data. This part of their analysis, in fact, represents their most notable contribution to psychology.

How far the attempt was successful is a matter for debate. Their critics, pointing to the numerous lacunæ in the work of individual writers, do not hesitate to pronounce the system a failure. Their defenders are few, and being for the most part misled by the prevailing misconceptions of associationism they have been unable to parry successfully many of the thrusts.

The writer believes that the association psychology in its fundamental concepts is quite capable of defense as against any intuitional or nativistic system. With the advance of physiological and psychophysical research certain amendments are obviously necessary to the original program of the school. Association may prove to be not the only kind of operation on the data. Nevertheless associationism, so far as it goes, affords a consistent interpretation of mental life.

To support this conclusion the present chapter will outline a representative system of psychology carried out along associational lines, and based on what appears to 
be the most typical interpretation of each mental phenomenon or function.

Elementary Data and their Relations.-The elementary datum of experience, according to the association school, is sensation or feeling. Sensations are due to stimulation of the organism by the environment. The evolutionists trace sensation back to a still simpler element-an awareness which accompanies the most primitive nervous discharge. This prototype of sensation is too indefinite, too vaguely experienced, to be described precisely; Spencer regards it as a species of shock, and Lewes calls it a tremor-terms which are highly suggestive of neural activity, and which also remind one of Hartley's vibration theory. None of the leaders of the movement, however, are materialists; they all distinguish the subjective experience, sensation or its simpler prototype, from the accompanying neural processes.

The associationists, like all other schools, classify sensations according to the receiving organ-the eye, ear, skin, etc. The number of different 'senses' or kinds of sensation is increased by successive associationist writers from the classic five to include the muscle sense, alimentary or organic sensations, and sensations of disorganization. The classification of sensations has no special significance for the association doctrine; it belongs to any system of psychology. But it is worth noticing that the empirical method of this school enabled it to break away from the traditional fivefold scheme, which the a priori school regarded as almost sacrosanct.

In picturing the derivation of actual experience from the ultimate sensory datum, two fundamental facts at once appear which run through the entire association psychology; these are the Psychophysical Relation, and Association.

(I) The psychophysical relation.-Spencer regards experience and neural activity as two aspects of the same 
unknown reality, and many associationists hold a somewhat similar view. But the school is not tied to any metaphysics. The essential characteristic of the relation between consciousness and neural processes is that the two phenomena are regarded as concomitant: the cerebral activity which succeeds stimulation of the sense organs accompanies the mental act of sensation, or gives rise to it immediately. The psychical and the physical are inseparably related.

(2) The process or fact of association.-The phenomenon of association appears almost at the very outset of experience. The primitive shocks or tremors coalesce and form definite sensations which are the first actual experiences of the conscious individual. Sensations, in turn, combine into simultaneous groups (percepts) and into sequences. The resulting groups combine into higher complexes and trains of thought. Thus the associative process runs through the whole gamut of mentality.

The two principles of Psychophysical Relation and Association are the instruments employed by associational psychologists to explain, account for, derive, or construct the entire framework and superstructure of consciousness. Both simultaneous and successive association operate to build up the derivative forms of experience. Perception means simultaneous association; by this process separate sensations which occur together in consciousness are grouped into single unitary experiences. The underlying physiological basis of perception is the passage of neural energy from center to center in the brain. The result on the side of consciousness is a consolidated experience which functions as a unit.

Transformation.-At this point, according to many of the associationists, a characteristic of the associative process appears which brings its results into closer conformity with vital processes than a mechanical view of grouping would indicate. It was observed that the asso- 
ciative union involves a certain transformation of the material. Just as in the act of chemical composition the product is qualitatively different from its constituents, so in mental association the elements are modified and the resulting complex experience becomes qualitatively unlike the simpler experiences which combine to form it. When discrete sensations are unified into a perception, a qualitative change takes place in the experience; and similar transformations occur in passing to higher stages of complexity.

Ideation.-Imagery or representative experience depends on successive association. Not only do coexistent sensations unite, but a sensation tends to recall or revive other elements of experience which were formerly united with it. These ' revived' experiences differ from sensations in vividness. They are called ideas.

Taking the school as a whole we find three slightly different interpretations of the ideational process. An idea is regarded (r) as a reappearance in consciousness of an enduring impression in the mental substance; (2) as a new state of consciousness patterned or copied after the original; or (3) as a renewal of the original sensation in fainter degree. In any case the instatement of an idea occurs through association with present sensations (or with other ideas present at the time) in accordance with 'laws' or relations.

The most adequate interpretation of the mode of operation by which ideas are produced appears to be that of Lewes: an ideational state is due to the stimulation occurring in some brain center and propagating out to other centers, where it renews the traces of a former stimulation. In other words, an idea is a modified sensationthe difference between the two being rather in degree than in quality. 


\section{Cognitive Experiences}

The phenomena of mental life exhibit a high degree of complexity. Many of the complications of experience are traceable to the complexity of the external world, and are explained as associations of sensory data. But apart from the differences attributable to external stimulation, introspection reveals other varieties of experience. Memory and imagination, conception and belief, feeling and emotion, conation and volition-these and other experiences remain to be accounted for along empirical lines.

Adopting the notion of ' mental chemistry,' or transformation, when elementary data are brought together into a complex experience the resulting compound is transformed and becomes qualitatively different from its constituents. According to this view a complex mental state does not 'consist of' elements-the elements coalesce and melt together, and certain of them actually disappear. The new state is, in fact, a transformation rather than a complication.

Perception and Imagery.-The first step in the growth of cognitive mental states occurs through the union of simultaneous sensations into single unitary experiences. These states are known as perceptions. They are due to the operation of association upon sensory data. The data received through different senses are combined into perceptions of ' objects.'

The most primitive development of 'secondary' experience is the image, which consists of many elementary data formerly experienced as sensations and revived by direct excitation of the appropriate brain centers. The elementary ideational data are united into imagery experiences by simultaneous association in much the same way as sensations unite to form perceptions.

The classification of imagery rests on an associative 
basis. The intermediate step between sensation and representation is the after-image, or after-sensation, which most nearly fulfills Hobbes's notion of 'decaying' sensation. It is merely a prolongation of the sensory experience after the stimulus has ceased.

Besides the after-sensation there are several varieties of true imagery. The memory image is one in which the associated elements correspond in character and arrangement with those of some specific sensory (or ideational) experience of earlier date. When a memory image arises it may call forth by association a large group of related images, which serve to place it in a definite setting of time and circumstance.

The imagination image or phantasy consists of a group of elements which have not been previously joined together in the form of a perception. The rise of imagination depends upon both successive and simultaneous association. Thus, some element in a present experience may suggest mercury, another element of the same experience may suggest a lake; these two simultaneous images may then combine into the imagination image of a lake of mercury.

The general image and the free image are each a revival which has lost its specific associations with the group in which it originally occurred, so that it does not appear in a definite setting. It may result from frequent repetition of partly similar experiences. Where the common elements are joined with various alternative elements, the outcome is a free image, as for example of some man whom we have seen in many different positions and from different angles. When the dissimilar elements drop out of the complex, the result is a general image, such as 'man.'

Not only do sensations induce images of these various types by the associative process, but one image may in the same manner induce another. Succession of images 
is thus brought about by association-a perception suggesting an image, this suggesting another, and so on.

While imagery and sensation are distinct types, they may be associated together in a single experience. In perception, certain faint imagery elements are often present, as when we 'taste' the uncut orange. Less frequently sensory elements enter into an image experience, as when our dream-image of a flower is tinged with a real sensory odor.

Thought.-In addition to perception and imagery the later associationists find a third type of cognitive experience, the symbolic idea, or thought. ${ }^{1}$

Symbolic ideas arise originally through association of an arbitrary element with the sensation or image. These arbitrary images are the names of things, whether auditory or visual. They are signs or symbols of other experiences, and do not resemble the things which they represent. In course of time, through repetition and association, the verbal element may become the chief factor in an experience, as when the name John Smith comes to be the local element in our thought of the man, in place of his features or other characteristics. In symbolic ideational experience or thought the characteristic elements which form part of the original percept tend gradually to fade away. At first the minor differentiæ disappear; the same idea comes to be attached to a number of different but similar objects, and we think in terms of concepts or general ideas. Then the more prominent sensory marks are lost and our thoughts are mainly verbal, with a faint fringe of the original elements which constitute the 'meaning.' The entire course of development may be attributed to the operation of association and the transformations which occur in such unions.

Concepts and judgments are special types of thought

1 Experiences of this type are called names by James Mill and signs by Lewes. 
in which the associations are limited more strictly by the characteristics of objects and relations found in nature.

Trains of Thought.-Trains of thought, like trains of imagery, proceed according to the laws of successive association.

Reasoning is a train of thought in which the successive experiences are concepts and judgments (not ordinary thoughts), and the successive associative steps are limited by objective and relational considerations. ${ }^{1}$

Reflection and self-consciousness are other special types of associative thinking, in which the experiences of 'self ' remain prominent through all the series of associations that are joined to this fundamental group. In thinking, reasoning, and reflecting, the subject-matter is symbolic. These mental processes are all successive associations of symbolic ideas.

Space Perception.-The perception of space, according to the associational view, results from the simultaneous presentation of sensations belonging to the same sense. Such associations tend to coalesce and to act as a definite unit with consequent modifications of the content of experience, and this modification takes the form of 'space' in conformity with our experience of actual spatial relations. The space schemes of the different senses, being constantly associated together in perceptions of objects, combine and are transformed into a general notion of space.

Belief, Meaning, Value.-It seems scarcely necessary to assume, with John Stuart Mill, a factor sui generis in the belief complex. This type of experience seems to have arisen as an evolutionary growth from certain conditions in experience. Belief is an associative reinforce-

${ }^{1}$ Lewes applies the term 'logic' to ail forms of successive association, whether involving perceptions, images, or symbolic thoughts. It seems preferable on historical grounds to limit the term to the specialized type of association which occurs in judgment and reasoning. 
ment of experience through reflection; a repeated association of this sort (between a presentation and the affirmation of a presentation) would tend to modify the nature of the total experience. The modification itself is the belief factor in the experience.

A similar explanation might be offered on behalf of associationism for the 'meaning' consciousness and 'value' consciousness. Meaning may be regarded as the 'image fringe' which accompanies a verbal idea or thought; it is the remnant of the representation of the sensation, which has been transformed and restricted as a result of repeated associations till no more than a rudiment remains. So too the value experience may be interpreted as that which remains of the intensity or quantitative factor in the original sensation and its image. This also is transformed by repeated verbal associations and is reduced to a mere rudiment.

\section{Conation}

Expressive Aspect of Experience.-The nervous system serves to establish relations between the organism and its environment. The nervous circuit includes three successive processes: sensory excitation, ${ }^{1}$ central coordination or integration, and motor discharge. Stimulation precedes this chain of neural activity, and reaction (movement) follows it. Each of these end-terms brings the organism into relation with its environment.

Corresponding to the three phases of neural activity introspective analysis brings out three phases of mental process, which Lewes calls affection, grouping, and impulse, an analysis which agrees closely with the threefold classification of traditional psychology. According to the associational view cognition (which is essentially the

1 Lewes calls this process stimulation. This term is applied more properly to the functions of the receptor organs. 
grouping process) means the association of affective elements or feeling, and this grouping results in impulse. The three phases appear to be inseparably bound together in actual experiences, and the entire process may be summed up in a single concept: behavior. ${ }^{1}$

The types of experience so far mentioned involve chiefly the sensory and central portions of the nervous arc. New varieties of experience appear in connection with the motor discharge. We have experiences of movement, or activity, from the muscles, as the later associationists pointed out. Some writers go further and speak of a 'striving to expression,' a motor-innervation feeling, a fiat. The notion that consciousness is an active phenomenon is further emphasized when images and ideas are viewed as desires or as representing needs which require satisfaction. From this standpoint mental life appears as a functioning activity, and the association psychology becomes something more than a mere analysis of cognition.

Motor Consciousness.-The motor aspect of mental life has caused recent writers considerable difficulty. It is not surprising, then, that the associationists who preceded them should fail to give a very clear account of this phenomenon. Motor consciousness has been treated in at least four different ways in psychology.

(I) The term occasionally denotes the motor-nerve impulses, muscular contractions, etc., which follow after the idea of action. These are purely physiological phenomena, however, and do not properly form part of the mental life. In spite of some ambiguity in language, none of the associationists seem really to have adopted this conception. Where the account is open to such interpretation there appears to be a verbal lapse of the

1 Lewes calls this conduct; since his time the term behavior has been generally adopted. 
same sort as when sensations are referred to as occurring in the sense organs.

(2) Motor consciousness may mean a consciousness of the outgo of energy along the motor nerves. According to Lewes's view some of this neural energy is reflected back to the brain and gives rise to the consciousness of impulse. This innervation theory has since been discarded by psychologists. While it is of importance historically, it forms no more essential a feature of associationism than Hartley's vibration theory. Both are physiological hypotheses, and modern physiology has shown each to be untrue. Their abandonment in no way affects the associational analysis.

(3) The term motor consciousness may be applied to the awareness of our movements and of the position of our members, which is derived directly from muscle sensations and indirectly from sight, contact sensations, etc., when we see or feel our members moving and assuming certain positions. The later associationists take these kinesthetic elements into account, though they do not give them the prominence accorded by more recent writers. ${ }^{1}$

(4) The motor aspect of consciousness may embrace the ideas and representations of acting, willing, moving, doing, etc., which immediately precede our motor impulses. This use of the terms seems to be included in Lewes's conception of 'mental impulse,' though he interprets impulse largely in terms of innervation feeling. Motor consciousness in this sense manifests itself also in acts of attention and in deliberation. ${ }^{2}$

The associationists use three of these concepts-inner-

1 Spencer speaks of 'resistance feelings,' and Lewes mentions the 'feeling of effort' which is reducible to muscle sensations.

2 The fourth interpretation of the motor consciousness seems to accord best with the associational analysis and would probably have been most strongly emphasized had the school continued to the present day. 
vation feelings, kinesthetic feelings, and motor ideas. All these appear to be included in Lewes's notion of impulse.

Evolution of Motor Experience.-The growth in complexity of motor consciousness can scarcely be accounted for without constant reference to the nervous system. The transition from reflex to instinct, the modification of inherited modes of expression into habits, depend essentially upon laws of neural activity. Hence, when we apply the associative principle to the conscious experiences which accompany these several forms of motor expression, the operations of the nervous arc are essential factors to be considered.

Spencer explains the consolidation of reflex action (the lowest form) into instinct and volition in accordance with his general evolution formula of increasing definiteness, coherence, and heterogeneity. In reflex action the association of the nerve impulses is largely simultaneous, while in instinct it tends more to the serial form, which is characteristic of higher mental experience. There is no chasm between instinct and volition. The essential feature of the latter is the interval of deliberation; in volition the passage from representation to impulse is not immediate, but involves a succession of intermediate representations. These deliberative factors are generally ideas of the purpose or end in view, the means, etc. They follow one another according to the principles of successive association.

Recent analysis distinguishes between sensorimotor and ideomotor experiences, or between pure conation and volition. In the sensorimotor type the antecedent term is a sensation or a perception; in the ideomotor type images or thoughts precede the motor experience. In each case, according to the associational interpretation, the train of experiences proceeds in accordance with the laws of successive association. The consolidation of the 
individual motor experiences (of whatever type) is the result of simultaneous associations, which occur repeatedly and transform the elementary kinesthetic and other data into a complex product that is qualitatively new.

A detailed examination of these processes would be out of place here. Research in psychology and physiology has advanced today far beyond the standpoint of traditional associationism. The explanation of the motor aspect of consciousness demands a much deeper analysis than that to which it was submitted by Spencer and Lewes. But it should be borne in mind that their work, resting on a consistent associational basis, indicated the direction which future analyses should take. There seems no reason why an analysis of the larger results of contemporary psychology in the motor field might not still be carried out according to rigorous associational principles.

\section{Affective Consciousness}

The associational analysis of affective experience is very imperfect. In their effort to reduce mental states to elementary sensations and ideas these writers have tended to overlook the specific characteristics of the hedonic components. With many of them, feeling and sensation are used interchangeably.

Moreover, some of the problems connected with this phase of experience have arisen since their time. The distinction between the pain sense and the hedonic qualities of pleasantness and unpleasantness is of recent origin. The James-Lange theory of emotion was not propounded till I884-5. Any attempt to determine how the school would have applied its principles to these new problems would be merely conjectural.

So far as complex affective phenomena are concerned there is no difficulty. The James-Lange theory lends 
itself to the associational interpretation perhaps better than the traditional conception of emotion. According to James's view the motor expression occurs and the emotional attitude is assumed before the emotional feeling is aroused. The expression, in fact, calls forth the feeling. The operation would appear to the associationist as a twofold process. First the perception or thought of some situation arouses the emotional expression by association; this in turn by a second act of association gives rise to the emotional feeling. Both of these steps involve successive association. But since the motor attitude persists along with the feeling, the two are united by the operation of simultaneous association. The distinctive experience called 'emotion' arises from this union of motor and affective elements.

Similarly the less intense affective complexes, which are sometimes called sentiments, may be treated as products of association. The appreciation of beauty (esthetic sentiment) appears to comprise both a feeling element (pleasure) and an idea of the beautiful or harmonious. The idea arouses the feeling by successive association. The two persist together; through simultaneous association they are welded together and transformed into an experience sui gencris.

The moral sentiments admit of the same interpretation. Here the idea is not of harmony, but of rightness, duty, justice. And so of other sentiments, such as the sublime, the true, or even the fantastic and the ludicrous.

When we come to consider the more elementary affective phenomena-the hedonic tone or feeling - the associational interpretation is less clear. If we regard pleasure-pain as a mere attribute of sensation, it is not easy to explain its origin as due to association. The quality and intensity attributes (or characters) of sensation are due directly to differences of quality (periodicity, etc.) and difference of intensity in the stimuli. Appar- 
ently the pleasure-pain experience is not due to any character of the stimulus. When we are cut by a knife or burned by a match, the resulting discomfort is not the conscious equivalent of something that exists in the knife or the match. Rather it is due indirectly to the destructive effect of the implement upon the tissues of the body.

It is possible, however, to regard the pleasantnessunpleasantness phenomenon as a sensory experience in its own right. It may prove to be a variety of sensation somewhat similar to the organic sensations of hunger, thirst, and digestion, whose stimuli are internal to the organism. Sherrington's conception of interoceptorssense organs or receptors connected with the internal processes-suggests this interpretation.

If this view be correct, then there are besides the external senses, which gather impressions from the outer world, certain other senses-the systemic - which receive impressions from within and inform us concerning the state of our own organs and tissues. The association school would find no difficulty in explaining affective consciousness under this hypothesis. A perception or thought with its hedonic accompaniment appears to be an associated complex of 'external' and 'internal' elements. The pleasure or pain element is the contribution by the organism itself, which is united to the impression received from the outer world (or to some thought based on external experience). The associated elements become so firmly united together and so transformed, that they constitute a unitary experience, and the hedonic tone appears to be a character of the external sensation itself.

\section{Completion of the Analysis}

Associationism, then, can readily account for affective phenomena, if they be regarded as based upon a separate and distinctive class of sensations. The only modification 
of the old associationist scheme required is to broaden the notion of sensation.

If, in addition, we -regard conation (and the motor aspect of consciousness generally) as based upon a third variety of senses-Sherrington's proprioceptors-the associational analysis is brought into still greater harmony with contemporary psychology. For this would presuppose as elements of experience three distinct classes of sensations-the external, systemic, and motor - together with ideas derived from them. All actual experiences, both simple and complex, according to the analysis outlined in this chapter would seem capable of interpretation as due to the operation of successive and simultaneous association upon these elements.

The case for associationism has been stated as strongly and fairly as the writer knows how. It would seem ungracious at the close of this examination to turn critic or censor. Still, it may not be inappropriate to suggest one or two points in the doctrine which seem inadequate to one who finds himself generally in sympathy with the movement.

First of all, it would appear from the discussion in this chapter that the associationists included under the term association two or three rather distinct operations. Simultaneous association and successive association operate in different ways; the former is a union, the latter a change or passage from one experience to another. Furthermore, the transformation or mental chemistry which occurs in simultaneous association seems to be still another sort of operation. To group these three operations under a single name, 'association,' is a verbal simplification scarcely justified by the facts with which we are dealing.

Again, the phenomena of attention and discrimination do not seem to be accounted for under the associationist's treatment. These phenomena appear to involve distinctive operations upon the elementary data. In other 
words, instead of accounting for all complications of experience by means of one single type of operation, we seem justified in assuming several different operations. A complete interpretation of experience would appear to involve at least discrimination, two synthetic processes, and transformation, in addition to the original sensibility and revival, and possibly also a focalizing factor. ${ }^{1}$

It may be suggested in closing that as association, in the view of these writers, is a psychophysical process, so these supplementary operations are psychophysical. To understand them fully and to distinguish which of them are really independent operations, would mean a thorough study of the physiology of the nerve impulse.

While this may seem far removed from the introspective method of the association school, it is in reality quite in harmony with their fundamental procedure. Hartley, the father of the movement, considered this neural interpretation the central problem of psychology. His failure to obtain satisfactory results was due to the backwardness of physiological research.

The problem of neural activity still remains unsolved. Until we know just what occurs in the nervous system between stimulation and response, the issue remains open. The physiological processes which occur in the neurons of the brain may or may not be reducible to a single operation. Until this is definitely determined we are not in a position to appraise fully the work of the association psychologists.

1 See the writer's 'Human Psychology' ch. 8. The mental operations given there were reached through long study of the association psychology. 



\section{.BIBLIOGRAPHY}

\section{A. History, Exposition, and Criticism of the Association DOCTRINE}

Arnold, F. Psychology of Association (1906).

Baldwin, J. M. Dictionary of Philosophy and Psychology (I901).

Blakey, R. History of the Philosophy of Mind (1848).

Bower, G. S. David Hartley and James Mill (I88I).

Claparède, E. L'association des idées (1902).

Coleridge, S. T. Biographia Literaria (1847).

Cousin, V. Philosophie sensualiste au XVIIIe siècle (5th ed. 1866).

Dewaule, L. Condillac et la psychologie anglaise contemporaine (1892).

Diogenes Laertes. Lives and Doctrines of Philosophers (A.D. 200 ca.).

Ferri, L. La psychologie de l'association (I883). [Cf. Italian original, 1878.]

Goblot, E. Le vocabulaire philosophique (IgOI); article on 'Association.'

Hamilton, Wm. Reid's Works: with notes (1846).

Höffding, H. Einleitung in die englische Philosophie unserer Zeit (I889).

Janet, Paul, and Séailles, G. Histoire de la philosophie (1887-8).

Kirchner, F. Wörterbuch der philosophischen Grundbegriffe (1886).

Lange, F. A. Geschichte des Materialismus (I866).

Lewes, G. H. History of Philosophy from Thales to Comte (1845-6; rev. 1880 ).

Mackintosh, James. Dissertation on the Progress of Ethical Philosophy (I83I).

Morell, J. D. Speculative Philosophy in the I9th Century (I846; rev. I858).

Morris, G. S. British Thought and Thinkers (1880).

Ribot, T. A. Psychologie anglaise contemporaine (1870; 2d ed. 1875).

Robertson, G. C. Association of Ideas. [Art. in 'Encycl. Brit.' 9th ed. and IIth ed.]

Stephen, I. English Thought in the 18th Century (1876).

Sollier, P. Essai sur l'association en psychologie (1907).

Stout, G. F. Associationism and Association of Ideas. [Art. in Baldwin's 'Dictionary of Philosophy and Psychology' Igor.] 


\section{BIBLIOGRAPHY}

Ueberweg, F. History of Philosophy (I862; several editions). Villa, G. La Psicologia contemporanea (1899).

Windelband, W. Geschichte der neueren Philosophie (1890-92).

B. Ancient and Medieval Contributors (to 1650)

Aristotle [B.c. 384-322]. De anima, bk. II, ch. 12; bk. III, ch. 2-4.

- Parva naturalia: De sensu, ch. I, 4, 7; De memoria et reminiscentia, ch. I, 2. [See esp. De mem., ch. 2, sec. 611.] Augustine [L. Aurelius Augustinus; A.D. 354-430]. Confessions, bk. X, sec. $13,14,28$.

Carneades [B.c. 213 ca.-129]. See Sextus Empiricus, Adv. Math., bk. VII, sec. 176 .

Chrysippus [в.c. ca. 281-208]. See Diogenes Laertes, bk. VII, 'Zeno,' sec. 36.

Descartes, René [A.D. 1596-1650]. Traité de l'homme (posthumous). Epicurus [B.c. 342-270]. See Diogenes Laertes, bk. X, sec. 21. Plato [B.c. 427-347]. Phaedo, sec. 73-6.

Vives, Juan Luis [A.D. I492-I540]. Commentary on Aristotle's De anima, bk. I, and bk. II, ch. De mem.

Zeno of Cittium [ca. B.c. 342-264]. See Diogenes Laertes, bk. VII, sec. $28,36,52$.

\section{The British Associationists}

Alison, A. [1757-1839]. Essays on the Nature and Principles of Taste (1790).

Austin, J. [1790-I859]. Lectures on Jurisprudence (posthumous). Bailey, S. [1791-1870]. Review of Berkeley's Theory of Vision ( 1842 ).

Letters on the Philosophy of the Human Mind ( 3 series, 1855, '58, '63).

Bain, A. [1818-1903]. Senses and Intellect (1855).

Emotions and Will (1859).

Mipd and Body ( 1866 ).

Mental Science (I868).

- Notes in James Mill's 'Analysis' (1869 ed.).

- Logic (1870).

Baxter, A. [1686-1750]. Enquiry into the Nature of the Human Soul (1730?).

Belsham, T. [1750-1829]. Elements of the Philosophy of the Human Mind (r8or).

Belsham, W. [1752-1827]. Essays Philosophical and Moral (1794). Bentham, J. [1748-1832]. Principles of Morals and Legislation ( 1789$)$. 


\section{BIBLIOGRAPHY}

Berkeley, G. [1685-1753]. Essay towards a New Theory of Vision ( I709).

Treatise concerning the Principles of Human Knowledge (I710, I734).

- Dialogues between Hylas and Philonous (I7r3).

New Theory of Vision Vindicated (1733).

Brown, T. [1778-1820]. Lectures on the Philosophy of the Human Mind ( 1820$)$.

Browne, P. [ca. 1665-1735]. The Procedure, Extent and Limits of the Human Understanding ( 1728 ).

Collier, A. [I680-I732]. Clavis universalis (I713).

Collins, A. [1676-1729]. Essay concerning the Use of Reasoning in Propositions ( 1707 ).

Cumberland, R. [163I-I718]. De legibus naturae (1672).

Darwin, E. [I73I-I802]. Zoonomia (I794).

Dodwell, H. [I64I-I7II]. De veteribus graecorum romanorumque cyclis ( I $70 I$ ).

Gay, J. [1699-1745]. Dissertation on the Fundamental Principle of Virtue. (Preface to Archbishop King's 'Origin of Evil,' trans. by Archdeacon Law).

Gerard, A. [1728-1795]. Essay on Taste (1758).

Hamilton, Wm. [1788-1856]. Lectures on Metaphysics (1859-60). [Law of Redintegration, in Lecture 3I.]

Hartley, D. [I705-I757]. Conjecturae quaedam de sensu, motu et idearum generatione (I73I?). [Reprinted 1837 by Parr in - Metaphysical Tracts by English Philosophers of the I8th Century.']

- Observations on Man, his Frame, his Duty; and his Expectations (I749).

Hobbes, T. [1588-1679]. Human Nature (1650).

- Leviathan (Engl. I651 ; Latin, I668).

Hume, D. [I7II-I776]. Treatise on Human Nature (I739).

- Enquiry concerning Human Understanding ( 1748 ).

Lewes, G. H. [18I7-1878]. Problems of Life and Mind (1875-77).

Locke, J. [1632-I704]. Essay concerning Human Understanding (I690).

Maine, H. J. S. [1822-1883]. Ancient Law (186I).

Mandeville, B. de [1670-I733]. Fable of the Bees (1705).

Martineau, J. [1805-I900]. Essay on Priestley (I866).

Mill, James [1773-1836]. Analysis of the Phenomena of the Human Mind ( 1829$)$.

Mill, J. S. [I806-I873]. Logic (I843). 
Examination of the Philosophy of Sir William Hamilton (I865).

Notes in James Mill's 'Analysis' (I869 ed.).

Morell, J. D. [18II-I89I]. Elements of Psychology (I853).

- Introduction to Mental Philosophy (I862).

Murphy, J. J. [1827-1894]. Habit and Intelligence (1869).

Priestley, J. [1733-1804]. Examination of Dr. Reid's Inquiry . . . and Dr. Oswald's Appeal to the Principles of Common Sense (i764).

Letters on Materialism and Hartley's Theory of the Human Mind (1775).

Disquisitions relating to Matter and Spirit (1777).

Smith, A. [I723-I790]. Theory of Moral Sentiments (1759).

On the External Senses (1795).

Spencer, H. [1820-1903]. First Principles (1862).

Principles of Psychology (1855, rev. 1870 ).

Tucker, A. [1705-1774]. The Light of Nature Pursued (1768).

[Anon.] An"Enquiry into the Origin of Human Appetites and Affections, etc. (I747). [Attributed to John Gay.]

[Anon.] Essay on the Nature and Existence of the Material World (I78I).

D. Continental Contributions to the Association Doctrine

Bardili, C. G. [176I-1808]. Ueber die Gesetze der Ideenassociation und insbesondere ein bisher unbekanntes Grundgesetz derselben (1778).

Beneke, F. E. [1798-1854]. Erfahrungsseelenlehre als Grundlage alles Wissens ( 1820 ).

— Psychologische Skizzen (2 vols. 1825-27).

- Pragmatische Psychologie (1832).

- Lehrbuch der Psychologie als Naturwissenschaft (I832).

- Die neue Psychologie (1845).

Bonnet, Ch. [1720-I793]. Essai de psychologie (1754).

- Essai analytique sur les facultés de l'âme (1760).

Cabanis, P. J. G. [1757-I808]. Rapports du physique et du morale de l'homme (1802).

Condillac, Etienne Bonnot de [1715-1780]. Essai sur l'origine des connoissances humaines (I746).

Traité des sensations (1754).

L'art de penser ( 1780 ).

Logique (1780, posthumous). 
Cureau de La Chambre, Marin [ca. 1596-1669]. Système de l'âme (i664).

Destutt de Tracy, A. L. Cl. [1754-1835]. Eléments d'idéologie (I80I-15).

Diderot, d'Alembert, etc. Encyclopédie ou Dictionnaire raisonné des sciences, etc. (175I-1765). [Art. 'Association des idées,' by Abbé Yvon.]

Dorsch, A. J. [1758-1819]. Ueber die Ideenverbindung und die darauf gegründeten Seelenverstände (1788).

Ernesti, Joh. Aug. [1707-178I]. De mente humana (1734).

Fortlage, Karl [1806-1881]. System der Psychologie als empirische Wissenschaft (I852).

Fries, J. Fr. [1773-1843]. Neue oder anthropologische Kritik der Vernunft (1807).

Galluppi, Pasquale [1770-1846]. Elementi di psicologia (1834).

Goerenz, Joh. Aug. [1765-1836]. Vestigia (1791).

Helvétius, Cl. Ad. [1715-1771]. De l'esprit (1758).

De l'homme, de ses facultés intellectuelles, et de son éducation (1784, posthumous).

Herbart, Joh. Fr. [1774-184I]. Lehrbuch der Psychologie (1816).

Hissmann, Mich. [1752-1784]. Geschichte der Lehre von der Association der Ideen (1777).

Jouffroy, Th. Simon [1796-1842]. Mélanges philosophiques (1833). La Mettrie, Offray de [1709-175I]. L'histoire naturelle de l'âme (I745).

L'homme machine (1848).

Laromiguière, P. [1756-1837]. Leçons de philosophie ou Essai sur les facultés de l'âme (1815-18).

Lotze, R. Hermann [1817-188I]. Medicinische Psychologie (1852). Maass, Joh. Geb. Ehr. [1766-1823]. Versuch über die Einbildungskraft (1792).

Maine de Biran, M. F. P. G. [1766-1824]. Influence de l'habitude sur les facultés de penser (1802).

Malebranche, Nic. [1638-1715]. De la recherche de la Vérité (1674). Mervoyer, P. M. [1805-ca. I866]. Etude sur l'association des idées (1864).

Müller, Joh. Peter [180I-1858]. Handbuch der Physiologie des Menschen (1833-40).

Spinoza, Benedict [1632-1677]. Ethics (1674).

Taine, H. Ad. [1828-1893]. De l'intelligence (I870).

Tetens, Joh. Nic. [1738-1807]. Philosophische Versuche über die menschliche Natur und ihre Entwicklung (1777). 
Zanotti, Fr. Maria [1692-1777]. Della forza attrativa delle idee (I747).

E. Recent Investigations of Association Problems

Allin, A. Ueber das Grundprincip der Association (I895).

Andrade, J. Du rôle de l'association des idées dans la formation des concepts métaphysiques du mécanisme. Rev. de mét., I889, 7, $176-182$.

Ardigò, R. Lo sforzo associative e la dinamica mentale. Riv. di filos. scient., 1889, 8, 65-88.

Aschaffenburg, G. Experimentelle Studien über Association. Psychol. Arb., I895, 1, 209-299; 1897, 2, I-83 ; 1902, 4, 235-373.

Baldwin, J. M. Senses and Intellect (I889).

Bechterew, W. von. Experimentell-psychologische Untersuchung von Verbrecher. J. f. Psychol. u. Neurol., I903, 2, I-3.

Bergström, J. A. Relation of the interference to the practice effect of an association. Amer. J. of Psychol., 1894, 6, 433-422.

Binet, A. L'étude expérimentale de l'intelligence (I903).

Bourdon, B. Les résultats des théories contemporaines sur l'association des idées. Rev. philos., I89I, 3I, 56I-6I0.

Recherches sur la succession des phénomènes psychologiques. Rev. philos., 1893, 35, 225-260.

Observations comparatives sur la reconnaissance, la discrimination et l'association. Rev. philos., I895, 40, I53-185.

Bradley, F. H. Association and thought. Mind, I887, I2, 354-381. Brochard, V. La loi de similarité dans l'association des idées. Rev. philos., I880, 9, 257-269.

Browne, C. E. Psychology of the simple arithmetical processes. Amer. J. of Psychol., 1906, 17, I-37.

Calkins, M. W. A suggested classification of cases of association. Philos. Rev., 1892, $I, 389-402$.

- Association. Psychol. Rev., I894, I, 476-484; 1896, 3, 32-49. - Association. Psychol. Monog., 1896, No. 2.

Memory and association. Psychol. Rev., I898, 5, 45I-462.

Carr, H. A. Length of time interval in successive association. Psychol. Rev., 1919, 26, 335-353.

Carr, H. A., and Freeman, A. S. Time relationships in the formation of associations. Psychol. Rev., 1919, 26, 465-473.

Cattell, J. McK. Experiments on the association of ideas. Mind, $1887,12,68-74$.

- Psychometrische Untersuchungen. Philos. Studien, I888, 3, 305-336, 452-492; 4, 24I-250. 


\section{BIBLIOGRAPHY}

and Bryant, S. Mental association investigated by experiment. Mind, 1889, 14, 230-250.

Cordes, G. Experimentelle Untersuchungen über Association. Philos. Stud., 1901, $17,30-77$.

Crane, H. W. A study in association reaction and reaction results. Psychol. Monog., 1915, No. 80.

Deffner, K. Die Aehnlichkeitsassociation. Zsch. f. Psychol., I898, $18,218-249$.

Dumas, Geo. L'association des idées dans les passions. Rev. philos., I891, 3I, 483-505.

Dumont, Ch. De la ressemblance et de la contiguité dans l'association des idées. Rev. de mét., I895, 3, 285-307.

Duprat, L. Association mentale et causalité psychologique. Rev. phil., 1913, 75, 452-470.

Eastman, F. C., and Rosanoff, A. J. Association in feeble-minded and delinquent children. Amer. J. of Insan., 1912, 69, 125-141.

Ebbinghaus, H. Ueber das Gedächtnis (1885).

Fite, W. The associational conception of experience. Philos. Rev., 1900, 9, 268-292.

Contiguity and similarity. Philos. Rev., I900, 9, 613-629.

Flint, R. Associationism and the origin of moral ideas. Mind, I875, I, 321-334.

Foster, W. S. On the perseverative tendency. Amer. J. of Psychol., 1914, 25, 393-426.

Foucault, M. Etude expérimentale sur l'association de ressemblance. Arch. de psychol., 19II, 10, 338-360.

Froeberg, S. Simultaneous versus successive association. Psychol. Rev., 1918, 25, 156-163.

Galton, F. Psytchometric experiments. Brain, I879, 2, I49-162.

Goblot, E. Sur la théorie physiologique de l'association. Rev. philos., $1898,46,487-503$.

Halévy, E. De l'association des idées. Bibl. du Congrès int. de phil., Sec. I, 1900, pp. 219-235.

Höffding, $\mathrm{H}$. Ueber Wiedererkennen, Association und psychische Activität. Vjsch. f. wiss. Phil., 1889, 13, 420-458; 1900, 14, 27-54, 167-205, 392-316.

Howe, H. C. "Mediate" association. Amer. J. of Psychol., I894, 6, 239-24I.

Huber, H. Ueber den Einfluss von optischen oder akustischen Reiz und grammatikalischer form des Reizwortes auf dem Assoziationsvorgang. J. f. Psychol. u. Neurol., 1918, 23, 171207. 
Hunter, W. S. A reformulation of the law of association. Psychol. Rev., 1917, 24, 188-196.

James, W. The association of ideas. Pop. Sci. Mo., 1880, 16, 577593.

- Principles of Psychology (1890). [Vol. I, pp. 550-604.]

Jastrow, J. Community and association of ideas. Psychol. Rev., $1894, I, 152-158$.

Jost, A. Die Assoziationsfestigkeit in ihrer Abhängigkeit von der Verteilung der Wiederholungen. Zsch. f. Psychol., 1897, 14, 436-472.

Jung, C. G., Bleuler, E., Ricklin, Fr., etc. Diagnostische Associationsstudien. J. f. Psychol, u. Neurol., 1904, 3, 55-83, 145-164, $193-215,283-308 ; 4,24-87$, I09-123, 129-143; 1905, 5, 73-90; 6, I-36, I26-154; 1906, 7, I-24, 223-252; 8, 25-60; 1907, 9, I88-197, 243-278; Io, I49-181 ; II, 65-95, 133-153; 1910, I6, 102-128.

Jung, C. G. Associations d'idées familiales. Arch. de psychol., $1907,7,160-168$.

The association method. Amer. J. of Psychol., 1910, 21, 219269.

Kellor, F. A. The association of ideas. Ped. Sem., 1901, 8, 34I358.

Kent, G. H., and Rosanoff, A. J. A study of association in insanity. Amer. J. of Insan., 1910, 67, 37-96, 317-390.

Kiesow, F. Ueber sogenannte 'frei steigende' Vorstellungen und plötzlich auftretende Aenderungen des Gemütszustandes. Arch. f. d. ges. Psychol., 1905, 6, 357-390.

Kirkpatrick, E. A. Experimental study of memory. Psychol. Rev., $1894, I, 602-609$.

Kraepelin, Emil. Experimentelle Studien über Associationen. Versamml. Deutsch. Naturf. u. Aerzte, Freiburg (1883).

Ueber den Einfluss der Uebung auf die Dauer von Associationen (I889).

Ueber die Beeinflussung einfacher psychischer Vorgänge durch einige Arzneimittel ( 1892 ).

Kramer, F., and Stern, W. Selbstverrat durch Assoziation. Beitr. z. Psychol. d. Aussage, 1905, 3, I50-I55. [Cf. 1906, 4, 1-32.]

Lay, A., and Menzerath, P. L'étude expérimentale de l'association des idées dans les maladies mentales (I9II).

Lay, W. Mental Imagery. Psychol. Monog., 1898, No. 7.

Lehmann, A. Ueber Wiedererkennen. Philos. Stud., 1888-89, 5, 96156.

Loring, M. W. Methods of studying controlled word associations. Psychobiol., 1918, 1, 369-428. 
May, M. A. The mechanism of controlled association. Arch. of Psychol., 1917, No. 39.

Mayer, A., and Orth, J. Zur qualitativen Untersuchungen der Association. Zsch. f. Psychol,, I90I, 26, I-13.

Meyer, E. Ueber die Gesetze der simultanen Assoziation und das Wiedererkennen (I9I0).

Mitchell, I., Rosanoff, I. R., and Rosanoff, A. J. A study of association in negro children. Psychol. Rev., 1919, 26, 354-359.

Müller, G. E., and Pilzecker, A. Experimentelle Beiträge zur Lehre vom Gedächtnis. Zsch. f. Psychol., Ergbd. I, 1900.

Müller, G. E., and Schumann, F. Experimentelle Beiträge zur Lehre des Gedächtnisses. Zsch. f. Psychol., 1893, 6, 81-190, 257-339.

Münsterberg, H. Beiträge zur experimentellen Psychologie, Heft I (I889).

Die Association successiver Vorstellungen. Zsch.f. Psychol., 1890, $I, 99-107$.

Beiträge zur experimentellen Psychologie, Heft 4 (I892). [Studien zur Associationslehre, pp. I-39.]

Nagel, F. Experimentelle Untersuchungen über Grundfragen der Assoziationslehre. Arch. f. d. ges. Psychol., 1912, 23, 156-253.

Offner, M. Ueber die Grundformen der Vorstellungsverbindungen. Philos. Monatsh., 1892, 28, 385-416, 513-347.

Paulhan, Fr. L'associationisme et la synthèse psychique. Rev. philos., 1888, 25, 32-64.

Peters, W. Ueber Aehnlichkeitsassociation (IgIo).

Piéron, H. L'association médiate. Rev. philos., 1903, 56, I42-149.

— La conception générale de l'association des idées et les données de l'expérience. Rev. philos., 1904, 57, 493-517.

Poppelreuter, W. Ueber den Versuch einer Revision der psychophysiologischen Lehre von der elementaren Assoziation und Reproduktion. Monat. f. Psychiat. u. Neurol., 19I5, 37, 278323.

Pillsbury, W. B. A study of apperception. Amer. J. of Psychol., I897, 8, 31 5-393.

Rosanoff, I. R., and Rosanoff, A. J. A study of association in children. Psychol. Rev., 1913, 20, 43-89.

Rusk, R. R. Experiments on mental association in children. Brit. J. of Psychol., 1910, 3, 349-387.

Schiessl, M. Untersuchungen über die Ideenassociation und deren Einfluss auf den Erkenntnissakt. Zsch. f. Philos. u. philos. Kr., $1872,61,247-282 ; 1873,62,1-30$. 
Schmidt, Friedrich. Experimentelie Untersuchungen zur Associationslehre. Zsch. f. Psychol., I902, 28, 65-95.

Scripture, E. W. Ueber den associativen Verlauf der Vorstellungen. Philos. Stud., I891-92, 7, 50-146.

Shepard, J. F., and Fogelsanger, H. M. Studies in association and inhibition. Psychol. Rev., 1913, 20, 290-311.

Smith, T. L. On muscular memory. Amer. J. of Psychol., 1896, 7, 453-490.

Smith, W. G. Zur Frage der mittelbaren Association (1894).

- Mediate Association. Mind, N. S., 1894, 3, 289-304.

Stern, W. Psychologische Tatbestandsdiagnostik. Beitr. z. Psychol. d. Aussage, I905, 2, 145-147.

Stout, G. F. Analytical Psychology (1896).

Stricker, S. Studien über die Association der Vorstellungen (1883). Sully, J. Outlines of Psychology (1884).

- Human Mind (1892).

Sutherland, A. H. Critique of word association reactions (I9I3). Tanner, A. E. Association of Ideas (1900).

Tanzi, E. Intorno all'associazione delle idee. Riv. di filos. scient., I888, 7, 602-609.

Thumb, A., and Marbe, K. Experimentelle Untersuchungen über die psychologischen Grundlagen der sprachlichen Analogiebildung ( I 901 ).

Titchener, E. B. Outline of Psychology (1896).

- Text-book of Psychology (1910).

Tolman, E. C., and Johnson, I. A note on association-time and feeling. Amer. J. of Psychol., 1918, 29, 187-195.

Trautscholdt, M. Experimentelle Untersuchungen über die Association der Vorstellungen. Philos. Stud., 1883, I, 213-250.

Wahle, R. Bemerkungen zur Beschreibung und Eintheilung der Ideenassociation. Vjsch. f. wiss. Philos., 1885, 9, 404-432.

Ward, James. Article 'Psychology' Encyclopedia Britannica, 9th ed. [Vol. XX (I886), pp. 37-85.]

Assimilation and association. Mind, N. S., 1893, 2, 347-362; 1894, 3, 509-532.

Wells, F. L. Some properties of free association time. Psychol. Rev., I9II, I8, I-24. (Cf. Practice effects in free association. Amer. J. of Psychol., 1911, 22, I-I2.)

- A preliminary note on the categories of association reactions. Psychol. Rev., 1911, 18, 229-233.

The question of association types. Psychol. Rev., 1912, 19, 253-270. 


\section{BIBLIOGRAPHY}

Association type and personality. Psychol. Rev., 1919, 26, 37I-376.

- Autistic mechanisms in association reaction. Psychol. Rev., $1919,26,376-382$.

Wertheimer, M., and Klein, J. Psychologische Tatbestandsdiagnostik. Arch. f. Kriminalanthrop., 1904, 15, 72-113.

Wertheimer, M. Experimentelle Untersuchungen zur Tatbestandsdiagnostik. Arch. f. d. ges. Psychol., 1905, 6, 59-131.

Wimmer, A. Ueber Assoziationsuntersuchungen besonders schwachsinniger Kinder. Monat. f. Psychiat. u. Neurol., 1909, 25, 169-182, 268-284.

Woodrow, H., and Lowell, F. Children's association frequency tables. Psychol. Monog., I917, No. 97.

Wohlgemuth, A. Simultaneous and successive association. Brit. J. of Psychol., 1915, 7, 434-452.

Woodworth, R. S., and Wells, F. L. Association tests. Psychol. Monog., I9I I, No. 57.

Wreschner, A. Eine experimentelle Studie über die Association in einem Falle von Idiotie. Allg. Zsch. f. Psychiat., 1900, 57, 24I339.

Die Reproduktion und Assoziation von Vorstellungen. Zsch. f. Psychol., Ergbd. 3 (1907-9).

Wundt, W. Grundzüge der physiologischen Psychologie. (Ist ed. 1874, 5th ed. 1902-3). [Section on Association, Vol. III.]

- Bemerkungen zur Associationslehre. Philos. Stud., I89I-2, 7, 329-36r.

Sind die Mitglieder einer mittelbaren Association bewusst oder unbewusst? Philos. Stud., I894, Io, 326-328.

Yerkes, R. M., and Berry, C. S. The association reaction method of mental diagnosis. Amer. J. of Psychol., 1909, 20, 22-57.

Ziehen, Th. Ueber Ideenassoziation des Kindes. Samml. v. Abh. a. d. Geb. d. päd. Psychol., I8g8, I, pt. 6; 1900, 3, pt. 4. 



\section{INDEX OF AUTHORS}

The principal discussion of each author is indicated by a double page reference, $e . g ., 125^{-1} 30$.

Incidental references to writers are not included in the Index.

Alison, A., 68, 275

Allin, A., 243

Andrade, J., 235

Ardigò, R., 202, 235

Aristotle, 4, 8, $15,23-28,5 \mathrm{I}$ n., $6 \mathrm{I}, 157,186,203,259,272 \mathrm{ff}$., $277,282,285$

Arnold, F., 22, 250, 254

Aschaffenburg, G., 228, 249 ff.

Augustine, 30, 274

Austin, J., 82

Bailey, S., II6

Bain, A., I6, 101, I04-II7, I18, $120,143,145,167-168,213,263$, $270,275,278,28 \mathrm{I}, 286 \mathrm{f}$.

Baldwin, J. M., 20, 242

Bardili, C. G., 204

Bechterew, W., von, 230

Belsham, T., $65 \mathrm{n}$.

Belsham, W., $65 \mathrm{n}$.

Beneke, F. E., 208-210

Bentham, J., $65 \mathrm{n}$.

Bergström, J. A., 219

Berkeley, G., I3 ff., I8, 40-42, I 16, 157, 26I f., 266 f., 274, 277

Bernard, C., 196

Berry, C. S., 232

Binet, A., 239

Blakey, R., 2I n., 6I n.

Bleuler, E., 230

Bonnet, C., I87-I89, 262, 284

Bourdon, B., $236 \mathrm{f}$.

Bower, G. S., 21

Bradley, F. H., 214

Brochard, V., 24I

Brown, T., 6 n., 13, I5, 70-80, 128, 134, 162-163, 178 n., 260 f., 264 f., $267,275,278$ f., 28 I f., $285 \mathrm{f}$.

Browne, C. E., 239
Browne, P., 47

Bryant, S., 247, 249

Cabanis, P. J. G., 192

Calkins, M. W., 220, 238, 249 f.

Carneades, 29, 274

Carpenter, W. B., 82 n.

Carr, H. A., 221

Cattell, J. McK., 222, 247, 249

Chrysippus, 29

Claparède, E., 22, I87, 250, 252

Clifford, W. K., I53

Coleridge, S. T., $2 \mathbf{I}$

Collier, A., 47

Collins, A., 47

Comte, A., I39

Condillac, E. T. de, I0, I6, I83I86, 191, 196, 199 n., 262, 284

Cordes, G., 228

Cousin, V., 2I

Cureau de La Chambre, M., 3 n., I8I

Darwin, C., 16, I 18

Darwin, E., 68-69, 274, 278

Deffner, K., 244

Descartes, R., II, 32, I55, I8I, 266, 274, 285

Destutt de Tracy, A. L. C., I9I192, 262

Dewaule, L., 185,284

Diogenes Laertes, 29

Dodwell, H., 47

Dorsch, A. J., 204

Dumas, G., 237

Dumont, Ch., 243

Duprat, L., 256

Eastman, F. C., 233

Ebbinghaus, H., 217 f.

Encyclopedists, I86

Epicurus, 29, 274

Ernesti, J. A., 203 
Fechner, 175, 212

Ferri, L., I8 f., 202

Fite, W., 225

Flint, R., 2I 4 n.

Fogelsanger, H. M., 240

Fortlage, K., 210

Foster, W. S., 240

Foucault, M., 245

Freeman, A. S., 22I

Freeman, E. A., 82 n.

Frenzel, B., $203 \mathrm{n}$.

Fries, J. F., 205

Froeberg, S., 246

Galluppi, P., 201

Galton, F., I 53, 215-216, 220

Gay, J., 47-49, 262, 275

Goblot, E., 243

Goerenz, J. A., 204

Grote, G., 82 n.

Halévy, E., 238

Hamilton, W., 2I, 24, 30 f., 95, I97 f., 204, 213, 284

Hartley, D., I2, I4 f., 46, 50-64, 7I, 82, IOI n., I28, I57-162, I67, $183,187,262,267,269$ ff., 276 ff., 283, 285, 292, 301 307

Helmholtz, 243

Helvétius, $\mathrm{Cl}$., I0, I89-I9I

Herbart, J. F., I I6, 24I

Hissmann, M., 204

Hobbes, T., 4 ff., I 4 f., 33-36, I 55, I63, I 90,259 ff., 267,27 I f., $274,277,285,296$

Höffding, H., 243

Holt, E. B., I79 n.

Howe, H. C., 227

Huber, H., 234

Hume, D., 5, I2, I4 f., 43-47, 52 n., 56, I 56 f., 183, I90, 200, $26 \mathrm{I}, 267,274,277$

Hunter, W. S., 246, 279 n.

Ideologists, I9I

James, W., I47 n., I7I, 24I, 304

Janet, P., 2I

Jastrow, J., 237

Johnson, I., 223

Jost, A., 2I9 f.

Jouffroy, Th. S., 195

Jung, C. G., 230, 250 f., 253
Kant, I., II, 46, I27 n., 162, 177, 213

Kellor, F. A., 229

Kent, G. H., 232 ff.

Kiesow, F., 228

Kirkpatrick, 'E. A., 219

Klein, J., 23I n.

Kraepelin, E., 229, 249 ff.

La Chambre (see Cureau de La C.)

La Mettrie, Offray de, 186

La romiguière, $P$., $193 \mathrm{f}$.

Lay, W., 233, 238

Lehmann, A., 242 f.

Leibnitz, G. W. L., 203

Lewes, G. H., I6, I20, I37-153, I72-I75, I98 n., 264, $270 \mathrm{f}$., 275 , 278 f., 284, 286, 292, 294, 297 n., 298 n., 299,300 n., 30 I ff.

Locke, J., 3 ff., I2, I4 f., 36-40, 93 , I $43,156,173$, I81 f., 190 , 262,266 f., $27 \mathrm{I}, 274,277,285 \mathrm{f}$.

Loring, M. V., 234

Lotze, H., 2 I I

Lowell, F., 233

Maass, J. G. E., 204

Mackintosh, J., $82 \mathrm{n}$.

Maine, H. J. S., 82 n.

Maine de Biran, M. F. P. G., I92-193, 202, 276

Malebranche, N., I8I f.

Mandeville, B. de, 47

Marbe, K., 223

Martineau, J., $82 \mathrm{n}$.

Maudsley, H., $82 \mathrm{n}$.

May, M. A., 22I

Mayer, A., 223

McCosh, J., I2

Menzerath, P., 233

Mervoyer, P. M., I94-I95, 284

Meyer, E., 22I

Mill, J., I6, 8I-94, 97 f., 100, III, II 5, I37, I63-165, 199, 235, 263 , 265 n., $270,275,286,297$ n.

Mill, J. S., I4, I6, 79, 87, 91, 95I03, II I, I63, 165-167, 173, I99, $264,270,275,278$ f., 282 f., 286 , 298

Mitchell, I., 233

Morell, J. D., 2I, II6

Müller, G. E., 218, 220 
Müller, J., 2I0-2II

Münsterberg, H., $225 \mathrm{f}$.

Murphy, J. J., I52

Nagel, F., 228

Offner, M., $248 \mathrm{f}$.

Orth, J., 223

Paulhan, Fr., 235

Peters, W., 245

Piéron, H., 228, 246

Pillsbury, W., 224

Pilzecker, A., 220

Plato, 23 f., 274

Poppelreuter, W., 246

Priestley, J., 5I, 67-68, 266 f., 274

Reid, T., 12, 46, 64, 204 n., 213

Ribot, Th., I8 f., I99-200

Ricklin, Fr., 230, 250, 253

Robertson, G. C., I9 f.

Rosanoff, A. J., $232 \mathrm{ff}$.

Rosanoff, I. R., 233

Rusk, R. R., 232

Schiess1, M., 2I3

Schmidt, F., 223

Schumann, F., 218

Scripture, E. W., 226

Séailles, G., 2I

Sextus Empiricus, 29

Shepard, J. F., 240

Sherrington, C. S., 305 f.

Smith, A., $65 \mathrm{n}$.

Smith, T. L., 237

Smith, W. G., 227

Sollier, P., 22, 250, 254

Spencer, H., I4, I6, I18, I20, I21-1 37, I 43, I49, I68, I70-I 72, $263,270,272,278$ ff., 283,286 , 292, 301 n., $302 \mathrm{f}$.

Spinoza, B., 203

Stern, W., 232

Stewart, D., 12 f., 70

Stoics, 28
Stout, G. F., 20, I75, 213

Stricker, S., 216

Sully, J., I I6 f., I75, 213

Sutherland, A. H., 234

Taine, H. A., 10, 16, 196-199, $265,276,284$

Tanner, A. E., 238 f.

Tanzi, E., 235

Tetens, J. N., 203 f.

Thumb, A., 223

Titchener, E. B., 27 n., 244 f.

Tolman, E. C., 223

Tourry, Marquis de 1a, 200

Trautscholdt, M., 216, 247 f., 250

Tucker, A., 6 n., $65-67,69,98$, 264, 275, 279

Ueberweg, 20

Vives, L., 3I, 274

Wahle, R., $247 \mathrm{f}$.

Ward, J., I75, 21 3, 242

Weber, E. H., 2 I I

Wehrlin, 230

Wells, F. L., 233 f., 25I, 255

Wertheimer, M., 23I

Wimmer, A., 232

Wohlgemuth, A., 245

Wolff, J. C. von, 9

Woodbridge, F. J. E., 28I n.

Woodrow, $\mathrm{H}_{\text {., }} 233$

Woodworth, R. S., 234

Wreschner, A., 229, 232, 240, 25I, 255

Wundt, W., I75, 212, 223 f., 227, $248 \mathrm{n}$.

Yerkes, R., 232

Yvon, C., 186

Zanotti, Fr., $200 \mathrm{f}$.

Zeno of Cittium, 29

Ziehen, Th., 222, 224 



\section{INDEX OF TOPICS}

Affection, 94, 174, 299, $303 \mathrm{ff}$.

After-sensation, 296

Alternative associates, 73

Apperception, 223 ff., 243

Apprehension, 246

A priori psychology, 9, II f., II9, 203

Arithmetical processes, 239

Assimilation, 225, 242

Association (see Contiguity, Laws of association, etc.)

alternative terms for, $6 \mathrm{n}$., 40 , $70,127,149,163,170,173$, $236,242,260,275,279$

classifications, 247-257

definitions, 6

experimental treatment, $2 \mathrm{r} 3 \mathrm{ff}$.

in animals, 22I, 24I

in children, 222

in criminals, $229 \mathrm{ff}$.

in the feeble-minded, $229 \mathrm{ff}$.

in the insane, $229 \mathrm{ff}$.

nature, 258-26I

Association of ideas (term), 3 , 36,149

Association psychology, passim adverse influence, $213 \mathrm{f}$.

applications, 176

estimate of, $175 \mathrm{ff}$.

historical stages, $15 \mathrm{f}$.

problems, 258-265

relation to philosophy, Io f., I3 f., 46

Association tests, $229 \mathrm{ff}$.

Attention, 37, 102, 20I, 245, 285, 306

preparatory, 22I

Attractive force, 201

Awareness of movements, 301 of relations, $28 \mathrm{I}$

Behavior, 174, 300

Belief, 59, 9I ff., 100 ff., I10, I66, 298

Causality, 43 f., 102
Chance association, 39

Chemical theory (see Mental chemistry)

Clearness, 245

Coalescence of ideas, 49

Coexistence (see Simultaneous association)

Cognition, I24, 295 ff.

Colored patterns, 227

Composition, 39, 66

Compound association, 108

Conation, 299 ff., 302

Conception, 90

Conduct, 174, 300

Conflict of ideas, 205, 2 I I

Consciousness, 153

fringe of, 147,297

motor, $160,300 \mathrm{ff}$.

primitive, I22, I39

unity of, 147

Constitutional tendencies, 73 , 285

Contiguity, 4, 6, 7, 23, 27 f., 30 , $33,35,37,42$ ff., $55,72,96 \mathrm{f}$., 106, I26, I28, I45, I59, I I I, I85, 195, 197, 201, 204, 225, 24 I ff. 283 f., 289

Contrast, 4, 8, 27 f., 31, 72, 96, I09, 209, 283

Correlation, 242

Data, elementary, I22, I39, I53, 292

mental, 82, 238, 28I, 288

Decaying sensation, 34, 272, 296

Decreasing gain, I29

Discrimination, I05, I14, 28I, 282 n., 306

Dispositions (see Traces)

Distance perception, 58, I16, 157

Dominant element, II

Double-aspect theory, 269

Dreams, 62

Drugs, 229

Duration, $73,285 \mathrm{f}$. 
Effort, I02, 301 n.

Emotion, 60, II3, I33, I43, I47, 237,303

Emotional congruity, 24I

Empirical method, 154, 213 ff.

Esthetics, 68

Esthetic sentiment, 304

Equivalence, principle of, 149

Evolution concept, II8 ff., I50, I52, 168

External association, 250

Feeling, 192, 223, 300

association of, 125,278

classes, I $22 \mathrm{ff}$.

logic of, 147

registration of, I4I

relations of, I22 f., I27, 135, I70

Fiat, 300

Forms of experience, 177

Free association, 215, 222, 228, $233 \mathrm{f} ., 236$

Frequency, 8, 37, 60, 73, 76 f., 85, 97, I29, I32, I34, I59, I85, I93, 217, 220, 245, 250, 256, $285 \mathrm{ff}$.

Functional psychology, 239

Fundamental concepts, 29I

Fusion, 28, 36, 66 f., 79, 88, 116, I73, 206, 264, 274, 279

Grouping (see Logic)

Habit, 36, 40 f., 76 f., I34, 159, I92, 24I, 244, 285 (see also Repetition)

Hedonic accompaniment, 37, 47, $58,285 \mathrm{ff} ., 304$

Higher mental states, I30

Ideas, 4 f., 4I, 43, 52, 139, I74 abstract, 235 complex, 38 decomplex, 55 duplex, 87 general, 38 genesis of, 53 innate, $32 \mathrm{f}$., II 8 , I 55 of relations, 38,78

Ideation (term), 83, 294 physiology of, 27 I

Identity, 284

Ideomotor experiences, 302
Imagery, I39, I47, $295 \mathrm{f}$.

Imagination, $34,40,62,76$, $109 \mathrm{f}$., 147

Imitation, 49

Impressions, 43, 44 n., 192

Impulse, I4I, $299 \mathrm{f}$.

Inconceivability, I49

Individual differences, 240 types, 223

Indissoluble association (see Inseparability) criticism of term, 98

Inheritance, 134

Inhibition, 240,256

Innervation feelings, $300 \mathrm{f}$.

Inseparability, 48, 86, 97, I00, I85

Instincts, $130 \mathrm{f}$., 302.

Integration, 206, 270

Intellect, I49

Intensity, 8, 73, 96, I85, $285 \mathrm{ff}$.

Interactionism, $267 \mathrm{ff}$.

Interest, I4I

Interference effect, 219, 240

Internal association, 250

Interoceptors, 305

Interpretation of association, typical, 287

Introspection, I40, I52, I72

Intuition, I44, I5I

Intuition psychology, 9, 12

Irradiation, I4I, I44, I98

James-Lange theory, 303

Japanese script, 226

Jost's Laws, $220 \mathrm{f}$.

Judgment, 186

Kent-Rosanoff tests, 233

Knowledge, I Io

Language, 148

Lapsed links, 66, 98

Laws of association, 24I, 282287,289

Ardigò's, $235 \mathrm{f}$.

Aristotle's, 25

Bain's, I06

Beneke's, 209

Brown's, 72, I 63

Darwin's, 69

Hartley's, 53

Hunter's, 246

Maine de Biran's, 193

J. Mill's, $84 \mathrm{f}$. 
J. S. Mill's, 96

Piéron's, 246

Primary, 72

Qualitative, $282 \mathrm{ff}$

Quantitative, 285 ff., 289

Secondary, 73, 80

Spencer's, I29

Sully's, I $6 \mathrm{f}$.

Taine's, I97

Titchener's, 245

Learning, methods of, 238

Local signs, 2 I I

Logic (associative), I4I, I43, I 47 ff., 173, 270, 276, 299

Logical types, 256

Matter, definition of, 199

Meaning, 297, 299

Mechanical theory, 87, II5, I66, 187,262

Mediate association, $225 \mathrm{ff}$.

Mental chemistry, 49, 79, 88, $98 \mathrm{f} ., \quad 103,136,163,165 \mathrm{f}$, $179,198,264,289,293,295$, 306

Mental diagnosis, $229 \mathrm{ff}$. faculties, 20I

forms, 127

operations, 307

tendencies, 208

Memory, 24 ff., 29 ff., 33 f., 60 f., $75,90,130,147,185,190,201$, 215

primary, 83

Mind, 5I, I33

Modes of association, 66, 273282

Moral sentiments, 304

Motives, II3

Motor association, 54, 56, 69, 237

Motor phenomena, 52, 167, 192, 302

Names, 89, 196, 297

Nativism, 177

Necessary connection, 44, 48, 274

Nervous arc concept, 151

Nervous shock, 122, 292

Neural activity (see Physiology of association)

Neural tremors, I40, 146, I73, 292

Nonsense syllables, 217 ff., 227, 237,245
Notion, general, I4

Not-self, I33

Oblivescence, 98

Organic motors, 143

Pain sense, 303

Parallelism, 5I, 262, $267 \mathrm{ff}$.

Parts of speech, 223, 234

Part-whole relationship, 243

Perception, 89, I46, I92, I99, 295

Perseveration, 215, 232, 236, 240, 245

Physiology of association, 32, 5I, 7I, II4, I24, I35, I40 f., I45, I 58, I78, I88 f., 206, 210, 266$273,280,288,307$

Pleasure-pain (see Hedonic accompaniment)

Power, I02

Practical effect, 229, 240

Predication, I00

Proprioceptors, 306

Psychophysical relation, 292, 307

Psychoplasm, I40

Quality, I46

Reaction time, 215 f., 221,222 f., 23 I f., 240,257

Reason and instinct, I3I

Reasoning, 63, 66, 93, 160

Recall and recognition, 219, 237

Recency, 73, 220 f., 239, 24I, $285 \mathrm{ff}$.

Recognition theory, $242 \mathrm{f}$.

Redintegration (see Reinstatement)

Reflection, ideas of, $37,47,52,65$, $93,156 \mathrm{f}$., 184,298

Reflex action, 130, 302

Reinstatement, 8, I42, I50, 197, 25I, 284

Reintegration (see Reinstatement)

Relations, association of, 125 revival of, 126

Relative suggestion, 77 ff., 279

Relativity, I05 f., I35, I68

Repetition (see Frequency)

Resemblance (see Similarity)

Resistance, feelings of, III, $301 \mathrm{n}$.

Restriction, 141, I44 
Retention, 105, 217

Revival, 72, 123 f., 128, I35, 142, I44, I 70, I98, $279 \mathrm{f}$.

Self, I32 f., I44

Self-consciousness, 298

Sensation, 34

alimentary, 83

association of, $45,195,277,289$

decaying, 34, 272, 296

laws of, I98

of disorganization, 82

psychology, Io

systemic, 152

Sensation psychology, I0, 34, I55, 184, 190, 238

Senses, 57, 292, 303

Sensibility, I4I

Sequence (see Successive association)

Signature, I4I

Signs, 4I, 140, I47, I50, I85, I96, 297

local, 2 II

Similarity, 4, 6, $7 \mathrm{f}, 23,27 \mathrm{ff}$., 3I, $33,37,41,43 \mathrm{ff} ., 55,72,96 \mathrm{f}$., I07, I36, I7I, I85, I95, I97, $203,209,236,24 \mathrm{I}$ ff., 244,250 , 283

Simultaneous association, 7,38 , $42,45,54,56,66$, 125, 128, 130, 156, 159, 164, 182, 202 , 209, 2 I I, 22I, 225, 242, 244 ff., $256,264,273$ ff., $282,304,306$

Social contract theory, I6I

Social phenomena, I39

Source books, 18

Space perception, 298 (see also Distance)

Specific nerve energies, 210

Statue, 183, 187

Subject and object, II, I32
Successive association, $7,29,4 \mathrm{I}$, $54,66,71,128,136,157,159$, I64, I73 f., 202, 209, 242, 244 , $250,256,273$ ff., $283,304,306$

Suggestion, 40, 70, $77 \mathrm{ff} ., \mathrm{I}_{3}$, 279

Synthesis, law of, 235 (see also Mental chemistry)

Systemic senses, I52

Temperament, types of, 234

Temporal proximity, 243

Tendencies, mental, 208

Testimony, psychology of, 232

Tests, associative, $229 \mathrm{ff}$.

Thought, 148, 160, 297 laws of, 103, I 49 trains, 35, 66, 239, 298

Traces, 35, 53, 209, 266

Transformation, 179, 263, 293, 306 (see also Mental chemistry)

Types of association, 216, 223, 234, 237, 239

Unconscious associations, 223

Understanding, 184, 194

Utilitarianism, 48, 65

Value, 299

Verbal association, 58 f., 208, 223

Vestiges (see Traces)

Vibrations, theory of, $50 \mathrm{ff}$., 68, I 58,292

Vividness, 85, I29, 185, 220, 24I, 286

Volition, 46, 60, 63, 93, II2 f., I32, I49, I68, 184, I94, 302

Weber's Law, I22

Will (see Volition)

Woodworth-Wells tests, 234 








\section{RINDING SECT.}




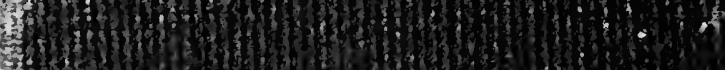

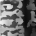

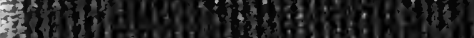

6.3

है।

Sis:

s.

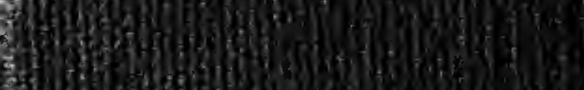
flowh at)



$\frac{1}{3}(2)$

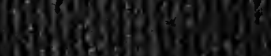

sendy 